\title{
A POST-COLONIAL CRITIQUE OF THE REPRESENTATION OF TAIWANESE CULTURE IN CHILDREN'S PICTUREBOOKS
}

\section{DISSERTATION}

\author{
Presented in Partial Fulfillment of the Requirements for \\ the Degree Doctor of Philosophy in the Graduate \\ School of The Ohio State University
}

\author{
By \\ Chien-hua Kuo, B.A., M.A. \\ $* * * * *$ \\ The Ohio State University \\ 2005
}

Dissertation Committee:

Approved by

Professor Michael Parsons, Adviser

Professor Kenneth Marantz

Advisor

Professor Barbara Kiefer

Graduate Program in Art Education 


\begin{abstract}
Due to the fact that Taiwan has been colonized by different political powers over the past four hundred years and has been influenced by globalization, a search for its identity has become a crucial mission. Because picturebooks as a cultural product have become an important means to transmit cultural traditions to young generations, they have together provided a myth which seeks to represent the national imagination. How these picturebooks tell their stories about Taiwanese culture offers a window to understand what ideologies are embedded in them.

This study investigates the representation of Taiwanese culture shown in three sets of picturebooks labeled "Taiwan" and containing 22 titles in total. They include the Firefly Picturebook Selection - Taiwanese Folktales, the Taiwanese Children's Picturebook Selection, and the Taiwanese Teenagers, produced by Taiwanese writers and illustrators and published in Taiwan during 2001 2004. A post-colonial critique of this collective cultural representation based on Bhabha's “cultural hybridity” and Fanon's "national culture" is provided.

The methodology of this study is qualitative research and the methods used for textual analysis include the analysis of narrative structure based on six literary elements (setting, characterization, theme, plot, point of view, and style) as well as Barthes'
\end{abstract}


semiotic approach (two orders of signification). Moreover, the text is situated in two particular contexts: first, the current discourse of localization in Taiwan, in which the development of Taiwanese consciousness is reviewed, and second, the related publishing context, including the objective of the picturebooks from the editors' perspective and the marketing strategies through the web promotions created by the publishing houses, is examined.

The data analysis shows thirty verbal and visual narrative patterns according to the six literary elements. The common cultural representation of the picturebooks, from the content aspect, illustrates a nostalgic aspect of an agricultural Taiwan, which represents a pure Taiwanese culture reflecting Han Chinese folkways without foreign cultural influences. In contrast, cultural hybridity is frequently shown in the format of the picturebooks. That is, a contemporary visual language is adopted in presenting local culture to attract today's young readers. This constructed representation can be seen as a strategy for recalling and reinstalling the local cultures that had been oppressed and missed in the Kuomintang era, which is in the second phase of the revolution of national literature within a post-colonial society, according to Fanon. This pure Taiwanese culture however may not be able to reflect current social reality.

According to Bhabha, culture is dynamic and hybrid; it is located in the site of struggles with conflicts and changes, which Bhabha calls the "Third Space." In this space, cultural difference is negotiated and on-going process, which is ambivalent and always "in-between" different cultures. His notion provides an alterative perspective for rethinking the definition of Taiwanese culture. That is, cultural purity, usually representing a romantic light on a culture, is not the only way to define what Taiwanese 
culture is. Cultural hybridity, seeing conflicts as a usual process of cultural formation, should be taken into consideration when editors, writers, and illustrators create stories. 
Dedicated to my parents

and

Those who have devoted their lives and love to Taiwan 


\section{ACKNOWLEDGMENTS}

This research project is part of my search for personal identity in responding to this era of globalization. It helps me reflect on my understanding of the culture in which I was brought up and my growing cross-cultural experience in the United States. It would be impossible without a collaboration based on the warmest support and encouragement of my family, professors, and friends both in Taiwan and the U.S.

I am most grateful to my advisor Dr. Michael Parsons for his intellectual recommendations that have helped shape a clear direction for this study. His insights have open a window for me to investigate culture from different perspectives. I am also

indebted to Dr. Kenneth Marantz who always challenges my thinking and reminds me of the relationship between theory and practice. I want to express my gratitude to Dr. Barbara Kiefer and Dr. Janet Hickman for their intellectual guidance and kind support. I also want to express my appreciation to my former advisor Dr. Don Krug for his strong belief in my potential of pursuing a Ph.D. degree.

Special thanks go to my best friend James Sampsel for his contributions to my study as a critical reader and editor as well as his family for their warm friendship that enriches my American experiences. My peer groups also share my appreciation due to 
their emotional supports and valuable critiques of my study. They are Shui-meei, Hsiaoping, Lien-fan, Karen Hsu, and Alice Lai.

The initial idea for this study is rooted in the experience I had when working for the Caterpillar Foundation of Philosophy for Children during 1999 2000. I gained a great deal of experience with the use of children's picturebooks while promoting reading programs and working with Dr. Peter Yang and the supporters of the foundation. I thank them for their devotion to reading programs for children and their parents because this inspired me to see the social value of the picturebook.

I also thank several expert practitioners of children's book publication for providing their insights into this study. They are Cheng Ming-jin, Taso Jun-yan, Chao Kuo-chong, Gao Ming-mei, Lin Husn-ming, Lin Chu-chi, Lain Tsuey-moh, and He Yuntzu. Moreover, I am grateful to the two publishing houses, Yuan-Liou Publishing and Children's Publications, who gave me their permissions to show the on-line images of the picturebooks. It is deeply appreciated.

Finally, I would like to share my achievement and appreciation with my parents and my elder brother's family for their love and support. 
VITA

January $25,1967 \ldots \ldots \ldots \ldots \ldots \ldots \ldots$

1989-1991

1991-1993

1993-1995

1996

1997-1998

1997-1998

$1999-2000$

2001-2005

$2002-2003$
Born- Taipei, Taiwan

B.A. Sociology,

National Chengchi University, Taipei, Taiwan

Staff,

King Car Educational Foundation, Taipei,

Taiwan

Administration Staff,

A Plus Communication Company, Taipei,

Taiwan

Art Teacher, Qing-Miao Art Institute, Taipei, Taiwan

Art Teacher, Columbus Chinese Academy, Columbus, Ohio

M.A. Art Education, The Ohio State University

Chief Executive Officer, Caterpillar Foundation of Philosophy for Children, Taipei, Taiwan

Graduate Teaching Associate, The Ohio State University

Preschool Teacher, Columbus Chinese Academy, Columbus, Ohio 


\begin{abstract}
AWARD
2005 The Manuel Barkan Endowed Fellowship

Department of Art Education, The Ohio State University
\end{abstract}

\title{
FIELDS OF STUDY
}

Major Field: Art Education 


\section{TABLE OF CONTENTS}

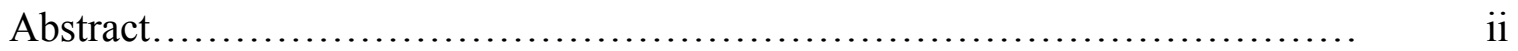

Dedication.......................................................... $\quad \mathrm{v}$

Acknowledgments...................................................... vi

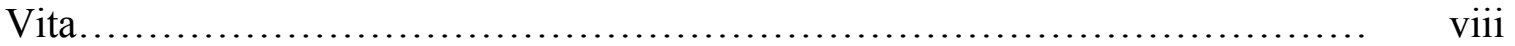

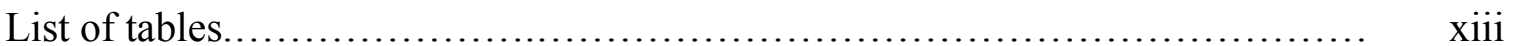

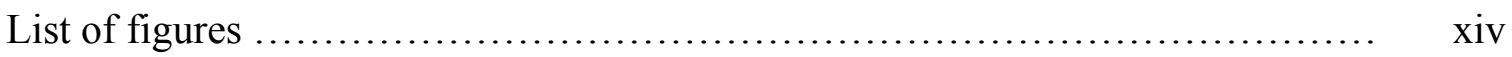

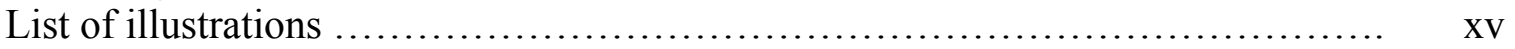

Chapters:

1. Introduction................................................... 1

Background to the study.................................. 1

Statement of the problem................................... 4

Research questions.................................. 5

Definitions of the terms.................................. 6

Purpose of the study....................................... 11

Conceptual framework....................................... 11

Reading the text: how I read the picturebook.............. 12

Interpretation of the text: how I decode/construct the meaning.....

Situating the text within the cultural context: how I make sense of the text.................................... 13

Methodology............................................... 13

Design and method of data collection .................... 13

Method of data analysis................................ 14

Rationale and significance of the study ......................... 15

Limitation of the study...................................... 16

Overview of the dissertation.................................... 17

2. Literature review.................................................... 18

Overview of the literature..................................... 18

Part I. Cultural context: the issue of globalization versus localization in Taiwan ........................................ 19

Definitions of the terms................................. 19 
Globalization as global capitalism accompanying cultural

diversity or cultural imperialism?...

Global-local approach to cultural globalization............. 24

Post-colonial literature regarding resistance

Resistance to or celebration of globalization in terms of the Taiwanese picturebooks.

Part II. Historical context: the development of Taiwanese Consciousness.

A search for the identity of Taiwan: the development of Taiwanese consciousness from a political perspective.... Taiwanese consciousness from a cultural scope: resistance to westernization - hsiang t'u (native culture) literary movement

Reflection on Taiwanese consciousness: resistance to Hancentrism from the indigenous cultural renaissance movement.

Taiwanese consciousness through art: from appropriation to establishing identity

A brief review of the development of Taiwanese consciousness

Localization in current children's picturebook movement...

Relevance to my research........................................ 75

3.

Overview of the methodological framework...................... 77

Qualitative basis.................................... $\quad 77$

Research assumption.................................. 78

Personal biases and ideologies............................ 81

The design of the study....................................... 86

Data collection........................................ 86

Methods............................................. 87

I. Meaning making through contextualizing the text........ 87

II. Interpretation of the text............................... 89

Part I. Narrative structure: verbal and visual............... 89

Part II. Barthes' approach to semiotics ................... 94

Rationale for choosing semiotics in textual analysis ........ 104

Trustworthiness............................................ 105

Limitations of the use of semiotics ............................. 106

Summary................................................ 109

4. Data analysis...................................................... 110

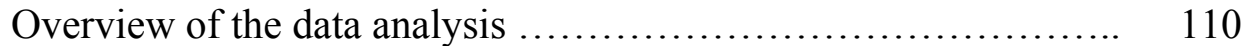

Part I. Analysis of the three sets of picturebooks from the publishing perspective ....

The objectives of the picturebooks ..................... 111

The publishing process for the picturebooks ............. 114

The Marketing Strategy for the Picturebooks ............. 117 
Part II. Analysis of the contents of the three sets of picturebooks Text-picture relation

Verbal and visual narrative patterns and their related meanings

Cultural clues

Summary

5. Discussion

Overview of the discussion

An interpretative critique of the cultural representations in the picturebooks

Approaches to culture from the perspectives of Bhabha and Fanon 221

A critique through the post-colonial lens ....................... 223

Regarding space ................................... 224

Regarding time ...................................... 228

Regarding ethnicity ............................... 238

Implications and suggestions .............................. 245

Implications of this study for publication................ 245

Implications of this study for education................ 246

Suggestions for the future studies..................... 247

Appendices

A A conceptual map of the study .............................. 249

B A book list of the selected Taiwanese picturebooks ............. 250

C Narrative analysis of each individual picturebook .............. 253

D Interview data ......................................... 280

E Website promotion for the picturebooks ..................... 290

References 


\section{LIST OF TABLES}

$\underline{\text { Table }}$

Page

Table 2.1 A summary of the cultural movements in Taiwan .................... 66

Table 4.1 A distribution of setting presented in the three sets of picturebooks..... 135

Table 4.2 Frequencies of the main characters' gender in the stories .............. 145

Table 4.3 A distribution of adult male characterizations presented in the three sets of picturebooks ............................................. 147

Table 4.4 A distribution of adult female characterizations presented in the three sets of picturebooks ......................................... 158

Table 4.5 A distribution of child characterizations presented in the three sets of picturebooks

Table 4.6 A distribution of supernatural beings characterizations presented in the three sets of picturebooks ............................................ 166

Table 4.7 A distribution of themes presented in the three sets of picturebooks 172

Table 4.8 A distribution of plot structure presented in the three sets of picturebooks

Table 4.9 A distribution of plot conflict presented in the three sets of picturebooks

Table 4.10 A distribution of point of view presented in the three sets of picturebooks

Table 4.11 A distribution of the use of language presented in the three sets of picturebooks

Table 4.12 A distribution of the artistic convention presented in the three sets of picturebooks

Table 4.13 A summary of the narrative patterns of the three sets of picturebooks

Table 4.14 A distribution of the use of symbol presented in the three sets of picturebooks 


\section{LIST OF FIGURES}

Figure

Page

Figure $3.1 \quad$ Saussure's sign model f........................................ 95

Figure 3.2 Different orders of signification ............................... 102

Figure 3.3 The myth of imperial France .................................. 102

Figure 4.1 The design of the homepage for promoting the Taiwanese Folktales 118

Figure 4.2 The map of the website for promoting the Taiwanese Folktales ...... 119

Figure 4.3 The design of the homepage for promoting the Taiwanese Children's Picturebook Selection ................................... 121

Figure 4.4 The map of website for promoting the Taiwanese Children's Picturebook Selection

Figure 4.5 The design of the website for promoting the Taiwanese Teenagers ... 124

Figure 4.6 The map of website for promoting the Taiwanese Teenagers .......... 124

Figure 5.1 The myth of Taiwanese identity (adopted based on Barthes' notion) 221 


\section{LIST OF ILLUSTRATIONS}

Illustrations

Page

Illustration 4.1 The design of a frame in three picturebooks

130

Illustration 4.2 A double-spread image shown in the My Father is Going to a

Illustration 4.3 A double-spread image shown in the Go Shopping on Dihua Street for Chinese New Year

Illustration 4.4 The use of metaphorical messages shown in the Selling Brooms with My Grandmother...........................................

Illustration 4.5 The use of metaphorical messages shown in the A River Resembling a Mother...

Illustration 4.6 The images of rural communities shown in the picturebooks ...

\section{The images of a supernatural being pretending to be an old}

Illustration 4.21 beggar

The image of the water spirit in the Shui-gui Cheng-huang ..... 
Illustration 4.26 The images of an omniscient perspective shown in the picturebooks ............................................

Illustration 4.27 The images of a limited omniscient perspective shown in the picturebooks ............................................

Illustration 4.28 The image of the first person perspective shown in the picturebooks ...............................................

Illustration 4.29 The images of the illustrations with the style of representational art

Illustration 4.30 The images of the illustrations with personal style ...............

The images of the illustrations in the A River Resembling $a$ Mother and Yi Gong-gong ...

Illustration 4.32

The image of animals shown in the picturebooks

200

Illustration 4.33

The images of the representation of the myth Shooting Suns ....

200

Illustration 4.34

The images of the bamboo products shown in the picturebooks

205

Illustration 4.35

The image of the design of the end papers in the Da-tou Has a

Son ....

206

Illustration 4.36

The image of the traditional craft shop in the Go Shopping on

Dihua Street for Chinese New Year........................... 207

Illustration 4.37 The image of the costume shown in the Yi Gong-gong ......... 208

Illustration 4.38 The image of the costume shown in the Story Map ............ 209

Illustration 4.39 The image of the Qing style costumes ......................... 210

Illustration 4.40 The image of the modified Chinese clothing ................... 210

Illustration 4.41 The image of the clothing worn by men .................... 210

Illustration 4.42 The images of the traditional Chinese palace architecture with

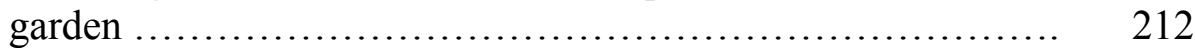

Illustration 4.43 The images of the funeral in the Yi Gong-gong ............... 215

Illustration 4.44 The image of the funeral in the A River Resembling a Mother... 215

Illustration 4.45 The image of the wedding in the Da-tou Has a Son ............ 216

Illustration 4.46 The image of the celebration for the newborn baby in the $L i$

Tain-luo .................................................. 


\section{CHAPTER 1}

\section{INTRODUCTION}

This study is a critique of the work of Taiwanese picturebook publishers who intentionally promote representations of Taiwanese culture based on my interpretation of post-colonial theory. These representations were constructed in a way to convey cultural codes and ideology to readers. They did not evolve without any cultural references and can not be analyzed without an understanding of their cultural context. In order to explain this research project more in-depth, this chapter is divided into eight segments. They include: background to the study, statement of the problem, purpose of the study, conceptual framework, methodology, rationale and significance of the study, limitations, and overview of the dissertation.

\section{Background to the Study}

According to W. J. T. Mitchell (1994), there is a pictorial turn in today's society and visual images dominate people's daily lives; these irresistible images usually raise issues regarding visual representations. Today, most learning experiences and information that children acquire heavily depend on visual representation in different formats, such as printing and digital images. Traditional stories, including folktales, myths, fables, fairy tales, everyday experiences, and the like, which pass down certain 
folkways, ethnic traditions, heritages, and cultural values from one generation to the next, relied on traditional oral storytelling in the past. However, they have been gradually transformed into various visual formats. Such transformations include products that are popular in the international book market, such as children's picturebooks, novels, CD Roms, E-books, and so forth.

Although the forms of storytelling may change, they maintain the same function to some degree in contemporary societies and still convey meanings in their own particular ways. Both traditional and contemporary stories are being produced in these formats. These visual representations contribute to the process of identity formation and to the construction of social reality for the viewer. In other words, they shape children's perception of who they are and how they see the world. As a result, more and more studies have been conducted to examine the issues regarding visual representation.

There are three studies that critically examine the visual representation of different cultures and ethnicities in children's picturebooks. Bradford (2003) adopts a postcolonial viewpoint to critically analyze the problem of the aboriginal visual representation shown in Australian picturebooks. She asserts that "books for children are inescapably ideological, Australian picturebooks offer the child reader versions of the post-colonial experience...oppositional ones...[and] privileging the imperial centre" (p.110). Cross (1995) adopts multiple voices to critically analyze how the cultural icon of Christopher Columbus was presented in different picturebooks. Her study raises the issue of what view was presented in any given picturebook and what is missing. Miranda (1994) conducted a cross-cultural comparative study of how India and its culture were presented in picturebooks published in the United States and India. In her study, she 
discusses the issues regarding stereotypes and authenticity through critically examining character, theme, and point of view in the picurebook.

The studies mentioned above indicate that children's books, as a product within a consumption driven world, convey implicit or explicit ideologies. In other words, "[p]icture books can, of course, exist for fun, but they can never be said to exist without either a socializing or educational intention, or else without a specific orientation towards the reality constructed by the society that produces them" (Stephens, 1992, p. 158). Thus, it is important to critically examine what is present or not present in children's picturebooks.

Children's picturebooks have rapidly grown in Taiwan's book market in recent years and they have been broadly adopted in school curriculums, book clubs, library activities, and the like (Bradbury \& Liu, 2003). However, most picturebooks published in Taiwan are translated from other languages, while only a small portion of them are made by Taiwanese writers and illustrators. In order to distinguish the characteristics of these Taiwanese picturebooks, publishers usually select several books to put in one set and create a special title for this set of books which emphasize Taiwanese culture. This strategy is an attempt to make Taiwanese picturebooks visible to consumers and fulfill a societal demand for learning about traditional Taiwanese folk lives and values. ${ }^{1}$ As a result, these types of picturebooks present some possibilities for interpreting Taiwanese culture.

\footnotetext{
${ }^{1}$ They oftentimes refer to the Chinese culture brought to Taiwan by the Han people from Mainland China who had immigrated to Taiwan during the Ming and Qing Dynasties; and, in order to adapt to the new environment, these immigrants have gradually evolved their particular ways of lives and values which are different from that of their home land. Therefore, the use of the traditional folk lives and values here, in particular, focuses on the Taiwanese culture without any influence by the Japanese colonial culture, the
} 


\section{State of the Problem}

Accompanying new curriculum standards for grades 1 through 12 established during 1998 in Taiwan, a new holistic educational philosophy involving curricula and teaching and learning was also emphasized (Lo, 1999). Because of this, the ideas of curriculum integration and multiple learning abilities have replaced the notions of single discipline-based education and traditional paper and pencil tests. Awareness of the humanities, democracy, Taiwanese culture, and the global world are taught to cultivate citizens in contemporary society (Lo, 1999). In addition, reading has been strongly encouraged in schools and communities since the Ministry of Education promoted a national movement of reading in 2000. As a result, children's books are welcome in schools, especially those created by Taiwanese writers and illustrators and telling stories about life experience in Taiwan from early times to the present.

In order to incorporate children's books into the curriculum, school teachers usually rely on getting information regarding recommended book lists from libraries, publishers, teacher conferences, and other sources. In nurturing students' interests in reading, parent volunteers also become involved in school activities, such as storytelling, reading, bookmaking, playing, and the like. Many parents are in favor of the stories reflecting the memory of their childhood, such as traditional Taiwanese folktales.

In order to fulfill the demand of children's picturebooks regarding Taiwanese culture, publishers create new book titles based on it. According to the book lists provided by publishers in the past four years, there were three sets of picturebooks named

Kuomintang's promotion of so-called orthodox Chinese culture, and the current American and Japanese popular cultures. 
Taiwanese picturebooks ${ }^{2}$ published by two of the main children's book publishers. In order to emphasize the characteristics of these picturebooks, the publishers create catalogs with a nostalgic atmosphere (the examples can be seen on the publishers' web pages). ${ }^{3}$ These picturebooks are marketed in a way to present a sense of Taiwanese culture mainly based on an agricultural society. These images and stories are articulated through Taiwanese traditional folktales and folk lives in Taiwan. Therefore, these picturebooks provide and reinforce readers with an idea of what Taiwanese culture should be about. This led me to wonder about the questions of what and whose ideas form the basis of Taiwanese culture. If these picturebooks do convey Taiwanese culture, then how is the culture represented through the picturebooks published in Taiwan?

\section{Research Question}

The research question is "how do Taiwanese writers and illustrators present Taiwanese culture in the three sets of children's picturebooks labeled Taiwanese picturebooks during 2001 2004?” To be more specific, I would like to identify what kinds of stories are retold and what kinds of cultural symbols are frequently represented in the picturebooks. I want to critically analyze the representation of meaning within a

\footnotetext{
${ }^{2}$ They include Firefly Picturebook Selection (including six titles of Taiwanese folktales and published in 1989 and reissued in 2001), Taiwanese Children's Picturebook Selection (including ten titles and published in 2002), and Taiwanese Teenagers (including six titles and published in 2003). The term "firefly" used for the title of the Taiwan traditional folktales is a metaphor, representing agricultural Taiwan because fireflies are oftentimes seen in a natural environment without pollution. When Taiwan was an agricultural society, fireflies were a popular type of insect. However, they are less frequently seen in industrial Taiwan today.

${ }^{3}$ The promotion of Firefly Picturebook Selection is shown at http://www.ylib.com/hotsale/firefly/deault.htm

The promotion of Taiwanese Teenagers is shown at http://www.ylib.com/hotsale/taiwan_tad/default.htm The promotion of Taiwanese Children's Picturebook Selection is shown at http://www.012book.com.tw/hot/taian/index.html
} 
basis of intertextuality and a current social context. In order to investigate this question in more depth, the following five specific questions must be discussed.

1. What are the objectives of the three sets of picturebooks and their marketing strategies? What meanings/ideologies are associated with them?

2. What kind of text-picture relationship between verbal and visual narrative patterns is shown in these picturebooks? How do these two narrative patterns complement each other?

3. What verbal and visual narrative patterns are in the picturebooks?

4. How do the elements used in the visual narrative patterns provide cultural clues?

5. How do these narrative patterns and cultural clues together suggest an interpretation of Taiwanese culture? Whose viewpoint is present? What meanings/ideologies are associated with it?

\section{Definitions of the Terms}

In order to clarify the important concepts of this study, the terms used for culture, representation of meaning, ideology, and the picturebook should be defined.

\section{Culture}

The term culture is a complex and complicated concept. According to Stuart Hall (1997a), culture contains at least three different aspects. First, "in more traditional definitions of the term, culture is said to embody the 'best that has been thought and said' in a society" (p. 2). Based on this definition, culture refers to "high culture" including the classic works of literature, painting, sculpture, music, and the like. In contrast, this 
definition is extended to "popular culture," which includes popular forms of literature, music, art, design, and things created or practiced by the majority of ordinary people on a day-to-day basis.

Second, from the anthropological perspective, culture refers to "the way of life of a people" (Hall, 1997a, p.2), which means culture as general patterns that can distinguish among groups of people based on their characteristics. It can be divided into two categories: nonmaterial culture (such as beliefs, values, behavior) and material culture (such as material objects, products) (Macionis, 1994).

Third, from the perspective of cultural studies and the sociology of culture, "culture is concerned with the production and the exchange of meanings - the 'giving and taking of meaning'-between the members of a society or group" (Hall, 1997a, p.2). Moreover, language which includes linguistic language, visual images, sound, and the like is "central to meaning and culture and has always been regarded as the key repository of cultural values and meanings..." (p. 1). Based on this view, meaning is what a group of people ascribe to the cultural production through their use of language. In other words, meaning is negotiable.

This study considers all three aspects of culture. In particular, the first definition reminds me of being aware of possible ideology of power relationships between high and low cultures. The second definition provides my study with a guideline to look at behavior and value systems of a culture through picturebooks. The third definition inspires me to see the picturebook serving as a medium that brings a group of people together, such as writers, illustrators, editors, publishers, and readers, to share their ideas. For this reason, I tend to perceive the picturebook as a cultural production within 
Taiwan's cultural context. And, I situate this context within a current cultural discourse regarding the issues of globalization versus localization.

\section{Representation of Meaning}

According to Hall (1997b), "there are broadly speaking three approaches to explaining how representation of meaning through language works" (p. 24). They include the reflective or mimetic approach, the intentional approach, and the constructionist approach. First, the reflective approach refers to the idea that meaning can be considered "to lie in the object, person, idea or event in the real world, and language functions like a mirror, to reflect the true meaning as it already exists in the world" (p. 24). Second, the intentional approach emphasizes that "the speaker, the author...impose his or her unique meaning on the world through language" (p. 25). For this reason, the author's intent is the key to understanding the meaning. Third, the constructionist approach believes that “[t]hings don't mean: we [as the viewer] construct meaning, using a representational system - concepts and signs" (p. 25). This approach does not refuse "the existence of the material world", but denies the idea of "the material world [conveying] meaning" (p. 25). In my study, I have adopted the constructionist approach to the representation of meaning. In this sense, the representation of Taiwan (the meaning) through the picturebooks (the material) is constructed based on my interpretation (the viewer) by using a semiotic analysis (signs and concepts).

\section{Ideology}

The term ideology is often associated with Karl Marx, who emphasized social inequality. He believed that society's rulers, who are in power to control resources and ideas, make the bourgeois class believe the false ideal or false consciousness that 
maintains the social hierarchy in favor of the rulers (Tyson, 1999). Thus, the bourgeois class accepts false consciousness as if a social norm. However, Marx's ideas of class conflict and false consciousness are not able to illustrate today's circumstances. As a result, his followers revised it. From a Marxist view, ideology can be defined as "cultural beliefs that reflect and support the interests of certain categories of people" (Macionis, 1994, p. 155) and it is "a product of cultural conditioning. For example, capitalism, communism, Marxism, patriotism, religion, ethical systems, humanism, environmentalism, astrology, and karate are all ideologies" (Tyson, 1999, p. 52).

The use of the term ideology in this study refers to Louis Althusser's main notion of ideology. That is, “...ideology [exists] not simply as a body of ideas, but as a material practice [which] is encountered in the practices of everyday life...[It] is the way in which certain rituals and customs have the effect of binding us to the social order" (as cited in Storey, 1993, p. 5). In this sense, "[t]he social norms, or that which is socially acceptable, are of course neither neutral nor objective" (Fiske, 1998, p. 307). However, ideologies "are not necessarily undesirable, and in the sense of a system of beliefs by which we make sense of the world, social life would be impossible without them" (Stephens, 1992, p. 8). These statements indicate that every thought or belief we hold true contains ideology to some extent. For this reason, the messages that are communicated between the picturebook and the reader contain ideologies.

\section{The Picturebook}

The term picturebook consists of at least two different definitions. One is specifically to refer to a book with text and pictures which intimately interact in telling a story (Nodelman, 1988; Shulevitz, 1985). The other one is a broad definition; that is, 
"[a]ny book with a picture-book format can be included under the umbrella term picture book" (Huck, Hepler, Kickman, \& Kiefer, 2001, p. 168). They include alphabet books, counting books, first books, and concept books, in which pictures "must be accurate and synchronized with the text" (p. 168). In addition, the broad definition refers to books with heavy text and fewer illustrations where the pictures may not amplify the text (Temple, Martinez, Yokota, \& Naylor, 2002). This is the illustrated book and it is excluded from my study.

In the first definition, Shulevitz (1985) provides an inclusive way to distinguish two different picturebook formats: story book and picturebook. According to him, “A story book tells a story with words. Although the pictures amplify it, the story can be understood without them. The pictures have an auxiliary role, because the words themselves contain images" (p. 15). Whereas a picturebook tells a story mainly with pictures and the use of words is a supplementary role. Nodelman (1988) provides an explanation of more specific relationships between text and pictures in the picturebook. The text develops narrative time sequences, whereas the pictures depict spatial clues. The most valuable way to appreciate the picturebook is to consider all the designed elements as a whole and perceive them "in a sequence in which the relationships among them-the cover, endpapers, typography, pictures - are crucial to understanding the book" (Marantz, 1994, p.3). In sum, I will tend to use Shulevitz's idea to categorize the selected picturebooks in this study. In order to emphasize the idea that a story book is also a picturebook format, I use the term the picture story book to replace it. 


\section{Purpose of the Study}

The purpose of this study is to provide a post-colonial critique of the representations of Taiwanese culture in the children's picturebooks with an emphasis on Taiwanese traditions and experiences. In doing this, the three sets of Taiwanese picturebooks published during 2001 2004 are the primary data. How both visual and verbal narratives in those picturebooks imply cultural codes and meanings/ideologies will be investigated based on the analysis of narrative structure and Barthes' semiotic approach. A discussion of how the representation of meaning is presented through the picturebooks in relationship to Taiwan's cultural context will be also provided.

\section{Conceptual Framework}

In the book, The Cultural Analysis of Texts, Lehtonen (2000) develops "a notion of the contextual and cultural nature of textual meanings" which is based on a theory of articulation (p. 1). In order to answer the question of where and how meanings are formed, he analyzes "the relationships between texts, contexts and readers in the formation of meanings" (p.2). This notion indicates that the formation of meanings can be analyzed from three aspects as a whole: the text, the context, and the reader. In this sense, Lehtonen's idea of “textual meanings" ignores the author's intent and places more weight on how meanings are socially constructed by the language we use within a cultural context. This notion is similar to Hall's constructionist approach to "representation of meaning through language."

The purpose of my study is to investigate textual meanings through Taiwanese picturebooks from a cultural aspect. Lehtonen's notion draws my attention to look at how 
I read these texts and what cultural context I base my interpretation on. Thus, my understanding of text analysis is based on the following three segments: (1) Reading the text: how I read the picturebook, (2) Interpretation of the text: how I decode/construct the meaning, and (3) Situating the text within the cultural context: how I make sense of the text. (A conceptual map of this study is accompanied. See the appendix A).

\section{Reading the Text: How I Read the Picturebook}

According to Lehtone (2000), "texts and readers never exist independently of each other, but in fact produce one another" (p. 133). For this reason, the reading process is an interactive one. Reading "is never a mere passive selection of meanings from texts by acknowledging the meanings of words and joining them together according to the rules of grammar" (p. 133). Rather, it is a process of decision making which includes "choosing what to read, organizing and linking them together in order to form meanings, as well as bringing the reader's own knowledge into texts" (p. 133). Therefore, I was aware of what decisions I made and thought about what was included or excluded according to the decisions.

Interpretation of the Text: How I Decode/Construct the Meaning According to Steven Mailloux (1995), the term "interpretation" has two meanings: "the action of expounding, explaining" and "a translation, a rendering"; moreover, in its etymology, interpretation provokes two concerns: "translation of a text and translation for an audience" (p. 121). These two etymological senses raise different questions regarding interpretation as "approximating what? translating how? and acceptable to whom?" (p.121-122). His discussion implies that interpretation tends to gain approximate meanings associated with a text based on the theories and perspectives 
chosen by the interpreters. And, as a result of this, different interpretations based on the same text are accepted by different audiences. Moreover, the question of "acceptable to whom" involves the issue of power relationships. Who holds the power to control interpretation is based on which lens is used. This notion inspired me to carefully select the lens used in this study and be aware of my bias and ideology. As a result, theories of globalization, post-colonial, and semiotics were adopted.

Situating the Text within the Cultural Context: How I Make Sense of the Text

Since my research interest is to investigate how the Taiwanese picturebook presents its culture, I tend to connect the text to a current dominant cultural issue, which is an emphasis on the discourse of globalization versus localization. The debates regarding this discourse have evolved since Taiwan intended to enter the World Trade Organization in 2002. Due to this fact, many scholars and educators have worried that traditional Taiwanese culture may be eliminated by the impact of globalization. In looking into this issue further, a debate regarding a discourse of culture has been frequently presented in the Taiwan's literary and art world. The issue of Taiwanese consciousness is a major part of this cultural discourse. Thus, a review of the development of Taiwanese consciousness and its influence and implication for the publishing industry in Taiwan were explored.

$$
\text { Methodology }
$$

\section{Design and Methods of Data Collection}

Since this study is intended to examine what ideology is embedded in the cultural representation of the picturebook under the labels regarding Taiwanese culture, 
qualitative research is the methodology and the methods consist of narrative analysis and structuralism based on semiotics. The data collection in this study included the three sets of picturebooks created by Taiwanese writers and illustrators and published during the years of 2001 2004 (for the book list see the appendix B). They include Firefly Picturebook Selection (including six titles of Taiwanese Folktales and published in 1989 and reissued in 2001), Taiwanese Children's Picturebook Selection (including ten titles and published in 2002), and Taiwanese Teenagers (including six titles and published in 2003). There are twenty-two titles in total which are available in the current Taiwanese book market. In order to have an in-depth sense of how these picturebooks are produced and promoted, the interviews with editors from the publishing houses and related commercial catalogs regarding the picturebooks on the publisher's web pages were also collected.

\section{Methods of Data Analysis}

The data analysis is divided into two major parts. The first stage is an overview of the general patterns shown in the twenty-two picturebooks based on the analysis of narrative structure, including setting, characterization, theme, plot, point of view, and style. The picturebooks are analyzed individually. Besides this, cultural clues shown in the pictures are identified and the implied meanings are also discussed. At the second stage, the picturebooks are examined within groups based on Barthes' approach to semiotics (1996), dealing with two systems of signification. And, an interpretive critique is used based mainly on the notion of cultural hybridity by Bhabha (1994). 


\section{Rationale and Signification of the Study}

In the postmodern era, culture has become a major component in academic research across different disciplines. Cultural studies, for example, take a special interest in cultural representation within popular culture, such as cartoons, toys, children's books, films, advertisements, MTV (Music Television), and so forth. A current trend in art education emphasizes popular visual forms playing a crucial role in shaping personal cultural identity. For this reason, art educators should help students to explore their identity through the variety of visual cultural forms (Ballengee-Morris \& Stuhr, 2001). International literature for children makes an effort to promote a better understanding of different cultures all around the world. Whether a work of literature provides an authentic cultural experience is a primary concern (Freeman \& Lehman, 2001). These three disciplines: cultural studies, art education, and international literature for children, strongly emphasize culture and its relationship to individuals, which include the formation of cultural identity and the understanding of cultural difference.

The picturebook is considered as a form of storytelling, a cultural production, a form of art, and an educational tool. All of these roles that the picturebook simultaneously plays are able to shape readers' perception of their own cultures and cultures from other countries. Especially, the picturebook broadly reaches young children and it is also one of the primary sources for them to investigate the concept of self and others, as well as family, community, and society. This study demonstrates a careful analysis of the picturebook and its representation of Taiwanese culture. The results provide an exemplar case that examines the ideologies embedded in children's picturebooks and discusses the characteristics of Taiwanese picturebooks and their 
cultural context. This study benefits interdisciplinary fields including cultural studies, art education, and international literature for children.

\section{Limitation of the Study}

This study is not intended to generate the one and only interpretation of Taiwanese culture. Rather, it is intended to critique what ideology is embedded in the picturebooks based on semiotics. Moreover, this study does not attempt to extensively discuss the aesthetic quality and experience of the picturebooks.

The approach used here is to analyze the text and not be concerned about who the implied reader is for the selected picturebooks. For this reason, the perspective of children and whether the reader is able to identify cultural meanings through the visual images in the picturebooks are not discussed in the study.

The criteria of book selection in this study are also restrictive. Some genre of picturebooks, such as illustrated books and wordless picturebooks are not considered, and how pictures in these picturebooks convey cultural meanings is not investigated. In addition, the selection of this study focuses on the picturebooks put into sets based on the themes related to Taiwanese culture and selected by publishers. Thus, those Taiwanese picturebooks in any sets labeled international master children's picutrebook selection or those winning national awards ${ }^{4}$ and published in Taiwan's book market are excluded from this study. ${ }^{5}$

\footnotetext{
${ }^{4}$ Currently, there are two major national awards for children's picturebooks. They include "Hsin-Yi Children's Literature Award" held yearly by the Hsin-Yi Foundation since 1988 and "Reed Pipe Award for Children's Literature" held biennially by the Mandarin Daily News since 1995. Each of them has different criteria for selecting the best picturebook for children. The former limits the appropriate reading range for children from age 3 to 8 , while the latter is from age 3 to 12 .

${ }^{5}$ The reason I did not choose these picturebooks is that there is a variety of difference among them. For example, there are at least two different paths to publish picturebooks in Taiwan. One is from the path of
} 


\section{Overview of the Dissertation}

This dissertation is divided into five chapters. Chapter two is a literature review, including three segments: (1) cultural context: a review of theories of globalization and post-colonialism and the issue of globalization and localization in Taiwan, (2) historical context: a review of the development of Taiwanese consciousness, and (3) the relevance of these reviews to this study. Chapter three presents methodology, in which an overview of the methodological framework, an explanation of the design of the study, a discussion of trustworthiness and limitations of this study, and a summary are provided. Chapter four is data analysis, in which data is presented based on two parts: (1) analysis of the picturebooks from the publishing perspective and (2) analysis of the contents of the picturebooks. Chapter five covers an interpretative critique, implications for publication and education, and suggestions for the future study. 


\section{CHAPTER 2}

\section{LITERATURE REVIEW}

\section{Overview of the Literature}

The purpose of this chapter is to review the literature regarding the cultural context in which the text is situated. It serves as a foundation for understanding Taiwan's local cultural practices in responding to globalization, namely, the movement of localization, which is to establish "Taiwaneseness" (Taiwanese identity). A historical review of this movement focuses on the emerging Taiwanese consciousness. This trend has influenced the children's picturebook publishing industry in Taiwan, encouraging an emphasis on Taiwanese consciousness in picturebooks. This can be seen as a resistance to the pressure of globalization on the one hand and a way of approaching a global market on the other hand. This is a negotiation brought about by the complexity of the relationship between globalization and localization.

To clarify this idea, theories of globalization and post-colonialism will also be discussed, in so far as they have implications for Taiwanese picturebooks in which publishers intentionally promote representation of Taiwan's culture. Moreover, to have an insight into the movement of localization in contemporary Taiwan's society, the political and cultural movements regarding the development of Taiwanese consciousness 
will be reviewed. As a result, this chapter is divided into two major segments: (1) cultural context: the issue of globalization versus localization in Taiwan and (2) historical context: the development of Taiwanese consciousness. In addition, the relevance of these reviews to my research will be included.

Part I. Cultural Context: The Issue of Globalization versus Localization in Taiwan

The work of Taiwanese picturebook publishers intentionally promoting a certain representation of Taiwanese culture can be seen as a resistance to the pressures of globalization based on two approaches, namely, theories of globalization and postcolonialism. Since both of these two approaches are involved in numerous discourses, the literature review regarding them will be limited to its relevance to my study. The discussion is divided into five segments: (1) definitions of the terms, (2) globalization as global capitalism or cultural imperialism, (3) a global-local approach to cultural globalization, (4) post-colonial literature regarding resistance, and (5) resistance to or celebration of globalization in terms of the Taiwanese picturebooks.

\section{Definitions of the Terms}

\section{What is Globalization?}

The term globalization has been used in the academic world since the 1960s, but has been mainly discussed by economists. It was not until the 1980s that the concept of globalization has been broadly explored, not only from a political and economic aspect, but also from a social and cultural perspective (for example, Lechner \& Boli, 2000; Robertson, 1992). Today it is a new social science "beyond interdisciplinary boundaries" 
(Voisey \& O'Riordan, 2001, p. 28). For this reason, I will briefly review the concept of globalization based on the economic, political, and cultural aspects because they are major factors affecting people's lives.

At the economic level, economic globalization refers to "economic internationalization and the spread of capitalist market relations... [T] he global economy is the system generated by globalizing production and global finance" (Pieterse, 2000, p. 99). Thus the theory of globalization emphasizes the field of economic transactions, including marketing, deregulation, financial ties, and so forth, which is similar to the world-systems approach. ${ }^{6}$

Political globalization includes at least three dimensions, according to Lechner \& Boli (2000):

First, the very fact that the entire world, with the exception of the arctic areas and a few small colonies and dependencies, is organized by a single type of political unit, the nation-state, is a sign of globalization...

Second, political globalization is indicated by the considerable uniformity exhibited by sovereign states in terms of their goals, structures, programs, and internal operations...

A third dimension of political globalization is the emergence in the past hundred years of intergovernmental organizations (IGOs)... (p. 195-6)

This also indicates that the growth of interdependence among nations has been increased.

Especially, new ideas and social actions have been adopted and performed in different

\footnotetext{
${ }^{6}$ According to So (1990), the theory of world-systems is one of three major approaches to the development discourse. They include theories of modernization, dependency, and world-systems. The modernization approach, based on evolutionary and functionalist theories, emphasizes that the western modern civilization is the best model for the Third World to adopt and achieve. The dependency approach, based on the ECLA program (the program of the U.N. Economic Commission for Latin America) and neo-Marxist theories, criticizes the fact that the Third World economically depends heavily on the Developed World. Unlike these two theories, rather than placing the research focus on the Third World and the binary relationship, the world-systems approach divides the whole world into three sectors: metropolitan, semi-periphery, and periphery based on economic development. In this model, several semi-periphery countries could formulate
} 
countries through the support from IGOs. For example, the Universal Declaration of Human Rights by the United Nation in $1948,{ }^{7}$ the Red Power National Indian Protest Movement in pursuing indigenous rights in the United States since the $1960 \mathrm{~s},{ }^{8}$ and the study on aboriginal rights by the United Nation in $1992,{ }^{9}$ have inspired and encouraged Taiwanese aborigines to pursue their rights.

In terms of cultural globalization, Robertson (1992) asserts, "Globalization as a concept refers both to the compression of the world and the intensification of consciousness of the world as a whole" (p. 8). Like Robertson, Inda and Rosaldo (2002) also emphasize "the intensification of global interconnectedness" (p.2). Among global cultures, media, like TV and the Internet, play a crucial role in helping local people reach out from their own immediate social institutions and organizations.

In sum, the main idea of these three aspects of globalization emphasizes the bringing together of people and nations around the world into a single global society. In this sense, globalization does not only exist at a government level, but also directly influences people's daily lives, where everyone needs to negotiate its implications and impacts.

\footnotetext{
an independent system and have high economic growth, such as the "Four Tigers" in Asia, including Hong Kong, Taiwan, South Korea, and Singapore.

${ }^{7}$ The declaration can be seen at http://www.un.org/Overview/rights.html.

${ }^{8}$ The Red Power National Indian Protest Movement has grown since the 1960s and continually pursues self-determination or self-rule. The movement has successfully gained several rights for Indians, such as the 1975 Indian Self-Determination and Education Assistance Act, the 1979 Archaeological Resources Protection Act, the 1983 Radioactive Waste Disposal Act, the 1983 Land Consolidation Act, and the 1988 Indian Gaming Regulatory Act. All of these "extended tribal sovereignty over the decision making and control of reservation land and resources" (Josephy, Nagel, \& Johnson, 1999, p. 8).

${ }^{9}$ The study can be seen at ftp://ftp.halcyon.com/pub/FWDP/International/untrtstd.txt.
} 


\section{What is the Postcolonial?}

Like globalization, the terms post-colonial, post-colonialism, post-coloniality, or post-colonial discourse are discussed across disciplines and the definitions of them may vary widely. ${ }^{10}$ This chapter is not an attempt to review all the important issues discussed in post-colonial studies. Rather, the concept of the post-colonial here is limited to the resistance to the pressure of globalization (which can be seen as global capitalism or cultural imperialism). In terms of post-colonial, I mainly adopt the use of Childs and Williams' notion (based on Helen Tiffin).

Helen Tiffin argues that post-colonialism can be characterized in two, related ways: one which constructs it in terms of those societies whose subjectivity has been constituted in part by the subordinating power of European Colonialism, and another which conceives it as a set of discursive practices involving resistance to colonialism and colonialist ideologies and legacies. (Childs \& Williams, 1997, p. 232)

Although this quote well describes the correlation between colonialism and postcolonialism, it emphasizes "European Colonialism" which is limited because it does not include the Asian colonies controlled by other colonizers such as Japan. It may be that the concept of colonialism was originally from European and then was adopted by Japanese imperialism to establish its own colonies. In this study, the use of the term post-colonial

\footnotetext{
${ }^{10}$ The use of the terms post-colonial, post-colonialism, post-coloniality, and post-colonial discourse is diverse. The use of these terms may be interchangeable, but sometimes it depends on how the word is used in a particular context. For example, Mishra and Hodge (1994) argue that the use of post-colonialism and postcolonalism is different. The term "post-colonialism", with a hyphen, refers to "after" colonialism which misleads the reader into thinking that colonialism is over. These authors emphasize that the conditions of colonialism and postcolonialism may exist simultaneously, such as in Australia. Thus the term postcolonialism should be used to clarify this idea. In this paper, I tend to use the term post-colonialism since it has been broadly used and it also covers the concern that Mishar and Hodege hold. For example, according to Ashcroft, Griffiths \& Tiffin (1995), “'Post-colonial' as we define it does not mean 'postindependence', of 'after colonialism', for this would be to falsely ascribe an end to the colonialism process.
} 
refers to all the cultural aspects affected by the imperial process, including military, political, economic, and/or cultural imperialism, from the beginning of colonization to present.

\section{Globalization as Global Capitalism or Cultural Imperialism?}

Globalization is generally due to global economic forces which involve nations around the world in global capitalism, in which labor, natural resources, and financial systems are shared. However, economic globalization also places weight on a cultural aspect; the widespread use of technology in communication beyond national boarders in particular (Reyes, 2001). As a result, lower prices and a variety of merchandise, as well as fast-paced and convenient lifestyles through new technologies, have spread in countries across national boundaries. These changes invoke both positive and negative concerns regarding the interaction between local or native cultures and global culture.

One of the major issues regarding globalization is that "global culture is dominated by the commodifying practices of global capitalism" (Tomlinson, 1999, p. 80). Due to the effect of global capitalism, global culture has moved toward a homogeneous rather than a heterogeneous state, which indicates an issue of global imperialism. America is the chief representative of global imperialism. According to Robertson (2002), "It is frequently stated that globalization is an American phenomenon —indeed, that it is a form of Americanization...American cultural imperialism is leading to the homogenization of world culture" (p. 31). Global corporations like MacDonalds, Nike, and Gap are representative examples that

Post-colonialism, rather, begins from the very first moment of colonial contact. It is the discourse of oppositionality which colonialism brings into being" (p. 117). 
demonstrate this statement. Even the term "MacDonaldization" is shown in a study on cultural globalization (for example, Pieterse, 2000), and it refers to "world-wide cultural standardization" (Pieterse, 2000, p. 99). Because there are many other cultural productions with a similar impact and influence like that of MacDonalds and Nike, the worry of American cultural imperialism replacing diverse local cultures inevitably exists in the non-American world. Particularly, post-colonialism criticizes the impact and influence of cultural imperialism accompanying global capitalism. In contrast, some scholars approach global cultures in a different way, which emphasizes the power of localization in reacting to globalization. Thus, I will review the concept of a global-local approach to cultural globalization and post-colonial literature regarding resistance to cultural imperialism, in the following sections, respectively.

\section{Global-Local Approach to Cultural Globalization}

\section{Theoretical Review on the Global-local Approach}

cultural revival as a resistance to globalization.

In the non-western world, the debates about globalization often involve ideologies, "in which globalization is viewed as either the cause or the cure of all local problems" (Grant \& Short, 2002, p. 7). In these debates, an emphasis on localization becomes a possible solution and, in responding to this situation, culture revival is oftentimes used as a strategy. As Hobsbawm and Ranger (1983) put it:

In addressing directly oppositional movements relating to globalization, it is necessary to emphasize that perhaps the most frequently expressed opposition is in support of so-called indigenous or national culture, identity, and tradition. Much of the concern with the preservation of these has resulted from "the invention of tradition." (as cited in Robertson, 2002, p. 31) 
Accompanying this strategy, traditions which are no longer practiced on a day-to-day basis become available cultural elements used to create new cultural productions. For example, the Taiwanese puppet show that had been popular on TV in the 1970s has become a local cultural symbol today. Another example is the invention of Taiwanese tea houses, which include the sale of traditional Taiwanese food and decoration that tries to promote a nostalgic feeling of the Taiwanese countryside. Moreover, to some extent, if local people consciously perform the invention of tradition and keep their "local diversity," then it can be considered as "a form of resistance to the proliferation of globalist capitalism...” (Tsing, 2002, p. 464-5).

\section{glocalization as a resistance to globalization.}

In contrast, rather than to see globalization as modernization or westernization, Pieterse (2000) argues that we should see globalization "as a process of hybridization which gives rise to a global mélange" (p. 99). The concept of glocalization is the best illustration of hybrid formations of local practices in responding to globalization. As

Pieterse puts this idea:

Globalization can mean the reinforcement of or going together with localism, as in "Think globally, act locally." This kind of tandem operation of local/global dynamics, global localization or glocalization, is at work in the case of minorities who appeal to transnational human rights standards beyond state authorities, or indigenous people who find support for local demands from transnational networks. The upsurge of ethnic identity politics and religious revival movements can also be viewed in the light of globalization... (p. 102)

In this sense, the local integrates global concepts into its practice rather than following its original systems. Pieterse (2000) also states that hybrid formations, shown in different 
social organizations and at different levels, is the reason why globalization should not be seen as a homogenization of global culture. In this sense, glocalization can be seen as a local resistance to the pressures of globalization.

example: Japanese anime-glocal cultural industry approach to a global market.

In short, from a global-local perspective, globalization is not a one-directional process. It is rather an intertwined process between the global and the local. In this view, the possibility of a local cultural industry joining a global market is also a result of this process. For example, Japanese anime, which is a currently popular style of animation that has become a cultural industry, was heavily influenced by American Disney cartoons at the early stage of its foundation. However, according to Levi (1996), Japan has localized the animation industry through establishing its own style based on its traditional drama and creativity. Moreover, the major features of Japanese anime include:

the high tech look, the creative fantasy worlds, the genuine tension created by the fact that bad things happen to good people, the multidimensional characters, the robots, powersuits and other mecha (drawn from English word "mechanical"), and the sexy and powerful women. (Levi, 1996, p. 20)

And, it eventually became an element of popular culture in the global market. This illustrates that localization plays a crucial role in considering the reaction to globalization. Another possible way to explain the case of Japanese anime is to consider "globalization as hybridization" (Pieterse, 2000). Due to the global influence on local culture, a new hybrid culture has been produced. Based on these two perspectives, globalization is not considered as westernization and it does not cause a homogenous global culture. 
Glocalization Example: Global Cultures in Taiwan

Hsiao Hsin-huang (2002), who is a Taiwanese scholar involved with studies on social movements, adopts the four categories of global cultures created by Berger and applies them to Taiwan. They consist of Davos culture or international business culture; McWorld culture or global popular culture; faculty club international or world intellectual culture; and new religious movements or popular religious culture. A brief summary of these is provided as follows.

\section{1. international business culture.}

Taiwan has been engaged in the world market since the 1960s. As a result, the use of business English is common and having an English first name is also highly recommended. In terms of management, due to the emphasis of personalism ${ }^{11}$ in Taiwan's society, multinational companies need to adjust their systems in order to adapt to local business culture.

\section{2. global popular culture.}

Americanization, Europeanization, and Japanization of lifestyles and popular culture are dominant in Taiwan. Besides these foreign influences, "there has also been a rise in 'repackaged' cultural localization and indigenization, in which many local cultures and traditional lifestyle elements have been revitalized and reinvented" and this can be considered as "a local response to globalization" (Hsiao, 2002, p. 57). Moreover, in responding to the world's wave of political democratization since the 1980s, a search for

\footnotetext{
${ }^{11}$ The term personalism refers to the notion that Chinese place heavy weight on personal relations. On a practical level, in a company, employers tend to recruit people who have a special connection to the company or its important employees. In so doing, the company has a special personal chain to tie the employees together. This is one reason why the popularity of family business is high in Taiwan.
} 
national identity raised an ideological debate on Chinese versus Taiwanese consciousness (this issue will be fully discussed in the part two.)

\section{3. world intellectual culture.}

In the late 1970s and early 1980s, young Taiwanese intellectuals who received advanced degrees from American universities returned to their homeland. They have formed a "new knowledge class" in different social institutions and have become "the 'carriers' and 'localizers' of many Western/global values" (Hsiao, 2002, p. 59). Since the 1980s, translated publications from different disciplines, written in English in particular, were welcome and have grown ever since in Taiwan's book market. And, the acceptance of readers of these translations is positive. Liberal ideas are usually introduced by Taiwanese intellectuals and they play a crucial role in leading social movements for particular agendas, such as environmental awareness, women's rights, laborers' rights, aborigines' rights, gay and listbians' rights, and the like.

\section{4. popular religious culture.}

Religious groups have been increasing not only with the new imported religions, such as those form India, Japan, Vietnam, and France, but also new Buddhist groups, which "have adopted a hands-on approach in reaching out to society... [and they] are involved in social welfare and medical services, education, publications, and environmentalism" (Hsiao, 2002, p. 63). This phenomenon illustrates "a religious response to meet the spiritual needs of the Taiwanese people who are under great pressure from over-modernization" (p. 63).

In reviewing Hsiao's study, it is obvious that global influences have been embedded in Taiwan's society and the results seem positive rather than negative. His 
observation also supports the notion of cultural hybridity in Taiwan. In other words, glocalization has been encouraged and promoted in Taiwan's society as a way to approach global influences.

\section{Post-colonial Literature Regarding Resistance}

According to Childs and Williams (1997), post-colonialism brings the view of racial and cultural dimensions into the analysis of the text. The most notable writers in this field, like Edward Said with his idea of knowledge and power, Frantz Fanon with his idea of national culture, Homi Bhabha with his idea of cultural hybridity, and Gayatri Spivak with her idea of the subaltern, contribute different approaches to post-colonial studies. Many other scholars have elaborated on the core concepts of these writers. In criticizing globalization, post-colonialism attempts to defend against homogeneous culture caused by global capitalism from the perspective of the colonized. Resistance, for example, is a broad arena in post-colonial discourse and it relates to many other issues.

According to Said, there are two types of resistances:

'primary resistance', literally fighting against outside intrusion, [and] secondary, that is, ideological resistance, when efforts are made to reconstitute a 'shattered community, to save or restore the sense and fact of community against all the pressures of the colonial system.' (as cited in Childs \& Williams, 1997, p. 252-3)

Here, I will focus the discussion on ideological resistance and limit the discussion to its relationship to the subjectivity of the colonized and national culture. This is relevant to my study because these two concepts tie together the current issues in Taiwan, namely, national identity, which consists of political identity and cultural identity. Among the post-colonial thinkers, Homi Bhabha's notion of colonial relations and Fanon's concept of national culture are often quoted to explain the issues of cultural identity and 
nationalism in Taiwan's cultural studies. As a result, this section is an attempt to analyze the post-coloniality of Taiwan and perceive its reaction to colonialism and cultural imperialism.

\section{Theoretical Review}

1. Homi Bhabha: ambivalence, mimicry and hybridity.

A mixture of psychoanalysis and deconstruction, applied to the analysis of colonial relations, is the major approach Bhabha adopts. Moreover, Foucault's discursive discourse $^{12}$ and power relationships are also taken into consideration. Unlike Said, rather than only focusing on the analysis of power relations from the aspect of the colonizer, Bhabha provides the analysis of colonial relations from both the colonizer and the colonized perspectives. His approach illuminates issues regarding colonial discourse, anti-colonial resistance, and post-colonial identity. It consists of three core concepts: ambivalence, mimicry, and hybridity (Childs \& Williams, 1997). These concepts are intertwined and they should be understood as a whole.

Here ambivalence and mimicry are the major concepts discussed within a process of identification. Bhabha points out that there is an ambivalent identification process between the colonizer and the colonized. That is because "[colonial] identity does not subsist in perceiving a self-reflection in human nature or a place for the self in a distinction between culture and nature, but in a relation to the Other" (Childs \& Williams,

\footnotetext{
${ }^{12}$ In Foucault's word, the term 'discourse' means "a group of statements which provide a language for talking about - a way of representing the knowledge about - a particular topic at a particular historical moment" (as cited in Hall, 1997, p. 44). He also believes that "the production of knowledge and meaning [are] not through language but through discourse" (p. 44).
} 
1997, p. 124). ${ }^{13}$ Moreover, the term mimicry used in a post-colonial context refers to "the desire for a reformed, recognizable Other, as a subject of a difference that is almost the same, but not quite. Which is to say, that the discourse of mimicry is constructed around an ambivalence" (Bhabha, 1994, p. 86).

To be more specific, in the process of identification the colonizer and the colonized identify their roles with the social norms set up based on colonialism. In this colonial system, the self-images of the colonizer and the colonized are constructed based on a binary conceptual system, such as master versus slave, good versus evil, industrious versus lazy, and the like. In other words, the colonizer is associated with positive characteristics while the colonized with negative. As a result, both of them adopt this constructed ideology. However, Bhabha suggests that the colonized also have their power to influence the system. That is, due to the difference, the meaning of civil matters which represent colonial authority, as performed by mimic men, is altered. For example, in his article, Signs Taken for Wonders, Bhabha (1994) discusses how the Bible became hybridized through its cultural transmission to the colonized in India. In this case, colonial authority is seen to shrink because the colonized/mimic men can articulate the colonial signs in different ways. As a result, it can be used as a resistance to colonialism. As Bhabha puts this idea:

Resistance is not necessarily an oppositional act of political intention, nor is it the simple negation or the exclusion of the 'content' of another culture, as difference once perceived. It is the effect of an ambivalence produced within the rules of recognition of dominating discourses as they articulate the signs of cultural

\footnotetext{
${ }^{13}$ The term the Other is a major concept in post-colonial studies. The Other is the opposite of European. It refers to Said's notion of Orientalism, which is a critically analysis of the representation of East in the Western literature in the nineteen century. Said argues that the concepts and knowledge associated with the Oriental were constructed by the West. The representations of the East oftentimes were portrayed negatively.
} 
difference and reimplicate them within the deferential relations of colonial power. (Bhabha, 1994, p. 110)

Rather than discussing the violence of colonialism, Bhabha places an emphasis on cultural hybirdity, in which he distinguishes within the colonial discourse a difference between "a self and its doubles, a "mother culture and its bastards"" (Childs \& Williams, 1997, p. 134). In the case of the Bible mentioned above, since what the colonized learns from the colonizer will be reinterpreted, "[h]ybridity shifts power, questions discursive authority, and suggests, contrary to the implication of Said's concept of Orientalism, that colonial discourse is never wholly in the control of the colonizer" (p. 136). In other words, when adopting the notion of cultural hybridity, one can think that the colonized tend to mix civil culture imported by the colonizer with their local practices, based on their own interpretation. This suggests that the power which the colonized holds is a resistance to colonialism.

\section{Frantz Fanon: national culture.}

Fanon was a Christian psychiatrist from Martinique who devoted himself to the fight for national freedom against the French colonialism and he inspired his followers to read back the colonial text and reexamine their beliefs toward the colonizer (Loomba, 1998). Since native traditions were oppressed during the colonial era, he suggests that "resistance to colonial rule is routinely 'attributed to religious, magical, fanatical behavior"' (as cited in Loomba, 1998, p. 139). The colonized had been told that they did not have culture and history before the settler/colonizer came. Thus, modern civilization gives birth to culture and history to the colony. In his article, The Wretched of the Earth, Fanon (1994) states: 
The settler makes history and is conscious of making it... Thus the history which he writes is not the history of the country which he plunders but the history of his own nation in regard to all that she skims off, all that she violates and starves." (p. 165)

Consequently, a loss of the native history and culture inevitably occurs. "Anti-colonial struggle therefore had to create new and powerful identities for colonized peoples and to challenge colonialism... the idea of the nation was a powerful vehicle for harnessing anticolonial energies at all these levels" (Loomba, 1998, p. 185). Thus, Fanon (1997) suggests that a national culture should widely represent the people and keep their existence alive. For this existence, native intellectuals play a crucial role in awaking people to their traditions. Moreover, native intellectuals are responsible for representing the subaltern because they cannot speak for themselves (Spivak, 1995).

In the quest to reveal national identity, national literature is a crucial matter.

Fanon (1997) identifies three phases of the evolution of national literature within a postcolonial culture, in which native intellectuals are involved.

In the first phase, the native intellectual gives proof that he has assimilated the culture of the occupying power. His writings correspond point by point with those of his opposite numbers in the mother country...In the second phase we find the native is disturbed; he decides to remember what he is... Finally, in the third phase, which is called the fighting phase, the native, after having tried to lose himself in the people and with the people, will on the contrary shake the people. Instead of according the people's lethargy an honored place in his esteem, he turns himself into an awakener of the people; hence comes a fighting literature, a revolutionary literature, and a national literature. (p. 101-2)

These phases also can be applied to establishing national works of art. Through this evolution, it is suggested that not only do native intellectuals resist the dominant ideology created by the colonizer, but also there is a process of decolonization operating. Example: Post-colonial Discourse within Taiwan's Cultural Context 


\section{1. debate: postmodernity or post-coloniality.}

Whether contemporary Taiwan is a postmodern or a post-colonial nation is debatable. Although both the major projects of postmodernism and post-colonialism are similar, ${ }^{14}$ post-colonialism is "consistently more politicized than postmodernism and resistant to the latter's hegemonic propensities" (Childs \& Williams, 1997, p. 17). Alongside this idea, postmodernism can promote cultural diversity in Taiwan's society while post-colonialism is able to criticize Chinese, American, and Japanese cultural imperialisms in Taiwan.

In their book, An Introduction to Post-Colonial Theory, Childs and Williams (1997) raise four questions in discussing the term post-colonial: when, where, who, and what is the post-colonial? The questions of when and who, in particular, are useful in discussing the post-colonial in Taiwan's cultural context.

\section{2. when is the post-colonial?}

If Taiwan is a post-colonial nation, then the question will be: when did postcolonialism begin? Although the conditions of colonialism and post-colonialism may exist simultaneously (Mishra \& Hodge, 1994), in current Taiwan's cultural context, the post-colonial condition is oftentimes discussed based on the period after the Japanese colonizer left Taiwan. There are two interpretations embedded in different ideologies: Chinese consciousness and Taiwanese consciousness. ${ }^{15}$ People who hold Chinese

\footnotetext{
${ }^{14}$ According to Ashcroft, Griffiths and Tiffin (1995), "the major project of postmodernism- the deconstruction of the centralized, logocentric master narratives of European culture, is very similar to the post-colonial project of dismantling the Centre/Margin binarism of imperial discourse. The decentring of discourse, the focus on the significance of language and writing in the construction of experience, the use of the subversive strategies of mimicry, parody and irony - all these concerns overlap those of postmodernism and so a conflation of the two discourse has often occurred" (p. 117).

${ }^{15}$ Chinese consciousness refers to a strong belief that the root of Taiwan is based on so-called orthodox Chinese culture brought by the Chiang Kai-shek government. In contrast, Taiwanese consciousness refers
} 
consciousness think that post-colonial Taiwan began right after Japan returned Taiwan back to China in 1945. Those with Taiwanese consciousness believe that it started after the martial law lifted in 1987 (Chiu, 2000; Chen, 2000). The major difference between these two interpretations is whether the Chiang Kai-shek government is perceived as a foreign power. If so, when the political elites from China took over Taiwan from Japan, an internal colonialism started with the Mandarin language (Standard Chinese) and socalled orthodox Chinese culture. There were strongly installed and practiced in schools while local dialects and folk cultures were prohibited. This was an attempt to reinforce Chinese consciousness on the one hand, and it was also to demonstrate the superiority of the orthodox Chinese culture on the other hand. As a result, Taiwanese consciousness had been oppressed during the Kuomintang (the Nationalist Party) era (1945-1987). It was not until the martial law lifted that the right of free speech was protected. Since then, Taiwanese consciousness has grown. Consequently, the issue of "de-Chineseness" and "re-Taiwaneseness" became a political and cultural trend. (This will be elaborated latter in this chapter.)

\section{3. who is the post-colonial?}

This question also depends on whose interpretation is taken. Based on the first interpretation, the Japanese are the colonizers while the Taiwanese, which includes aborigines and the Han immigrants from China before the Japanese colonial era, are the colonized. According to the second one, the Japanese and the Kuomintang and its followers from China in 1947, are the colonizers while the Taiwanese, the colonized.

to its root having grown in this land since the Japanese colonial era (a detailed discussion will be presented in the part two). 
However, these two interpretations are problematic from the perspective of aborigines because the history of Taiwan embedded in these two interpretations is based on Hancentrism rather than that of the land itself. In this sense, the aborigines' voice is usually excluded in this debate.

Today, it is urgent for Taiwan to fight for its national identity because the debate over Taiwan's independence has been argued between Taiwan and Mainland China for the past four decades. That is because the Chiang Kai-shek government lost its membership in the United Nation in 1971 and Mainland China received the legitimated position representing old China. Since then, Taiwan has become a name for the island rather than for a nation. Although Mainland China has never physically taken over Taiwan, its hegemony has prevented Taiwan from participating in global events. And, China strongly insists on the notion of its ownership of Taiwan.

The application of post-colonial theory is widely used to explain the foreign cultural influence as cultural imperialism, such as American and Japanese cultural imperialism. The major example is the importation of American and Japanese popular culture through the media to Taiwan. Under this influence, Taiwanese including aborigines, Han immigrants, and Mainlanders (immigrants from China after 1947) are the post-colonial population.

In short, post-colonial discourse in Taiwan, with a broad definition, can be briefly divided into resistances to four dominant cultural influences, namely, against the Japanese colonialism, against the Kuomintang monocracy, against the hegemony of Mainland China, and against the American and Japanese popular cultural imperialism. 


\section{4. decolonization: de-Chineseness or re-Taiwaneseness.}

When discussing cultural imperialism in Taiwan, there are three major forces. They are Chinese, American, and Japanese. Among them, recently, Chinese cultural imperialism is the most debatable. Based on Fanon's idea (1997), restoring national culture and reconstructing national identity are a way to decolonization. Accompanying the political and social movements since the 1980s, "de-Chineseness" and "reTaiwaneseness" have become important ideals associated with political and cultural policy (Hsiao, 2002). As a result, reconstructing and restoring memories of the past, which have not always been honestly told, is extremely important.

However, it needs to be clarified that the term "de-Chineseness", at least, implies two different ideologies. One tends to get rid of all Chinese influence including Mandarin and Chinese culture. In this sense, its supporters believe that they are Taiwanese and not Chinese. In doing this, Taiwan can become truly independent. In contrast, the other one proposes that Chinese culture is one of the fundamental roots of Taiwan and there is no need for the change of official language because Mandarin has been popularly used and accepted. Based on Bhabha's idea of mimicry and hybridity, Mandarin and Chinese culture can be adopted to show a resistance to Chinese hegemony (Chiu, 2000). If Min-na Hua (major local dialect in Taiwan) replaced Mandarin because it represents 70 percentage of the population, then it implies the ideology of Hokklo-centrism (the major population of the Han in Taiwan is the Hokklo group). Although supporters with this idea agree that they are Taiwanese and also Chinese culturally, they resist the "Sinocentrism", which is cultural essentialism, held by Mainland China (Chu, 2003). In other words, they defend against the hegemony of Chineseness, controlled by Mainland China, 
and embrace a Chinese of difference in Taiwan. Personally, I take the stance of the second ideology because I believe that the first ideology oversimplifies the post-colonial condition of Taiwan and it implies cultural essentialism which can prevent one from appreciating cultural diversity and cultural hybridity.

5. embrace cultural imperialism: English as a global language.

"[T]he English language is a tool of power, domination and elitist identity, and of communication across continents" (Kachru, 1995, p. 291). The colonial English language, such as that in India, has established its superior social status in society and is still in control. Currently, many Asian countries are involved in promoting English education due to its function as an international communication tool. In Taiwan, English and Japanese are two major foreign languages, with American English having crucial influence. The Ministry of Education announced that the EFL (English as a Foreign Language) program would become part of the school curriculum at lower grade levels in 1997. It has reinforced the demand for English education. Bilingual kindergartens can be seen everywhere in urban and suburban areas. The use of English in curriculums across disciplines is also highly recommended in higher education. People with better English ability are more competitive in the job market and English also has become a requirement for present government officers with higher ranks. This is because Taiwan highly relies on international business and the trend of globalization forces the local to be more internationalized. As a result, English literacy has become a national movement. As in India, English is considered a superior language and it has formulated an ideology in Taiwan. For example, many parents believe that young children need to be exposed to an English environment early in life. Learning local dialects is not as important because 
English will be more helpful to children in the future. In college, majoring in English language is considered better than studying in Chinese. In this sense, American cultural imperialism has gradually and firmly grown its roots in Taiwan.

\section{Resistance to or Celebration of Globalization in Terms of the Taiwanese Picturebooks}

I think that the work of Taiwanese picturebook publishers, who intentionally promote representation of Taiwanese culture, should be considered not only as resisting the pressures of globalization, but also as celebrating the values of globalization. This is because there are at least two different perspectives to approach cultural globalization. One is to consider that a homogenous global culture is a result of globalization, which is the major issue regarding cultural imperialism. The other is to emphasize that localization in responding to globalization, namely glocalization, tends to maintain cultural diversity in locals and, in this sense, global culture is a stimulus for cultural change. I will elaborate on this discussion in the following sections based on the literature reviewed above.

\section{Cultural Imperialism: A Resistance to the Pressures of Globalization}

Based on the concept of globalization as global capitalism and cultural imperialism, theories of cultural globalization and post-colonialism argue that Western cultural hegemony controls the underdeveloped and developing countries through a process of global economics. The publication of children's picturebooks in recent Taiwan's book market well illustrates this issue. The major project of post-colonialism is to resist cultural imperialism and to deconstruct the "Center/Margin binarism of imperialism discourse" (Ashcroft, Griffiths and Tiffin, 1995, p. 117). The work of 
Taiwanese picturebook publishers to intentionally promote representations of Taiwanese culture can be considered a way to resist this cultural imperialism.

Due to globalization, more and more foreign picturebooks (most of them from English speaking countries) have been translated with the advantage of lower-cost and, as a result, these translated picturebooks occupy most of children's picturebook publication in Taiwan yearly. Moreover, picturebooks published in English have been directly imported because of the demand for English education. They are inevitably dominant in Taiwan's book market, which limit the room for local picturebooks. Moreover, these picturebooks usually represent western cultures and values. This raises the critical issue that these translated and English picturebooks take a major position to represent the world to Taiwanese children. As a result, the view from Taiwan's local cultures is missing and should be addressed. The work of Taiwanese picturebook publishers who intentionally promote representations of Taiwanese culture is to approach this missing cultural representation. In other words, these Taiwanese picturebooks can be seen as a means to recall a memory of native culture or to create an invention of a tradition, which is oftentimes used as a strategy in competing with global culture (Robertson, 2002).

In addition, the concept of de-Chineseness and re-Taiwaneseness is an example to illustrate the ideological resistance to foreign influence, as Said mentioned above. These ideas are also present in Taiwanese picturebooks through the emphasis of the representation of local culture and local dialects. This is to strengthen children's local knowledge and to cultivate their national identity. Therefore, the work of these Taiwanese picturebooks should be seen as a resistance to the pressures of globalization/cultural imperialism. 
Glcoalization: A Possible Approach to a Global Market

Taiwan devotes itself to high tech and recreational industries in order to raise its competition in a global market at the present time. Based on this direction, technology education and foreign language education (mainly English) are encouraged. This policy intends to make the Taiwan market more internationalized in order to successfully integrate itself into the global market, which tends to embrace globalization. Moreover, locals are encouraged to develop their own businesses which contain their unique local cultural elements based on their own traditions, namely, creative cultural industry. In this sense, the policy can be seen as a strategy of glocalization and it is not only a resistance to the pressures of globalization, but also a possibility to approach global economics. Moreover, if one considers "globalization as hybridization" (Pieterse, 2000), then the work of Taiwanese picturebooks can be seen as a potential local cultural production, which is a combination of a modern western picturebook format and the content of Taiwanese life experience and scenery, to reach the international book market which places an emphasis on cultural diversity. In this sense, local stories become a unique cultural characteristic in competing with picturebooks from different countries around the world. For example, the picturebook The Mouse Bride: A Chinese Folktale, illustrated by Lesley Liu and retold by Monica Chang, ${ }^{16}$ won the best illustration of the year for 1994 in one of the international award competitions. And, this book has been published in several different languages, such as Chinese, English, Japanese, Korean, Spanish, and Vietnamese. Due to globalization, the international exchange of picturebooks has become

\footnotetext{
${ }^{16}$ The English names of the illustrator and writer for the picturebook are printed on the book cover. This indicates the popularity of English names used in the business world of Taiwan, as Hsiao (2002) mentioned above.
} 
more possible and accessible. In addition, this can be seen as a successful glocalized production.

Part II. Historical Context: the Development of Taiwanese Consciousness

This section will focus on cultural movements and the national political movements, as a way to show the continuing development of a unique Taiwanese consciousness. It will analyze both the political and cultural movements in terms of this emerging Taiwanese consciousness. From a political perspective, three aspects of Taiwanese consciousness will be discussed: (1) resistance to the Japanese colonialism, (2) resistance to the Kuomintang's monocracy, and (3) resistance to the hegemony of Mainland China. From a cultural perspective, the important cultural movements associated with Taiwanese consciousness will be reviewed: (1) the "hsiang-t'u" (native culture) literary movement in the 1970s, (2) the indigenous cultural renaissance movement since the 1980s, and (3) the debates in the art world in the 1950s and 1990s. The common motivation of these movements is to defend against a modern or foreign influence and to reflect the identity of Taiwanese culture in responding to social reality. Due to evolving social change, each of these movements provides different perspectives toward cultural matters and has had differing levels of success. Based on this framework, I will discuss the current picturebook movement as a calling for Taiwanese identity.

A Search for Taiwanese Identity:

The Development of Taiwanese Consciousness from a Political Perspective A Brief History of Taiwan before the Japanese Colonialism

Taiwan is a multicultural society due to the different political powers which have ruled this territory and imposed their cultures during the past 400 hundred years. 
Originally, people of Malay-Polynesian descent settled in the low-lying coastal plains. They were the ancestors of the present-day aborigine groups. They have lived in different areas of Taiwan, but never unified as one powerful political group to control Taiwan. It was not until the $16^{\text {th }}$ century that Portuguese navigators "discovered" Taiwan and called it Ilha Formosa, the beautiful island, that Taiwan was recognized in western history. Since then, both the Spanish and Dutch colonized parts of Taiwan because of their economic interests.

In 1661, after being defeated by the Manchus in China (who created the Qing Dynasty), Cheng Chen-gong, the last general of the Ming Dynasty (which was created by the Han Chinese), ${ }^{17}$ lead 25,000 nobles, soldiers, and pirates to invade Taiwan and expelled the Dutch. In 1683, Cheng Chen-gong's descendents and soldiers lost Taiwan after a battle with the Manchus, which allowed the Qing Dynasty to take over western Taiwan. During the Qing Dynasty era (1683-1895), more and more Han Chinese settled in Taiwan. As a result of this immigration, the Han Chinese became the major population in Taiwan.

\section{Taiwanese Consciousness as a Resistance to the Japanese Colonialism}

The roots of Taiwanese consciousness can be traced back to the Japanese colonial era (1895-1945) and it has been growing up to the present day, according to Huang Jiunjie, a history scholar (2000). During the Cheng Chen-gong era (1661-1683) and the Qing dynasty (1683-1895), Han immigrants rarely had a Taiwanese consciousness, but strongly held different local consciousness based on where their ancestry originally came

\footnotetext{
${ }^{17}$ The Han Chinese are the majority of the population in old China. And, the so-called orthodox Chinese culture followed by the Han Chinese is based on Confucianism, which has become a dominant culture. As a result, the Han-centrism became a particular ideology shown in history and politics.
} 
from. ${ }^{18}$ In 1895 , the Sino-Japanese War ended and China ceded Taiwan to Japan. It was

not until Japan took over Taiwan that these Han immigrants developed a sense of

togetherness as Taiwanese, which differed from the colonizer Japanese, and another

colonized group, the aborigines. ${ }^{19}$ Thus, Taiwanese consciousness became a resistance to

colonialism (Huang, 2000).

Taiwanese Consciousness as a Resistance to the Kuomintang's Monocracy

After Japan lost World War II in 1945, Taiwan finally returned to China and was

ruled by the government of the Republic of China (R.O.C.), which took over after the

Qing dynasty lost her legitimate political power in 1911. During the period from 1945 to

1949, Taiwan was ruled by a local government and governor who was assigned by

Chiang Kei-shek. His government was the Kuomintang (the Nationalist Party), which

was involved in a civil war on the Chinese Mainland with the communists. ${ }^{20} \mathrm{An}$

important event occurred when a local investigation of illegal cigarettes turned into riots

\footnotetext{
${ }^{18}$ These Han immigrants from different regions of the Fu-chien and Guang-tong Provinces (south coast of China) were mainly divided into three groups: Quan-zhou, Chang-zhou, (both Quan-zhou and Chang-zhou are Hokklo and speak Min-nan Hua, but with different accents) and Hakka (who speaks Hakka Hua). Due to the use of different languages, the practice of rituals and customs, and different time periods of immigrating to Taiwan, these Han immigrants competed with each other for Taiwan's natural resources. Since Quan-zhou was the first group and had the major population moving to Taiwan, they occupied most plains. Because the population of Chang-zhou was less than Quan-zhou and came later, they took the rest of the undeveloped plains. Hakka came after these two groups, so they developed mountainsides and lived near aborigines. As a result, aborigines were either forced to move into the mountains or assimilated to Han Chinese.

${ }^{19}$ These Han immigrants, the settlers, believed that they were superior to aborigines because they were proud of their Chinese culture. And they through that the aborigines were uncivilized. In this sense, these Han immigrants did not identify with the aborigines as the same group of people. It was not until the Wushe Incident occurred, which was a violent resistance to Japan by a tribe of aborigines in 1930, that Taiwanese intellectuals were aware of the fact that aborigines were part of the Taiwanese (Chen, 1998).

${ }^{20}$ Modern China (the Republic of China) was established in 1912 by the Kuomintang founded by Sun Yehshen when democracy was promoted to replace the traditional autocratic monarchy held by the Qing dynasty. Meanwhile, Sun Yeh-shen became the national father and the Kuomintang was the first and only one legal political party in China. After the death of Sun, Chiang Kei-shek was the successor as the leader of the party.
} 
and massacres in the cities of Taipei and Kaohsiung on February 28 in $1947 .^{21}$ It caused a political repression in which many innocent Taiwanese intellectuals and folks were killed or disappeared because they were suspected of being communist spies. This was called the "228 Incident" and it became a taboo to talk about this in Taiwan's history. After that, folks in Taiwan were taught not to become involved in politics and families of the victims in the "228 Incident" kept silent. Accordingly, Taiwanese consciousness transformed from resisting the Japanese colonialism to resisting the Kuomintang's monocracy (Huang, 2000).

The Chiang Kei-shek government and his followers fled to Taiwan in 1949 after being defeated by the communists. Later, Chiang Kei-shek was elected by senators, who were elected by the people in China, as the president of the Republic of China (R.O.C.) for all the rest of his life. During the era of Chiang Kei-shek and Chiang Ching-kuo (the son and successor of Chign Kei-shek), the Kuomintang represented the nation and controlled the national resources, as well as, political, military, economic, and social aspects of Taiwanese society. According to Winkler (1994), the objective of the Kuomintang was to reinforce "Chineseness" in Taiwan during 1945 1960 (as cited in Chou, 1998). A strong ideology of patriotism of "Great China" was promoted in society and it limited free speech for those with criticisms about the Kuomintang. The myth of "Great China" was to emphasize that Taiwan was the successor to a five-thousand-year

\footnotetext{
${ }^{21}$ The 228 Incident that led to a riot was not accidental because the society was controlled by an unfair government system which made the economic and social conditions worse after World War II. Taiwanese had a high expectation for the Chinese government after Taiwan was returned to the new democratic China. However, they were disappointed with the local government from China after several months when they realized that these officers were not as good as the Japanese and they worried about whether Taiwanese would be treated worse than when under the Japanese colonial rule. Besides this, language difference between the officers and soldiers from China and local folks caused misunderstanding. As a result, this
} 
Chinese traditional heritage which followed the orthodox Confucianism and which was intended to create a unified singular national narrative. Compared with this grand narrative, the island of Taiwan was placed in a marginal position. Thus, Taiwanese consciousness was oppressed due to a firm and strict political control. Meanwhile, Taiwanese intellectuals devoted their consciousness of Taiwan to literature rather than politics. These literary works encouraged the younger generation to resist the political repression. As a result, more and more Taiwanese intellectuals began devoting themselves to political movements for the right of free speech in the 1980s, one result was the "Mei-li Dao Incident.",22

During this era, the identity of the early Han immigrants was Chinese in the Taiwan Province. The population in Taiwan was categorized as "wai-sheng ren" (which means mainlanders, including followers of the Chiang-Kei-shek government from China), "ben-sheng ren" (which means state-residents, including the early Han immigrants), "ping-di shan bao" (which means plain aborigines living in cities), and

tragedy inevitably happened. This summary is based on the information gathered from the government archives database, at http://www.archives.gov.tw/228/.

${ }^{22}$ Mei-li Dao means beautiful island, drawn from the word Formosa in Portuguese. It was a political magazine established in the summer of 1979, which often criticized the Kuomintang. During the martial law era, mass media was controlled by the Kuomintang. Any criticism about the government was excluded from the dominant media, such as TV and newspapers. Therefore, political elites who resisted the Kuomintang's monocracy formulated a political group and published magazines to criticize the government. According to the martial law, it was illegal to organize any political party and collective demonstrations. Thus, these non-Kuomintang political elites attempted to fight for the remove of the martial law and to protect the right for free speech. On December 10, 1979, International Human Rights Day, the non-Kuomintang political elites organized a demonstration for supporting the declaration of international human rights in Kaohsiung. However, this demonstration was considered illegal by the local police. Unfortunately, physical conflicts occurred between the crowd and the police. As a result, it turned into a riot and later the major political activists were arrested and were put into jail due to this illegal collective activity. This summary is based on the information provided by the website of the Education Ministry, at http://content.edu.tw/local/kaushoun/dazen/country/38/index.htm. In 1986, the nonKuomintang political elites organized their own party, namely the Democratic Progressive Party (DPP). Through constant resistances to the Kuomintang's monocracy during the 1980s, the martial law was finally lifted in 1987. In 1991, the DPP passed a program of proposing Taiwan's independence. And, the party won the presidential elections in 1996 and 2004. 
"shan-di shan-bao" (which means mountain aborigines living in mountains). During this period, the term Taiwanese narrowly referred to "ben-sheng ren."

\section{Taiwanese Consciousness as a Resistance to the Hegemony of Mainland China}

According to Song Kuo-cheng (2003), a researcher of the Center of International Relation at the Chenchi University, the idea of indigenization originally came from a resistance to the political oppression and invasion by Mainland China. Since the postChiang Ching-kuo era (during the late 1980s), the government of the R.O.C. has gradually shifted its attitude from being a democracy fighting for the legitimate position of representing old China to being an independent democratic nation. As a result, the concept of indigenization is now a means to identify with Taiwan itself rather than the imagery of old China. Therefore, many Taiwanese born politicians have been assigned the higher positions in the government body, which was impossible during the Chiang Kai-shek era. This implies that the government has tended to indigenize its political power and public policy.

After the death of Chiang Ching-kuo, Li Deng-hui (a vice president of Chian Ching-kuo) became the first president voted into power by the people in 1990. Since Li was a "ben-sheng ren" (state-resident), his identity caused the movement of indigenization to carry a significant political meaning. That is, Taiwan was finally ruled by a Taiwanese president, although he was a leader of the Kuomintang. In Li's view, rather than using the name of "the R.O.C. in Taiwan" to represent the island, the term "Taiwan" should be used to stand for this nation. This notion has become a political agenda and it has provoked Mainland China, who proposes its ownership of Taiwan. In order to clarify the debate of the definition of Taiwanese, Li claimed that all people who 
live in Taiwan and are willing to devote their lives to this land are Neo-Taiwanese. In this sense, the Taiwanese population body is categorized as Hokklo, Hakka, "hsin-chu-min" (which means new residents or mainlanders, immigrants from China after 1945), and "yuan-chu-min" (which means aborigines). This new definition is meant to prove the idea of Taiwan's independence ${ }^{23}$ and to unify Taiwanese consciousness as a means to resist the hegemony of Mainland China.

The current president Chen Shui-bian, who succeeded Li Deng-hui in 1996, has continually practiced Li's indigenization based on Taiwanese consciousness. Like Li, he is a "ben-sheng ren" (state-resident) and his party, the Democratic Progressive Party (DPP), represents Taiwanese intellectuals who promote Taiwan's independence. It is an irony that Chen's party has taken over the country in the name of the R.O.C. since 1996. As a result, the DPP highly emphasizes Taiwan as the national name on many important occasions, which is a strategy to promote the individuality of Taiwan. ${ }^{24}$ During the DPP era, the government body has gradually been becoming more indigenized. For example, "ben-sheng ren" (state-residents) have been promoted as administrators at higher levels and the use of everyday language has not been limited to Mandarin. Moreover, it is obvious that Taiwanese consciousness has heavily influenced public issues and policy making. For example, recent cultural policy for strengthening Taiwanese consciousness consists of promoting an equal right for different native languages (including local dialects like Min-nan Hua, Hakka Hua, and various aboriginal languages), preserving and

\footnotetext{
${ }^{23}$ However, Sun (2000), who is an aboriginal scholar, criticizes this definition because it is based on the Han-centrism and it is problematic. (This will be elaborated in the section of Criticism of Taiwanese consciousness: from an indigenous perspective.)
} 
researching traditional Taiwanese cultural heritage (including historical buildings, local customs, and rituals), promoting cultural creative industries, and recruiting and training cultural volunteers and professionals (Council of Cultural Affairs, 2004). All these local cultural practices and political movements of a calling for national identity are based on Taiwanese consciousness as a means to resist the hegemony of Mainland China.

\section{Summary}

In sum, from a historical view, Taiwanese consciousness, basically, is a resistance discourse, which has transformed from the resistance to the Japanese colonialism, to the resistance to the Koumintang's monocracy, to the resistance to the hegemony of Mainland China (Huang, 2000). However, when taking cultural influence into consideration, we should also review the significance of Taiwanese consciousness embedded in the "hsiang-t'u" (native culture) literary movement, namely, its resistance to western cultural imperialism or American cultural imperialism in particular (Chen, 1998).

Taiwanese Consciousness from a Cultural Scope: Resistance to Westernization and the Kuomintang's ideology-Hsiang T'u (Native Culture) Literary Movement

\section{Historical Background}

As mentioned above, Taiwan was controlled by the Kuomintang's monocracy from 1949 to 1987, which is a "re-colonial" era in Taiwan based on Chen Fang-ming ${ }^{25}$ (2002), a scholar in Chinese literature. The right of free speech was restricted by the martial law. And, the "228 Incident" had a great impact on the local population. Due to

\footnotetext{
${ }^{24}$ However, the Kuomintang and its related parties have argued the existence of the R.O.C. in Taiwan. Although different parties hold their own interpretation toward the idea of Taiwanese consciousness, the common goal of it is to resist the hegemony of Mainland China (Chen, 1998).
} 
the political repression, popular themes of literature in Taiwan during the 1950s and 1960s were patriotism, anti-communism, and nostalgia for the homeland. Another literature trend was to adopt modern literary theories to investigate new form of writing. ${ }^{26}$ This development was intended to avoid touching any political taboo. As a result, these literary works were not able to reflect social reality in Taiwan's society.

During the 1970s, Taiwan faced dramatic changes in international politics. In order to protest the fact that the United Nation accepted communist China as a member, the Chiang Kei-shek government decided to withdraw from this international organization in 1971. Japan and the United States in succession broke off diplomatic relations with the R.O.C. and established relations with Mainland China in 1972 and 1979, respectively. As a result, Taiwan became an isolated island losing important diplomatic support and questioned international justice. Besides this, in 1971, the "Tiaoyu Tai (or Senkaku) Incident" ${ }^{, 27}$ provoked collective demonstrations in the United States organized by Taiwanese students. Taiwanese intellectuals and colleges students also enthusiastically joined the "Defending Tiao-yu Tai Movement" in Taiwan. Alongside

\footnotetext{
${ }^{25}$ Chen (2002) classifies the colonial history of Taiwan into three categories. They consist of the colonial era (ruled by Japan), the re-colonial era (controlled by Kuomintang), and the post-colonial era (present). ${ }^{26}$ During the Cold War era, the world was divided into two parts: democracy and communism. The United States was the leader of the democratic world. In order to strengthen a democratic bond, the U.S. helped the Third World to develop their countries based on the idea of democracy. Thus economics, politics, and culture in these countries were influenced by the American academia. Since formalism, which is not interested in social context and is kept out of politics, was popular during the Cold era, it was also popular in Taiwan's literary world.

${ }^{27}$ According to Chen (1991), "The Tiao-yu Tai was a group of islands to the northeast of Taiwan occupied by the United States since the end of World War II. Both Japan and Taiwan laid claim to these islands after oil had been discovered there. The United States, nevertheless, decided to return them to Japan in 1972" (p. 64-5).
} 
these changes, college students have been encouraged to participate in forums regarding social and political issues. And, in doing this, they have gained more national consciousness.

Major Issue: A Resistance to Western Cultural Imperialism

This national consciousness has gradually become cultural awareness which drew attention to native culture. Consequently, a trend of embracing native culture was popular in the literature and art world. For example, folk art, rituals, and local dialects were adopted in the modern dances and novels. In responding to this social trend, many Taiwanese intellectuals, who held a socialist idea, criticized the current literature and writers for either losing themselves in the past or engaging in a literary utopia. In other words, their writings could not reflect social reality. Thus, they proposed a need for the literature of social realism. Meanwhile, the concept of "hsiang-t'u" was evolving as a literary movement inspiring many writers to look into their cultural roots. However, due to different ideologies regarding the notion of native culture, there inevitably emerged both a Chinese consciousness and a Taiwanese consciousness of "hsiang-t'u" literature. According to Chen (1991):

While "hsiang-t'u" theoreticians often rhetorically equated "hsiang-t'u" literature with 'national literature', the reality reflected in the literature itself was in fact confined to that of Taiwan rather than the Chinese reality as a whole. So while some "hsiang-t'u" theoreticians, such as Chen Ying-zhen, Yu Tien-tsung, and Wang To, shared a strong sense of 'Chinese consciousness' and a common political ideal, calling for a great, reunified China, there were other advocates of "hsiang-t'u" literature, such as Yeh Shih-tao, and Sung Tung-yung, who stressed "Taiwanese consciousness" over "Chinese consciousness," partly because of the current political reality and partly because of Taiwan's colonial past which had separated Taiwan from China. (p. 4-5) 
Despite the difference, the common goal of these two consciousnesses was to resist western imperialism in general because it represented modernization which brought a dramatic social change to Taiwan's society in the 1970s. In addition, the goal was to resist western literary influence in particular because western literary theories had dominated in Chinese modern literature in the 1960s.

As a result, the debate between the two different approaches, social realism versus formalism, was discussed in the forums of literary journals from 1972 to 1973. For example, Yen Yuan-shu, a scholar in western literature, argued that the functions of literature were more than serving for the social change proposed by "hisang-t'u" literature writers and it should not insult other functions of literature. In his article, What Crime Does a Poet Commit, Yu Guang-chong, a famous poet, also emphasized the value of good poems. "To $\mathrm{Yu}$, the ultimate obligation of a poet was to write good poems, not to reform the society" (Chen, 1991, p. 70). This also suggests that the value of aesthetics in relationship to literary work is also important. It is significant that this debate was to clarify the impact of modernism on Taiwan's modern poetry movement and the relationship between modernism and western colonialism or imperialism was discussed (Chen, 2002).

Since "hsiang-t" $u$ " literature intends to reflect the social reality of Taiwan in the 1970s, it is "generally perceived as a body of literary works which speak out for the poor and the downtrodden" (Chen, 1991, p. 149). In so doing, the setting of stories is usually in the rural or the urban in which the main characters suffer from economic and social change. The work by Huang Chun-ming, a representative writer, is frequently discussed 
for example. His stories fall into these two categories: the rural and the urban, and he creates different moods in these two different settings. As Chen (1991) analyzes his work:

Huang's rural stories are usually narrated in a lyrical, nostalgic mood, while the narrative stance in his urban stories is mainly nationalist and satirical. Both Huang's nostalgia of the agricultural society and his nationalist stance of antiwesternization may all result from the same feeling of profound loss of past simplicity and purity through the ravages of modernization, a close equivalent of westernization for Taiwan society. (p. 117)

It is obvious that the writer is in favor of agricultural society and criticizes the social change caused by modernization. The resistance to western influence shown in "hsiangt'u" literature comes not only from the content, but also the style of writing. In order to present the peasants' voice, writers need to imitate the daily language they use with a simple and plain tone. Thus, western modern literary theories are useless in this case. Major Issue: A Resistance to the Kuomintang's ideology

Accompanying the growth of diverse "hsiang-t'u" literary works with different approaches to the idea of native culture, criticisms around definitions and related issues regarding "hsiang-t'u" literature were continually discussed from 1976 to 1977 . One group thought that the concept of native culture should connect to Chinese cultural traditions, while another proposed that it should be based on Taiwanese identity. Therefore, it finally became an ideological debate between Chineseness and Taiwaneseness. Chen (2002) remarks that the first debate of the "hsiang-t'u" literary movement indirectly criticized the government, while the second one directly challenged Kuomintang's ideology. 
In short, "hsiang-t'u" literature supporters attacked the idea of adoption of western literary theories to the analysis and creation of Chinese modern literature because it limited its popularity and the acceptance by the general public. In contrast, modern literature followers argued that "hsiang-t'u" literature limited their vision of the literary world. Both criticisms pointed out the weakness of the other's approach. However, the debate is still a dilemma for writers, researchers, and readers today because of different political ideologies they hold.

\section{Summary}

According to Wang To, who is a representative theoretician of "hsiang-t'u" literature, in order to resist cultural imperialism, it is necessary to reevaluate and revise native culture and use it as a foundation on which new culture is established (Chiu, 2003b). This is one reason why "hsiang-t' u" literature contains a strong sense of national consciousness. In short, as Chen (1991) states:

Politically speaking, "hsiang-t'u" literature stands for a progressive force which is confronted more directly with socio-political issues, while modernist literature often shies away from them. Culturally speaking, however, 'hsiang-t'u" literature represents a conservative force which clings more to indigenous culture and resists Western influences. (p. 10)

Thank to "hsiang-t'u" literature, some aspects of Taiwanese culture during the transitional period from an agricultural society to an industrial one are preserved. Moreover, local consciousness was also embedded in this movement, which helped create a strong demand for localization based on Taiwanese identity. 


\section{Reflection on Taiwanese Consciousness: Resistance to Han-centrism-}

\section{From the Indigenous Cultural Renaissance Movement}

Chinese consciousness has gradually decreased since the 1970s while deChineseness and Taiwanization have strongly grown since the $1980 \mathrm{~s} .{ }^{28}$ As a result, the concept of Taiwanese identity has become a challenging issue across different disciplines, such as literature, art, education, cultural studies, politics, and so forth. For example, accompanying the debate of "hiang t'u" literature in the 1970s, Taiwanese consciousness has grown stronger into literature. It was not until the 1980s that the vision of native culture became wider and clearer. Because of this, the major issue of the literary world became how to define: “What is Taiwanese literature?"(Chiu, 2003a; Li, 1993). ${ }^{29}$ This question indicates that the indigenization movement addresses a national culture discourse; namely, it is necessary for Taiwan to establish its own account of a national literature. $^{30}$

According to Chiu Kuei-fen (2003a), a scholar in Taiwan's literature and foreign languages and literature, Taiwan's literature, based on Taiwanese consciousness, emphasizes that the content of this literature should be rooted in the life experiences embedded in this land. This suggests that Taiwanese consciousness is not limited to the

\footnotetext{
${ }^{28}$ The "Meei-li Dao Incident" helped to raise Taiwanese consciousness in the general public; by the same token, Chinese consciousness has decreased (Hsieh, 1995).

${ }^{29}$ There are at least two different interpretations of this question. One interpretation is that Taiwanese literature is a branch of Chinese literature. People who hold this idea believe that the use of language in both Taiwanese literature and Chinese literature is the same. And, the basis of Taiwanese literary roots are in Chinese literature. The other one is that Taiwanese literature is one genre of literature, which differs from Chinese literature, because it is embedded in a different cultural context. People in favor of this notion tend to challenge the Sino-centrism of Chinese literature. They argue that the Chinese language is used as a sign system in different areas, such as Malaysia, Singapore, and Taiwan, but each of them has its unique cultural context. Thus, their literatures have evolved in different directions. It would be inappropriate to see them as different braches of Chinese literature.
} 
binary thinking of "China versus Taiwan" or the political view of "nation versus native land." Rather, it should include diverse life experiences from all walks of life in this land. This indicates that the celebration of cultural diversity in Taiwan is crucial. Moreover, as Huang (2000) remarks, Taiwanese consciousness should move from a resistance discourse to a culture discourse. It is positive that the variety of literature has increased to present different aspects of Taiwan, including indigenous literature, women's literature, gay and lesbian literature, senior veteran literature, and environmental literature, which cover different issues regarding ethnicity, gender, class, sexual orientation, and environment.

In particular, indigenous literature represents a significant step to criticize the Han-centrism. This oftentimes provides a way to decode the racial relation in Taiwan's cultural contexts. For this reason, it is important to review the indigenous cultural renaissance movement and to gain an insight from the perspective of the indigenous population toward Taiwanese consciousness. This is a voice that was previously excluded.

\section{Indigenous Languages and Cultures Have Gradually Died out}

Originally, people of Malay-Polynesian descent settled in the low-lying coastal plains. They were the ancestors of the present-day indigenous groups. They have lived in different areas of Taiwan, but never unified as one powerful political group that took over the whole land. There are ten different tribes and each tribe has its own language, rituals and customs. They have been approached by the Han group since the Ming dynasty.

\footnotetext{
${ }^{30}$ Taiwanese literature has emerged as an independent genre of literature in the academic world. Scholars with different ideologies (Chinese consciousness and Taiwanese consciousness) hold different opinions toward this change.
} 
When a large population of the Han Chinese moved to Taiwan, they soon occupied most of the plains. As a result, aborigines were gradually forced to move into the mountains.

During the Japanese colonial era before 1939, the colonial rulers were liberal so that Taiwanese could keep their local dialects and customs. It was not until the policy of assimilation, known as "Kominka" (which means Japanization), was put into force in 1939 that Taiwanese were forced to learn the Japanese language and culture (Chen, 1991). During the Kuomintang era, the policy of assimilation was more firm and radical. As a result, indigenous languages and cultures have rapidly collapsed.

\section{Writing as Empowering Indigenous Culture}

Since the 1980s, cultural diversity has become gradually acceptable in Taiwan's society. Minorities have pursued their positions through social movements. An indigenous human rights movement is one of them and its mission is to fight for their own rights in order to establish their own identity. This movement questions and challenges the authority and privilege of the Han-centric ideology. The political and social actions include naming themselves and their children based on their traditional customs, reviewing the regulation of hunting in their mountains, restoring their mother tongues and cultures, and the like. Alongside these actions, many indigenous intellectuals started to express their native cultures through a written format with Mandarin which is an alternative way to document their history and cultures. Formerly, there was a lack of written language system in their indigenous cultures. However, the early literary works of Taiwan indigenous literature with a written form can be dated back to 1932, and these were written in Japanese, according to Walisi Nogang, an indigenous writer (Taiyi tribe) (2000). 
There are at least two different concerns about the definition of Taiwan indigenous literature, according to Walisi Nogang (2000). The first concern supported by Sun Da-chuan, an indigenous scholar in ethnic studies (Beinan tribe) is that Taiwan indigenous literature should be based on the author's indigenous identity no matter what subject matters they write about. The second concern proposed by Pu Chong-cheng, an indigenous scholar in language (Ziu tribe) is that the literature should consist of literary work dealing with the subject matters or contents related to aborigines without considering the author's ethnic identity. These two definitions tend to include as many literary works as possible into Taiwan indigenous literature.

However, some criticism regarding the use of Mandarin in writing Taiwan indigenous literature is inevitable. That is, the use of written language in Mandarin to tell indigenous history and cultures is debatable because Mandarin is not able to translate or may mistranslate some meaning embedded in indigenous cultures which can not be found in Han culture. Some indigenous intellectuals propose that new written language systems based on indigenous languages should be created. And, they believe that indigenous literature should be written in their own languages. Despite these different concerns about the definition of Taiwan indigenous literature, many Han intellectuals are also involved in the research or criticism of the literary works written by aborigines. As a result, these writings have formed a body of Taiwan indigenous literature (Sun, 2003).

In terms of the position of Taiwan indigenous modern literature in relationship to its social context, Walisi Nogang (2000) classifies three periods based on the political influence by different government bodies: the period of de-identity (1930 1945), the neglectful period (1946 1988), and the period of identity reconstruction (1988 present.) 
Recently, the notable indigenous writers who have been highly discussed in the academic world include Monaneng, Tianyage, Walisi Nogang, Xiaman Lanboan, and Awu (female). The motivation of most indigenous writers to tell their stories is similar. That is, they are sensitive to their ethnic identities and tend to establish their own identity through presenting their voices. To do this, they want to retell their history and cultures from an indigenous perspective. Many of their writings challenge the representations of aborigines and their cultures in the texts written by Han Chinese. They criticize the dominant Han-centrism in these texts and resist the stereotypes of aborigines constructed by Han. In order to reflect social reality in the indigenous community, these writers return to their native locations and are involved in cultural revival movements because they intend to practice their social actions from a cultural aspect. In this sense, writing can be seen as a means to empower indigenous intellectuals to reconstruct their own native cultures.

Criticism of Taiwanese Consciousness: From an Indigenous Perspective

According to Sun (2000), the indigenous people's voice was excluded in Taiwan's history due to its lack of a written language, although they have rich oral history traditions. Taiwan's history is essentially based on Han-centrism, even including the definition of Taiwanese. As mentioned above, the former president Li redefined the term Neo-Taiwanese as consisting of Hokklo, Hakka, "hsin-chu-min" (mainlanders), and "yuan-chu-min" (aborigines). Sun (2000) argues that this definition is in favor of ethnic Han Chinese because the first three groups are Han. They are separated into three categories due to political concerns. On the contrary, there are more than ten different 
tribes of aborigines, but all put into one category. ${ }^{31}$ That is because aborigines are not as important as Han Chinese in terms of sharing political resources. To some extent, Taiwanese consciousness should not limit its imagination to the Han-centrism based on a political view. It should be elaborated to include rich indigenous cultures originally from Malay-Polynesian heritages. In echoing this perspective, Tuobas Tamapima, an indigenous writer (Bunong tribe), asserts that Taiwan's literature already existed before Han Chinese immigrants came to Taiwan three hundred years ago, but it was spread in an oral form (including indigenous oral myths and tales) (as cited in Walisi Nogang, 2000).

\section{Taiwanese Consciousness through Art:}

\section{From Appropriation to Establishing Identity}

This section will review two major debates in the art world in the 1950s and 1990s, respectively. That is because, like literature in Taiwan, the western art influence is an invisible force affecting Taiwanese artists, critics, and audiences. The debate in the 1950s reflects the issue regarding tradition (based on Chinese consciousness) versus modern (namely, westernization), while that in the 1990s focuses on the notion of localization (based on Taiwanese consciousness) versus westernization. These two debates illustrate the complexity of the negotiations between tradition and the modern, as well as between localization and westernization.

\section{Rediscover Taiwan Art: A Political Agenda}

As mentioned above, due to the different political powers having established their ideas of culture in Taiwan, the artwork representing the nation has also varied over time.

\footnotetext{
${ }^{31}$ Taiwanese aborigines were officially divided into nine different ethnic groups in 1954. Recently, Pingpu plains aborigines, for example, were officially recognized by the government as an ethnic group. However, there are ten different tribes in the category of Pingpu plains aborigines. 
Today, many artworks by Taiwanese senior artists, who were born and educated in the Japanese colonial era, are collected by the Taipei Fine Arts Museum, which was established for modern art collection, research, and education. And, their artworks, depicting the landscape and folk life in the early 20 century of Taiwan, have been oftentimes used as cultural icons in the past decade due to Taiwanizaiton (based on Taiwanese consciousness). However, during the Koumintang era, these artworks were considered as Japanized painting, named "tong-yang-hua,", 32 which was inferior to socalled orthodox Chinese painting, named "kuo-hua" (based on Chinese consciousness) (Lin, 1987). This dramatic change indicates that political factors heavily influence the art world. And, the artwork may serve as a cultural symbol to represent a national identity or national consciousness. To some extent, these Taiwanese senior artists honestly depicted the surrounding they lived in during the early $20^{\text {th }}$ century, which was based on a western modern idea through the art education provided by Japan. It was not intend to express their Taiwanese consciousness. However, their artworks, which are now relocated in a trend of localization, have become representative artworks to visualize Taiwanese consciousness. This shows that the Taiwan art world tends to appropriate new concepts of art style from the western world, but has not established its own identity rooted in this land. The debates in the 1950s and 1990s demonstrate this dilemma.

Debate in the 1950s: Tradition versus Modern

As soon as the Chiang Kei-shek government took over Taiwan, the Mandarin language and orthodox Chinese culture were strictly enforced in society in order to

\footnotetext{
${ }^{32}$ According to Lin (1987), the term "tong-yang-hua" (Eastern painting) used in Japanese refers to Asian art in general. And, it is used to distinguish from the term "xi-yang-hua" (Western painting). Today, this type
} 
replace and reduce the Japanese influence. Many so-called orthodox Chinese artists, ${ }^{33}$ followers of Chiang Kei-shek, argued that the orthodox Chinese painting had not been inclusively introduced to Taiwan; therefore, "ben-shen ren" (state-residents) did not understand the difference between "kuo-hua" (orthodox Chinese painting) and "tongyang-hua" (Eastern painting) (Hsieh, 1998). They suggested that it was necessary to host exhibitions and demonstrations in order to educate the public. As a result, the art world was controlled by the conservative and patriotic oriented Chinese artists while the Taiwanese artists trained by Japanese were excluded. ${ }^{34}$

Accompanying the American influence which grew in Taiwan, young artists adopted western modern art theories through translated or imported publications. They were disappointed with the current environment and formed their own studio groups; the May Painting Society and the Eastern Painting Society were established in 1957. Both of them enthusiastically studied abstract expressionism, which was popular in the 1960s in the Western world (Lin, 1987). These new groups argued that the present art competition system discouraged creativity and it rather encouraged repetition of the old style. They

of artwork is called "jiao-cai-hua" (gouache painting), which is named based on the material used in the artwork.

${ }^{33}$ In the 1930s, artists in China were divided into two different groups. One group of artists incorporated the western method - life drawing - into their artwork and attempted to create a new form of Chinese art. The other group truly embraced the Chinese art tradition. When communists occupied China, these orthodox Chinese artists fled to Taiwan. They represent a conservative power.

${ }^{34}$ Official art competitions in Taiwan were established in the Japanese colonial era. They were divided into two genres: "tong-yang-hua" (Eastern painting) and "xi-yang-hua" (Western painting). The system and criteria were learned from Japan. Taiwanese artists who won the competition in Japan were greatly honored and gained a high social reputation in Taiwan. When the Chinese artists took over the official art competition, orthodox Chinese painting replaced "tong-yang-hua." Thus, Taiwanese artists whose speciality was "tong-yang-hua" lost their authority in the art world. In contrast, those of "xi-yang-hua" still kept their positions in the art world, but they were disappointed with the politic-economic reality and the language barrier (Lin, 1987). 
tried to establish a new theory ${ }^{35}$ to support their idea of Chinese modern painting. In this sense, western modern theories provided these young Taiwanese artists with new concepts and courage to challenge old Chinese art traditions. The integration of Chinese and Western philosophies as a way to explain a universal principle was the strategy they adopted. As a result, old conservative artists were not able to defend against this modern trend. This illustrates that modernization was dominant in Taiwan's society during the period of the 1950 s to 1960 s. Although this modern approach was criticized by the "hsiang-t'u" literary movement in the $1970 \mathrm{~s},{ }^{36}$ this western influence has been kept alive in Taiwan's art world.

\section{Debate in the 1990s: Localization versus Westernization}

In his 1991 article, Western Art Made in Taiwan: A Critique on Taiwan Modern

Art, Ni Zai-qin, an art critic, asserted that Taiwanese artists have excluded themselves from social reality and have engaged in the art world as a romantic project $(\mathrm{Ni}, 1994)$. Many artists disagreed with his argument and this debate finally turned into a forum with discussions in the Hsiung-Shih art journal from 1991 to 1993. The debate covers several topics, such as Taiwanese art history, criticism in Taiwan's context, Taiwanese consciousness, and the identity of Taiwan art. According to $\mathrm{Yeh}^{37}$ (1994), this debate is

\footnotetext{
${ }^{35}$ The development of painting is from realism to abstract form. An absolute abstract form can be achieved by the process of imitating nature, to giving away the form of nature, then catching the essence of nature (Lin, 1987). However, this theory was not able to defend against the new art theory, pop art, later introduced to Taiwan.

36 "Hsiang-t'u" movement also had an impact on Taiwanese artists because they tended to depict a nostalgic atmosphere of countryside or seashore. It was not until super-realism was introduced to Taiwan in the 1970s that "hsiang-t'u" artists found their support. As a result, "hsiang-t'u" realism became a form of art that adopted the skills of super-realism and chose the motifs of countryside (Lin, 1987; Ni, 1994). This is different from the idea that the work should reflect social reality, which is held true by "hsiang-t'u" literature. Eventually, "hsiang-t'u" realism lost its attraction in the early 1980s (Ni, 1994).

${ }^{37}$ The articles published in the Hsiung-Shih art journal were collected and published into a book format in 1994. Yeh is the major editor and she wrote an introduction to this debate.
} 
considered a cultural discourse: Chinese versus Western. There are two different approaches to perceive Taiwan art within this debate, namely, localization and westernization. To extend this idea:

Westernization followers believe that modernism is the key for becoming a developed country, while localization supporters argue that modernism is the core of social problems. As a result, modernists follow their individual wills and pursue the concepts of self, freedom, and independence, which believe "art for art sake." Localization supporters tend to see art from the holistic perspective of the socio-political-cultural-historic aspect, which emphasizes art for social end. (Yeh, 1994, p. 30)

This statement is an attempt to conclude the basic assumptions associated with the essence and the function of art held by these two approaches. The author assumes that modernization equates with westernization and localization is an attempt to defend against modernization, which is a narrow view to perceive the relationship between localization and modernization. This statement also tends to categorize localization as a means to encourage art for society, which also suggests that art should reflect social reality. In this sense, Yeh's logic is similar to Ni's idea.

It is inevitable that Taiwan modern art heavily relies on western art theories because it was first introduced to Taiwan by Japan based on western art education. ${ }^{38} \mathrm{Ni}$ (1994) argues that when appropriating a western art theory, Taiwanese artists tend to adopt the form of art without having an understanding of the socio-cultural context in which the art was created. As a result, their artworks do not reflect Taiwan's social

\footnotetext{
${ }^{38}$ According to Lin (2000), art education becoming a subject in Japanese public schools started in 1872 because the empire intended to absorb the western civilization to reform Japan. Thus, the content of art education was totally based on western ideas. Since Japan had ruled Taiwan from 1895 to 1945, in order to transform Taiwanese from Chinese to Japan's colony, public schools were established in Taiwan. Accompanying the new concept of art education in Japan, Taiwan's public schools were also involved in this change. After the Opium War (1840-1842), the Qing dynasty realized the power of the Western new weapons. Many modern schools were founded to learn about western new technology. In 1902 art
} 
reality. These artists may create a fad but it cannot exist too long. In contrast, Chen Ruiwen, an artist, believes that cultural hybridity is the characteristic of Taiwan art. Based on this understanding, artists should systematically absorb the essence of modernity and transform it without hesitation to a hybrid "culture made in Taiwan" (Chen, 1994, p. 149). These two arguments represent two typical attitudes toward modernization or westernization in particular. The first argument point outs a lack of the identity of Taiwan art due to the appropriation of foreign theories, while the second one provides an alternative Taiwan centric view to perceive this cultural phenomenon.

\section{Summary}

It is obvious that Taiwanese consciousness was oppressed in the 1950s and 1960s because of the debate in the 1950s, which focused on the challenge between the modernists and old Chinese tradition. Although Chinese consciousness was strongly held by the conservative artists from Mainland China, they were not able to protect their beliefs. In contrast, the young artists (most of them were "wai-seng ren"- mainlanders) were inspired by the western modern concepts and believed that modernization would help them to change old systems.

In the 1990s, localization became the major issue in the art world accompanying the social trend. The construction of the identity of Taiwan art became a crucial assignment for artists, art theorists, art historians, art critics, and art educators. The debate in the early 1990s generated some reflections on, and strategies for, this identity. Since this is an on-going process, no conclusion has yet been reached.

education was put into the school curriculum in China, which adopted the content from Japan, which aimed 


\section{A Brief Review of the Development of Taiwanese Consciousness}

From a political perspective, the Taiwanese consciousness has evolved based on three steps: resistance to the Japanese colonialism (1895-1945), resistance to the Kuomintang's monocracy (1945-1987), and resistance to the hegemony of Mainland China (1987-present). From a cultural perspective, it contains different concepts: oppression by the Chinese consciousness and modernization (the art debate in the 1950s), resistance to westernization and the Kuomintang's ideology ("hsiang-t'u" literary movement in the 1970s), resistance to the Han-centrism (indigenous cultural renaissance movement in the 1980s), and establishment of a Taiwanese identity (the art debate in the 1990s). The specific strategies applied to achieve the proposition of each movement are listed in Table 2.1. The framework discussed above provides a broad cultural context, in which Taiwanese children's picturebooks are situated. Based on this understanding, localization in current children's picturebook movement is discussed.

\begin{tabular}{|c|c|c|c|}
\hline Time & Movement & Proposition & Strategy \\
\hline $1950 \mathrm{~s}$ & Art debate I & $\begin{array}{c}\text { Embracing } \\
\text { modernization }\end{array}$ & $\begin{array}{l}\text { - Appropriating western theories } \\
\text { - Creating modern Chinese art }\end{array}$ \\
\hline 1970s & $\begin{array}{l}\text { "Hsiang-t'u" } \\
\text { literary } \\
\text { movement }\end{array}$ & $\begin{array}{l}\text { Resistance to } \\
\text { westernization }\end{array}$ & $\begin{array}{l}\text { - Resisting western theories } \\
\text { - Reflecting local cultures }\end{array}$ \\
\hline $1980 \mathrm{~s}$ & $\begin{array}{l}\text { Indigenous } \\
\text { cultural } \\
\text { renaissance } \\
\text { movement }\end{array}$ & $\begin{array}{l}\text { Resistance to } \\
\text { Han-centrism }\end{array}$ & $\begin{array}{l}\text { - Appropriating the written language } \\
\text { system from Mandarin } \\
\text { - Reflecting native cultures }\end{array}$ \\
\hline 1990s & Art debate II & $\begin{array}{c}\text { Establishment } \\
\text { of a Taiwanese } \\
\text { identity }\end{array}$ & $\begin{array}{l}\text { - Reflecting local cultures } \\
\text { - Adopting the idea of cultural hybridity }\end{array}$ \\
\hline
\end{tabular}

Table 2.1: A summary of the cultural movements in Taiwan 


\section{Localization in Current Children's Picturebook Movement}

This section presents the localization movement in current children's

picturebooks. It tends to highlight the key events in the past that are relevant to discuss the recent movement. Moreover, since the picturebook is a commodified cultural production, a review of the publishing industry in Taiwan is also necessary. Thus, this section consists of three segments: (1) a classification of the development of Taiwanese children's literature, (2) production and consumption in contemporary Taiwan's publishing industry, (3) exploring and developing the identity of Taiwanese children's picturebooks.

\section{A Classification of the Development of Taiwanese Children's Literature}

Hong Wen-chun ${ }^{39}$ (2004a), a scholar in Taiwanese children's literature, classifies five stages of the development of Taiwanese children's literature. They consist of: (1) the standstill period, 1949 1963, in which children's literature had served as a means to promote the orthodox Chinese culture; (2) the period of introduction to modern children's literature, 1964 1970, in which modern concepts regarding writing and editing children's books had been introduced to Taiwan; (3) the period of growth of modern children's literature, 1971 1979, in which the first generation of well-educated Taiwanese editors and writers had created books for children; (4) the period of professional differentiation of modern children's literature, 1980 1987, in which children's literature associations, professional journals, children's literature for the ages of $0 \sim 8$, and professional children's theaters had grown; and (5) the period of celebration of pluralism in modern children's

\footnotetext{
${ }^{39}$ Hong has devoted himself to researching the history of Taiwanese children's literature. He has collected historical materials regarding Taiwanese children's literature and has documented important events occurring in the field.
} 
literature, 1988 present, in which children's literature has become more diversity regarding its content and commodified production.

This classification is mainly based on the notion of children's literature as a professional discipline and its popularity in Taiwan's market. Additionally, the modernity of Taiwanese children's literature is a major concern and its features reflect the adoption of western modern concepts of children's books, which suggests using the concept of cultural hybridity to perceive Taiwanese modern children's literature. This includes the mix of content based on Taiwanese life experience with the use of western techniques and concepts regarding story writing and illustration as well as book editing.

Like the literary and art movements mentioned above, Taiwanese children's picturebooks are also heavily influenced by foreign countries, mainly Japan and the United States. It is obvious that the concept of modern picturebooks came from the western countries, mainly the United States (Hong, 2004b). In 1964, the first official organization for children's publication, the Editorial Team for Chinese Children's Books, sponsored by the Children's Foundation of the United Nation, was established.

Meanwhile, modern concepts about children's publication from the United States were also introduced to Taiwan's editors. Thus, this official children's publication organization established a foundation for publishing picturebooks and cultivated the first generation of Taiwanese picturebook illustrators. It was not until 1971 that the first set of picturebooks, including eight books for young children created by Taiwanese writers and illustrators, was published (Hong, 1994a).

Accompanying the internationalization in Taiwan, technology and knowledge regarding picturebook making have grown rapidly. In the article, Everywhere a 
Children's Book: The View from Taiwan, Bradbury and Liu (2003) point out that children's picturebooks in Taiwan's book market have rapidly grown in recent years. Due to Taiwan publishers actively participating in the international book market, more and more picturebooks have been translated and published in Taiwan. Some publishers have also pushed their products into a global market. ${ }^{40}$ Since global capitalism has become a powerful force affecting the children's picturebook market in Taiwan, it challenges the Taiwanese writers and illustrators to compete with foreign picturebooks, which are also published in Taiwan's book market. In order to have a better understanding of Taiwan's publishing industry, a review of its current environment is provided in the next section.

\section{Production and Consumption in Contemporary Taiwan's Publishing Industry}

\section{1. the demands from the market.}

Educational policy and curriculum reform have contributed to the consumption of children's picturebooks. In 1997, the Ministry of Education announced that the EFL (English as a Foreign Language) program would become part of the school curriculum at the lower grade levels. Accompanying this trend "a boom in English-language imports [have grown] over the last few years" (Bradbury \& Liu, 2003, p. 239). In addition, the concepts of curriculum integration and multiple assessments are emphasized in the recent

\footnotetext{
${ }^{40}$ Grimm Publishing, a major children's picturebook publisher in Taiwan, is a good example to illustrate the intertwined process between the local and the global market. In order to complete with other wellknown publishers, Grimm Publishing cooperates with notable illustrators from various countries and, in so doing, it has gained a high reputation in publishing the picturebooks winning the best illustration awards. Therefore, Grimm Publishing has become one of the important publishers in the global picturebook market. However, on its book list, a few Taiwanese illustrators are included because, according to its strategy, the company looks for the best illustrators for their products based on the quality of the work, not the nationality of the illustrator. In this sense, Grimm Publishing embraces the global capitalism and created their book list based on a global view, such as publishing international classical literature and classical English literature by William Shakespeare in a picturebook format. By using this strategy, one Taiwanese
} 
school reform in Taiwan. Thus, uniform textbooks no longer dominated in public schools and non-textbooks of good quality and accuracy have been encouraged for use in school curricula, especially, child's books regarding six issues: gender, environment, information, home economics, human rights, and career (Hong, 2005). In responding to the Year of International Reading in 2001, the Ministry of Education promoted a national reading movement during the years of 2001 to 2003. The goal of this promotion was to encourage students to establish a good reading habit. In so doing, it also attracted school teachers and parents to participate in the reading programs. As a result, it stimulated the consumption of children's books.

\section{2. how publishers work in this business.}

Publishers play a crucial role in producing, introducing, and promoting children's picturebooks. Unfortunately, a lack of professional book reviews still exists. In order to make a good sale and profit, children's picturebooks are selected and sold in a set based on different themes because of the limited, although growing, market in Taiwan. These sets include, for example, international master picturebooks, the 100 best picturebook selection, Taiwanese picturebooks, and the like. Well-trained salespersons and reading guidebooks for these sets of picturebooks educate consumers about what picturebooks are and how they can provide children with a good quality of learning experience in reading, art appreciation, and understanding of mental health. These guidebooks usually consist of several segments: background information on the authors, art appreciation of the illustrations, educational strategies based on related themes, and recommendations from expert educators, writers, artists, and senior editors. These strategies have been successful 
at making great sales. However, they may limit individual readers' book choices based on their own interests. And, the interpretations of the picturebooks may be restricted because of the guidebooks.

In order to catch consumers' interests, picturebooks are selected and introduced to them based on the books' reputations from receiving national or international awards or because of particular themes that publishers want to encourage. As a result, most children's picturebooks published in Taiwan are translated from various languages or are English-language imports. There are limited opportunities for Taiwanese writers and illustrators because business promotions tend to emphasize popular authors or books. Picturebooks created by Taiwanese writers and illustrators may also have greater sales if they receive national or international attention, such as winning a national award or having a chance to participate in an illustration exhibition held by any international book fair in Europe. These European book fairs include, for example, the Bologna Ragazzi Award, the Catalonia Premi International Dillustracio, and the Biennale of Illustrations Bratislava (BIB). The impact and influence of the books selected by these national awards and international book fairs have enlarged the scope of picturebooks in Taiwan. Establishing the Identity of Taiwan's Children's Literature

\section{1. the demand for supporting Taiwanese picturebooks.}

As the global influence has grown, indigenization movements also have increased. Like "hisang-t'u" literature, which devoted itself to local cultures, motifs based on local cultural themes are shown in the current Taiwanese picturebooks. For example, picturebook sets with titles like Spring in Countryside and The Beauty of Tainan reflect 
local Taiwanese themes and consciousness. ${ }^{41}$ In addition, some illustrator like Chen Chih-yuan and Chang You-ran present their individual picturebooks that have won national awards or gained international attention and which also present current local cultures. $^{42}$

Besides this, social institutions are an important sector in promoting localization in picturebooks. For example, the Hsin-Yi Foundation has devoted itself to local young children's publication since 1978. The Hsin-Yi picturebook award was established in 1987 and it has encouraged Taiwanese writers and illustrators to create pictuerbooks for Taiwanese children.

Additionally, a new government-publisher cooperation model occurred in 2001. The Council for Cultural Affairs and Children's Publications co-published a set of Taiwanese Picturebooks Selection, in which Cheng Ming-jin, Taso Jun-yan, and Su Chen-ming were invited to be consultants. Their ideas were to emphasize and promote traditional Taiwanese values through these books (J. Taso, personal commuication, December 14, 2003). In response to the demand for native cultural education, Yuan-Liou Publishing reissued a set of Traditional Taiwanese Folktales in 2001 and proposed and published a set of picturebooks Taiwanese Teenagers in 2003, which depicted six life stories of Taiwan in the 1950s $\sim 60$ s. These recent publications together demonstrate a trend of localization in the Taiwanese children's book market. In response to this movement, Hong (2004a) points out:

\footnotetext{
${ }^{41}$ There are 100 picturebooks in each set. They were edited for introducing traditional customs, local industries, and the natural environment to children. They are more like information picturebooks.

${ }^{42}$ Chen's book, On the Way to Buy Eggs, won the Hsin-Yi picturebook award in 2001 and it was translated in English and published in the Untied States in 2002. Chang's book, Goddess Dancing in the Woods, was selected for the illustration exhibition held by the Bologna international book fair in 2003.
} 
A calling for localization in recent children's picturebooks can be seen through two factors: first, motifs regarding local cultures have been increased, and second, a demand for establishing a Taiwanese brand of picturebooks has been broadly discussed. The former includes children's books with diverse themes, such as native culture, environment, and aborigines. The latter can be seen as a means to present Taiwanese consciousness, which has a close relationship to the pursuit for Taiwan's internationalization (this is a tricky relationship, which the general public may not recognize.) That is, the intention of the Taiwanese writers and illustrators who actively participate in the international book market is to make Taiwanese children's books visible on a global scale. Thus, international buyers can recognize their existence and even purchase the copyrights of these books, which imply an intention of promoting the brand name "made in Taiwan." And, it is significant that the implied meaning associated with this action is also a reflection of Taiwanese consciousness. (p. 63)

Hong's remarks indicate that Taiwanese children's picturebooks can be considered as a means to make Taiwan visible on the international stage. In so doing, it resists the hegemony of Mainland China.

2. exploring and developing the identity of Taiwan's children's picturebooks.

Many children's literature scholars and editors, who are in favor of Taiwanese culture or hold a strong Taiwanese consciousness, such as Cheng Ming-jin, ${ }^{43}$ Hong Wenchun, and Taso Jun-yan, ${ }^{44}$ have worried about the limited number of Taiwanese picturebooks competing with numerous translated piturebooks. They also argue that the style shown in the current Taiwanese picturebooks are westernized and lack a sense of Taiwanese culture. Like the art world, the foundation of Taiwan's modern children's picturebooks is based on the western concepts. Accompanying the western theories regarding children's literature introduced to Taiwan, a lack of Taiwanese identity is

\footnotetext{
${ }^{43}$ Cheng Ming-jin, who is one of the pioneers in promoting modern picturebooks in Taiwan, won the title "the father of Taiwanese picturebooks" due to his devotion to introducing the concepts and functions of the picturebook to editors, illustrators, educators, and parents. He also has collected and documented important events in the field.
} 
observable in the picturebooks. It is unavoidable because the style and design in Taiwanese picturebooks are westernized.

However, the movement for identity has now resulted in research projects regarding the early Taiwanese picturebooks, the style of illustration in Taiwanese picturebooks, the studies of senior Taiwanese illustrators, and the like. For example, the Graduate Institute of Children's Literature (GICL), ${ }^{45}$ at the National Taitung University, has established a collection of Taiwanese picturebooks and has conducted research on the development of Taiwanese picturebooks. Current topics for children's literature conferences are also related to Taiwanese picturebooks. The conference hosted in November of 2004 by the Society of Children's Literature of the Republic of China ${ }^{46}$ and the GICL presented and published nine papers regarding research on Taiwanese picturebooks and their illustrators in the early time period. ${ }^{47}$ As a result of this, Taiwanese picturebooks have become not only a commercial production, but also an area of study associated with Taiwanese culture.

\section{Conclusion}

The current Taiwanese picturebooks movement, like the literary and art movements, is constructing its identity based on a Taiwanese consciousness. Based on

\footnotetext{
${ }^{44}$ Taso Jun-yan is one of a few pioneers in making and promoting picturebooks in Taiwan since the 1960s. Today he is an important figure whose comments about picturebooks are often quoted.

${ }^{45}$ The Graduate Institute of Children's Literature was established in 1996, and is the first and currently the only, graduate institute in children's literature in Taiwan. It symbolizes the demand for academic studies on children's literature in Taiwan. It also directs the interpretation and construction of new theories in Taiwanese children's literature (Hong, 2004a).

${ }^{46}$ There are two different associations regarding children's literature in Taiwan. One is named the Society of Children's Literature of the Republic of China and the other one is called the Society of Children's Literature of Taiwan. The titles of these two institutions show their ideologies in considering Taiwanese consciousness in children's literature.

${ }^{47}$ The title of this publication is For children and literature: Taiwanese senior picturebook writers and illustrators and their works, published by the Society of Children's Literature of the Republic of China.
} 
my historical review of the cultural movements, it appears that western theories

oftentimes have been overused in Taiwan. In particular, liberal reformers have used them for proposing a reason for social change. This has provoked public discussions. From the post-colonial perspective, western theories can be considered as a cultural hegemony in the Third World context. In other words, they oftentimes occupy a superior position in society which may limit the development of local cultures. In Taiwan's context, the influence of appropriation of western theories and experiences in literature, art, and children's literature are still debatable. Currently, localization seems to have an advantaged position in promoting local cultures. However, there should be an awareness of the growth of a narrow view of local consciousness, such as with Hokklo-centrism, because the celebration of a wider cultural diversity is a key element of localization.

\section{Relevance to My Research}

The literature reviewed in this study consists of two major segments: cultural context and historical context. The first part discussed the intertwined process of globalization and localization within theories of globalization. Moreover, the impacts and concerns of globalization on locals were discussed based on theories of globalization and post-colonialism. According to both theories, the concept of cultural hibridity can be seen as a negotiation to the pressures of globalization. That is, glocalization is a strategy where locals adopt to deal with global culture and reshape its practice in a way to create a new local culture (Pieterse, 2000). In addition, the colonized reinterpreting and reconstructing the culture brought by the colonizer is a means to challenge its authority (Bahbah, 1994). These notions provide me with not only a theoretical framework to understand the issues of globalization versus localization and cultural appropriation, but also a perspective to 
explain cultural hibridity in Taiwan. In particular, they help me to clarify my stance in considering cultural issues when ideologies regarding Chinese consciousness and Taiwanese consciousness are involved, such as, in the case of language and identity, where an issue is whether the use of Mandarin should be replaced by Min-nan Hua.

The second part historically reviewed the important political and cultural movements in Taiwan from a view of the development of Taiwanese consciousness. Its brief introduction to Taiwan's history serves as background information. Beside this, it provides me with a close look at why and how present ideologies are oftentimes associated with politics. Consequently, the values I hold true have resulted from these ideologies. Therefore, this awareness can be used to examine not only the text, but also the researcher herself. Moreover, the review illustrates that American and Japanese cultural influences have dominated Taiwan's academic world and people's everyday lives. This indicates that I should be aware of my biases caused by the academic training in the United States. 


\section{CHAPTER 3}

\section{METHODOLOGY}

In this chapter, I present the methodology that has guided my study, which consists of an overview of the methodological framework, an explanation of the design of the study, a discussion of trustworthiness, limitations of this study, and summary.

Overview of the Methodological Framework

\section{Qualitative Basis}

Qualitative research is the methodology and the major methods consist of two segments: (1) particular contextual information regarding editors' intentions and marketing strategies for the selected picturebooks based on interviews and web promotions for the picturebooks and (2) text and picture analysis of the selected picturebooks based on the analysis of narrative structure and Barthes' approach to semiotics.

The paradigm of this study is based on postpositivism. According to Yvonna S. Linclon and Egon G. Guba (2000), postpositivism believes that reality is constructed by social and cultural interaction as well as an individual's previous experiences. Thus, there are multiple realities that are dependent on how people interpret them through social interaction. In this sense, reality becomes relative and value-mediated. Moreover, there is no one right way to interpret reality because knowledge is socially constructed. However, this brings up a question of which interpretation is better than others. According to Terry 
Barrett (2003), a better interpretation consists of looking at evidence from multiple perspectives and careful analysis. In order to construct an interpretative critique of the picturebooks, multiple perspectives were used, including different editors' views, as well as a theoretical lens from Barthes' semiotic approach (this will be reviewed later in this chapter) and post-colonial theories based on Bhabha's major idea of "cultural hybridity" and Fanon's notion of "nation culture" (both were discussed in chapter two).

\section{Research Assumptions}

General Models of Textual Analysis

According to Lindkvist (1981), "[t]he meaning of a text can be identified with the producer, the consumer, and the interpreter of the text or with the text itself" (p. 23).

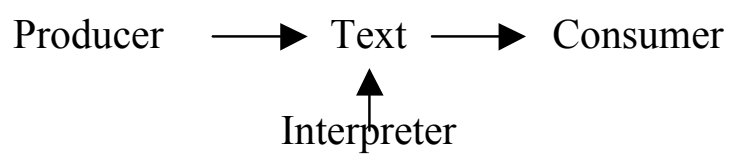

The producer's meaning refers to the intention of the author while the consumer's meaning is based on "the consumer's (reader's, receiver's) experience of the text" and the interpreter's meaning is an ascription of the interpreter (p. 25). These textual meanings mainly deal with the subject based on different roles of the text. In contrast, there are four different approaches to textual analysis with an emphasis on the text itself, including content analysis, analytical semantics, structuralism, and hermeneutics. The common theme of these four different approaches include the idea that "texts 'hide' something and the idea that the analysis must be systematic in one way or another" (p. 28). However, each of them has its own assumption, as Lindkvist states:

Content analysis has in common a fundamental assumption about the interest of the text producer and the quantitative profile of the text. The text 'hides' the interest of the text producer, but it can be revealed by quantitatively measuring the 
text. The manifest text is coded, but when relating the measured result to a general communication model, the character of different textual elements can be explained. Semantics presupposes that there is a basic ambiguity and vagueness in language. The grammar of a text 'hides' linguistic functions, which can be revealed by means of precizations. Structuralists often assume that the diachrony of the text 'hides' its synchrony or vice versa. In the synchrony/diachrony of the text basic structures are 'hidden'. Hermeneutics supposes that the text 'hides' the intentions of the author or that it is possible to reveal basic contradictions, instincts, or different kinds of social, psychological, or cultural entities. (p. 28)

These different approaches to textual analysis provide different potential interpretations regarding the meaning of the text.

Beside the model above, Selden, Widdowson, and Brooker (1997) mention that different theories address different questions about the text based on their own interests. Thus, they sum up a diagram as follows.

$\begin{array}{cl}\text { WRITER }> & \text { CONTEXT (MARXIST) } \\ \text { WRITING (FORMALIST) } & \text { CODE (STRUCTURALIST) }\end{array} \quad \begin{aligned} & \text { READER } \\ & \text { (ROMANTIC HUMANIST) }\end{aligned} \quad$ CODER ORIENTED)

This diagram may help to clarify that each theory has its own interest in research subject. However, "none of these approaches totally ignores the other dimensions of literary communication" (p. 5). Moreover, more recent theories, such as feminism, poststructuralism, postmodernism, post-colonialism and queer theory, challenge this origin diagram. For example, poststurcturalists argue for a minimal consideration of subject matter in decoding the deeper structure in structuralism. As a result of considering the criticism made by the contemporary theoretical fields, the approaches used in this study are selected across the models mentioned above and their research assumptions will be discussed in the following section. 


\section{Research Assumption of the Study}

This study has two major assumptions: first, the textual meaning can be revealed based on an analysis of the underlying structure and the meaning-making process by the researcher, and second, the role of the researcher is not only as an interpreter, but also as a reader. The methods of analysis in this study are mainly structuralism, which include the analysis of narrative structure based on literary elements and visual grammar used in the picturebook (the idea of literary elements is adopted from Huck, Hepler, Hickman \& Kiefer, 2001; Temple, Martinez, Yokota \& Naylor, 2002; the notion of visual grammar is adopted from Kress \& van Leeuwen, 1996; Nodelman \& Reimer, 2003). In addition, the analysis of ideology according to Barthes' semiotic approach is used, which deals with two systems of signification (Barthes, 1996). Both of these methods emphasize a systematic analysis of the text itself and emphasize that meanings can be uncovered by following a systematic process. The justification for the use of these two methods is that meanings are shaped by the use of language, which mediates the communication process. In analyzing the text itself with these methods, internal meanings of the text can be acquired. However, an explanation of the text's external meaning is missing because the context of the narrative is excluded from these two methods. Thus, the idea of intertextuality from poststructuralism is used to complement this absence (the concept of intertextuality will be discussed later in this chapter). In this sense, this study assumes that there is no contradictory between the uses of the concepts from both structuralism and poststructuralism. Rather, it is considered as a complementary choice.

In the meaning-making process, the researcher plays two different roles, namely, the interpreter and the reader. As an interpreter, the researcher decodes the textual 
meaning based on the related literature while she, as a reader, engages the text based on her personal life experience. Both are relevant to the textual analysis. The assumption of these two different positions taken by the researcher is that there is no value-free and objective role that a researcher can play. Therefore, this study takes an advantage of the researcher's personal life experience in helping to analyze the text. In order to clarify the researcher's personal biases, a discussion of personal ideologies is provided.

\section{Personal Bias and Ideologies}

Personal biases are generated based on an individual's life experience. Family, education, social norms, or cultural values may contribute to it and they are separately discussed in this section.

\section{My Family Background}

I was born and raised in Taipei City during the industrializing era of Taiwan (1960s 80s). Both my parents' families came from Mainland China and have lived in Taiwan for more than five generations. Both my parents came from working class families. Because of their limited education, after becoming young adults, my father ran a small business with his older sister and brother while my mother worked as a staff member in a university. Accompanying the economic growth in Taiwan during the 1980s and 1990s, my father had an opportunity to make his business successful. As a result of this, he always encouraged his children, two sons and one daughter, to receive higher education and make a fortune by running their own business. Although my parents do not have gender discrimination in terms of the use of educational resources, both of them have different expectations about boys and girls. Namely, they believe that happiness for a girl is to marry a good husband rather than having her own successful career without 
having a marriage. Especially, my mother strongly believes that a well-founded family relies on whether the wife can hold the family together.

My Education

Like most Taiwanese born after 1950s, I was educated in schools based on socalled orthodox Chinese culture. That is, I learned about how to speak and write Standard Mandarin and studied the version of five thousands years of Chinese history and national geography covering the whole of Mainland China. This knowledge in the uniform textbooks was the major content required for passing high school and college entrance examinations. Before I went to elementary school, Taiwanese was the major language used in my family because my grandparents were not able to understand Standard Mandarin and my parents felt more comfortable when speaking Taiwanese. However, the more Chinese culture I learned in school, the less I experienced a connection to the Taiwanese culture of my parents and grandparents. It was not until I went to college and participated in some training programs about Taiwanese local cultures that I had opportunities to visit different places and discover traditional Taiwanese folk rituals, festivals, and celebrations in person. These experiences opened a door for me to rethink the land I have lived in.

American higher education has influenced my thinking, not only in academic areas but also in shaping my identity. Currently, cultural studies has a heavy impact on other disciplines. Social and cultural theories have been adopted in education. Since my undergraduate major was sociology, I am fond of using the lens of those theories to perceive cultural phenomena. In particular, I tend to examine social issues from two 
different aspects, which include a functional view of society and a conflict view of society. ${ }^{48}$ However, I am not an enthusiastic social reformer because I think that any radical advocacy and reform would cause more negative results than positive results. Rather, social reform should be a gradual process. Constructivism is a dominant theory in my teaching philosophy. I believe that knowledge is socially constructed and learners construct their own understanding. For this reason, I oftentimes rethink what I believe in relationship to what I have learned and have been taught. This makes me think more about my cultural roots and identity according to the social reality I encounter on a dayto-day basis.

\section{My Ideologies Regarding National, Cultural, and Religious Identities}

According to the ideology of the formal education I received, my island home was the Republic of China and it was the authority representing traditional China. However, due to social reality, Taiwan has become the name of the island for the rest of the world for the past three decades. The political debate over the ownership of Taiwan is complex. Personally, I do not belong to any politic party and am not a supporter for any of them. I think that power relations among politicians from both Mainland China and Taiwan play a major role in controlling this ownership game. It was not until I came to study in the United States that I recognized that I am a Taiwanese. That is, I identify with the life style in Taiwan and the Chinese culture which has been used to educate me in Taiwan. However, I do not identify with Mainland China as my home country. This clarifies my stance on national identity.

\footnotetext{
${ }^{48}$ These two aspects were generated based on my sociological training. Funcitionism tends to see a society as a system with parts that operate or function to hold it together. In other words, it emphasizes social order and stability. In constrast, a conflict perspective pays attention to conflicts in humban society.
} 
Both sides of my parents' families are Han Chinese, which make up the majority of the population in Taiwan, and I had been educated in public schools based on the socalled orthodox Chinese culture. Therefore, the ideology of "Han-centrism" may affect the way I perceive the world. In terms of religious belief, my family follows the traditional Chinese rituals to worship our ancestors. I respect these family traditions. Personally, I am a Buddhist and tend to believe that the nature of life and death is based on Buddhism.

\section{My Experience with Picturebooks}

When recalling my childhood memories, I remember that I had a few picturebooks bought by my parents. And, the stories were about Chinese historical figures, such as those showing filial obedience to parents, loyalty to emperors, fraternal love to siblings, and moral integrity to one's duty. Most picturebooks I read were borrowed from my school library and they were published by the Editorial Team for Chinese Children's Books. The children's books I enjoyed most were fairy tales and animal fantasy. One of my favorite picturebooks that I can remember was Bambi, published by Disney, because it contained beautiful pictures.

Unlike the Ministry of Education reading movements promoted since 2000, reading with parents was not a popular concept when I was a child in the 1970s. Thus, my parents rarely read to me. That is because children's books were considered a form of after school entertainment and they were not helpful for passing entrance examinations for high school or college. For this reason, most parents asked their children to study textbooks for school exams and to stay away from children's books except for entertainment. 
I have collected children's picturebooks since 1994, after I had attended a children's literature workshop hosted by the Hsin-Yi Foundation. At that time, I was interested in the visual more than the story in a picturebook because I thought picturebooks were valuable resources for teaching art. It was not until I participated in a training program of philosophy for children, ${ }^{49}$ hosted by the Caterpillar Foundation of Philosophy for Children (CFPC) in 1995, that I learned about the value of the story for helping children develop their ability to think critically.

From 1998 to 2000, I worked for the CFPC and introduced picturebooks to parents and teachers as part of a series of story-telling programs. During this period, I studied and established some theoretical concepts regarding the picturebook introduced in the book "Words about Pictures" by Perry Nodelman. As a result, I developed the idea of the text-picture relationship as a major criterion for evaluating picturebooks. My personal picturebook collection was mainly written in English because I did not want to buy picturebooks sold in a set and I thought it was hard to find quality Taiwanese picturebooks. Therefore, it was not until I became involved in this study that I paid more attention to Taiwanese picturebooks. Placing Taiwanese picturebooks within a cultural context has changed the way I perceived them. I learned that the study of Taiwanese picturebooks involves more than dealing with just their formal quality.

\footnotetext{
${ }^{49}$ This program was adopted from Dr. Matthew Lipman, who established the Institute for the Advancement of Philosophy for Children (IAPC) at Montclair State University. This institute "provides curriculum materials for engaging young people (pre-school through high school) in philosophical inquiry and provides teacher preparation in the pedagogy of the classroom community of inquiry" (Montclair State University, Retrieved June 8, 2005, from http://cehs.montclair.edu/academic/iapc/).
} 


\section{The Design of the Study}

\section{Data Collection}

The data collection in this study consists of the three sets of picturebooks created by Taiwanese writers and illustrators and published during the years of 2001 2004 (for the book list see the Appendix B). They include the Firefly Picturebook Selection (including six titles of Taiwanese Folktales published in 1989 and reissued in 2001), the Taiwanese Children's Picturebook Selection (including ten titles published in 2002), and the Taiwanese Teenagers (including six titles published in 2003). There are twenty-two titles in all. In order to have an in-depth sense of how these picturebooks are promoted, the related commercial catalogs of the picturebooks on the publisher's web pages were also collected.

\section{Inclusion/Exclusion Criteria}

The reason for choosing these criteria is because this study investigates the representation of Taiwanese culture through a Taiwanese perspective presented in current publications. First, only Taiwanese writers and illustrators are selected because they have lived in this land and have gained a cultural sense of Taiwan. They share common cultural conventions and social norms related to this land. As a result, they have a better understanding of Taiwanese culture when they create their picturebooks. Second, only current publications are selected because they usually provide the readers with information regarding recent cultural trends in the contemporary society. Therefore, an examination of the current children's picturebooks not only provides a view of what aspects of Taiwanese culture are presented in the picturebooks, but also shows what publishing condition make these picturebooks visible in the Taiwanese book market. 
The selection of three sets of picturebooks rather than that of individual picturebooks is made because a set of books not only reflects the authors' views, but also the editors' views. Children's book publication is not a neutral process, but rather it depends on a series of decisions - involving selections of stories, writers, and illustrators, and marketing strategies as well. Thus, sets of pictuebooks indicate a particular theme provided by publishers. The publishers give a title or label to the set of picturebooks and this theme can be used to interpret each individual book grouped in the set. For this reason, it is important to decode the meaning associated with each individual picturebook in a set and also to analyze the set of picturebooks as a whole.

\section{Methods}

The discussion of the use of methods is divided into two segments: (1) meaning making through contextualizing the text and (2) interpretation of the text.

\section{Meaning Making through Contextualizing the Text}

This study investigates the ideologies embedded in the picturebooks. The social construction of picturebooks is an important aspect of these ideologies. Thus, contextual information regarding a broad cultural context as well as the specific publishing context of the three sets of picturebooks are included in order to examine the picturebooks. The broad cultural context situated in the current cultural issue of localization was reviewed in chapter two. The specific context regarding the selected picturebooks includes the editors' intentions and marketing strategies for the picturebooks. In order to collect the information, interviews with the editors and a review of the web promotions for the picturebooks, created and maintained by the publishing houses, were necessary. 


\section{Interview}

The purpose of the interviews with the editors from Yuan-Liou Publishing and Children's Publications, which published the three sets of Taiwanese picturebooks, was to understand the editors' intentions and objectives for their publications. Their personal accounts serve as contextual information to understand their concerns about Taiwanese culture. Since these interviews were informal conversations, interview questions were unstructured. However, the conversations were based on three main ideas: (1) the objective of the particular set of the picturebooks, (2) the making process of the picturebooks, and (3) the marketing strategy for selling the picturebooks. These ideas are paraphrased in the following questions:

1. Objective-What is the goal or objective of the picturebooks, and how did the ideas evolve?

2. Process - How did the editors select the subject matters, the writers, and the illustrators? What was the collaboration model between the writer and the illustrator in the making process? What challenges did the editors meet in the publishing process regarding the picturebooks?

3. Marketing — How did the publishing house develop the marketing strategy for selling the picturebooks?

Analysis of the Web Promotions

This analysis was of the on-line promotions regarding the three sets of Taiwanese picturebooks. The information was gathered from the websites, which were created and maintained by the two publishing houses of: Youn-Liu Publishing and Children's Publications, and was accessed on April 4, 2005. These promotions present the 
perspectives of the publishing houses when they considered the major targeted consumers - parents and teachers. The contents of these promotions reinforce the ideologies of the publishing houses as they attempt to get the buyers' attention and fulfill their educational demands for children. These provide contextual information that can help the researcher examine the text from an aspect of commercial concern.

As a result, two interviews were conducted on December 2004 (the transcriptions of the interviews are in the appendix D). In addition, a page-by-page review of the three web promotions for the picturebooks were examined (the review data and description are in the appendix E.)

\section{Interpretation of the Text}

The analysis of the text consists of two parts. First, the analysis of the narrative structure of each individual picturebook is based on literary elements and its purpose is to identify the general verbal and visual narrative patterns shown in the twenty-two picturebooks (the analysis of each individual picturebook is in the appendix C). Second, the analysis of ideologies embedded in the narrative patterns is based on Barthes' approach to semiotics; here, the picturebooks will be discussed within groups with similar ideologies. These two analytical tools will be reviewed in parts one and two.

\section{Part I. Narrative Structure: Verbal and Visual}

The term "narrative" used in this study includes both verbal and visual and refers to "the representation of a series of event" which consists of "a longitudinal structure of time and action" (Onega \& Landa, 1996, p. 5). There are a range of approaches to 
narrative structure. This study is limited to an approach relevant to the genre of the picturebook, namely those literary elements and visual grammar often used in analyzing the structure of the picturebook.

\section{Literary Elements}

The literary elements of the story used in this study include: setting, characterization, plot, theme, point of view, and style, adopted from Huck, Hepler, Hickman, and Kiefer (2001) and Temple, Martinez, Yokota, and Naylor (2002). The specific analysis of the structure is based on the following criteria and related questions:

1. Setting: Where is the location of the story? Does it indicate a particular place in words or imply a general place in pictures? When did the story occur? Does it indicate a specific or a general time period in words?

2. Characterization: How do characters appear within the story? How are characters portrayed in the story through the interaction with others?

3. Themes: What are explicit and implicit themes in the story?

4. Plots: How does the story happen, including what happens to whom and why it happens? In this category, plot structures as well as plots and conflicts are considered.

(1) Plot structures - a common structure includes a beginning (posing a problem or a goal), progress (effort to solve the problem or achieve the goal), climax (the turning point showing success or failure of the effort), and ending.

(2) Plots and conflicts - these sub-categories consist of conflict between characters, conflict within a character, conflict between a character and the environment, and conflict between a character and society. 
5. Point of view: How is the story told? Is the story told through an omniscient perspective or a view of focalization? Is the story told in the first person or the third person?

6. Style: What is the use of sound and voice in verbal narrative? What is the use of style in visual narrative?

\section{Visual Grammar of the Picturebook}

General semiotics provides explanations of linguistic texts by using language grammar. Many scholars have attempted to establish visual grammar based on semiotics in order to examine visual images such as advertisements, films, and comics (e.g. Kress \& van Leeuwen, 1996; O’Toole, 1994). Particularly, Nodelman and Reimer (2003) provide a framework for deconstructing pictures in the picturebook. They focus on the basic elements in constructing meanings through pictures. Rather than discussing the system of signification based on the notion of underlying structures, Kress and van Leeuwen (1990) emphasize the process of sign-making in society which places more weight on the sign-maker in different social contexts. In this sense, the interaction between the text and the viewer created by the sign-maker is one major issue in their visual analysis. They are interested in power relationship constructed in pictures. In short, both the studies of Nodelman and Reimer as well as Kress and van Leeuwen provide me

with models for analyzing pictures. These will be discussed respectively in the following sections.

\section{Nodelman and Reimer's model.}

In their book, The Pleasures of Children's Literature, Nodelman and Reimer (2003) discuss how pictures provide information about stories, which is relevant to the 
analysis of the visual narrative in the picturebook. As they emphasize the role of pictures

in the picturebook, their idea is that,

[a]s visual representations, pictures obviously stand for something else that they depict; a picture is a classic example of a sign. Any given picture not only represents something but also communicates further information about the thing it depicts by means of the way in which it depicts it. (Nodelman \& Reimer, 2003, p. 236)

In this model, the analysis is divided into five segments: (1) format and first impressions (concerning covers and inside a book), (2) mood and atmosphere (concerning color, black $\&$ white, shape \& line, and media), (3) style (concerning the use of different styles, including surrealism, impressionism, national styles, styles of individual artists, the meaning of borrowed styles, and the meaning of visual objects), ${ }^{50}$ (4) pictorial dynamics including two-dimensional effects (concerning size, location \& composition, figure \& ground, left to right and top to bottom, ${ }^{51}$ and color) and three dimensional effects (concerning perspectives, point of view, focus, overlap, light sources and shadow, and blocking), and (5) movement and time in pictures (concerning incomplete action, lineal continuance, distortion, left-to-right movement, continuous narrative, context, and the context of other pictures). ${ }^{52}$

\footnotetext{
${ }^{50}$ According to Nodelman and Reimer (2003), both impressionism and surrealism separately refer to the styles mentioned in the western art history of the late $19^{\text {th }}$ century and the first half of the $20^{\text {th }}$ century. For example, they refer to notable artists like Claude Monet in impressionism and Salvador Dali and René Magritte in the surrealist style. Picturebooks tell stories from different countries across the world and the illustrations convey the stories by using the art style often used in the regions where the stories have been told. These art styles vary from region to region and can be classified as national styles, such as with Chinese folk tales illustrated in Chinese painting. Styles of individual artists refer to an illustrator who adopts a particular artist's style to his or her work. For example, Mistumasa Anno uses techniques of the graphic artist M. C. Escher to create his picturebooks. Besides these styles, the meanings of borrowed styles and the meanings of visual objects also contribute meanings to stories in picturebooks.

${ }^{51}$ The directions of left-to-right and top-to-bottom are considered because the verbal text in the western languages, such as English, French, Germany, and so on, are written following these directions. As a result, readers who are in these language systems tend to read the text based on this principle.

${ }_{52}$ Movement and time in pictures is considering how two-dimensional static pictures indicate movements and consequences.
} 


\section{Kress and van Leeuwen's model.}

Kress and van Leeuwen (1990) developed a system of visual grammar based on a functional semiotic approach to visual images. Based on this visual grammar, in the book Teaching Multiliteracies across the Curriculum, Unsworth (2001) discusses how to describe visual literacies shown in a classroom setting, including images from textbooks, picturebooks, CD Roms, and teaching materials displayed. Particularly, the section of "interactive meanings: constructing viewer/image relations" in this book is helpful for analyzing the power relation between the text and the viewer. They include seven segments: (1) interaction: visual demands and offers, (2) social distance: close-up, medium, and long shots, (3) attitude: perspective and involvement or detachment, (4) power: high angle, low angle, and eye-level views, (5) realism: color, context, detail, depth, and light, (6) objective images: cut-aways, cross-sections, and explosions, and (7) coding orientation: what counts as real.

In sum, the six literary elements of the narrative structure in a picturebook provide a fundamental skeleton of analysis. The Nodelman and Reimer's model of visual grammar offers a basic idea of reading the design of the picturebook as a whole. Since ideologies are examined in my study, the interactive meanings associated with the viewer and being viewed, suggested by the Kress and van Leeuwen's model of visual grammar, provide me with a tool to investigate some possible power relationships embedded in the images. However, the major concept of decoding meaning in this study relies on semiotics in general and Barthes' approach in particular. 


\section{Part II. Barthes' Approach to Semiotics}

In order to have a better understanding of Barthes' approach to semiotics, a review of the basic concepts of semiotics is necessary because these concepts help to explain codes used in the picturebooks. Although semiotics is defined as the science of signs or the study of signification, which mainly focuses on what signs are and how they function, it does not contain a unifying point of view (Nöth, 1990). It has been broadly used in different disciplines, such as philosophy, mathematics, literature, art history, and cultural criticism, and it has evolved different schools and branches, such as structural semiotics, functional semiotics, visual semiotics, social semiotics, post-structural semiotics and the like. There are various semiotic traditions, for example, modern linguistic semiotics, represented by Saussure and philosophical semiotics, represented by Peirce. Rather than reviewing semiotics from the perspective of its historical development, a comparison of its different traditions, or its theoretical implication in a broad way, the discussion of this section is limited to the basic concepts used in my study. In other words, this section will focus on the basic concepts of general semiotics directly guiding my study and its implication will be discussed along with each group of concepts, including Barthes' approach to semiotics. In addition, a rationale for choosing semiotics as a method for my data analysis will be provided.

The basic concepts of semiotics reviewed in this section consist of: (1) sign, (2) syntagmas and paradigms, (3) denotation, connotation, and myth, and (4) intertextuality. 1. Sign

Ferdinand de Saussure, a Swiss linguist (1857-1913), and Charles Sanders Peirce, an American philosopher (1839-1914), have similar fundamental concepts regarding the 
nature of the sign, but they express the system of signs differently. Saussure is interested in linguistic signs in particular and uses the term semiology to indicate the study of signs. In contrast, Peirce's work concerns universal signs in general and the term semiotics is used in his case. Since the term semiotics refers to the study of signs in a broader way, it has become the general term used to represent it (Nöth, 1990). However, some scholars still distinguish between the uses of these two terminologies. Thus, the term semiotics is adopted in this study for its general use.

a. sign, signifier, signified.

According to Saussure, a sign is a unit of information, which consists of two parts: signifier and signified. A signifier refers to a form we read or see (sound-image) and a signified is the corresponding concept or object accompanying the signifier in our minds (see figure 1). For example, the word "dog" (a signifier of the image we see and

\begin{tabular}{|l|l|}
\hline \multirow{3}{*}{ Sign } & Signified (concept or object) \\
\cline { 2 - 2 } & Signifier (sound-image) \\
\hline
\end{tabular}

Figure 3.1: Saussure's sign model

the sound (we hear) means the concept and object of a dog (a signified literal meaning in English associated with the word). In Saussure's view, the relationship between signifier and signified is "arbitrary"; in other words, "[t]here is no natural or inevitable link between the signifier and the signified" (Culler, as cited in Hall, 1997, p. 31). Rather, the relationship depends on the agreement within a community. For example, the literal 
meaning of "dog" can be written as "chien” in French, “狗” (pronounced “gou”) in

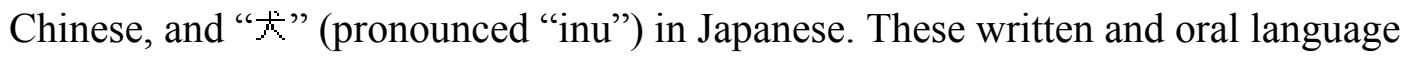
systems are different, but their signified meanings are the same. However, when I first learned the meaning associated with the word "chien" in French, a different understanding of my first name “建華” translated in English as Chien-hua was formed. This example illustrates that the relationship between signifier and signified can be changed based on different cultural knowledge.

\section{b. binary opposition.}

"Signs, Saussure argued, are members of a system and are defined in relation to the other members of that system" (as cited in Hall, 1997, p. 31). It is difficult to define the term "father" individually without placing it in relation to other terms like "mother" and "children" for example (Hall, 1997). Moreover, meanings are produced based on different signs that can be identified, such as the difference between similar sounding words like "bear" and "beer," "peal" and "pear." Thus, "the binary opposition as a fundamental operation of the human mind basic to the production of meaning" is a simple way to mark the difference between signs (Culler, as cited in Berger, 1995, p. 98).

c. the representamen, object, and the interpretant.

The theory of signs, from Peirce's perspective, explains in more detail the relationship between signifier and signified (in Saussure's term) and the classification of signs. As Peirce defines his idea of sign:

A sign, or representamen, is something which stands to somebody for something in some respect or capacity. It addresses somebody, that is, creates in the mind of that person an equivalent sign, or perhaps a more developed sign. That sign which it creates I call the interpretant of the first sign. The sign stands for something, its object. It stands for that object, not in all respects, but in reference to a sort of 
idea, which I have sometimes called the ground of the representamen. (as cited in Bal, 1994, p. 166)

Based on this account, it is obvious that a sign can represent its object based on some sort of reference. The concept of reference is emphasized in Peirce's theory, which is absent in Saussure's.

d. iconic, indexical, and symbolic signs.

Peirce's theory of signs applies not only to the linguistic aspect. Rather, his theory is an attempt to establish universal categories which can include all different signs based on his premise that "the entire universe is perfused with signs, if it is not composed exclusively of signs" (as cited in Nöth, 1990, p. 41). As a result, he divided signs into three different categories: iconic, indexical, and symbolic. The major difference between these three kinds is based on the relationship between a sign and its object. According to Barnard:

In an iconic sign, the relation between sign and object is one of 'likeness'..., [while in] an indexical sign, [there is] an existential, or causal relation. The indexical sign is 'really affected' by the object, as Peirce has it... Confusingly, Peirce's symbol is very similar to Saussure's sign, in fact. In a symbol, the sign and the object are connected or related by convention, or 'law'. (Barnard, 2001, p. 147-8)

For example, paintings or photographs like portraits and landscapes are iconic signs because the sign (a portrait painting) looks like its object (the person). The Statue of Liberty (part) is an indexical sign of New York City (whole) and the Horse Shoe football stadium (part) is an index of Ohio State University (whole) because they are existentially linked to these places. In other words, they consist of a part-whole relation. Traffic signs are a good example of symbolic sign since they are put into force by law. 


\section{e. implication for my study.}

The concept of the signs discussed above does not provide a practical model in the analysis of the picturebook. However, it does offer an epistemological account that meaning is culturally conditioned. My study intends to find what cultural codes are used in the visual narratives of the selected picturebooks. Both Peirce and Saussure emphasize that signs, or symbols in particular, are mediated by cultural conventions and this supports my assumption. The visual images in the picturebook, even representational images, require cultural knowledge to some extent in order to understand the underlying meanings associated with the symbols shown in the pictures.

\section{Syntagmas and Paradigms}

According to Saussure, meanings are produced through different linguistic signs working in relationship to other ones. He divided these differences into two parts: syntagmatic and paradigmatic. Syntagmatic means a sequential combination between signs which indicates the relationship of "this-and-this-and-this", for example, "a+cat+running" means a cat running. Paradigmatic means possible substitutions among signs which focus on the relationship of "this-or-this-or-this", for example, the replacement of the word cat can be dog, bear, or others. In Saussure's view,

[t]emporally, syntagmatic relations refer intratextually to other signifiers copresent within the text, whilst paradigmatic relations refer intertextually to signifiers which are absent from the text. The 'value' of a sign is determined by both its paradigmatic and its syntagmatic relations. Syntagms and paradigms provide a structural context within which signs make sense; they are the structural forms through which signs are organized into codes. (Chandler, 2001, Paradigms and Syntagms section, para.1) 
This indicates that an analysis should concern signs presented together as different codes within intratextual and intertextual relationships. And, "what is not present" is also an important clue to put into consideration in a process of decoding. Rose also applies the concept of syntagmatic and paradigmatic to the analysis of image. He states:

"Syntagmatic signs gain their meaning from the signs that surround them in a still image, or come before or after them in sequence in a moving image...

Paradigmatic signs gain their meaning from a contrast with all other possible signs" (Rose, 2001, p. 78).

In this sense, since the picturebook contains both verbal and visual texts (except wordless picturebooks), the sequence of pictures with different frames on one page and sequences of different pages are important syntagmatic signs. In other words, a part-whole relationship is a major concern in analyzing the picturebook. The notion of paradigmatic signs provides a strategy of asking what possible decisions could be made by the writer and the illustrator before the final version of the work was decided.

\section{Denotation, Connotation, and Myth}

a. denotation and connotation: a general concept.

According to Chandler (2001), "denotation and connotation are terms describing the relationship between a signifier and its signified, and an analytic distinction is made between two types of signifieds: a denotative signified and a connotative signified. Meaning includes both denotation and connotation" (Denotation, Connotation and Myth section, para. 2). In the linguistic sign, denotation refers to 'literal' meaning ${ }^{53}$ associated with what we read while connotation "is used to refer to the socio-cultural and 'personal'

\footnotetext{
${ }^{53}$ According to Chandler (2001), "For most semioticians both denotation and connotation involve the use of codes. Structural semioticians who emphasis the relative arbitrariness of signifiers and social semioticans who emphasize diversity of interpretation and the importance of cultural and historical contexts
} 
associations (ideological, emotional etc.) of the sign" (Denotation, Connotation and Myth section, para. 2). Although connotations may vary because they depend on the interpreter's gender, class, ethnicity, and the like, there is a collective cultural basis that individuals are able to access in order to decode meanings. In this sense, even though readers' responses to the picturebooks are not considered in this study, the analysis of the picturebooks through the codes provided by the authors and decoded by the researcher can provide one constructed reality, but not the only one, based on shared cultural codes.

\section{b. linguistic message, coded iconic message, and non-coded iconic message.}

Roland Barthes, an influential thinker in semiotics, thinks that, in addition to linguistic signs, visual signs can also constitute texts and can be analyzed based on denotation and connotation. Thus, in his article, Rhetoric of the Image, Barthes (1977) used the ideas of denotation and connotation to analyze a Panzani advertisement, which is a photo of food products, and he points out that there are three messages in this image. They include a linguistic message, a coded iconic message, and a non-coded iconic message. The linguistic message is twofold and consists of: denotational and connotational, which are similar to the concepts mentioned above. A coded iconic message, referring to the understanding of the signs, requires a general cultural knowledge of the icon. In this sense, like the linguistic message, the coded iconic message also contains denotative signified and connotative signified. On the other hand, one can understand a non-coded iconic message without any cultural knowledge of the icon. It is impossible to separate the two iconic messages when the viewer looks at a photo. Rather, the viewer spontaneously receives both the perceptual message and the 
cultural message. In order to understand the whole structure of the image, the viewer needs to analyze the interrelationship of these three messages. Like this advertisement, the picturebook also consists of the three messages. Moreover, it is necessary to analyze the picturebook on a sequential narrative basis because of its multiple pages.

c. denotation, connotation, myth: three orders of signification.

Barthes adopted Louis Hjelmslev's ${ }^{54}$ notion of different orders of signification (see figure 3.1) in analyzing different levels of meanings embedded in the image (Chandler, 2001). As figure 3.2 shows, a sign consists of a signifier, which is also a sign divided into another signifier and signified, and a signified. In this case, there are two levels of signification.

The first order of signification is that of denotation: at this level there is a sign consisting of a signifier and a signified. Connotation is a second-order of signification which uses the denotative sign (signifier and signified) as its signifier and attaches to it an additional signified. In this framework connotation is sign which derives from the signifier of a denotative sign (so denotation leads to a chain of connotations).... (Chandler, 2001, Denotation, Connotation and Myth section, para. 6)

In Barthes' terms, the first order of signification is denotation and the second, connotation. And ideology, called myth, is produced based on the combination of denotation and connotation. Other scholars call this the third order of signification (Chandler, 2001).

para. 4).

54 "Louis Hjelmslev (1899-1965) was the founder of a school of radically structuralist linguistics, known as glossematics or the Copenhagen School of Linguistics" (Nöth, 1990, p. 64). 
The first order of signification (Denotation)

The second order of signification (Connotation)

\begin{tabular}{|r|c|}
\hline 1. Signifier & 2. Signified \\
\hline 3. Sign & \\
I SIGNIFER & II SIGNIFIED \\
\hline \multicolumn{2}{|c|}{ III SIGN } \\
\hline
\end{tabular}

Figure 3.2: Different orders of signification magazine cover, which was a photo of a black boy, with military dress, who is saluting a French flag, published during the Algerian war of independence (O'Neill, 1992). This concept can be shown as a diagram (see figure 3.3.) Unlike structural semiotics, based on Saussure's ideas, which excludes social and historical contexts from the study of signs, Barthes' ideas concerned the contexts in which the text is situated. In other words, he is concerned not only with the text internally, but also externally, including the social contexts associated with the image. In this analysis, the ideology embedded in the image is imperialism which can be decoded based on the elements of sign.

\begin{tabular}{l|c|c|c|}
\cline { 2 - 3 } Language & $\begin{array}{c}\text { D.1. SIGNIFIER } \\
\text { Photographic image }\end{array}$ & $\begin{array}{l}\text { D.2. SIGNIFIED } \\
\text { Negro saluting } \\
\text { French flay }\end{array}$ \\
\cline { 2 - 4 } Myth & \multicolumn{2}{|c|}{$\begin{array}{c}\text { D.3. SIGN } \\
\text { C.I. SIGNIFER }\end{array}$} & $\begin{array}{l}\text { C.II. SIGNIFIED } \\
\text { Colonialist nationalism, } \\
\text { militarism }\end{array}$ \\
\hline \multicolumn{2}{|c|}{ C.III. SIGN } \\
\hline
\end{tabular}

Figure 3.3: The myth of imperial France (O’Neill, 1992, p. 75) 


\section{Intertextuality}

Julia Kristeva, the author of semanalysis, which is an important poststructuralist semiotic text theory, introduced the notion of "intertextuality" to semiotics. Rather than considering the idea of textural understandings depending on the communicative process of "sender-receiver", Kristeva perceives the text as "signifying practice and productivity" (Nöth, 1990). In her terms, this means that "every text is from the outset under the jurisdiction of other discourses which impose a universe on it" (Kristeva, as cited in Culler, 1981, p.105). In other words, there is "the interconnectedness of human language, its patterns, images, and meanings" (Nodelman \& Reimer, 2003, p. 184) that helps the reader to understand textual meanings. In Kristeva's view, intertextuality can be divided into two axes: a horizontal axis (the connection between the author and reader of a text) and a vertical axis (the connection between the text and other texts) (Chandler, 2001). On a practical level, the notion of intertextuality in relationship to reading a text indicates that the reader is able to make sense of the text through the strategy of bringing their own life experience to the text, which is similar to the author's, and connecting the text to other texts. Therefore, the reader plays a crucial role in making connection to the text from the two paths in order to gain a textual understanding. implication for my study.

The notion of "intertextuality" inspired me to think about the role of the researcher that I play (the reader) in relationship to the picturebooks (the text). Based on this idea, it is impossible to gain a textual understanding through reading each individual text without making any connection to other texts and to the shared culture of the author. Thus, I needed to make meanings through investigating the connections between texts 
and extending my cultural knowledge about them. It was necessary to keep this in mind while I was reading, decoding, and analyzing the picturebooks.

\section{Rationale for Choosing Semiotics in Textual Analysis}

\section{Semiotics Helps to Find In-depth Meanings}

Semiotics is a study of meaning formation through signs. It provides a way to investigate deeper meanings associated with objects or things that we usually take for granted. That is because, from the semiotic perspective, every object or human behavior can be considered as signs consisting of explicit and implicit messages. Moreover, it suggests that meaning is socially constructed (Rose, 2001). As Berger (1995) puts it:

Semiotics and semiology focus our attention on how people generate meanings... What semiotics and semilogy do is provide us with more refined and sophisticated ways of interpreting these messages - and of sending them. In particular, they provide us with methods of analyzing texts in cultures and cultures as texts. (p. 100)

This approach not only supported the epistemology of this study, which is that meaning is socially constructed, but it also methodologically provided me with strategies to organize my analysis as mentioned in the section above.

\section{Application of Semiotics to both Visual and Literary Texts}

Since semioticians consider every thing and object as signs in the universal, words and images can be transformed into basic units - signs - according to this notion. The picturebook is a combination of verbal and visual narratives telling a story. Thus, a semiotic approach to the picturebook provides the researcher with common basic concepts dealing with these two different narratives. I do not propose that verbal signs and visual signs share the same sign system. It is rather that they have their own ways of communication. However, they can be analyzed according to some similar principles 
discussed in the section of general semiotics. In my study, the pictures were observed based on the visual grammar mentioned above.

\section{Trustworthiness}

In discussing credibility, Lincoln and Guba use the term trustworthiness to replace validity used in quantitative research and suggest several strategies for guiding qualitative research (Denzin, 1994). Basically, I adopt the criteria of credibility from Lincoln and Guba's techniques for establishing trustworthiness and discuss them as follows.

\section{Prolonged Engagement}

According to Lincoln and Guba (1985), prolonged engagement refers to an appropriate amount of time that researchers spend in the field in order to achieve the purpose of their research. In my study, I have already spent two years exploring this topic. This prolonged engagement allows me to be more sensitive to book selection and data analysis.

\section{Awareness of Subjectivity and Bias}

According to Lather (1991), the development of self-awareness in a research study can increase its validity, that is, research designs demand "a vigorous self-reflexivity" (p.66). Janesick (2000) further suggests that in order to create trustworthiness in research, at the early stage, researchers should clarify their own biases and "articulate the ideology of conceptual frame for the study" (p. 385). Moreover, researchers should evaluate their study by keeping "a critical reflective journal on the entire 
research process and the particular role of the researcher" (Janesick, 2000, p. 385). In this study, I kept writing a critical reflective journal after each step of data analysis. I examined the content and material of what I was doing during the process and wrote down mistakes I made and suggestions in order to improve the techniques regarding data analysis. I also checked what I was thinking and how these thoughts affected my study.

\section{Peer Debriefing}

During the research process, criticisms and comments from knowledgeable colleagues help researchers rethink their studies from different points of view (Lincoln and Guba, 1985). In my study, the professors from my department discussed my initial research design. During the research process, I have also invite them to contribute their knowledge to my data analysis and presentation.

\section{Limitation of the Use of Semiotics}

According to a post-positive paradigm, there are multiple interpretations regarding social reality. Thus, the perspective or theoretical lens used in text analysis has its limitations. Since this study is based on semiotics, limitations of the use of semiotics in analysis of the picturebook will be discussed.

\section{Lack of the View of Human Subject}

The motivation of early semioticians was to establish a natural science of semiotics. For this reason, the major focus of semiotics is on the sign itself and underlying structures and this is called structural semiotics. It assumes that underlying structures on which meaning is made are stable and unchangeable. Therefore, social, 
historical, and political contexts are excluded from this proposition. Moreover, the human subject is ignored. Wolff (1975) concludes some criticisms of this approach:

Such critics present structural and semiological approaches as a sterile formalism, unable to explain content... Other critics have dismissed structural approaches as 'immoral' (Wolff, 1975), because it ignores the human side, the role of the human subject, the individual producer and consumer of signs. (as cited in Barnard, 2001, p. 145)

In other words, structural semiotics lacks an awareness of responses from the audience and self-reflexivity (Rose, 2001). A strong argument held by most critics is that it is impossible that the text can be analyzed outside its social context because the text itself, including its producer and consumers, all exist in the social world. Thus, social semioticians shift the focus of semiotic study from the system of signs to the process of sign-making. As a result, sign-makers and contexts are important matters.

\section{Lack of the Pleasure of Reading}

Since semiotics tends to investigate underlying meanings associated with the text, it blocks one from a pure aesthetic experience, which may be considered as a disinterested approach to viewing. For example, one may enjoy an appealing image with an impressionistic style in a picturebook. However, if adopting a semiotic approach to perceive the same image, the reader needs to focus the use of style in relationship to meaning-making in this particular picturebook. This generates a specific interest in analyzing the images. As a result, an aesthetic experience gained from the pleasure of reading or viewing for its own sake is excluded from semiotic study.

\section{Requirement of Rich Cultural Knowledge}

The relationship between signifier and signified is arbitrary and is based on cultural conventions. Therefore, both words and pictures “don’t convey much meaning 
until viewers know the language in which they are expressed" (Nodelman \& Reimer, 2003, p. 236). In this sense, in order to decode deeper meanings associated with symbols, in Peirce's terms, requires previous knowledge regarding the systems of cultural codes. Thus, the semiotic approach to picturebooks from different cultures or time periods may limit the accessibility of readers who do not share the same cultural codes.

\section{Confusion of the Use of Terminology in Semiotics}

Although most semioticians share some basic concepts of signs, terms in semiotics are not agreed upon by all scholars. According to Rose (2001), "Semiology tends to invent new terminology for its own sake...The use of a somewhat elaborate terminology leads to another issue that needs some thought when semiology is employed as a method" (p. 97-8). For example, the terminologies used to define the concept of sign by Saussure and Peirce are different. As a result, this may cause some confusion for the reader.

\section{Possibility of Misinterpretation or Overinterpretation}

Eco (1979) asserts that if one can use the system of signs to investigate a truth, by the same token, it also can be used to tell a lie. This raises an issue of the possibility of misinterpretation or overinterpretation due to the assumption that the relationship between signifier and signified is arbitrary. As a result, the gap between signifier and signified is open to interpretation. As Eco (1990) comments on interpretation:

Texts are the human way to reduce the world to a manageable format, open to an intersubjective interpretive discourse. Which means that, when symbols are inserted into a text, there is, perhaps, no way to decide which interpretation is the 'good' one, but it is still possible to decide, on the basis of the context, which one is due, not to an effort of understanding 'that' text, but rather to a hallucinatory response on the part of the addressee. (p. 21) 
This suggests that a text may contain multiple interpretations and the role of the reader is important in deciding which interpretation is appropriate to the text. Even though structural semiotics avoid considering human subjects, it is still problematic to rely on the so-called underlying structures on which structural semiotics is based.

\section{Summary}

This chapter reviews assumptions, study design, trustworthiness, and limitations. This study is based on postpositivism and focuses on textual analysis of the picturebooks, which include two stages. First, the analysis of narrative structure is used for identifying the verbal and visual narrative patterns based on six literary elements, including setting, characterization, theme, plot, point of view, and style. The findings are presented in chapter four. Second, the use of Barthes' approach to semiotics as a means to explore ideologies embedded in the picutrebooks when situating them in a broad cultural context. The discussion and critique of the cultural representations in the picutrebooks are presented in chapter five. Moreover, in order to have a better understanding of the social construction aspect of the picturebooks, such as editors' intentions and marketing strategies, interviews with editors and an analysis of web promotions for the picturebooks are included. These findings are presented in chapter four. 


\section{CHAPTER 4}

\section{DATA ANALYSIS}

\section{Overview of the Data Analysis}

This chapter is divided into two parts. The first part is an analysis of the three sets of picturebooks from the publishing perspective. This analysis serves as contextual information which helps the researcher situate the three sets of picturebooks within the publishing industry; in so doing, it supports the assumptions of this study. That is, the editors play a crucial role in shaping the contents for each set of picturebooks. Moreover, these contents reflect the cultural concerns that the publishing houses hold when considering their targeted customers.

The second part is an analysis of the contents of the picturebooks. The discussion of this section includes three major segments. The first one is an analysis of the textpicture relationship between verbal and visual narrative patterns in the picturebooks and an examination of how these two narrative patterns complement each other. The second one is an analysis of verbal and visual narrative patterns shown in the picturebooks and their implied meanings. They are discussed based on six elements: setting, characterization, theme, plot, point of view, and style. The third one exemplifies the use of cultural clues through visual narrative patterns in the picturebooks, namely the articles 
of daily use, costumes, architecture, and rituals. Thus, the analysis will be presented based on the order mentioned above.

Part I. Analysis of the Three Sets of Picturebooks from the Publishing Perspective The purpose of this section is to analyze the three sets of picturebooks, from the publishing perspective, based on the interview data and information gathered from two publishing houses' websites: Yuan-Liou Publishing and Children's Publications. The focus of this analysis will be divided into three segments: the objectives, the publishing process, and the marketing strategy for the picturebooks.

\section{The Objectives of the Picturebooks}

It is obvious that the editors are an influential factor directing the objectives of the picturebooks. Based on the interviews with two editors and one publisher from the two publishing houses, their personal accounts reflect their visions of proper cultural representation in the picturebooks as it relates to Taiwanese children. In other words, their publishing decisions depict what children should learn about Taiwanese culture. Lain Tsuey-moh (Ms. Lain) is the senior editor of the Taiwanese Teenagers from YuanLiou Publishing, while Lin Chu-chi (Ms. Lin) is the chief editor and Lin Husn-min (Mr. Lin) is the publisher of the Taiwanese Children's Picture Selection from Children's Publications. Since the original editor of the Taiwanese Folktales, also published by Yuan-Liou Publishing, no longer works for the publishing house and the current editor is not able to provide the publishing information regarding it, the editor's account for this set of picturebooks is not presented in this analysis.

A comparison between the Taiwanese Teenagers and the Taiwanese Children's Picturebook Selection shows that the editorial concerns regarding these two sets of 
picturebooks may differ, but the objectives of the picturebooks remains the same. That is, they intend to help Taiwanese children have a better understanding of traditional Taiwanese customs which are still practiced in today's society.

\section{The Objective of Yuan-Liou Publishing}

According to Ms. Lain, the senior editor of Yuan-Liou Publishing, the intention of the Taiwanese Teenagers was to provide children with opportunities to read the stories written by famous Taiwanese writers. This notion was inspired by Japanese novelist Kenzaburo Oe, who won the 1994 Nobel Prize for Literature, because he asserted that every writer should create a story for children (T. Lain, personal communication, December 15, 2004). Based on this simple thought, she sent invitation letters to famous writers asking them to write something for children. She reached some and received their responses. In order to make the editorial direction more specific, the idea of an unforgettable childhood memory of a person, place, or event became the focus of the stories. And, she decided that there should be no limited number of such picturebooks on her list and she would keep publishing picturebooks in this category. The first six titles of this type were published in 2003 because some writers' manuscripts were finished earlier than others.

The common themes shown in these six stories depict childhood memories in the Taiwan agricultural era during the 1950s 1960s. These stories just happened to demonstrate diverse life experiences from different regions of Taiwan, although this was not necessarily the editor's intention. However, this idea seems to have grown in her mind as Ms. Lain mentioned that the 1950s and 1960s was the period when segregation between local Taiwanese and Mainland Chinese was most serious. The film The Time to 
Live and the Time to Die ${ }^{55}$ directed by Hsiao-hsian Hou, vividly depicted the situation. Ms. Lain thought that there should have been more communication between people in order to have a better understanding of each other. Taiwan was growing. The title Taiwanese Teenagers was intended to show the energy of the Taiwanese. The stories in the Taiwanese Teenagers are diverse, like different pieces of a puzzle, but come together to reveal an overarching Taiwanese culture (T. Lain, personal communication, December $15,2004)$. She also stated that these picturebooks were designed for children and their parents; through reading together, the parents could share and discuss their childhood memories with their children. In so doing, the conversations will keep old memories alive by passing them down to the younger generation. Her accounts surprised me because the Taiwanese Teenagers was not published based on a concrete proposal that intended to show the concept of cultural diversity as its promotion emphasized (This analysis will be discussed later).

\section{The Objectives of Children's Publications}

Ms. Lin and Mr. Lin, from Children's Publications, have a different approach to the Taiwanese Children's Picturebook Selection. They intend to introduce different subject matters associated with Taiwanese culture to children, based on three categories: folkways, art, and environment. Moreover, they want to present these subject matters in a story picturebook format rather than just presenting knowledge about them in an information book format. The key to connecting children to the life experiences presented

\footnotetext{
${ }^{55}$ This film, released in 1985, depicts a family story of three generations. The main character's father was Mainland Chinese, coming to Taiwan after 1947. He thought the government would take them back to their homeland. However, he died because of sickness. The main character's mother and grandmother also passed away after the death of the father. When the grandmother was alive, she frequently asked the main character to take her to visit her hometown in Mainland China. The film conveys a sorrowful and nostalgic
} 
in the stories is to tell the stories in association with the traditional customs which are still practiced in contemporary life throughout different regions of Taiwan. Mr. Lin stated that they had clear ideas about what subject matters they wanted to introduce to children, but how to present them in a story format was a challenge. In other words, finding good stories was the key. In addition, they also intended to present a new way of storytelling in picturebooks by using visual languages with which children are familiar, such as the use of a cartoon style in the illustrations.

According to Ms. Lin and Mr. Lin, the Taiwanese Children's Picturebook Selection is an on-going project, although the first ten titles were published in 2002. These ten picturebooks were part of the partnership project shared with the Council for Cultural Affairs and involved a one-year contract. There was a publishing deadline and the time issue was a major concern. As a result, they needed to work closely with writers and illustrators who already had a good understanding of the topics. Although it was time consuming to produce these picturebooks, they completed the contract on time. However, they decided to continue the project on their own. Ms. Lin stated that there were some other picturebooks in this category in the publishing process and they would be published without the pressure of time limitation.

\section{The Publishing Process for the Picturebooks}

The publishing process for the picturebooks mainly follows the procedures of: (1) setting up an editorial proposal, including possible subject matters, (2) searching for writers to produce stories based on the subject matters chosen by the editors, (3) finding appropriate illustrators to create pictures based on the stories, and (4) printing the 
picturebooks. For example, the proposal for the Taiwanese Teenagers was to tell famous writers' childhood memories, then invite these writers to produce their stories based on this theme, then find local illustrators to create pictures for the stories, and then print the books.

It is a challenge to find appropriate writers and illustrators who can match the results that the editors expect. Moreover, the collaboration between writers and illustrators relies on mediation by the editors. Part of the reason is that the writers and illustrators may not be familiar with the text-picture relationship in a picturebook format, according to Ms. Lain (personal communication, December 15, 2004). In order to put their ideas into practice, the editors need to deal with problems related to this challenge. There are two different considerations regarding searching for writers and illustrators in the two publishing houses.

\section{The Model of Yuan-Liou Publishing}

The first model, adopted by the senior editor of Yuan-Liou Publishing, is to find inexperienced illustrators for the stories written by well-known writers. By doing this, new illustrators are encouraged to create picturebooks for children although they are not yet recognized by readers. However, the reputation of the writers helps to promote their work, which is used as a marketing strategy. For example, the promotion for the Taiwanese Teenagers at Yuan-Liou Publishing's website emphasizes the collaboration of the well-known writers and local illustrators. In their opinion, the use of Taiwanese writers and illustrators telling the childhood memories is authentic and appropriate because it reflects collective memories belonging to all Taiwanese. 


\section{The Model of Children's Publications}

The second model, used by the chief editor of Children's Publications, is to search for someone who already has a good understanding of the topics that editors expect or has a good sense of making picturebooks. Part of the reason for this approach is because of the pressure of time limitation, due to contracts such as that with the Council for Cultural Affairs mentioned above. In terms of the selection of writers and illustrators for this set of picturebooks, they tended to invite those who had studied the subject or were from the particular geographical area related to the subject. For example, the picturebook Mei-shu A-gong is a story of the senior artist Li Mei-shu. They found the writer Su Chenming, who had studied the artist before he wrote the story, and the illustrator Chen Mingjie, who was from the artist's hometown of Sanshia (personal communication, December $23,2004)$.

In contrast, the author of the picturebook about the aboriginal myth Shooting Suns is not an aborigine, but he has published several picturebooks and his illustrations are known for his personal style with a sense of humor. This is the main reason that the editor decided to use his work to interpret this traditional myth through a contemporary perspective. According to Mr. Lin, they first found an aboriginal illustrator for this book when choosing this story. However, it did not work out and this led them to rethink their choice and shift their direction to considering the individual's ability to deal with the story rather than having an illustrator because of his/her ethnic identity (personal communication, December 23, 2004). Despite the fact that Mr. Lin might have his own idea of the representation of this aboriginal myth and evaluate the illustrator's work based on it, his account echoes the similar notion suggested by bell hooks, a feminist critic, in 
her critical essay, Making Movie Magic. She comments that "the essentialist belief that merely the presence of larger numbers of visible black filmmakers would lead to a more progressive and/or revolutionary cinematic representation of blackness has been utterly challenged by the types of films that are being made" (hooks, 1998, p. 141). This indicates that ethnicity of the author is not the major factor for providing an accurate representation of aborigines.

\section{The Marketing Strategy for the Picturebooks}

According to Mr. Lin, there were 4,000 children's books published in 2003. Most of them were not displayed in book stores for more than 2 or 3 months. They were considered out of date because too many new books were waiting for display (personal communication, December 23, 2005). Publishing houses' websites have become a channel for keeping books on display due to the popularity of the Internet use. Since the two publishing houses have their reputations in the publishing field, the websites for promoting the three set of picturebooks are well designed and accessible. These websites mainly target educators and parents rather than children because of their emphasis on the ideas of cultural transmission and educational purposes. The specific marketing strategies regarding each set of picturebooks are discussed below (The description of each web page of the promotion is in the appendix D).

Firefly Picturebook Selection-Taiwanese Folktales

The promotion for the Taiwanese Folktales on the website consists of five separate web pages (for the design of the homepage see Figure 4.1; for the map of the website see Figure 4.2). The homepage provides an overview of the picturebooks and the information of a special discount and free gift when one purchases the whole set of 
picturebooks. There are six links on this homepage, which include (1) characteristics of the picturebooks, (2) CD producer's statement, (3) an introduction to a free gift, which consists of six audio CDs (this link connects to the page of the CD producer's statement), (4) recommendations from three references (including one elementary teacher, one mother who represents a parents' body in an elementary school, and one expert who is a well-known writer and consultant of a children's theatrical group), (5) summaries of each picturebook, and (6) purchase information (this link connects to the page of characteristic of the picturebooks).

\begin{tabular}{|l|l|l|l|}
\hline Homepage: http://www.ylib.com/hotsale/firefly/default.htm \\
\hline
\end{tabular}

Figure 4.1: The design of the homepage for promoting the Taiwanese Folktales 


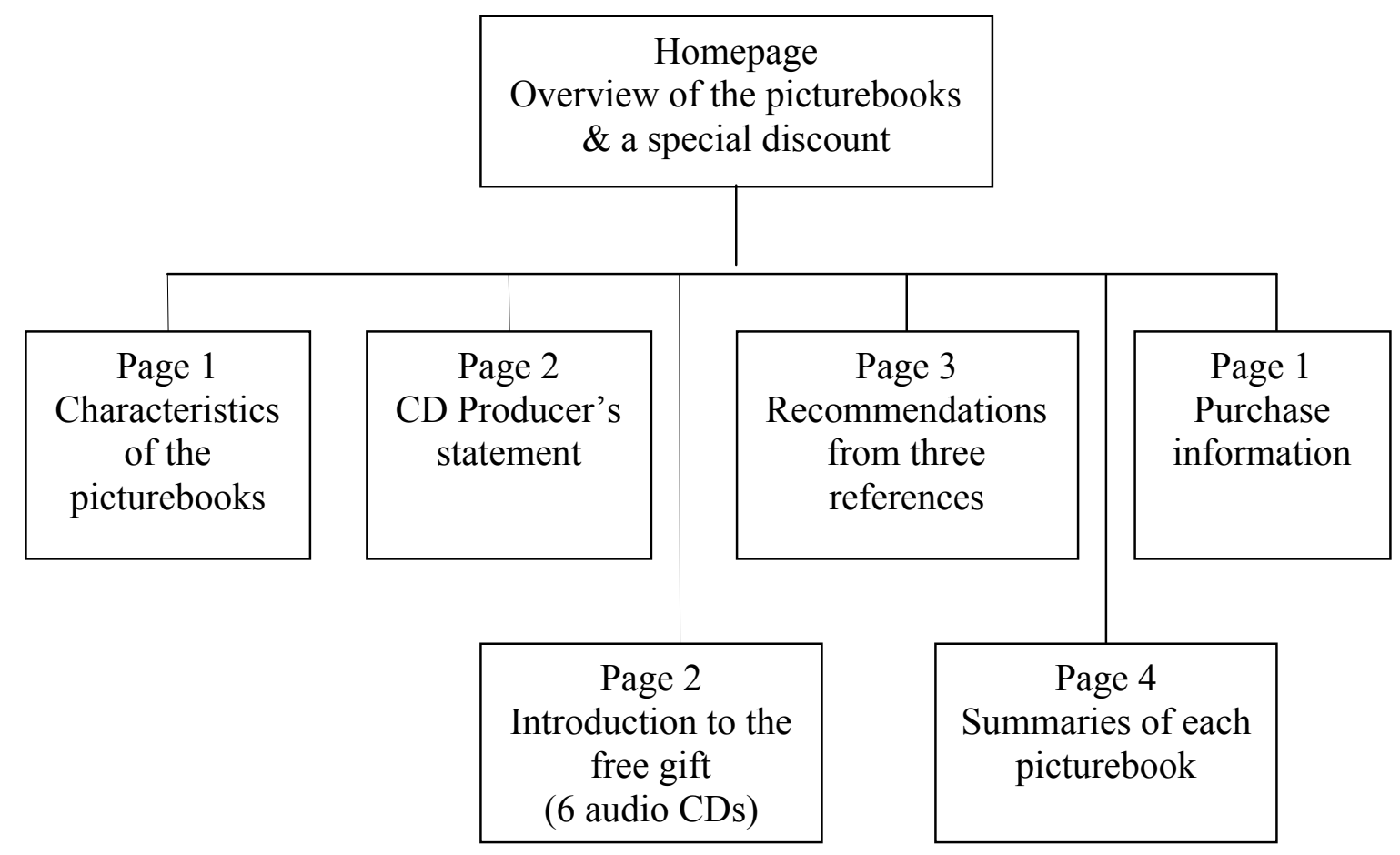

Figure 4.2: The map of the website for promoting the Taiwanese Folktales

The main point in this promotion is to emphasize parents' responsibility to transmit cultural traditions to the next generation in a globalized Taiwanese society. To do this, the Taiwanese Folktales serves as an educational means that can help children gain a taste of their cultural heritages which has been passed down from generation to generation. On this website, six free audio CDs accompanying the whole set of picturebooks are emphasized. These CDs consist of the six folk tales in both Mandarin and Min-nan Hua, retold by a mother who has devoted herself to storytelling and is a leader of a storytelling association in Taipei County. Her personal statement on the web page recalls her childhood memories of hearing the Taiwanese folktales from elders and also gives a personal account of the reason that it was a meaningful task to produce the 
CDs of these folktales for children. This implies that it is an important mission for parents to keep the cultural heritage received from the older generation alive in contemporary life.

Moreover, the art of these picturebooks is also emphasized in the summary of each picturebooks. The summary mentions that the pictures were created by well-known illustrators with diverse art styles and materials. Highlighting the value of the illustrations reinforces the quality of the picturebooks, which tends to convince readers to purchase them not only for the stories, but also the value of the illustrations.

\section{Taiwanese Children's Picturebook Selection}

The promotion for the Taiwanese Children's Picturebook Selection on the website consists of seven separate web pages (for the design of the homepage see Figure 4.3; for the map of the website see Figure 4.4). The homepage is divided into two sections: one section shows a summary of each individual picturebook and the other section consists of seven links. They include: (1) a book list, connecting to the homepage, (2) publishing statement, which explains the reason for publishing the picturebooks, (3) characteristics of the picturebooks, (4) international illustration exhibition, hosted by the publishing house, (5) the exhibition related activities, (6) future promotion for the picturebooks, and (7) cards for collection, which are reproductions of the illustrations in the picturebook Taiwanese Nursery Rhythms and were designed for the exhibition. 


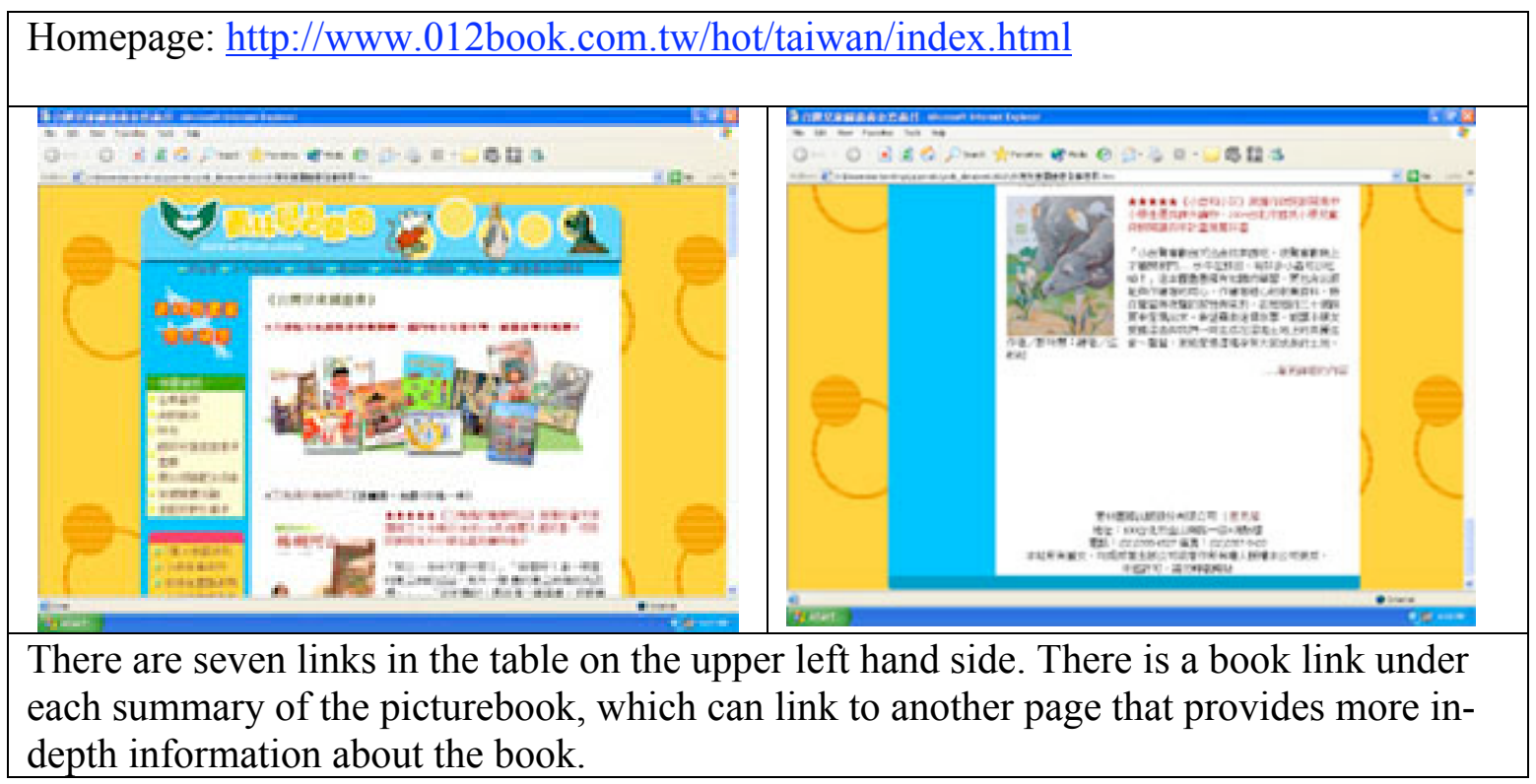

Figure 4.3: The design of the homepage for promoting the Taiwanese Children's Picturebook Selection

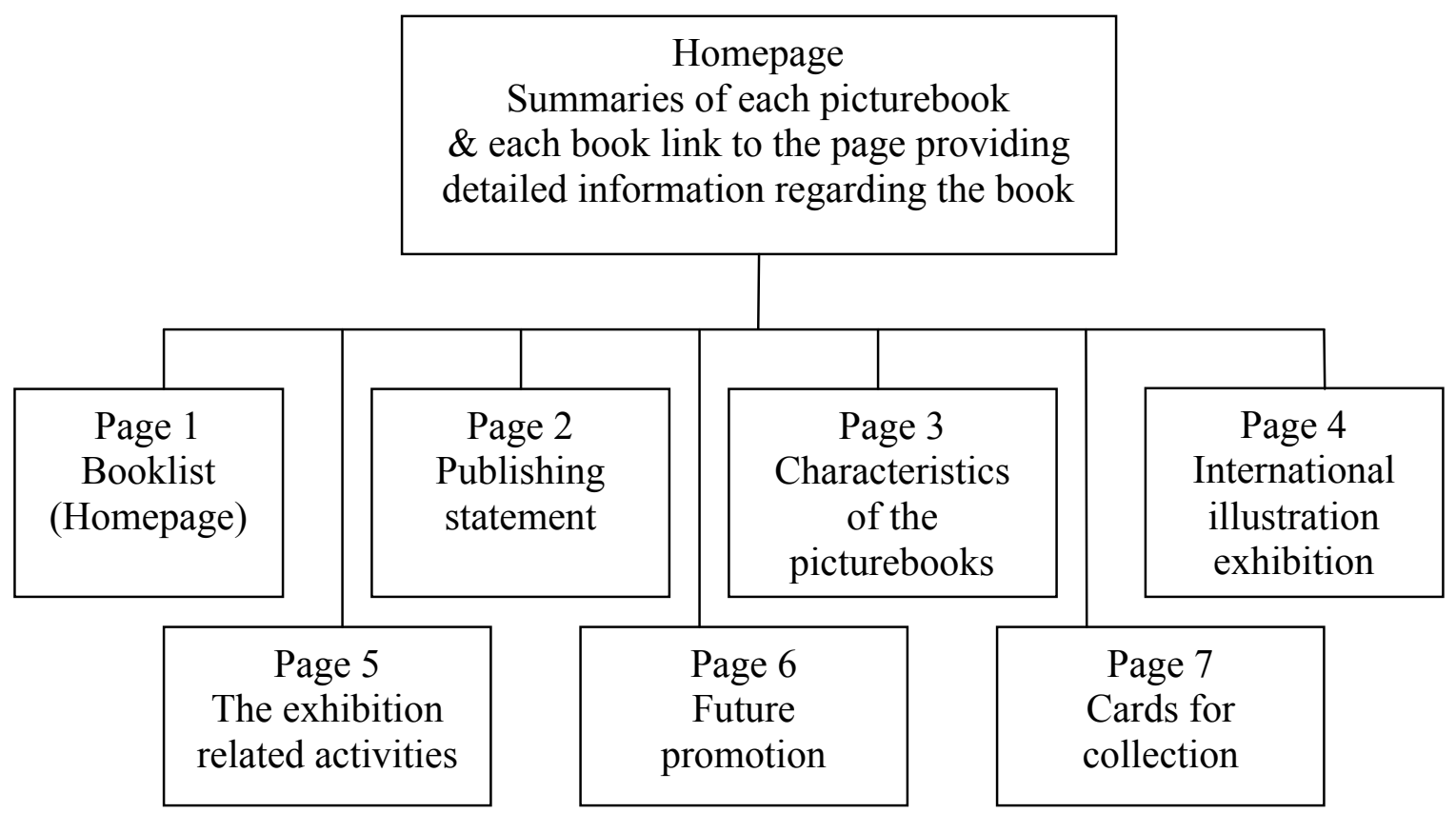

Figure 4.4: The map of website for promoting the Taiwanese Children's Picturebook Selection 
The information on the web page 1, 2 and 3 is closely related to the content and publishing statement of the picturebooks, while that on the web page 4,5 , and 7 is about the illustration exhibition hosted by the publishing house, in which some original illustrations for the picturebooks were on display. These kinds of exhibitions and related activities are promotions usually used by Children's Publications. According to Mr. Lin, they promoted their publications by holding special events for the books, sponsoring book clubs, providing special discounts, and having book autographing activities (personal communication, December 23, 2004).

On the web page of the publishing statement is provided information about the first collaborative model of the government and a private publishing house for investment in publication affairs. I translated part of the text into English as follows:

This publishing project is the first case of investment by the government with a private publishing house. In 2000 the Council for Cultural Affairs called for a project partner on line for publishing "Taiwanese Children's Picturebooks." This project was to fulfill the goal of "art education for citizens," proposed by President Chen in his cultural policy, and to support the curriculum of art and culture, which would be promoted by the Ministry of Education in 2001. This project is also to encourage local writers and illustrators to create picturebooks for children. This opportunity hopes to raise the quality of illustration, which will enable competition with others in the international children's picturebook market. ("Publising Statement," n.d.)

Moreover, Mr. Lin mentioned that they had planned to publish picturebooks that introduced folktales from different places in Taiwan, such as the town of Tamsui and the island of Pengwu (personal communication, December 23, 2004). The text and Mr. Lin's personal account indicate that cultural policy plays an influential role in guiding the publishing direction. Since native education has been emphasized in current public 
education, local cultures and artists have become valuable subject matters, and these are represented as major themes presented in the Taiwanese Children's Picturebook

\section{Selection.}

The major point of the promotion for the Taiwanese Children's Picturebook Selection is to emphasize the representation of traditional cultural practices within current Taiwanese life experiences. Moreover, the quality of art in the picturebooks and the collaboration of local artists from different generations are highlighted on the webpage as characteristics of the picturebooks. As Ms. Lin and Mr. Lin mentioned, and as presented in their editorial intention, discussed in the previous section, these picturebooks tend to connect children to the traditional cultural practices in the stories through an emotional identification. This is also the point that the promotion attempts to convey. Thus, these picturebooks do not only tell stories, but they together provide children with opportunities to explore life experiences from the past, that will continue into the present, and hopefully, be adopted and carried into the future.

\section{Taiwanese Teenagers}

The promotion for the Taiwanese Teenagers on the website consists of five separate web pages (for the design of the homepage see Figure 4.5; for the map of the website see Figure 4.6). The homepage highlights the main theme of this set of picturebooks, which is to promote the six well-known writers' childhood memories and their collaboration with six local illustrators. There are four links on this page, including: (1) characteristics of the picturebooks, (2) individual writer's statements, (3) summaries of each story, and (4) purchase information. 


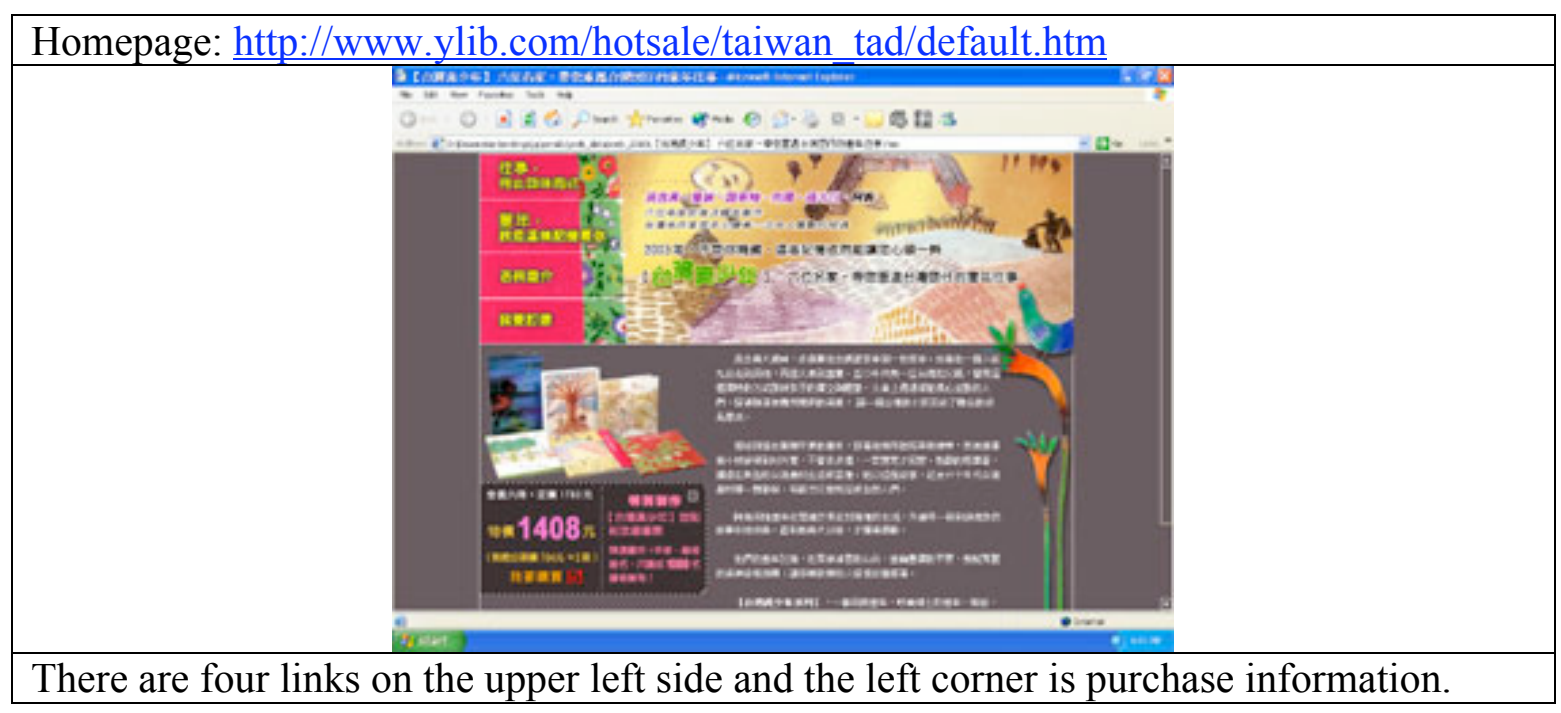

Figure 4.5: The design of the website for promoting the Taiwanese Teenagers

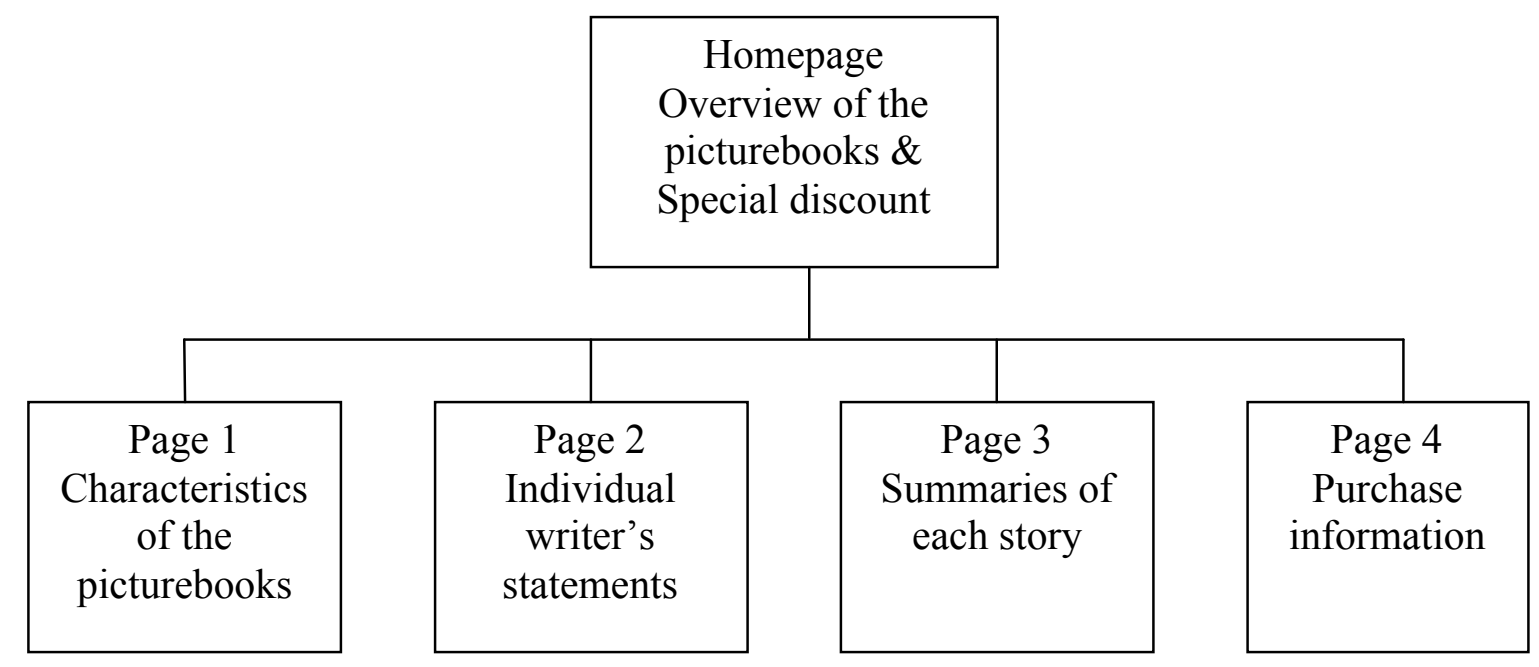

Figure 4.6: The map of website for promoting the Taiwanese Teenagers

The market strategy shown on this website tends to create a nostalgic feeling. It targets the parents who grew up during the 1950s 1960s, which is the childhood period 
depicted in the six stories. One statement, on the homepage translated by the researcher indicates, "[The six writers'] memories also depict the beauty of nature and culture in Taiwan. The warm and touching stories shown in the picturebooks connect the collective memories of the older to the young generation" ("Wu Nian-cheng, n.d.). This statement tends to elaborate the connection of the individuals' life experiences to a larger social fabric. In so doing, they believe that the collective memories of the 1950s 1960s refer to certain cultural values, such as simplicity, honesty, industriousness, and hospitality, which represent aspects of Taiwanese culture in the past.

Although Ms. Lain, the senior editor of the Taiwanese Teenagers, did not intend to make this impression, the marketing team identified the strength of these picturebooks and made decisions on their own when considering the book market. Ms. Lain mentioned that she was not involved in the marketing affairs regarding these picturebooks (personal communication, December 15, 2004). The different concerns regarding the Taiwanese Teenagers between the senior editor and the marketing team show their different interests. In this case, it is obvious to see how the marketing strategy can create a new perspective for perceiving the products (the Taiwanese Teenagers) and drawing readers' attention to the points they desire. For example, one statement, translated by the researcher, about the Taiwanese Teenagers on the web page describing the characteristics of the picturebooks shows:

This is a set of picturebooks that can pass down our cultural heritages: As time goes by, the grandparent generation has gone and landscapes have been changed. Could we leave something for the young generation? The Taiwanese Teenagers provide the six writers' unforgettable memories of a person, a place, or an event. We hope that the young Taiwanese generation can learn something from the early Taiwanese way of thinking, life, and values by experiencing the lives told in the picturebooks. ("Past Events," n.d.) 
This statement encourages parents to take responsibility for maintaining their cultural heritages, which date back to the early Taiwan. This notion implies the significance of the cultural roots shared in this land.

In order to reinforce the strengths of the Taiwanese Teenagers, the promotion also emphasizes the representation of cultural diversity and the artistic presentations in these picturebooks. In other words, the six writers' childhood memories reflect ethnic and geographical diversity. They consist of two aboriginal writers (one male and one female) and four Han writers (three males and one female) who lived in different regions (such as the plains, mountain, and riverside, including the north, south, east, and west parts of Taiwan). Although most of the illustrators are new names to readers, they are promoted as a group of "local artists" who are able to authentically present local cultures.

Therefore, the homepage contains a statement about this first time collaboration for making children's picturebooks by the six well-known writers and six local artists and illustrators.

Part II. Analysis of the Contents of the Three Sets of Picturebooks Three sets of pictuebooks are examined in this study. Brief information regarding each set is as follows: (1) the Firefly Picturebook Selection-Taiwanese Traditional Folktales, published in 2001 by Yuan-Liou Publishing, includes six traditional Han Chinese folktales; (2) the Taiwanese Children's Picturebook Selection, published in 2002 by Children's Publications, consists of ten titles that fall into the three categories of folkways (5 titles), art (4 titles), and environment ( 1 title), according to the publisher, $\mathrm{Mr}$. 
Lin; and (3) the Taiwanese Teenagers, published in 2003, include six stories about the well-known writers' childhood memories.

Since words and images together tell a story in the picturebook, it is inevitable that one needs to comprehend a story though reading both. For this reason, the data analysis regarding verbal and visual narrative patterns will be discussed together. Therefore, the presentation of this section will be divided into two segments: (1) textpicture relation and (2) verbal and visual narrative patterns in the stories and their related meanings.

\section{Text-Picture Relation}

Most of the picturebooks are the results of collaboration between writers and illustrators. Moreover, according to the publishing processes used by Yuan-Liou Publishing and Children's Publications, their collaborative model shows that the editors acquired stories from the writers, and then they looked for the illustrators. In this model, the role of editors is to critically examine the text-picture correspondence, especially when writers do not have the concept of the text-picture relation in the picturebook. However, there are three exceptional cases in the Taiwanese Children's Picturebook Selection, including the picturebooks Shooting Suns, Free Tea for Everyone, and Yueyue's Dancing Lessons. In each of these picturebooks, the text and pictures were produced by the same persons and they have already published several picturebooks and established their reputations in the field. Therefore, their works show a sense of wholeness since they could deal with words and pictures in the stories simultaneously. According to Nikolajeva and Scott (2001), there are three types of text-picture relationships. They consist of: (1) a complementary relation, (2) a symmetrical relation, 
and (3) a relation of enhancement and counterpoint. A complementary relation means "words and images fill each other's gaps wholly" and the reader passively receives the messages (p. 17). For example, My Friend Rabbit by Eric Rohmann, ${ }^{56}$ the winner of the Caldecott Medal of 2003, well illustrates a complementary relation. A mouse, the narrator in the story, mentions that "My friend Rabbit means well. But whatever he does, wherever he goes, trouble follows." Accompanying this statement, the pictures show what trouble he made. Thus, the gap between words and images are filled by the author, and the reader can receive the message that the author intends to convey.

A symmetrical relation refers to the idea that both words and images together tell a complete story and there is no gap between them or the gaps are alike. In other words, the reader can read the picture narrative and get the same idea from the verbal narrative. Folktales with a picturebook format oftentimes present a symmetrical relation (Nikolajeva \& Scott, 2001). For example, the story depicted by the text and pictures are identical in the picturebook Cinderella illustrated by Marcia Brown, ${ }^{57}$ the winner of the Caldecott Medal of 1955.

A relation of enhancement and counterpoint means "words and images provide alternative information or contradict each other in some way," so the readers need to fill in the gaps with their interpretations (Nikolajeva \& Scott, 2001, p. 17). For example, the text in the picturebook Rosie's Walk by Pat Hutchins ${ }^{58}$ describes the movement of a hen named Rosie in a peaceful tone, but the pictures shows the action of a fox trying to capture the hen and this implies the danger she might encounter. Thus, the reader needs

\footnotetext{
${ }^{56}$ Rohmann, E. (2002). My friend rabbit. Roaring Brook Press.

${ }^{57}$ Brown, M. (1954). Cinderella. New York: Scribner. The text was written by Charles Perault.

${ }^{58}$ Hutchins, P. (1968). Rosie's walk. New York: Macmillan.
} 
to actively interpret the two different messages suggested by the text and the pictures in order to fill in the gap between words and images.

The text-picture relationship shown in the three sets of Taiwanese picturebooks falls into the symmetrical category. That is because words play the major role of telling the stories and the stories can be understood without images. Moreover, the illustrations fill a secondary role which tends to provide visual references based on the stories. Therefore, the gaps between words and images are identical and the reader plays a passive role in the reading process. It is inevitable, when the purpose of the publication is set up beforehand and the subject matters are already decided, that picturebook illustrators have limited freedom to create their work and explore different possibilities within the text-picture relationship.

Despite this limitation, there are three different ways the illustrations add visual excitement to the text. First, it catches readers' attention when the design of a frame shows the sequence of a plot around one or two large images, with a major focus of the plot on a double-spread page. This strategy is used in three picturebooks, including the picturebooks Bo-zei Chi (a tale of a man using his wits to cheat a rich and greedy man of his money), Li Tian-luo (a tale of an honest but poor man becoming rich due to marrying a good wife), and Hao-bi-shi (a tale of why ants have a good sense of smell) all in the Taiwanese Folktales (see Illustration 4.1). 

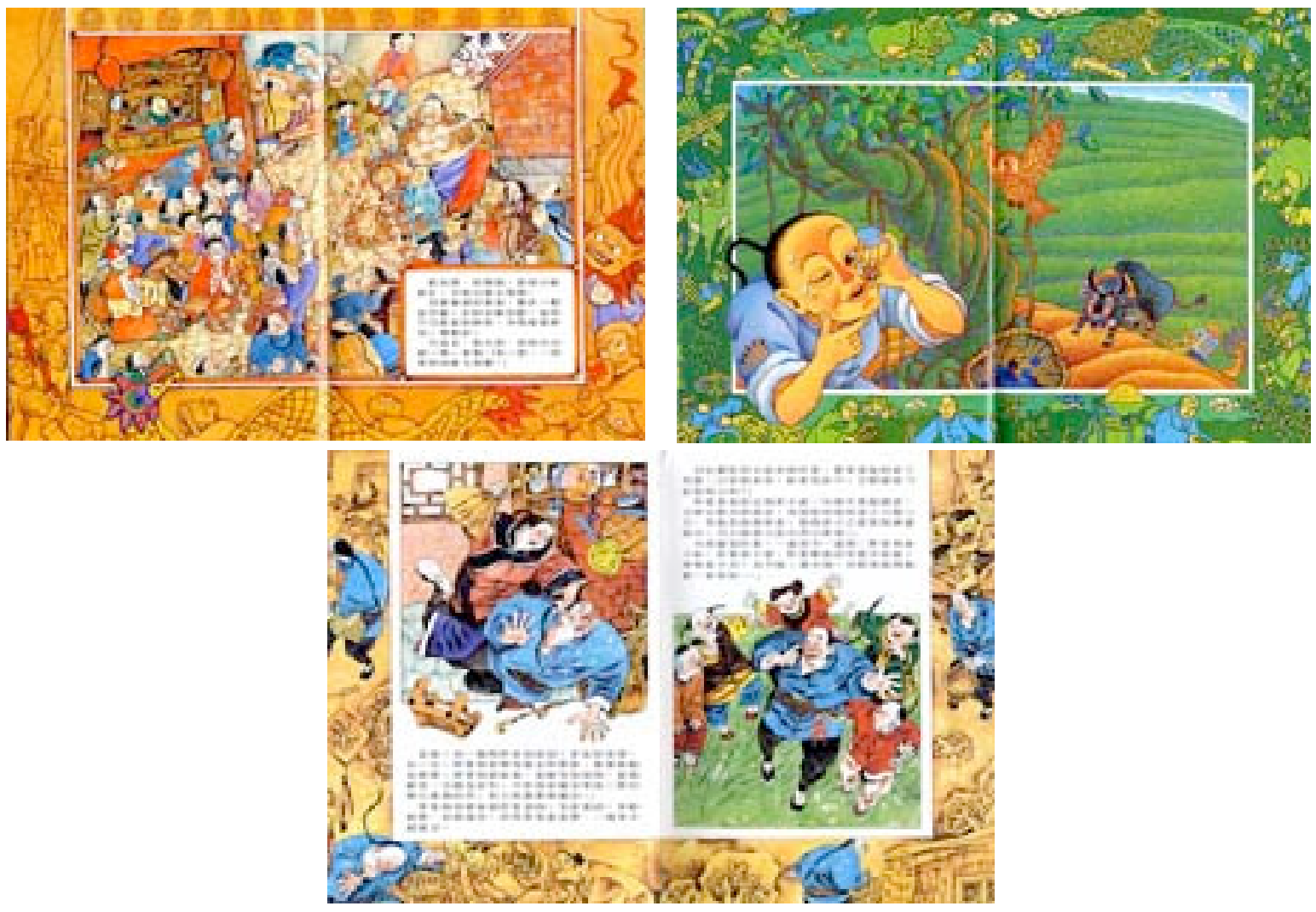

Illustration 4.1: The design of a frame in three picturebooks

Second, interest is generated when the design shows the impressive scenery mentioned in the stories narratives. To do this, the picturebook employs double-spread image. There are two picturebooks in the Taiwanese Children's Picturebook Selection showing this strategy, including the image of a high stage with twelve barge-poles in the picturebook My Father is Going to a Festival Competition (see Illustration 4.2) and the picture of a row of buildings depicted with a Baroque architectural style on a street in the picturebook Going Shopping on Dihua Street for Chinese New Year (see Illustration 4.3). 


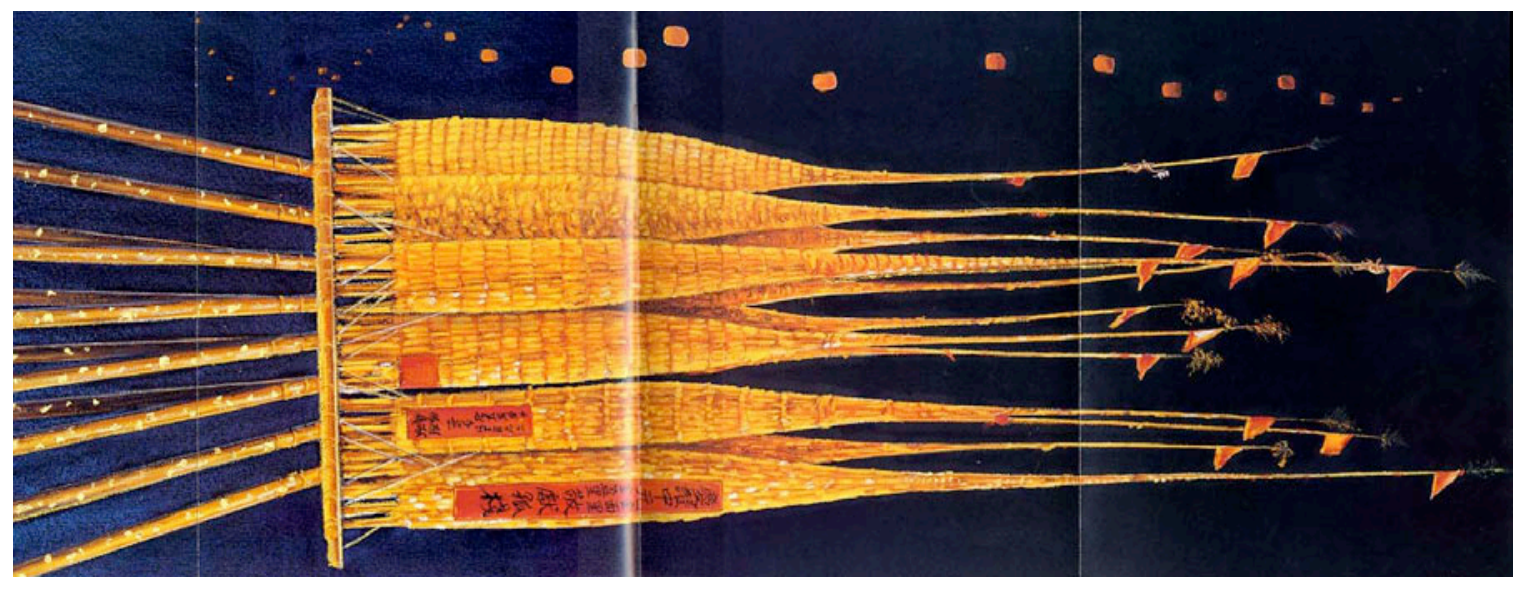

Illustration 4.2: A double-spread image shown in the My Father is Going to a Festival Competition

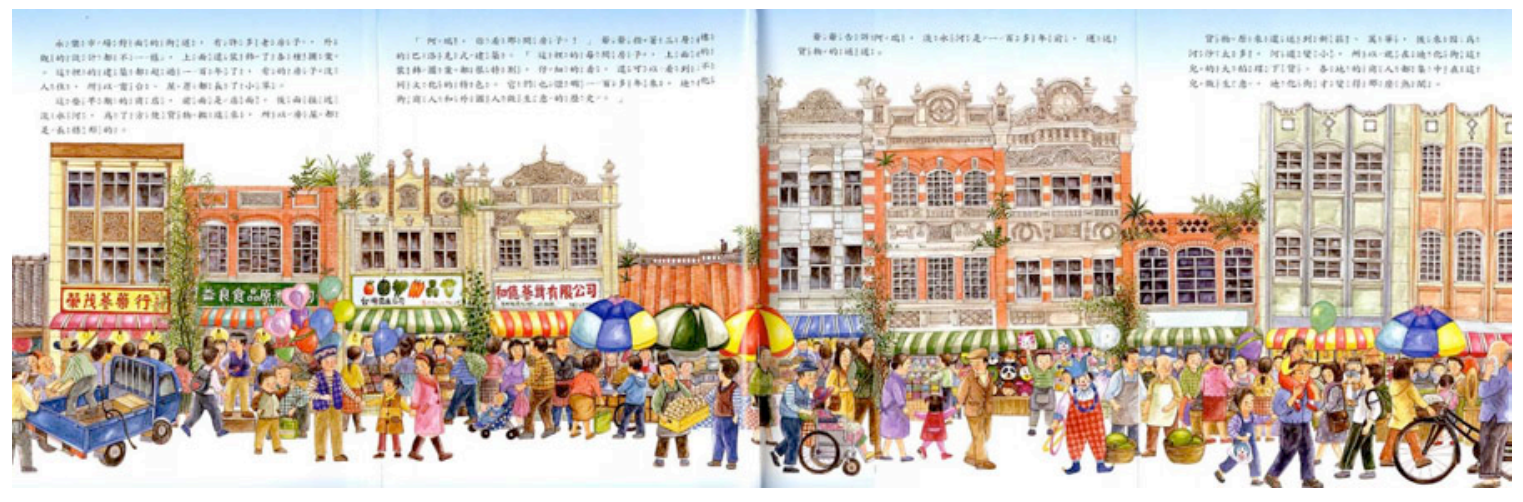

Illustration 4.3: A double-spread image shown in the Going Shopping on Dihua Street for Chinese New Year

Third, the picturebooks can provide metaphorical messages, that take readers into the stories from an emotional aspect, though the visual images and these messages contain different implicit and explicit meanings. This strategy is shown in two picturebooks in the Taiwanese Teenagers. In the picturebook Selling Brooms with My Grandmother, the use of different materials with a collage technique in the illustration to 
symbolize the weather mentioned in the text provides an artistic interpretation of the emotional feeling regarding the weather (see Illustration 4.4). In the picturebook A River Resembling a Mother, the images of a woman holding an umbrella (implying the dead mother looking over her child) and a cat looking over its kittens (implying the mother's love for children), which are not described in the text, add a sense of a mother's love to the story by the illustrator ${ }^{59}$ (see Illustration 4.5 ). In sum, these examples show some strategies for making the text more appealing to the reader.
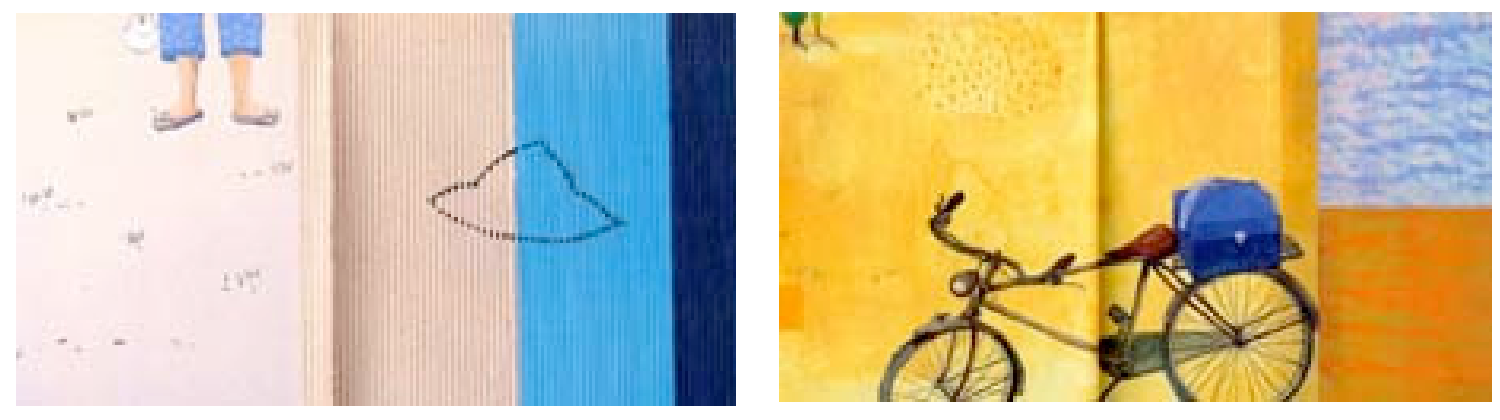

Illustration 4.4: The use of metaphorical messages shown in the Selling Brooms with My Grandmother

\footnotetext{
${ }^{59}$ Although the illustrator in the book, A River Resembling a Mother, provides her own interpretation regarding the story, which is different from the writer's, most of the illustrations in this book tend to present what the text already mentioned. Therefore, I still classify this book in the category of the symmetrical relation.
} 


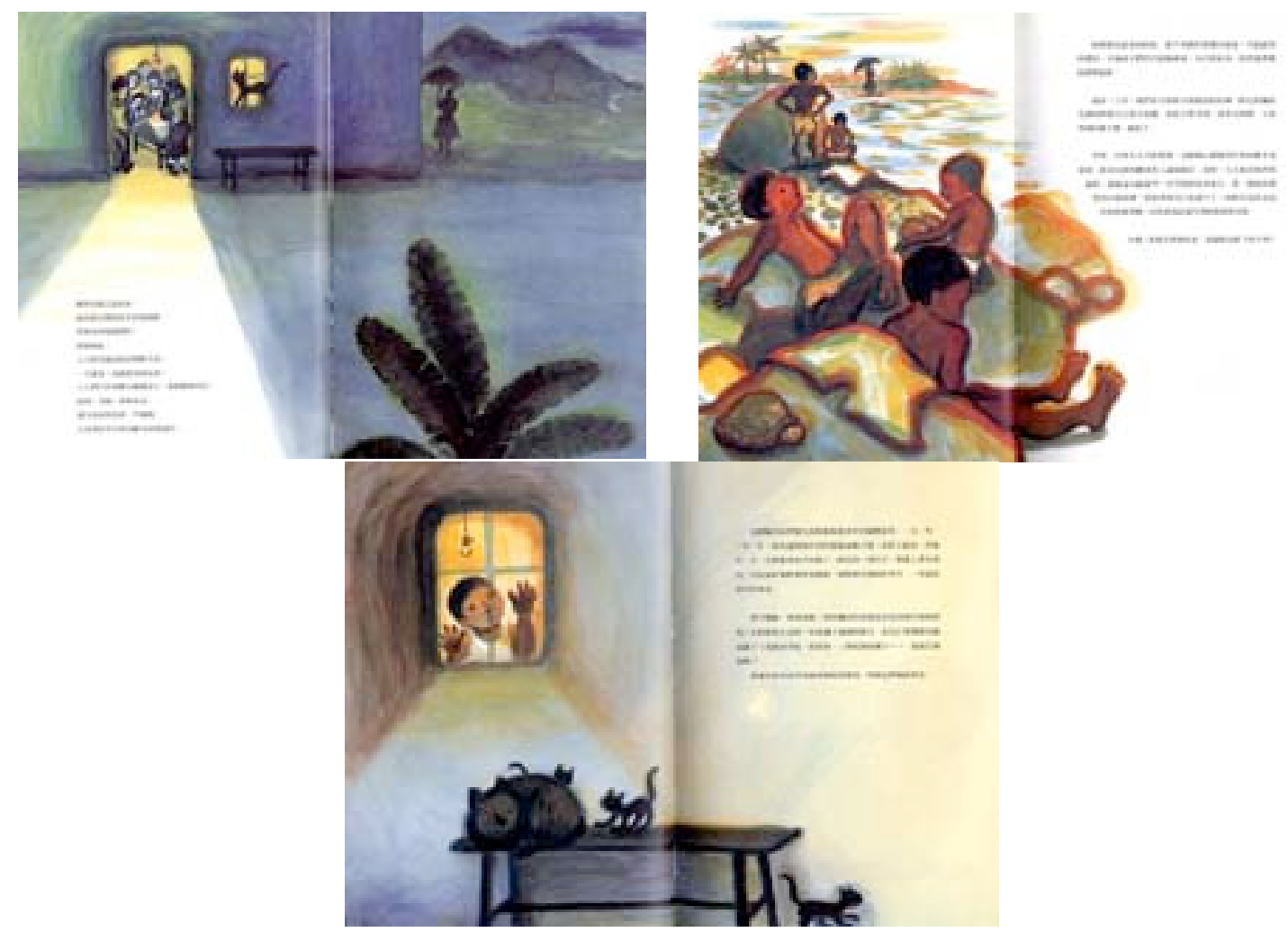

Illustration 4.5: The use of metaphorical messages shown in the A River Resembling a Mother

\section{Verbal and Visual Narrative Patterns and Their Related Meanings}

This section will be presented according to literary elements of children's literature, which are based on the notion of the evaluation of children's fiction suggested by Huck, Hepler, Hickman, and Kiefer (2001) and the artistry of literary elements provided by Temple, Martinez, Yokota, and Naylor (2002). Thus, the analysis consists of six major components: (1) setting, (2) characterization, (3) theme, (4) plot, (5) point of view, and (6) style. According to Nikolajeva and Scott (2001), the description of setting and character "can be both verbal and visual, agreeing or counterponting in various ways," while "the summary of events, and the comments on events, or the characters" 
actions... are predominantly verbal in picturebooks" (p. 118). Therefore, in the six categories, setting, characterization, point of view, and style will be discussed from both verbal and visual aspects, while theme and plot will primarily based on a verbal aspect. Setting (Time and Place)

The settings of the stories depicted in the three sets of picturebooks can be classified into three categories: (1) settings in folktales, (2) settings during a particular time period in the past, and (3) settings in the present time. Both words and images help readers identify the setting in each picturebook. The illustrations provide not only spacial information about a particular place, but also costumes, architecture, and articles of daily use for indicating a specific time period, especially when words do not mention time in the story.

Eighteen of the twenty-two picturebooks directly indicate the time of the stories in the words and depict the place of the stories in the pictures. Three picturebooks rely on the pictures to specify the time period. A few picturebooks also verbally describe the place in more detail, such as the name and the physical environment of the place. The distribution of the picturebooks regarding setting is shown in the following chart (see Table 4.1). 


\begin{tabular}{|c|c|c|c|}
\hline Category & Picturebook & Verbal Pattern & Visual Pattern \\
\hline $\begin{array}{l}\text { Settings in the } \\
\text { Folktales and } \\
\text { Rural } \\
\text { Communities }\end{array}$ & $\begin{array}{l}\bullet \quad \text { G1-01, G1-02, } \\
\text { G-1-03, G1-04, G1-06 } \\
\text { (Qing dynasty, the } 17^{\text {th }} \\
\sim 19^{\text {th }} \text { century) } \\
-\quad \text { G1-05 (Ming } \\
\text { dynasty, the } 14 \sim 17^{\text {th }} \\
\text { century) } \\
-\quad \text { G2-02 (aborigines) }\end{array}$ & $\begin{array}{l}\text { The term "Once upon } \\
\text { a time" is repetitive } \\
\text { in different stories. }\end{array}$ & $\begin{array}{l}\text { The costume and } \\
\text { architecture } \\
\text { indicate the time } \\
\text { period. }\end{array}$ \\
\hline $\begin{array}{l}\text { Settings during a } \\
\text { Particular Time } \\
\text { Period in the Past } \\
\text { and } \\
\text { Suburban/rural } \\
\text { Communities }\end{array}$ & $\begin{array}{l}\text { G2-01 }(1940-60 \mathrm{~s}, \\
\text { suburban }), \\
\text { G2-03 }(1940-70 \mathrm{~s}, \text { rural }) \\
\text { G2-04 }(1940-80 \mathrm{~s}, \text { rural }) \\
\text { G2-10 (1950-70s, rural) } \\
\text { G3-01 (1970s, rural), } \\
\text { G3-02 (1950s, } \\
\text { suburban), } \\
\text { G3-03 (1970s, a tribe), } \\
\text { G3-04 (1950s, a tribe, } \\
\text { rural), } \\
\text { G3-05 (1950s-60s, } \\
\text { rural), } \\
\text { G3-06 (1950s-60s, } \\
\text { rural) }\end{array}$ & $\begin{array}{l}\text { 1. To imply it is } \\
\text { happening now (G2- } \\
01, \mathrm{G} 2-03) \\
\text { 2. To indicate the age } \\
\text { of the writer in the } \\
\text { story (G3-02, G3-04, } \\
\text { G3-06) } \\
\text { 3. To indicate a } \\
\text { general time period } \\
\text { (G3-01, G3-03) } \\
\text { 4. A lack of } \\
\text { description in words } \\
\text { (G2-04, G2-10, G3- } \\
05)\end{array}$ & $\begin{array}{l}\text { The costume, } \\
\text { architecture, } \\
\text { landscape, and } \\
\text { articles of daily use } \\
\text { indicate the time } \\
\text { period. }\end{array}$ \\
\hline $\begin{array}{l}\text { Settings in the } \\
\text { Present Time and } \\
\text { Suburban/Urban } \\
\text { Communities }\end{array}$ & $\begin{array}{l}\text { G2-06 (suburban), } \\
\text { G2-07 (urban), } \\
\text { G2-08 (urban), } \\
\text { G2-09 (urban) }\end{array}$ & $\begin{array}{l}\text { 1. To mention the } \\
\text { term "Today" (G2- } \\
07, \mathrm{G} 2-09) \\
\text { 2. To indicate a } \\
\text { particular holiday } \\
\text { (G2-06, G2-08) }\end{array}$ & $\begin{array}{l}\text { The costume, } \\
\text { architecture, and } \\
\text { articles of daily use } \\
\text { indicate the time } \\
\text { period. }\end{array}$ \\
\hline
\end{tabular}

Table 4.1: A distribution of setting presented in the three sets of picturebooks

1. settings in the folktales and rural communities use the term "once upon a time" to start the stories.

In the first category, the term "once upon a time" was frequently used to start the stories. There are five Han folktales and one aboriginal myth showing this pattern. The translation of the beginnings of each story are as follows. 
Once upon a time, there was a liar living in Taiwan, whose name was A-chi. He was naughty when he was young and liked to make fun of people as he grew up...(G1-02)

Once upon a time, there was a rich man, named Peng, living near Miaoli County. He had three daughters... (G1-03)

Once upon a time, there was a man named $A-f a$, who was afraid of his wife. One day, his wife sent him to buy food, but he went out gambling... (G1-04)

Once upon a time, there were two brothers who shared a farming cow. The elder brother treated the cow badly and could not farm his land well, while the younger brother was nice to the cow and his land was farmed neat and tidily... (G1-05)

Once upon a time, there was a rich man who had numerous farms for rent. When autumn was coming, he needed to collect rent from his tenant-farmers... (G1-06)

This story is one of the oldest myths passed down from generation to generation on the land we live... Once upon a time, there were no star and moon in the sky, but only one sun. The aborigines in different tribes worked hard, farming, hunting, weaving during the day. They happily sang, danced, and drank at night. And then they went to bed and slept tight. Their life schedule followed the routine of sunrise and sunset. Their lives were joyful. (G2-02)

The first five Han folktales repeat the same pattern, which is to first state the term "once upon a time," and then to introduce the characters. Most of the writers did not mention any specific locations where the stories came from. Only one story identifies its location near Miaoli County, where a big population of the Hakka group lived. By doing this, it gives credit to the Hakka group. It also helps readers situate their expectations within a particular culture. In other words, as soon as readers learn that the story is about the Hakka from the text, they can predict the story or bring their life experience to the story based on their understanding of that particular culture.

Moreover, in the aboriginal myth, the writer wrote "the aborigines in different tribes...," which indicates a general feeling that this story belongs to aborigines as a whole rather than a particular tribe. According to the publisher, Mr. Lin, the myth 
Shooting Suns had different versions and could be found in different tribes, so their intention in this picturebook was to create a story about aborigines in general (personal communication, December 23, 2004). Therefore, the author can avoid possible criticism about the issue of authenticity because he provides his own interpretation of this myth rather than giving an authentic oral history.

Although the Han folktales do not point out a particular time in words, the pictures imply the time frame through the costumes and architecture depicted in the picturebooks. It is obvious that the same costumes and architecture repetitively are shown in five of the six folktales, which refer to the Qing dynasty (the $17^{\text {th }} \sim 19^{\text {th }}$ century). One exception is the picturebook Mai Hsiang-pi (Fragrance for Sale-a tale of two brothers), in which the use of style in the illustration is based on Chinese shadow puppetry. The design of the costumes and architecture in this picturebook refers to the Ming dynasty (the $14^{\text {th }} \sim 17^{\text {th }}$ century). Despite this difference, all the folktales and the myth depict rural communities in the stories, which reflect folks' lives in an agricultural society.

\section{2. settings during a particular time period in the past and suburban/rural communities} start the stories by using four different types.

There are four ways to indicate a particular time period in the past. First, the words may imply that the story happens today but, when following the plots and pictures, readers can recognize the stories happened in the past. For example,

In the early morning, when the sky was getting bright, grandfather Mei-shu took his paint brushes, walked through an old street, and went to the bank of the Sanshia River... (G2-01)

This story introduces a senior artist Li Mei-shu and the plot focuses on one day of the artist's daily life. In so doing, it implies how this artist had insisted on his ideal of art and 
put it into his daily practice. However, the use of a rickshaw for transportation shown in a picture presents the idea of when the story happened.

Second, to indicate the age of the writer in the story is a way to tell readers about the time of the story and implies that it is real based on his or her personal life experiences. There is a pattern showing that when the writers mention their age in the stories, the year functions as a turning point in their lives. For example, one writer recalls his memory of receiving a challenging training from his father when he was eight. He wrote,

My father left for work as a miner in the town of Jiufen, which was far away from his hometown, when he was fifteen... He believed that all boys should be brave and independent, especial his eldest son. I am his son, the eldest one. When I turned eight, he seemed to think it was the time to give me a challenging task. (G3-03)

Two male writers also recall their memories of facing the death of their parent or relative when they were very young. The death made them recognize their relationships with the significant persons and the impact on their lives.

Third, a general time period can be indicated in the stories by playing an emphasis on the seasons. For example, one writer mentioned her childhood memory of running away from home during the summer.

One summer, I decided to run away from home because I had a fight with my mother...It was interesting that I made two mistakes. One mistake was I didn't understand that it took more than one day to walk to my destination from the tribe where I lived. The other one was that the scenery on the way was so beautiful that it made me fall asleep, especially because it was a hot summer. (G3-03)

Another writer also tells of her childhood memory of her grandmother and mother making straw brooms for sale in autumn. All the activities depicted in the story reflect rural life in autumn. 
Fourth, unlike the three ways indicating time in words, three picturebooks lack description in words and rely on the pictures to tell the particular time period in the narrative. For example, the picturebook Da-tou Has a Son, written with a rhyming format, has a content designed to introduce Taiwanese traditional local food and occupations. Accompanying the growth of the son, the pictures show changes over the years. In this case, the articles of daily use and architecture, intentionally created by the illustrator, depict the images often shown during the 1940s 1980s in Taiwan.

Rural communities are the most popular locations shown in the pictures while only two of the picturebooks show suburban scenery. Open space and natural landscapes are used to portray a rural location (see Illustration 4.6). Rows of houses next to each other along a street represent a suburban location (see Illustration 4.7). 

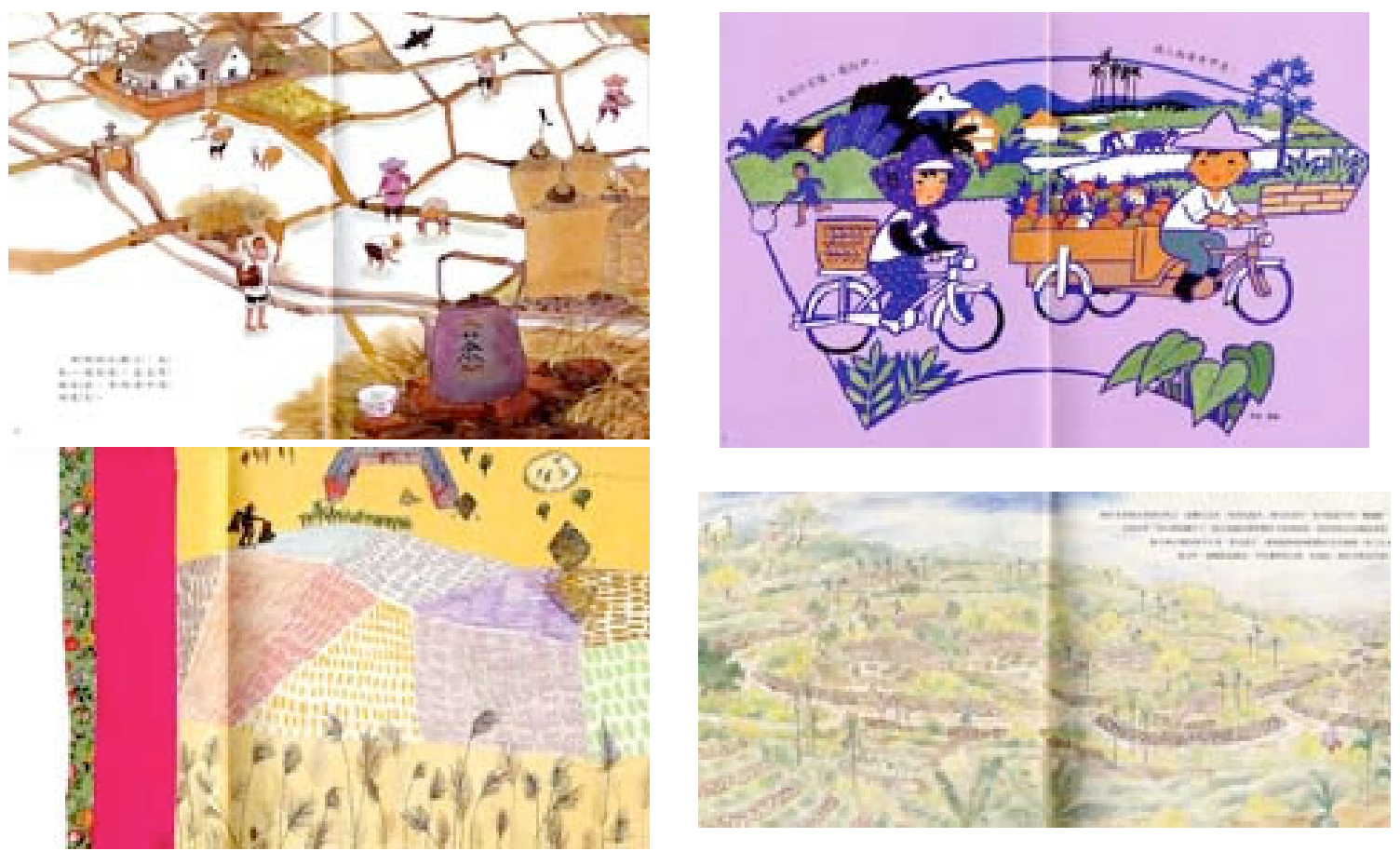

Illustration 4.6: The images of rural communities shown in the picturebooks
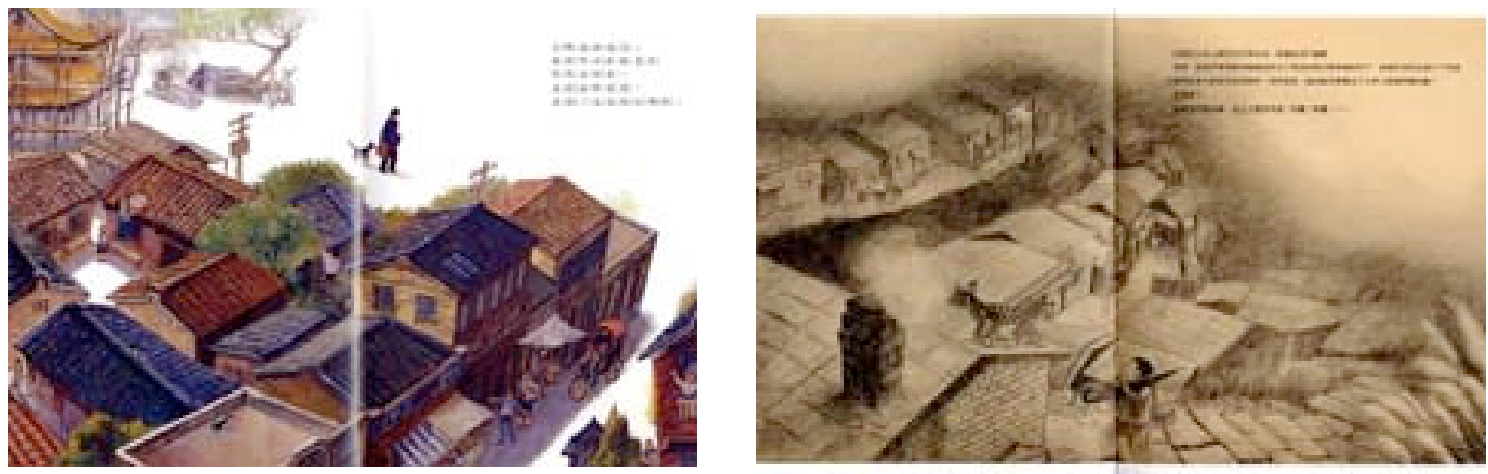

Illustration 4.7: The images of suburban communities shown in the picturebooks 
3. settings in the present time and suburban/urban communities use two ways to indicate the time.

There are two ways to present time in the stories situated in current society. The first way is to mention what the main character is going to do, or is doing now, after the term "today" at the beginning of the story. This invites readers to identify with the main character and predict what will happen in the story. For example, two writers start with this pattern in their stories.

Today, Hsiao-tong is excited because she is going to visit an art museum ... (G207)

May 20. Today, it is Yue-yue's first dancing lesson. However, she is not willing to go into the classroom... (G2-09)

In contrast, the second way is to indicate a particular holiday in the story which implies that the main characters will engage in the activity mentioned in the story during the present time period. For example, two writers point out the purpose for doing something by mentioning a particular holiday.

Tsung-tsung's father told his family that "We will go to participate in a ritual competition in the town of Toucheng on midnight of July $29^{\text {th }}$, on the lunar calendar." (G2-06)

Chinese New Year is coming soon. One day, the sky was so blue. My grandfather said, "Let's go shopping on Dihua Street for Chinese New Year." (G2-08)

An assumption of the first pattern is that "art museum" and "dancing lesson" are intelligible terms for children. However, the writers adopting the second way were concerned with the possible unfamiliarity the reader might have. For this reason, they needed to provide a reliable reason for starting their stories. 
The visual representations of these "urban" picturebooks, in terms of location, are different from those of the other picturebooks. More indoor scenes are shown. It is significant that there is no contemporary architecture shown in these picturebooks. One of the four picturebooks in this category shows its location in a classroom and the story is about the growth of a little girl participating in a series of dancing lessons. Therefore, a change in location is not emphasized in the story. The locations in the three "urban" picturebooks consist of an art museum in Taipei City, an old street in Taipei City, and a suburban community in Yilan County. In these picturebooks, the illustrations show the traditional architecture with three different styles: traditional Chinese Palace (the art museum, see Illustration 4.8), early western style (Baroque ${ }^{60}$ - the old street, see Illustration 4.9), and traditional southern house (the suburban community inYilan County, see Illustration 4.10). What is not present in the pictures, such as contemporary buildings, is also important in analyzing the visual narrative pattern.

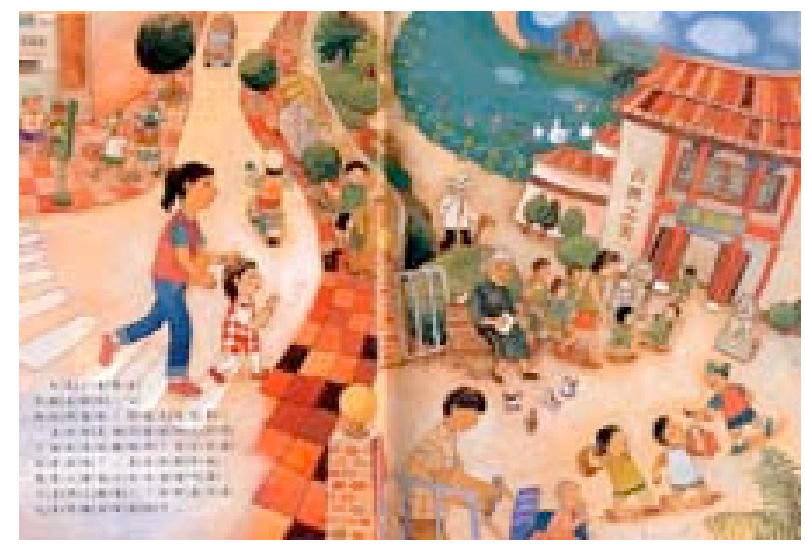

Illustration 4.8: The image of a traditional Chinese Palace

\footnotetext{
${ }^{60}$ Architecture with Baroque style was introduced to Taiwan during the Japanese colonial era. The presidential palace in Taipei is one of the representative buildings with Baroque style in Taiwan. Although this style does not have roots in traditional Chinese culture, it has become part of Taiwanese culture.
} 


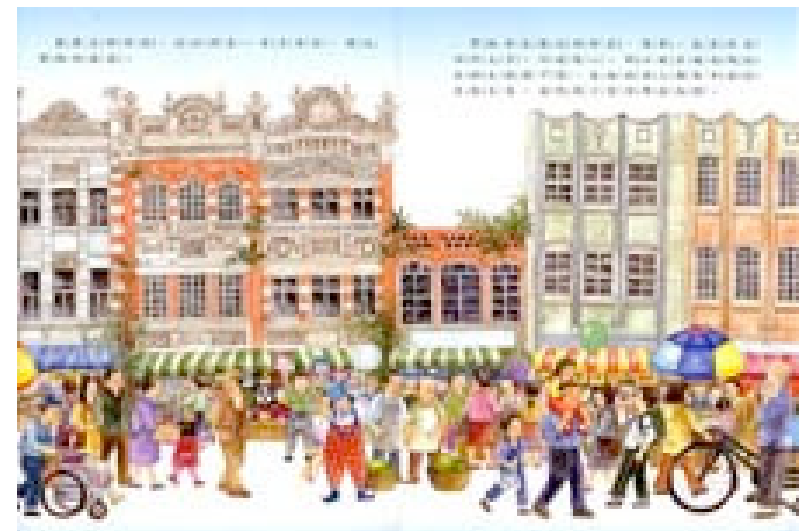

Illustration 4.9: The image of buildings with the Baroque style

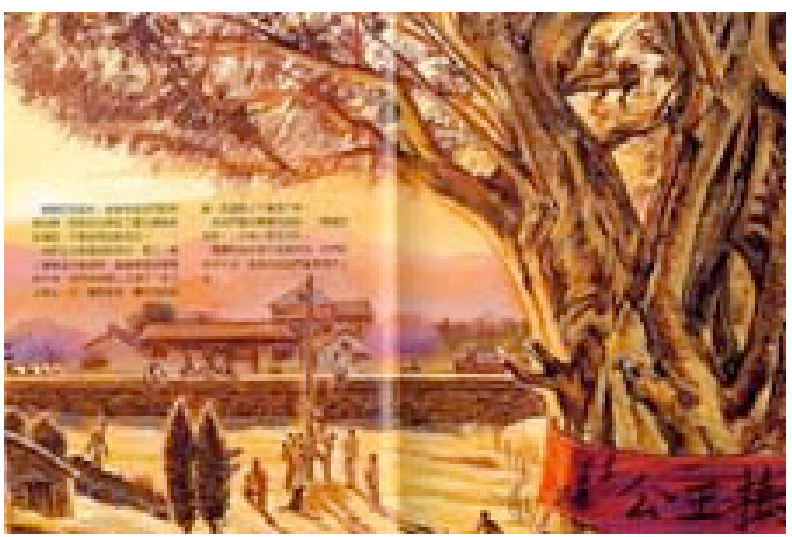

Illustration 4.10: The image of the suburban community in Yilan County

\section{Characterization}

Due to the nature of the picturebook, the story needs to be told in a number of pages which limits the development of characters in the story. Moreover, picturebooks usually are plot-oriented rather than character-oriented; for this reason, "most characters are static rather than dynamic, and flat rather than round" (Nikolajeva \& Scott, 2001, p. 82). Due to this limitation, story characters are more identifiable, which helps young 
readers recognize their roles and characteristics. Verbal descriptions of the characters in these picturebooks are limited, while pictures provide more information about how the characters look and act. Settings in the stories, such as those of folktales or realistic life experience, also shape the characteristics of these characters to some degree. In addition, the development of characters heavily relies on the relationship between the characters and their actions throughout the stories. Thus, the interaction between characters, such as who plays the active role or passive role in the story, is also a consideration. In order to illustrate these patterns, the story characters are divided into four different groups: male adult, female adult, child, and supernatural beings.

An analysis of these characters shows that: (1) male roles show domination in the picturebooks; (2) stereotypes of adult male roles in folktales are reinforced by the visual; (3) adult males play a responsible and strict role in the stories; (4) female roles emphasize human relationships; (5) stereotypes of some female roles in the picturebooks have changed, but some remain the same; (6) diverse child characters are shown in both gender roles; (7) the role of the child is to receive teaching from the elders; (8) supernatural beings in Han stories show gods' judgment on humans; (9) spirits of the dead who died accidental deaths behave like humans; (10) supernatural beings in aboriginal stories bring blessings to the folks; and (11) wizards are a bridge between gods and humans.

\section{1. male roles show domination in the picturebooks.}

It is obvious that males (both adults and children) play the major characters in most of the picturebooks. More than half of the picturebooks are male dominated in the stories, while less than one quarter of the picturebooks focus mainly on the female 
experience. Especially, the male adult dominates in the traditional Han folktales and usually plays a more active role in the story than the female does (see Table 4.2).

\begin{tabular}{|c|c|c|c|c|}
\hline $\begin{array}{l}\text { Category/ } \\
\text { Frequency }\end{array}$ & Male & Both & Female & Not Apply \\
\hline \multirow[b]{2}{*}{$\begin{array}{l}\text { Taiwanese } \\
\text { Folktales }\end{array}$} & 4 & 1 & 1 & 0 \\
\hline & $\begin{array}{c}\text { G1-02 (two males), } \\
\text { G1-04 (brothers), } \\
\text { G1-05 (a liar), } \\
\text { G1-06 (friends) }\end{array}$ & $\begin{array}{c}\text { G1-03 } \\
\text { (a couple) }\end{array}$ & $\begin{array}{l}\text { G1-01 } \\
\text { (a girl) }\end{array}$ & NA \\
\hline \multirow[b]{2}{*}{$\begin{array}{c}\text { Taiwanese } \\
\text { Children's } \\
\text { Picturebook } \\
\text { Selection }\end{array}$} & 5 & 1 & 2 & 2 \\
\hline & $\begin{array}{c}\text { G2-01, G2-08 (grandfather } \\
\text { \& grandson), } \\
\text { G2-02 (three generations), } \\
\text { G2-03 (supernatural } \\
\text { beings), } \\
\text { G2-04 (father) }\end{array}$ & $\begin{array}{c}\mathrm{G} 2-06 \\
\text { (a couple) }\end{array}$ & $\begin{array}{l}\text { G2-07, G2-09 } \\
\text { (mother \& } \\
\text { daughter) }\end{array}$ & $\begin{array}{l}\text { G2-05, } \\
\text { G2-10 }\end{array}$ \\
\hline \multirow[b]{2}{*}{$\begin{array}{l}\text { Taiwanese } \\
\text { Teenagers }\end{array}$} & 3 & 1 & 2 & 0 \\
\hline & $\begin{array}{l}\text { G3-04 (granduncle } \\
\text { \& grandnephew) } \\
\text { G3-05, G3-06 (a boy) }\end{array}$ & $\begin{array}{l}\text { G3-02 } \\
\text { (a boy \& an } \\
\text { old lady) }\end{array}$ & $\begin{array}{c}\text { G3-01, G3-03 } \\
\text { (grandmother \& } \\
\text { granddaughter) }\end{array}$ & NA \\
\hline Total $(n=22)$ & 12 & 3 & 5 & 2 \\
\hline Percentage & $55 \%$ & $14 \%$ & $24 \%$ & $9 \%$ \\
\hline
\end{tabular}

Table 4.2: Frequencies of the main characters' gender in the stories

In addition, the book titles illustrate this notion. That is, three out of six picturebooks in the Taiwanese Folktales had titles based on the names of the main male characters in the stories. They include Bo-zei Chi (meaning the liar named Chi), Hao-bishi (meaning the person having a good sense of smell), and Li Tian-luo (meaning the person selling field snails named $\mathrm{Li}$ ). These titles indicate that the story is about a particular person and one major characteristic of the person, such as behavior, 
appearance, or occupation. The first two picturebooks mainly depict the two major male characters in the stories and the development of the characters of their wives is not specific.

Li Tian-luo, which is about an honest but poor man becoming rich due to marrying a good wife, is the only one picturebook placing an equal weight on both gender roles in the Taiwanese Folktales category, but it was given a book title according to the name of the main male character. It is interesting that the development of the main female character, named San-mei (meaning the third sister), is greater than that of the male role in the story. Due to the book title placing a focus on the honest man Li Tianluo, it leads readers to perceive the story from a male perspective, which is to emphasize the idea that marrying a good wife can bring a good life. Although San-mei is one of the major characters in this story, she is excluded from the book title, which implies her passive role in the story.

2. stereotypes of adult male roles in folktales are reinforced by the visuals.

Characters tend to be portrayed based on traditional stereotypes when the story setting is in folktales. Four different stereotypes of male characters in folktales are identified, including greedy and arrogant, honest and kindhearted, witty, and authoritative (see Table 4.3). In addition, the illustration reinforces the stereotypes of the characters. The appearances of these different characters shown in the picturebooks can be divided into three types: comical or funny looking, solemn looking, and good-looking. 


\begin{tabular}{|c|c|l|}
\hline Category & \multicolumn{1}{|c|}{ Character } & \multicolumn{1}{|c|}{ Picturebook } \\
\hline \multirow{4}{*}{$\begin{array}{c}\text { Adult Males } \\
\text { in Folktales }\end{array}$} & $\begin{array}{c}\text { Greedy and } \\
\text { arrogant }\end{array}$ & $\begin{array}{l}\text { G1-02 rich man (ruthless) } \\
\text { G1-03 rich men } \\
\text { G1-05 elder brother (lazy, bad temper) }\end{array}$ \\
\cline { 2 - 3 } & $\begin{array}{l}\text { Honest and } \\
\text { kindhearted }\end{array}$ & $\begin{array}{l}\text { G1-03 honest man (hard working) } \\
\text { G1-05 young brother (kindhearted, hard working) } \\
\text { G1-06 fishing man (filial obedience, kindhearted) }\end{array}$ \\
\cline { 2 - 3 } & - Witty & G1-02 liar (lazy) \\
& G1-04 liar (having a dominating wife) \\
\cline { 2 - 3 } & e Authoritativ & G1-01 police officer \\
& G1-04 court officer \\
& G1-05 police officer, emperor \\
\hline
\end{tabular}

\begin{tabular}{|c|c|l|}
\hline $\begin{array}{c}\text { Adult Males in } \\
\text { Aboriginal } \\
\text { Stories }\end{array}$ & $\begin{array}{c}\text { - Bearing a } \\
\text { responsibility } \\
\text { for people }\end{array}$ & $\begin{array}{l}\text { G2-02 hunters } \\
\text { G3-04 granduncle (good hunter, leader) }\end{array}$ \\
\hline $\begin{array}{c}\text { Adult Males in } \\
\text { the Stories based } \\
\text { on Realistic Life } \\
\text { Experience }\end{array}$ & $\begin{array}{c}\text { Being firm } \\
\text { in one's } \\
\text { belief or } \\
\text { decision }\end{array}$ & $\begin{array}{l}\text { G2-01 grandfather (artist's idea of art) } \\
\text { G2-06 father (participating in a ritual competition) } \\
\text { G3-02 father (giving a challenging task to his son) } \\
\text { G3-06 father (educating children) }\end{array}$ \\
\hline
\end{tabular}

\begin{tabular}{|c|c|c|c|c|c|c|}
\hline $\begin{array}{c}\text { Adult Male } \\
\text { Character }\end{array}$ & $\begin{array}{c}\text { Greedy } \\
\text { and } \\
\text { arrogant }\end{array}$ & Honest & Witty & Authoritative & $\begin{array}{c}\text { Bearing a } \\
\text { responsibility } \\
\text { for people }\end{array}$ & $\begin{array}{c}\text { Being firm in } \\
\text { one's } \\
\text { belief/decision }\end{array}$ \\
\hline $\begin{array}{c}\text { Taiwanese } \\
\text { Folktales }\end{array}$ & 4 & 3 & 2 & 3 & 0 & 0 \\
\hline $\begin{array}{c}\text { Taiwanese } \\
\text { Children's } \\
\text { Picturebook } \\
\text { Selection }\end{array}$ & 0 & 0 & 0 & 0 & 1 & 2 \\
\hline $\begin{array}{c}\text { Taiwanese } \\
\text { Teenagers }\end{array}$ & 0 & 0 & 0 & 0 & 1 & 2 \\
\hline
\end{tabular}

Table 4.3: A distribution of adult male characterizations presented in the three sets of picturebooks

Characters that are greedy and arrogant in the stories usually are rich men or one who wants to reap without sowing, while honest men in the stories tend to fulfill their obligation. It is obvious that these two different types of characters are opposite and they 
provide a contrast. In terms of appearance, characters who are greedy and arrogant are portrayed as comical looking (see Illustration 11), while the honest men are good-looking (see Illustration 12). Particularly, in the picturebook Mai Hsiang-pi (Fragment for Sale), a Taiwanese tale of two brothers, the main characters illustrate this contrast. The younger brother was honest and kindhearted, which caused him to have good fortune. However, the elder brother was lazy and jealous about his brother's fortune. These two characters indicate that honest is good and greedy is bad, which illustrates a dualistic concept. And, the images of the two brothers also reinforce this contrast (see Illustration 13).
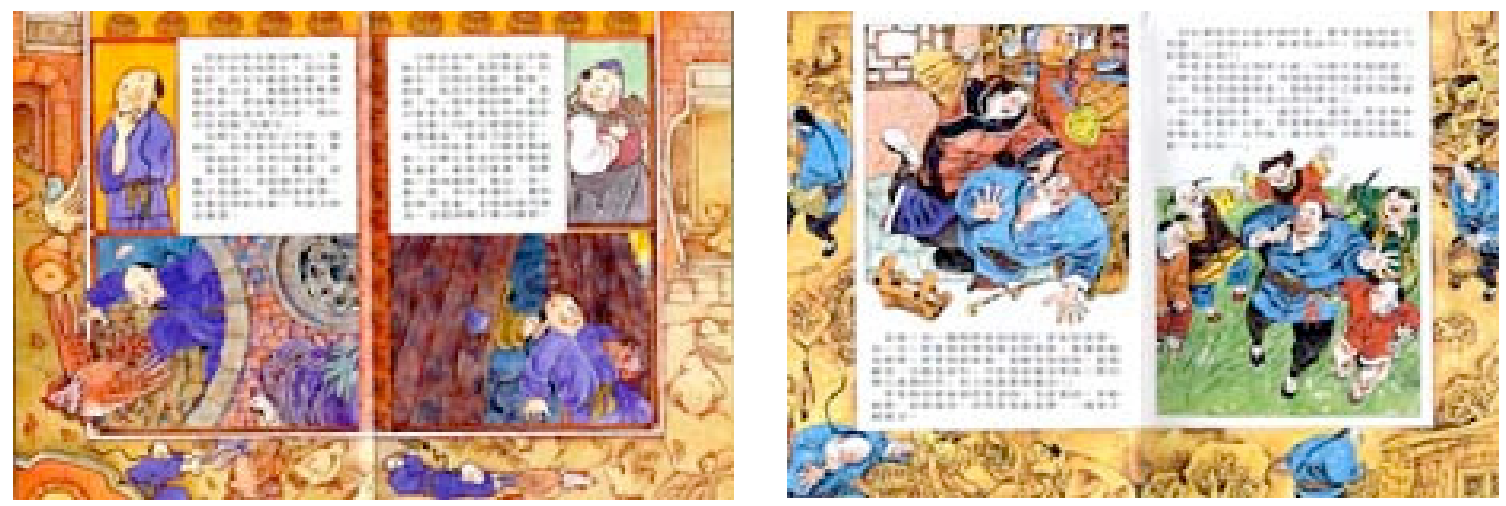

Illustration 4.11: The images of comical looking 

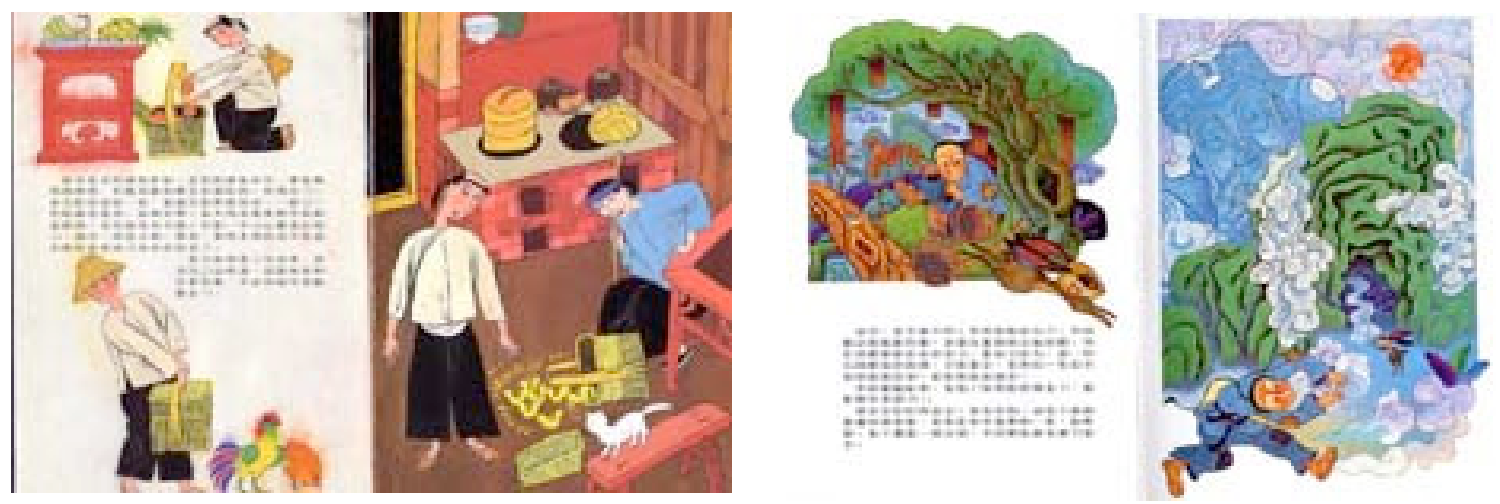

Illustration 4.12: The images of good-looking

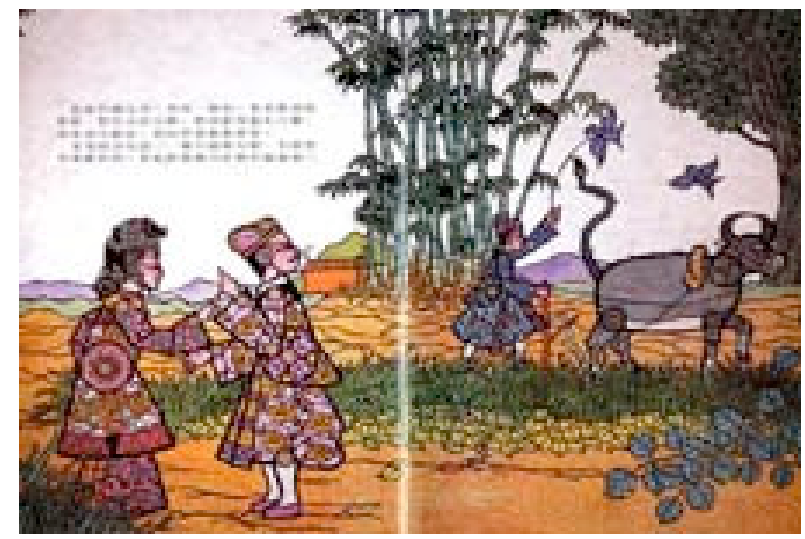

Illustration 4.13: The image of the two brothers in the Fragment for Sale

Two of the Taiwanese folktales are about two witty men and they are funny looking in the pictures. They include Bo-zei Chi and Hao-bi-shi. The former was good at deceiving people and cheated a greedy rich man out of his money by his tricks. In contrast, the latter lied about having a magic nose in order to hide the fact that his nose was bitten by his wife. Due to the humor of these two stories, their facial expressions and 
body language are more dramatic and exaggerated than that of the good-looking characters in other stories (see Illustration 14).

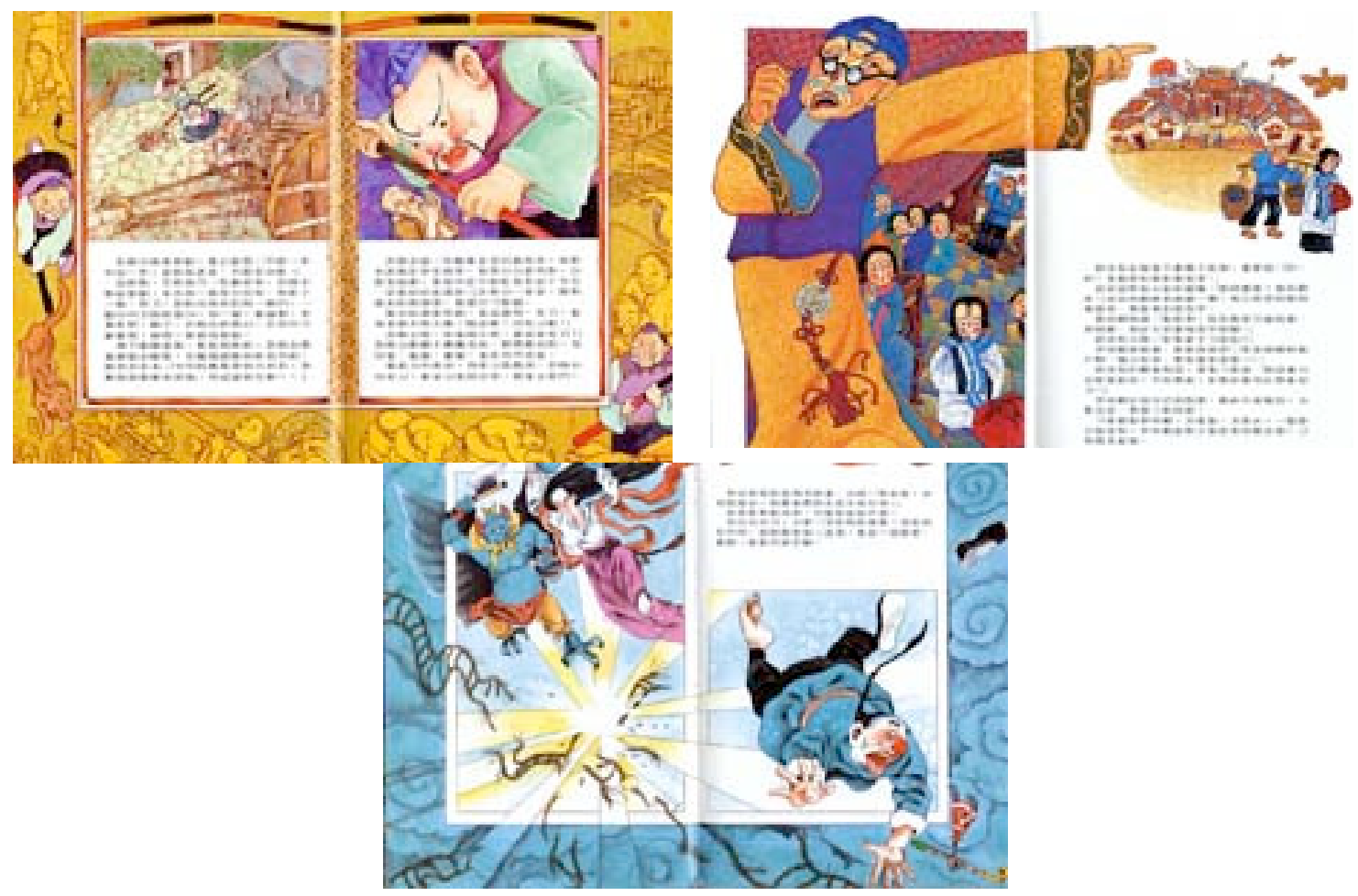

Illustration 4.14: The images of the dramatic and exaggerated expression

The image of officers portrayed in the folktales contains a stereotype. They are authoritative and ruthless and the illustrations also show that they are solemn looking (see Illustration 15). Their judgment shown in the stories only consists of two sides: either right or wrong. And, the result of it is to either give a reward or punishment. This shows that the folktales tend to give moral lessons that tell folks about what is right and what is wrong, and the consequences of doing right or wrong as well. 


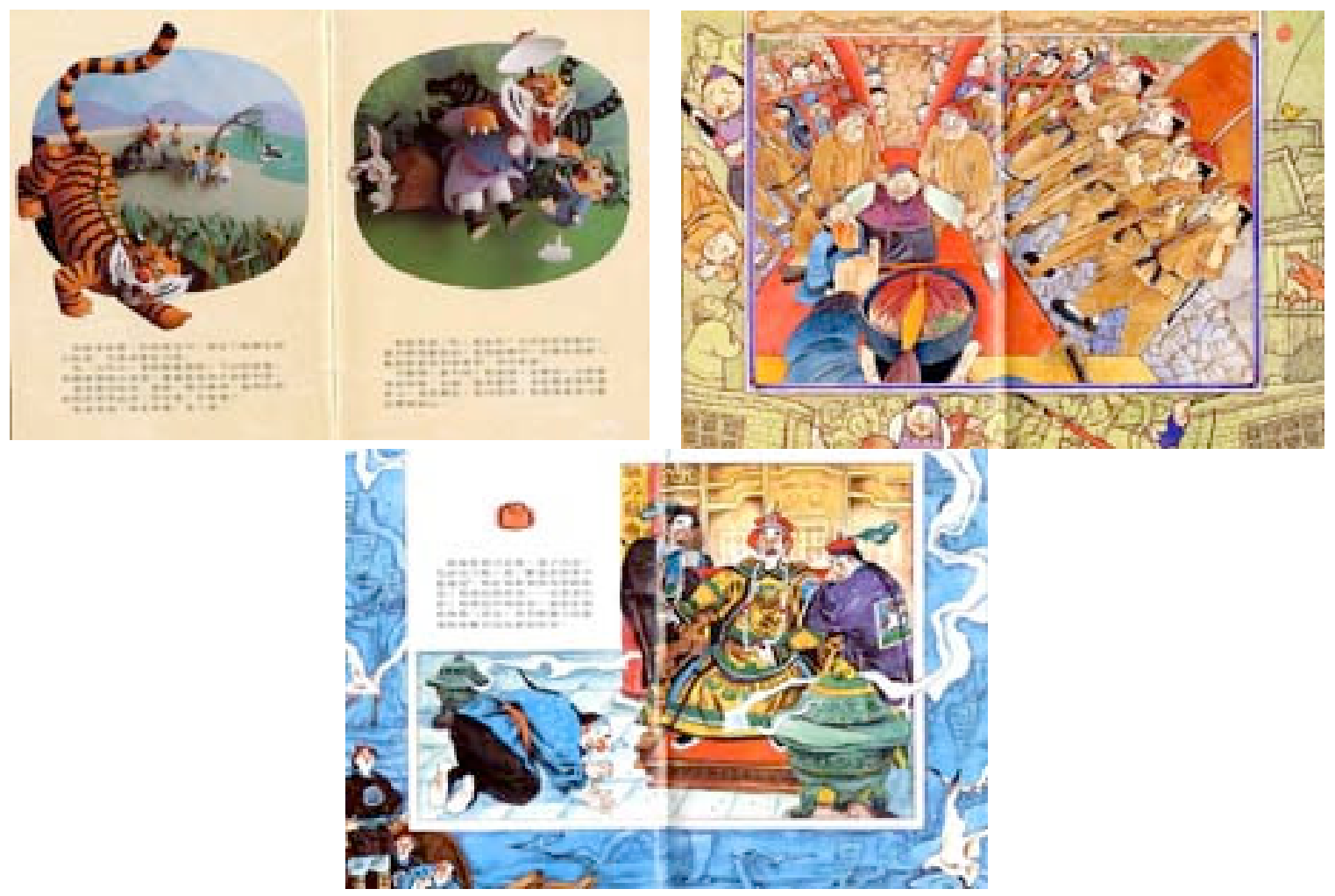

Illustration 4.15: The images of solemn looking

In sum, the illustrations of these folktales tend to use a simplied representational art style and some of the stories contain a sense of humor. Therefore, the overall expression of these picturebooks is dramatic rather than realistic.

3. adult males play a responsible and strict role in the stories.

Adult males usually play the role of taking action to make changes or insisting on their beliefs (see Table 4.3). For example, the role of hunters shown in two aboriginal stories is to be wise and bear social responsibility to maintain the well being of their tribes. In the picturebook Shooting Suns, the greatest hunter took his son and grandson on a journey to shoot down a sun. The role of granduncle in the picturebook Yi Gong-gong 
(meaning granduncle) shows his leadership in taking care of the reconstruction of his tribe after a fire disaster and negotiating relationships with other tribes.

Besides the aboriginal stories, males actively participate in public activities as also shown in Han stories. For example, the role of the father in the picturebook $M y$ Father is Going to a Festival Competition is portrayed as a man with no fear. $\mathrm{He}$ participated in an annual ritual for worshiping the dead. This honored the immigrants from China who unfortunately passed away on the way to Taiwan or died due to accidents in the process of developing uncultivated land during the Qing dynasty. The ritual involved competing with others by climbing a 12 foot high large pole, covered with sticky butter, in order to be the first to seize special offerings and a flag on a stage at the top. The meaning of this ritual was to experience the difficulty that the early immigrants experienced as they made their way to Taiwan and settled down here. It was also to share the offerings with the dead on their last day before going back to hell on July $29^{\text {th }}$, based on the lunar calendar. ${ }^{61}$ In the story, the father explained the meaning of the ritual to his family and was proud of his participation in this competition.

Adult males in the picturebooks also are firm in their own beliefs. For example, the artist Li Mei-shu, in the picturebook Mei-shu A-gong (Grandfather Mei-shu), insisted on painting the beauty of his hometown and ignored the criticism about his artwork from young artists. A father, in the picturebook When I was Eight, I Went on a Journey, assigned a special task to his son in order to make him a man despite others'

\footnotetext{
${ }^{61}$ According to traditional Taiwanese customs, the spirits of the dead annually come back to the human world during July based on the lunar calendar (July $1^{\text {st }}$ through $29^{\text {th }}$ ). During this period, Taiwanese folks need to be careful of their safety. In order to avoid bad luck, most Han Taiwanese prepare offerings for the spirits on the $15^{\text {th }}$ and the last day of July. By doing this, they also show their respect and sympathy for the dead.
} 
disagreement and advice. His son was expected to take a train alone for hours and get an umbrella from a distant relative's home. Another father, in the picturebook A River Resembling a Mother, was firm in teaching his son about mathematics and language pronunciation by himself because he could not afford to send his son to school. And, he forced his son to concentrate on studying. These male roles together demonstrate their own expectations and a rigid attitude.

\section{4. female roles emphasize human relationships.}

In contrast, adult females oftentimes play the role associated with human relationships. For example, adult females playing main characters in the five out of twenty-two picturebooks show their roles as a wife or grandmother. As a wife, such as the characters in the picturebook Li Tain-luo and My Father is Going to a Festival Competition, they are portrayed as their husbands' supporters. The wife of the former appreciated her husband's industriousness and hard work, while the wife of the latter supported her husband's plan to participating in a competition, although she first disagreed with his idea. The implicit meaning of their support for their husbands indicates a strengthening of the marriage bond.

In terms of the role of grandmother, such as the characters in the picturebook Selling Brooms with My Grandmother, Story Map, and When I was Eight, I Went on a Journey, they are caring and kind. For example, a grandmother, in the Selling Brooms with My Grandmother, made and sold her hand-made brooms and after she earned some money from it, she would buy some snack to reward her grandchildren for helping her make the brooms. Another grandmother, in the Story Map, was a good storyteller and she usually told her granddaughter the history and stories about their tribe. A grandmother 
figure, represented as an old lady, ${ }^{62}$ in the When I was Eight, I When on a Journey, showed her kindness to a little boy on a train by giving him fruit when he got on and he accepted it. Moreover, when she put several coins in his hands before he got off the train, the little boy refused to accept the coins by saying:

I don't want them. My ma told me, "Don't take money from strangers." However, the old lady said, "Don't be silly. When your ma asks you about the money, you say, 'the money was given by a grandma.' A grandma is not a stranger." (G3-02)

Their actions in the stories illustrate their concern for young children, and these interactions build closed relationships between grandmothers and grandchildren.

5. the stereotypes of some female roles in the picturebooks have changed, but some are remained the same.

In the Taiwanese Folktales, female adult roles are portrayed as either a positive role following social norms or a negative role with dominating behaviors. For example, in the picturebook Li Tain-luo, San-mei, the wife, is described as a plain and kindhearted person. She took care of her ill mother without any complaint until her mother died. Sanmei married the husband chosen by her father and then she did her obligations for her husband, including working hard to help family economics and having a boy baby. Her character represents a typical traditional ideal wife in the Chinese family in an agricultural society. This social norm is that a woman should devote her life to her family and show her obedience to her parents and husband.

In contrast, two wives in the Taiwanese Folktales are portrayed as dominating although they play an active role in the story. The elder brother's wife in the Mai Hsiang-

\footnotetext{
${ }^{62}$ According to Taiwanese customs, the terms "A-ma" (meaning grandmother in Min-na Hua) can be used to call someone who is similar to the age of one's grandmother although they are not relatives. The terms
} 
pi (Fragrance for Sale) was greedy and tricky. She had conversations with her husband in two plots of the story. First, she suggested that her husband acquire the ownership of the cow they shared with his younger brother by using a trick. Second, she urged her husband to find the reason why his young brother became wealthy. The liar's wife, shown in one plot of the story Hao-bi-shi, is a flat but active character. That is, she ordered her husband to buy food, but he lost his money on gambling and made a lie that someone stole his money so he bought nothing. However, she grasped a broom and beat her husband for lying. These two wives demonstrate a dominating aspect of women in marriage, which differs from the ideal type of good wife.

When comparing the three folktales mentioned above, they indicate that an honest and industrious man deserves a good wife, while a greedy or lazy man has a dominating wife in return. By the same token, from the female perspective, a kindhearted and dutiful woman marries a good man, whereas a woman with bad temper or deceitfulness takes over her husband. Moreover, like male characters in folktales, visual representations of these female characters also strengthen their characteristics. A good wife tends to have a good looking and proper behavior shown in the pictures, while a dominating wife is a comical figure and behaves dramatically (see Illustration 16).

"A-gong" (meaning grandfather in Min-na Hua) functions the same. By doing this, respect is paid to the elder. 

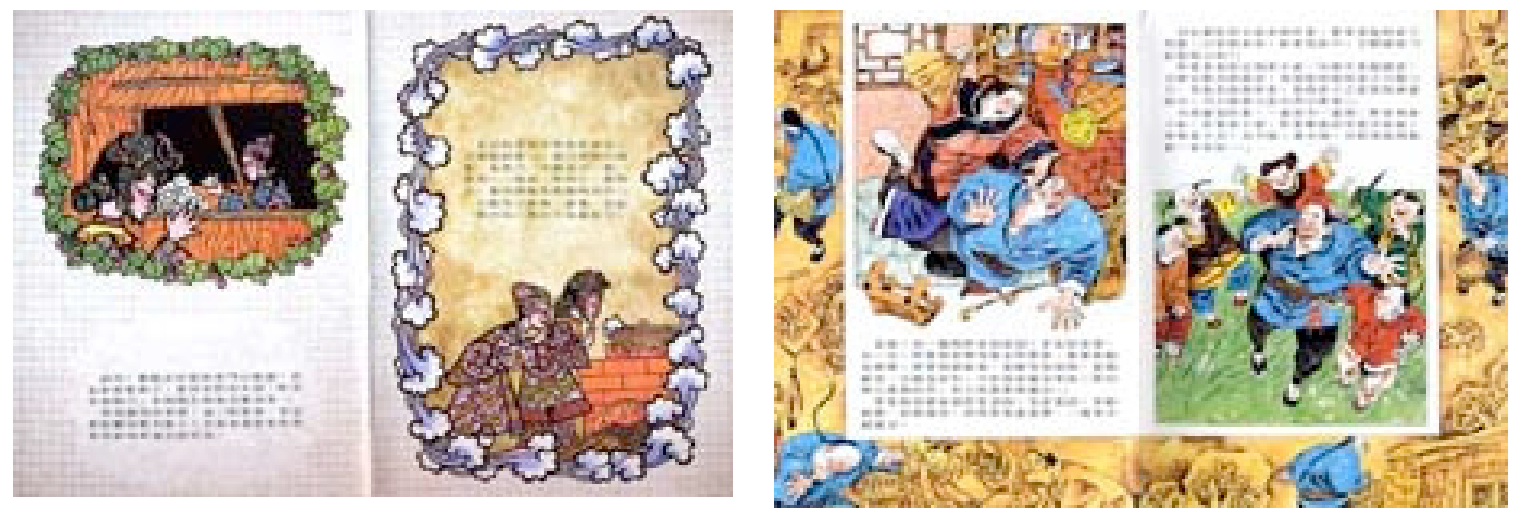

Illustration 4.16: The images of the dominating wives shown in the picturebooks

In addition, three other female characters are portrayed as helpless when they relate to three major characters in the stories. For example, a mother in the picturebook Hu Gu-po (Grandaunt Tiger - a tale of the Little Red Hook) found the fact that her son was eaten by a tiger while she was not home. The picture shows her holding her daughter and they are crying together. A mother, in the Li Tain-luo, had a good temper but was ill and her third daughter, San-mei the ideal good wife mentioned above, took care of her. An old mother, in the Shui-gui Cheng-huang (a tale of a water spirit becoming a city ruling deity), relied on her son and he showed filial obedience to her. The first story shows that the mother was not able to protect her son, while the other two stories indicate the dependence of women on their children for help when they become ill or old. These characters are flat but important for informing readers about the other major characters and plots in the stories.

However, why women play these helpless roles in folktales rather than men is to suggest the social status of these female roles. That is, the second story indicates that the mother had a rich husband. After she passed away, her husband remarried a new wife. In 
contrast, both the first and third story imply that these two mothers were single without support from their husbands. Their family economics were insufficient. The former was a young mother who needed to leave for work over night, so it was the time the magic tiger came into her house and ate up her son. The latter was an old mother who had to depend on her son.

The female characters portrayed as helpless or dominating in the folktales are not present in the picturebooks based on realistic experience. However, the concept of the ideal good wife can be found in some other picturebooks telling realistic experiences during the Taiwan agricultural era. Being a husband's helper, being caring, and being industrious are the major characteristics of adult female roles shown in the picturebooks other than the Taiwanese Folktales (see Table 4.4). For example a wife in the Da-tou Has a Son, is supportive of her husband even though he oftentimes changed his small businesses. A mother and grandmother, in the Selling Brooms with My Grandmother, made brooms by hand and sold them in nearby villages. Their work demonstrates not only making additional family incomes by using natural resources, but also the value of industriousness they held true. The visual representation of these characteristics shows an aspect of the physical labor in which they are involved (see Illustration 17). 


\begin{tabular}{|c|c|c|}
\hline Category & Character & Picturebook \\
\hline \multirow{5}{*}{$\begin{array}{c}\text { Adult } \\
\text { Females }\end{array}$} & - Helpless & $\begin{array}{l}\text { G1-01 single mother (her role was not well } \\
\text { developed in the story. Her son was eaten by a } \\
\text { tiger when she was not home) - her husband is not } \\
\text { mentioned in the story. } \\
\text { G1-03 mother (having a good temper, illness) } \\
\text { G1-06 old mother (dependent on her son) }\end{array}$ \\
\hline & $\begin{array}{l}\text { - Playing an } \\
\text { active role }\end{array}$ & $\begin{array}{l}\text { G1-04 the elder brother's wife (deceitful, } \\
\text { dominating) } \\
\text { G1-05 the liar's wife (dominating) } \\
\text { G2-06 the wife (proposing a disagreement with her } \\
\text { husband, but finally agreeing with him) }\end{array}$ \\
\hline & - Being Helper & $\begin{array}{l}\text { G1-02 the liar's wife (helping her husband cheat on } \\
\text { others) } \\
\text { G1-03 the third daughter (a nice wife, hard working) } \\
\text { G2-04 the wife (helping her husband's business) } \\
\text { G3-01 mother and grandmother (making and selling } \\
\text { brooms for helping family economics) }\end{array}$ \\
\hline & - Caring & $\begin{array}{l}\text { G1-03 the third daughter (taking care of her ill mother) } \\
\text { G2-01 grandmother (serving fruit to her husband and } \\
\text { grandson) } \\
\text { G2-07 mother (taking her daughter to visit a museum) } \\
\text { G2-09 mother (taking her daughter to participating in } \\
\text { dancing lessons) } \\
\text { G3-01 grandmother (buying food for her grandchildren } \\
\text { after selling brooms) } \\
\text { G3-02 grandmother (waiting for her grandson's safe } \\
\text { turn home after finishing a task), } \\
\text { an old lady (being nice to a young boy, acting like } \\
\text { a grandmother) } \\
\text { G3-03 grandmother (good storyteller who remembers } \\
\text { history and tales about her tribe) } \\
\text { G3-06 the dead mother (her spirit looking over her son) }\end{array}$ \\
\hline & - Industrious & $\begin{array}{l}\text { G1-03 the third daughter (hard worker) } \\
\text { G3-01 grandmother (hard worker) }\end{array}$ \\
\hline
\end{tabular}

Table 4.4: A distribution of adult female characterizations presented in the three sets of picturebooks (continued) 
Table 4.4 (continued)

\begin{tabular}{|c|c|c|c|c|c|}
\hline $\begin{array}{c}\text { Adult Female } \\
\text { Character }\end{array}$ & Helpless & $\begin{array}{c}\text { Playing an } \\
\text { active role }\end{array}$ & $\begin{array}{c}\text { Being } \\
\text { Helper }\end{array}$ & Caring & Industrious \\
\hline $\begin{array}{c}\text { Taiwanese } \\
\text { Folktales }\end{array}$ & 3 & 2 & 2 & 1 & 1 \\
\hline $\begin{array}{c}\text { Taiwanese } \\
\text { Children's } \\
\text { Picturebook } \\
\text { Selection }\end{array}$ & 0 & 1 & 2 & 2 & 0 \\
\hline $\begin{array}{c}\text { Taiwanese } \\
\text { Teenagers }\end{array}$ & 0 & 0 & 1 & 4 & 1 \\
\hline
\end{tabular}
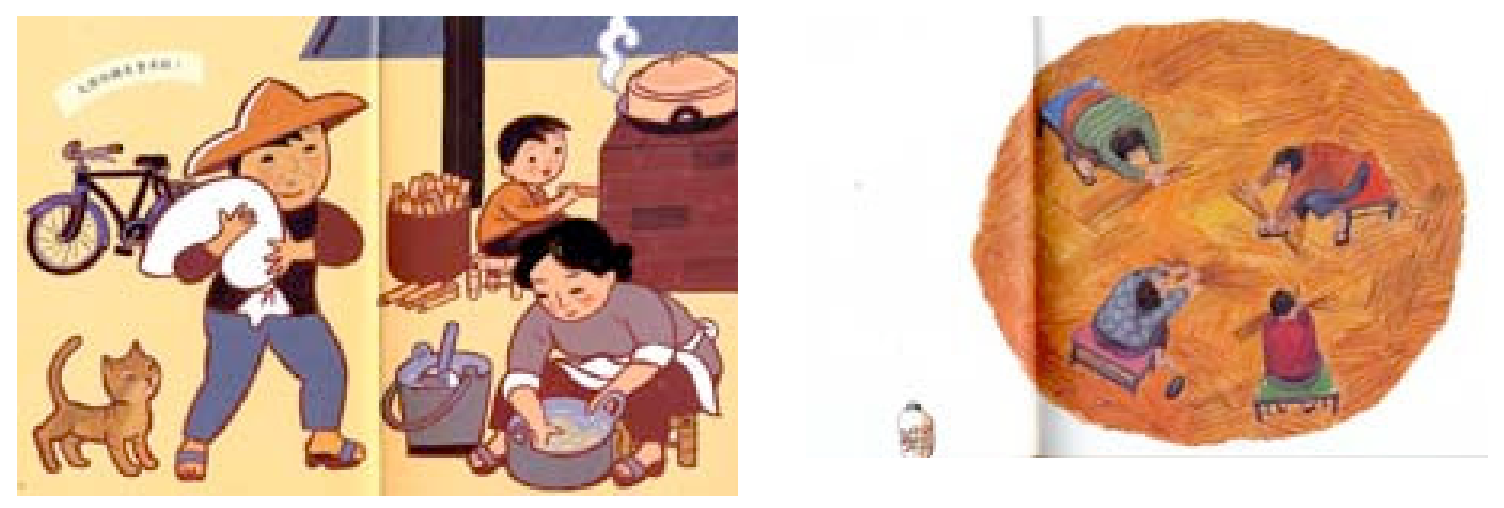

Illustration 4.17: The images of the physical labor shown in the picturebooks

A grandmother, in the Mei-shu A-gong (Grandfather Mei-shu), served fruit to her husband and grandson while they were talking about her husband's paintings. Another grandmother, in the When I was Eight, I Went on a Journey, expressed her caring by waiting for her grandson to safely return home after finishing a task assigned by his father. A mother, in the A Sparrow in the Museum, took her daughter, Hsiao-tong, to visit a museum. When Hsiao-tong was disappointed with losing a clue for finding a sparrow in 
a painting, her mother comforted her and drew her attention to look at other figure paintings. Another mother, Yue-yue's Dancing Lessons, is also patient with her daughter when she was afraid of participating in a new class within a new environment. All these examples demonstrate the female role associated with caring no matter whether they are the grandmother's or the mother's generation.

In sum, the female role has usually been portrayed as passive, dependent, and devoted to family in the folktales. When strong female characters are shown in the folktales, they oftentimes are depicted negatively rather than positively. Although these traditional female stereotypes may not match the current situation in society, some particular stereotypes of traditional female roles are still shown in the stories, such as being a helper for the family and caring for children.

6. diverse child characters are shown in both gender roles.

The presentation of the child characters in the picturebooks is diverse (see Table 4.5). Male children are portrayed in nine out of twenty-two picturebooks, while female children are shown in five of them. Both genders share some characteristics, which include enjoying the arts, being a helper, and learning from the elders. Braveness, enjoying the outdoors, and studying hard are also included in male children's characteristics. The additional characteristics for female children consist of cleverness and capricious. 


\begin{tabular}{|c|c|c|}
\hline Category & Character & Picturebook \\
\hline \multirow{8}{*}{ Child } & - Brave & G3-02 son \\
\hline & - Clever & G1-01 daughter \\
\hline & - Capricious & G3-03 granddaughter \\
\hline & - Enjoy arts & G2-01 grandson, G2-07 daughter, G2-09 daughter \\
\hline & - Enjoy outdoors & G3-05 son, G3-06 son \\
\hline & - Study hard & G2-04 son \\
\hline & - Being helper & G2-04 son, G3-01 granddaughter \\
\hline & $\begin{array}{l}\text { - Learning from } \\
\text { the elder }\end{array}$ & $\begin{array}{l}\text { G2-01, G2-02, G2-08 grandson, G2-06 son, } \\
\text { G2-09 daughter, G3-04 grandnephew }\end{array}$ \\
\hline
\end{tabular}

\begin{tabular}{|c|c|c|c|c|c|c|c|c|}
\hline $\begin{array}{c}\text { Child } \\
\text { Character }\end{array}$ & Brave & Clever & $\begin{array}{c}\text { Capric- } \\
\text { ious }\end{array}$ & $\begin{array}{c}\text { Enjoy } \\
\text { arts }\end{array}$ & $\begin{array}{c}\text { Enjoy } \\
\text { outdoors }\end{array}$ & $\begin{array}{c}\text { Study } \\
\text { hard }\end{array}$ & $\begin{array}{c}\text { Being } \\
\text { helper }\end{array}$ & $\begin{array}{c}\text { Learning } \\
\text { from the } \\
\text { elder }\end{array}$ \\
\hline $\begin{array}{c}\text { Taiwanese } \\
\text { Folktales }\end{array}$ & 0 & 1 girl & 0 & 0 & 0 & 0 & 0 & 0 \\
\hline $\begin{array}{c}\text { Taiwanese } \\
\text { Children's } \\
\text { Picturebook } \\
\text { Selection }\end{array}$ & 0 & 0 & 0 & $\begin{array}{c}3 \\
2 \text { girls } \\
1 \text { boy }\end{array}$ & 0 & 1 boy & 1 boy & $\begin{array}{c}5 \\
4 \text { boys } \\
1 \text { girl }\end{array}$ \\
\hline $\begin{array}{c}\text { Taiwanese } \\
\text { Teenagers }\end{array}$ & 1 boy & 0 & 1 girl & 0 & 2 boys & 0 & 1 girl & 1 boy \\
\hline
\end{tabular}

Table 4.5: A distribution of child characterizations presented in the three sets of picturebooks

Children enjoying the arts is presented in different ways. They may naturally enjoy art activities; for example, the boy liked drawing in the Mei-shu A-gong and the girl had a good experience in an art museum in the $A$ Sparrow in the Museum. They may need to take time to explore an art form in a new environment. For example, a girl was sent to a dancing class and learned about body movement in the Yue-yue's Dancing Lessons. The common characteristic shared among these characters is imagination. Imagination helps them to engage in art activities and express themselves or interact with artwork in a museum. 
Industriousness and thoughtfulness are emphasized in the story when the child characters are portrayed as helpers. Because adults were busy with making a living, the boy in the Da-tou Has a Son and the girl in the Selling Brooms with My Grandmother, are shown as helping with part of the work that the adult where engaged in. The pictures show that both children were willing to help and seemed to enjoy the helping process as represented by their smiling faces shown in the pictures (see Illustration 18).
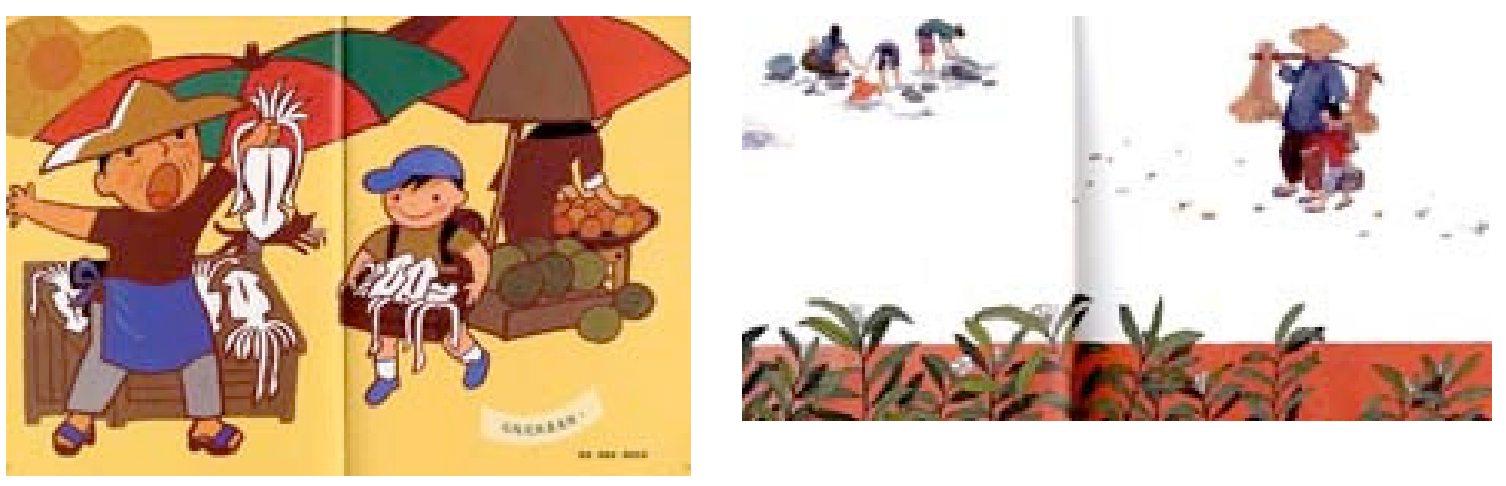

Illustration 4.18: The images of the children helping the family

In the picturebook When I was Eight, I Went on a Journey, the little boy completed a task to prove his bravery. Two boys in the two picturebooks, A Memory of Tea Plantation and A River Resembling a Mother, were enjoying the outdoors as shown by their personal accounts about activities, such as swimming in a river, capturing frogs, stealing yams, and the like. In the picturebook Da-tou Has a Son, the son is portrayed as a good student who studies hard while helping his father, according to the images. The first three boys reflect a typical male image associated with adventure, while the last boy demonstrates a good boy image, which fulfills parents' expectations. 
Although the major characters of the Taiwanese Folktales are dominated by adult males, one exception to this category is the picturebook Hu Gu-po (Grandaunt Tiger), a Taiwanese tale of the Little Red Hook. A little girl and a magic tiger are the main characters. The little girl is portrayed as fearful and helpless, while the magic tiger can transform into a human form and is fond of eating children. Although this tiger pretended to be a grandaunt, the little girl realized its trick and relied on her cleverness to save her life. Compared with the other picturebooks, this survival story is unusual because the little girl independently defeated the tiger, representing an adult role.

Another picturebook also shows an independent female child figure. It involves a capricious girl in the Story Map, who planned to run away from home because she had a fight with her mother and wanted to prove her independence by acting like a big girl. However, her plan failed because she spent time on recalling the stories told by her grandmother on the way toward her adventure and by doing this, it delayed her plan. Eventually, she decided to return home. Her character is developed based on her active behavior, which also provides an atypical female child role.

To sum up, the child characters in the picturebooks are portrayed more diversely than adult characters. Part of the reason is that the stories are based on current life experience rather than folk tales. Life styles have changed and the expectations concerning children are more dynamic in contemporary society.

\section{7. the role of the child is to receive teaching from the elder.}

The picturebooks were created for children. It is obvious that the purposes of these picturebooks are not only for entertainment, but also for education and cultural transmission. Taking a child's position to learn about something from an adult is a 
common way of telling stories. Accordingly, young readers should be of a similar age to the child characters in the story so that they can easily identify with the character. Six picturebooks indicate this usage and they can be divided into two groups based on whether the child plays an active or passive role.

First, the child character takes an active role in the learning process which means they ask questions and engage in conversations with the elders. Two picturebooks show this pattern, consisting of: (1) the artist's grandson asked the artist questions about his paintings and he recalled his memories of how he became an artist in the Mei-shu Agong; and (2) the son wondered why his father wanted to participate in a dangerous competition and his father explained the meaning of this traditional ritual in the $M y$ Father is Going to a Festival Competition. Curiosity is the common characteristic shared in these two child characters and it makes them active learners.

Second, the child character is a passive receiver, which means they unexpectedly learn from their elders. However, the children do show their interests in learning from them. Four picturebooks illustrate this idea, including: (1) Going Shopping on Dihua Street for Chinese New Year, where the grandfather told his grandson about the history of a street while they were shopping on the street; (2) Shooting Suns, where the grandfather passed on knowledge of hunting, oral history, and customs to his grandson on the way to look for suns; (3) Yi Gong-gong, where the granduncle gave a lesson to his grandnephew about the meaning of studying in school before his first school day; and (4) Yue-yue's Dancing Lessons, where the teacher taught the little girl named Yue-yue how to engage in different body movement activities. 
It is significant to see that the role of grandfather and granduncle tends to emphasize passing down their knowledge or beliefs to the younger generation within an informal learning environment. In these stories, the notion of learning is to transmit knowledge from the elder to the younger. Therefore, the information regarding the knowledge is the main focus in the story and the development of the child character is secondary. In contrast, the picturebook Yue-yue's Dancing Lessons demonstrates a different learning environment in a classroom setting. And, the learning is based on a child-centered concept, which means that child development is taken into consideration while teachers plan curriculum. Thus, the role of teacher is presented as a learning mediator and the learning process shows the growth of the little girl. To do this, the story itself places an emphasis on the child character rather than the knowledge itself.

8. supernatural beings in Han stories show gods' judgment on human.

Four characteristics of supernatural beings shown in the picturebooks are identified. They include: evaluating human's merits and demerits; behaving like human beings; providing blessing; and acting as a bridge between god and humans (see Table 4.6). The first two are associated with Han stories, while the last two are related to aboriginal beliefs. 


\begin{tabular}{|c|l|l|}
\hline Category & \multicolumn{1}{|c|}{ Character } & \multicolumn{1}{c|}{ Picturebook } \\
\hline \multirow{4}{*}{$\begin{array}{c}\text { Supernatural } \\
\text { Beings }\end{array}$} & $\begin{array}{l}\text { Evaluating human's } \\
\text { merits and demerits }\end{array}$ & $\begin{array}{l}\text { G1-03 old beggar } \\
\text { G1-05 heaven god } \\
\text { G2-03 village deity, heaven god }\end{array}$ \\
\cline { 2 - 3 } & $\begin{array}{l}\text { Behaving like human } \\
\text { beings }\end{array}$ & $\begin{array}{l}\text { G1-06 good spirit } \\
\text { G2-06 spirits who died during the } \\
\text { immigrant's trip to Taiwan }\end{array}$ \\
\cline { 2 - 3 } & \begin{tabular}{c} 
Blessings \\
\cline { 2 - 3 }
\end{tabular} & $\begin{array}{l}\text { G2-02 spiritual bird is a messenger of god } \\
\text { G3-03, G3-04 forefathers' spirit }\end{array}$ \\
\cline { 2 - 3 } & $\begin{array}{l}\text { Being a bridge between } \\
\text { gods and humans }\end{array}$ & G2-02 wizard \\
\hline
\end{tabular}

\begin{tabular}{|c|c|c|c|c|}
\hline Character & $\begin{array}{c}\text { Evaluating one's } \\
\text { merits \& demerits }\end{array}$ & $\begin{array}{c}\text { Behaving like } \\
\text { human beings }\end{array}$ & Blessings & $\begin{array}{c}\text { Being a bridge between } \\
\text { gods \& humans }\end{array}$ \\
\hline $\begin{array}{c}\text { Taiwanese } \\
\text { Folktales }\end{array}$ & 2 & 1 & 0 & 0 \\
\hline $\begin{array}{c}\text { Taiwanese } \\
\text { Children's }\end{array}$ & 1 & 1 & 1 & 1 \\
$\begin{array}{c}\text { Picturebook } \\
\text { Selection }\end{array}$ & & 0 & 2 & 0 \\
\hline $\begin{array}{c}\text { Taiwanese } \\
\text { Teenagers }\end{array}$ & 0 & & & \\
\hline
\end{tabular}

Table 4.6: A distribution of supernational beings characterization presented in the three sets of picturebooks

In terms of supernatural beings in Han folktales, gods tend to give one a reward or punishment based on one's merits and demerits. Moreover, the visual representation of gods is different according to their ranks and the occasions on which they appear. In the picturebook Hao-bi-shi, the heaven god in his court shown in the picture is portrayed as a Chinese emperor, wearing a traditional Han emperor costume (see Illustration 19). His character is more authoritative and ruthless. 


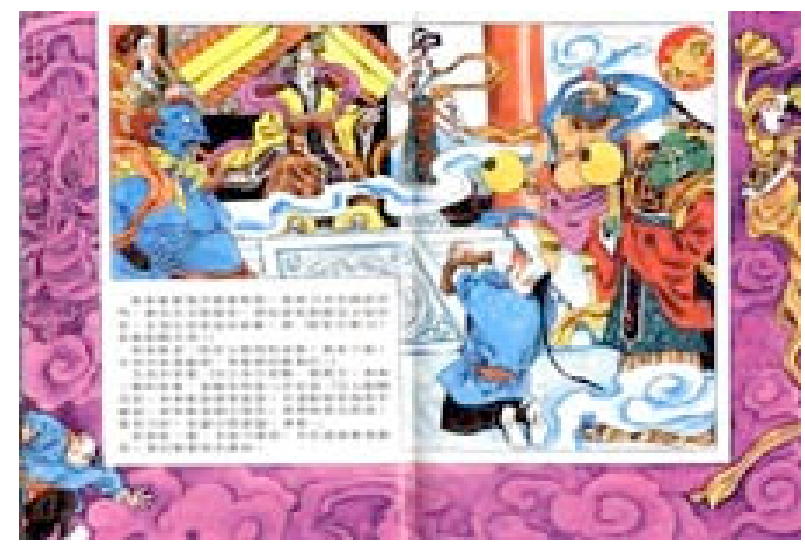

Illustration 4.19: The image of the heaven god portrayed as a Chinese emperor

However, supernatural beings, such as a village deity, can change their identity in order to investigate folks in the human world. For example, in the folktale Li Tain-luo, a supernatural being pretending to be an old beggar received genuine help from San-mei (the good wife) and transformed her from being plain looking into a beauty. In contrast, San-mei's elder sisters with bad tempers were mean to the old beggar, and then they were transformed from beauty to ugliness. In the picturebook, the old beggar wears a long beard and long eyebrows and has an ever-merciful and benignant look, which symbolizes his kindness and identity of being a supernatural being (see Illustration 20). Although the images of gods in Han culture may differ, the way they judge folks' behaviors remains the same. 

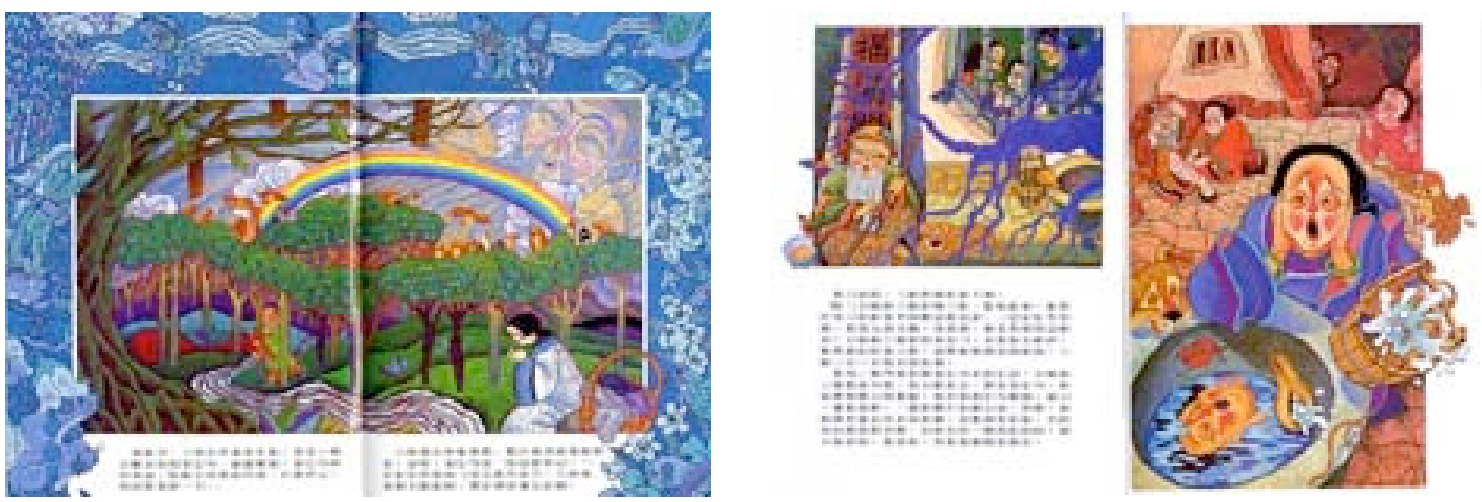

Illustration 4.20: The images of a supernatural being pretending to be an old beggar

9. spirits of the dead who died accidental deaths behave like human.

The spirits of the dead who died accidental deaths may not necessarily be considered as evil spirits (see Table 4.6). According to Taiwanese customs, they are called "Hao Hsiong-di"(meaning good brothers). In the picturebooks, they are portrayed as common people who died unexpectedly. For example, in the Shui-gui Cheng-huang (a tale of a water spirit becoming a city ruling deity), a rich man was murdered by two laborers due to his wealth. He was a nice water spirit (because his body fell into water), and became a good friend with a poor young fishing man. He helped the man catch more fish in order to make additional money for taking care of the man's mother. Visually, he wears a light blue face to indicate his death without circulation of blood in his body (see Illustration 21). 


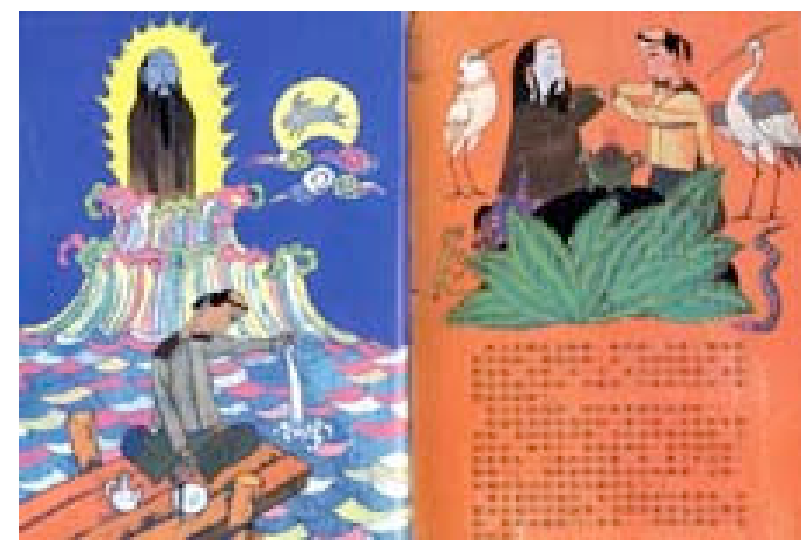

Illustration 4.21: The image of the water spirit in the Shui-gui Cheng-huang

The other example regarding "good brothers" is mentioned in the My Father is Going to a Festival Competition. There is no visual representation of the spirits in the pictures. Rather, one characteristic of "good brothers" is described in the story:

Tsung-tsung asked, "Is it horrible to invite the spirits to participate in this ritual?" "They are like human. There are good spirits and evil ones. When they feel your goodwill, they will be kind in return," his father said. (G2-06)

These two examples illustrate that the dead spirits behave like human beings. Their reactions depend on how one treats them. This also implies a view of death and life from a Han Taiwanese perspective. That is, paying one's respect to the spirits of the dead is a way to avoid bad luck.

10. supernatural beings in aboriginal stories bring blessings to folks.

Being blessed by a supernatural being is an important concept in aboriginal stories (see Table 4.6), such as the blessing from a spiritual bird representing a messenger of god in the Shooting Suns and blessing from the forefathers' spirit in both the picturebooks Story Map and Yi Gong-gong. The spiritual bird guided three hunters to look for suns and 
protected them on the way (see Illustration 22). There is no visual image shown in the pictures to represent the forefathers' spirit however. It is described in words. Anther example is in the Story Map, when a girl attempted to run away from home and go out on her own adventure:

That summer, I did not leave home too far. Finally, I went home because I slept on the road. Grandmother said, "It was the blessing given by forefathers' spirit. They watched over the naive child, who intended to run away from home. No matter how far she went, she eventually came home." (G3-03)

This description indicates that the forefathers' spirit has lived with the tribe and has protected them.

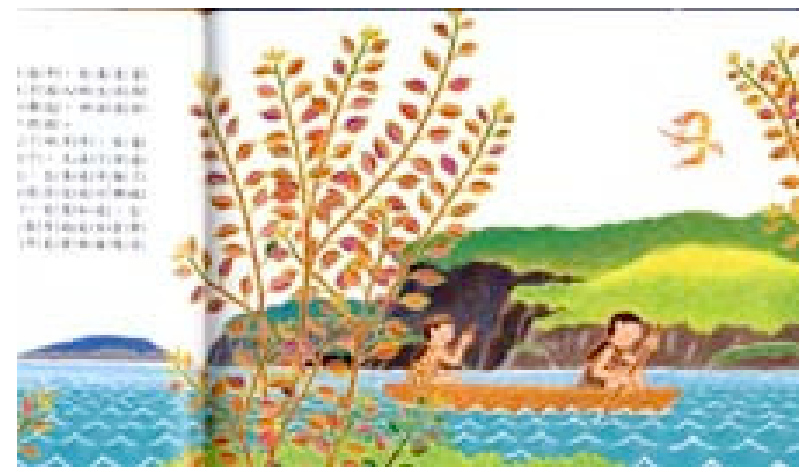

Illustration 4.22: The image of the spiritual bird in the Shooting Suns

11. wizards are a bridge between gods and humans.

A wizard plays the role of a communicator between gods and humans in aboriginal cultures. The wizard in the Shooting Suns is a person who is able to divine and predict the future. The illustration in the picturebook shows that she listens to the 
message delivered by a spiritual bird (see Illustration 4.23) and the text describes, "[she] thought they must shoot down a sun." In this sense, a wizard is a consultant and a bridge between gods and humans.

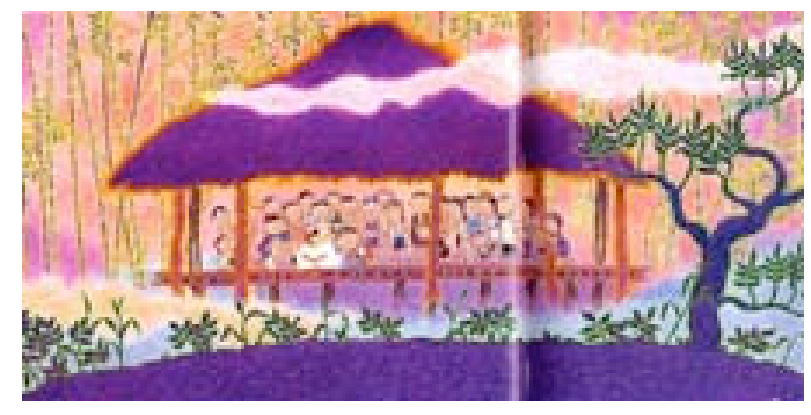

Illustration 4.23: The image of the wizard in the Shooting Suns

\section{Themes}

There are two perspectives from which to perceive the themes presented in the three sets of picturebooks. One is the editors' perspective, which was discussed in part one of this chapter, while the other is based on the contents of the picturebooks, which is the focus of this section. As a result, three major themes and related sub-themes are identified, primarily based on the verbal narratives. The theme patterns in the picturebooks (see Table 4.7) are discussed as follows: (1) the concept of consequences teaches moral lessons, but some exceptional examples demonstrate different perspectives; (2) the ways of filial obedience are implicitly demonstrated in the picturebooks; (3) the values of industriousness, friendliness, and human sympathy are explicitly and implicitly emphasized in the stories and the authors' notes; (4) the theme of mental 
growth is often shown in the Taiwanese Teenagers; and (5) hunting, storytelling, and forefathers' spirit are the common motifs shown in the aborigine related stories.

\begin{tabular}{|c|c|c|c|}
\hline .Category & & Theme & Picturebook \\
\hline & \multicolumn{3}{|c|}{ I. Based on the criteria made by the publishing houses } \\
\hline $\begin{array}{l}\text { Yuan-Liou } \\
\text { Publishing }\end{array}$ & \multicolumn{2}{|c|}{ Traditional folktales } & G1-01 G1-06 \\
\hline \multirow[t]{3}{*}{$\begin{array}{l}\text { Children's } \\
\text { Publications }\end{array}$} & \multicolumn{2}{|c|}{$\begin{array}{l}\text { Folkways (traditional myth, custom, } \\
\text { occupation, and street) }\end{array}$} & $\begin{array}{l}\text { G2-02, G2-03, G2-04, } \\
\text { G2-06, G2-08 }\end{array}$ \\
\hline & \multicolumn{2}{|c|}{ Art (artist, museum, dance) } & G2-01, G2-07, G2-09 \\
\hline & \multicolumn{2}{|c|}{ Environment (typical Taiwanese creatures) } & $\mathrm{G} 2-10$ \\
\hline $\begin{array}{l}\text { Yuan-Liou } \\
\text { Publishing }\end{array}$ & \multicolumn{2}{|c|}{$\begin{array}{l}\text { Childhood memories (an unforgettable } \\
\text { person, even, or place) }\end{array}$} & G3-01 G3-06 \\
\hline \multicolumn{4}{|c|}{ II. Based on the contents of the picturebooks } \\
\hline \multirow{8}{*}{ Values } & \multirow{5}{*}{$\begin{array}{l}\text { Consequence } \\
\text { of }\end{array}$} & - doing good thing & G1-06 \\
\hline & & - being simple and honest & G1-03, G1-04 \\
\hline & & - being greedy & G1-02, G1-04 \\
\hline & & - lying & G1-02, G1-05 \\
\hline & & - hard work & $\mathrm{G} 2-04, \mathrm{G} 2-06$ \\
\hline & \multicolumn{2}{|c|}{ - Filial obedience } & G1-03, G1-06, G2-04 \\
\hline & \multicolumn{2}{|c|}{ - Industriousness } & G2-04, G3-01 \\
\hline & \multicolumn{2}{|c|}{ - Friendliness, human sympathy } & G2-03, G3-01 \\
\hline \multirow[t]{3}{*}{ Mental Growth } & \multicolumn{2}{|l|}{$\begin{array}{l}\text { - Death } \\
- \text { Adventure }\end{array}$} & G3-04, G3-06 \\
\hline & \multicolumn{2}{|l|}{ - Adventure } & G3-02, G3-03 \\
\hline & \multicolumn{2}{|c|}{ - Adaptability of a new environment } & G2-09 \\
\hline \multirow[t]{3}{*}{ Aborigines } & \multicolumn{2}{|l|}{ - Hunting } & G2-02, G3-04 \\
\hline & \multirow{2}{*}{\multicolumn{2}{|c|}{$\begin{array}{l}\text { - Storytelling } \\
\text { - } \text { Forefathers' spirit }\end{array}$}} & G3-03 \\
\hline & & & G2-02, G3-03, G3-04 \\
\hline
\end{tabular}

Table 4.7: A distribution of themes presented in the three sets of picturebooks

\section{1. the concept of consequences teaches moral lessons, but some exceptional} examples demonstrate different perspectives .

Consequences are usually shown in folktales and tend to provide moral lessons. In the Taiwanese Folktales, four different types of consequences are presented, including consequences of doing good things, being simple and honest, being greedy, and lying. 
Doing good things and being simple and honest represent fine behaviors and one will be eventually rewarded due to practicing one of them. For example, in the Shui-gui Chenghuang, a water spirit was assigned the duty of city ruling deity from the hell god because he voluntarily gave up the opportunity of being reborn by refusing to pull someone else into the water to replace him. Before becoming the city ruling deity, the spirit was stopped from murdering two people by a fishing man, who was his good friend. As a result, this fishing man received a reward from the city ruling deity due to his kindheartedness. The notion of simple and honest men having good luck is also told in two picturebooks. The poor honest man in the Li Tain-luo married a good wife and the simple young brother in the Fragrance for Sale gained a good fortune. A common point shared in these characters is that they receive their rewards unexpectedly.

On the contrary, being greedy and lying are considered morally negative and the results of them usually produce punishments. For example, the greedy rich man in the picturebook Bo-zei Chi and the greedy lazy elder brother in the picturebook Fragrance for Sale received their official punishments from the court officers due to their bad behaviors. However, there is an exception in the Taiwanese Folktales category. That is, there are two stories about liars told in two different picturebooks which illustrate different consequences of lying.

The picturebook Hau Bi Shi shows that the man who lied about his magic nose eventually received a punishment from the heaven god due to his lie, although he succeeded in cheating people with good luck in the human world. This implies that one can fool people into believing him, but gods can not be deceived. Another liar in the Bozei Chi, however, escaped from a possible charge because he cheated a greedy rich man 
of his money by selling him a fake magic stick, which supposedly could make one die and bring one's life back. The greedy rich man believed the lie and used the stick to beat one of his tenant farmers because he could not afford to pay his land rent. The farmer died. Therefore, the greedy rich man was captured and sent to a court. Meanwhile, the liar safely run away from the town and never returned. Although the liar did not receive a punishment, this story provides another lesson. It is that " $a$ wicked person should have someone to cope with" (G1-02), as mentioned at the end of the story. This implies that the behavior of the greedy rich man is worse than what the liar did to him. The greedy rich man deserves the punishment due to his ignorance and vicious behavior to his tenant farmers, which is reasonable when considering this story was told in an agricultural society.

Besides the folktales, two picturebooks in the Taiwanese Children's Picturebook Selection exemplify the positive consequence of hard work. The picturebook Da-tou Has a Son, which is a contemporary Taiwanese story in rhymed verse, shows the son eventually earning success through working hard and studying hard. This rhyme also implies that the success of a son is the success of his father, according to the last line of the rhyme:

Da-tou's son has brilliance, Working hard to earn his success. Father and mother are pleased. Oh! They are really pleased. (G2-04)

The image accompanying this line shows that the son takes his parents to an airport and a map of Taiwan is shown on the baggage held by the son (see Illustration 24). The 
illustrator's note on the publishing page explains the meaning associated with this picture. He remarks:

Besides the fact of Da-tou and his wife worked hard to make a living, I also depicted Da-tou's son not only voluntarily helping his parents when he was growing, but also studying hard while helping them. Eventually, he was able to take his parents to travel abroad [which represents his success]. Like Taiwan placing itself on a global stage, Da-tou's family also sees the outside world. I hope that children can learn these implied meanings from the pictures I created. (G2-04)

The writer of this rhymed verse is interested in introducing traditional Taiwanese food to young children. However, the illustrator reinforces the idea of the beneficial consequence of hard work in his pictures. Moreover, he also intends to promote the notion of situating Taiwan on a global stage.

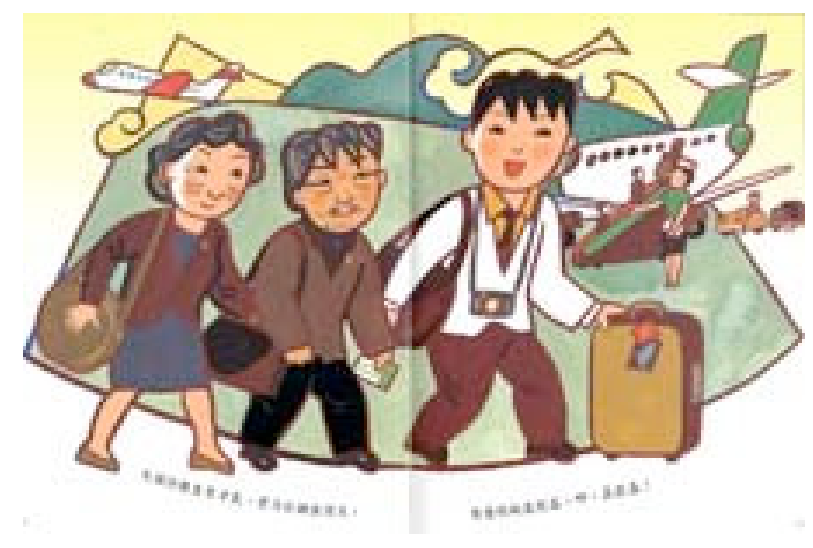

Illustration 4.24: The image of the family traveling in the Da-tou Has a Son

On the other hand, in the picturebook My Father is Going to a Festival Competition, the father's team failed to win the competition although they had firm training and devoted their time and energy to it. At the end of this story, the writer intends to redefine the meaning of success: it is to participate in the process rather than to 
win the competition. He wrote, "The team failed. But, all wives of the team members said that the team won and all participants in this competition were winners" (G2-06). According to Mr. Lin, the publisher of Children's Publications, he agreed with this writer and wanted to provide different perspectives for rethinking cultural conventions in contemporary society, which is a new way to approach subjects related to traditional Taiwanese culture.

2. the ways of filial obedience are implicitly demonstrated in the picturebooks.

Filial obedience is one of the major moral values emphasized in Confucianism. Although none of the picturebooks conveys this particular value in the story through a didactical form, three picturebooks imply the ways of filial obedience through the actions taken by the characters. For example, the female character, San-mei in the Li Tain Lou takes care of her ill mother without any complaints until she passed away.

The fishing man, in the Shui-gui Cheng-huang (a tale of a spirit becoming a city ruling deity), made a living from fishing in order to take care of his old mother. $\mathrm{He}$ avoided fishing in the deep and dangerous area, so he could not have a good catch of fish. It was not until he had gold given to him by a city ruling deity that "[t]he fishing man had the money, which was enough for taking care of his mother, so he no longer took the risk of fishing everyday" (G1-06). This story implies that one should not take any risk or do anything that would puts one's life in danger because of the responsibility to look after one's parents.

The son in the Da-tou Has a Son is a character without his own voice. He is shown growing up throughout the pictures. Among the fifteen double spread pages, five of them show his infant and toddler period, when he was carried while his parents were 
working. Six of them depict his different developing stages from being an elementary student through becoming an adult. Since he was old enough to work, he willingly helped his parents.

It is obvious that the priority of the parents' needs is more important than that of the individual's, according to these three stories. Taking care of parents' health and helping the family business are some ways to show one's filial obedience.

3. the values of industriousness, friendliness, and human sympathy are explicitly and implicitly emphasized in the stories and the authors' notes.

On the dedication page of the picturebook Selling Brooms with My Grandmother, the writer remarks, "In memory of Taiwanese farming families who were industrious, persistent, and helped others in achieving a common goal in the 1960s" (G3-01). This idea also carries on throughout the story. That is, the writer recalled her memories of making straw brooms and selling them with her grandmother. According to the writer, making brooms was a family business done by adult females like mothers and grandmothers in her village. In order to sell their hand-made brooms to nearby villages, the grandmother needed to bear a stick on her shoulder with brooms hanging from both ends (see Illustration 25). In one village, the grandmother chatted with other female folks while selling her brooms. They were friendly as they shared their life experiences and family stories, which implies that selling a broom is also a way of making a friend.

It was not until the grandmother sold out all the brooms that she was willing to return home. When the writer wanted to go home, her grandmother insisted on selling out her last broom. Meanwhile, one male popsicle vendor wanted to share his three leftover and incomplete popsicles with them for free because he intended to call off his business 
for the day. As a result, the grandmother decided to give the last broom to the vendor for two popsicles, which echoes the notion of helping others in achieving a common goal. To sum up, the grandmother and other female folks portrayed in the story represent the values of industriousness and friendliness. Moreover, the transaction between the broom and popsicles demonstrates a sense of human sympathy.
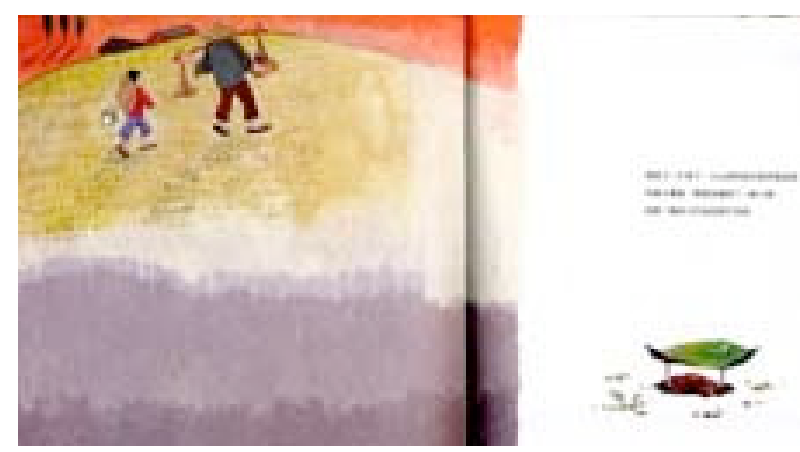

Illustration 4.25: The image of the grandmother carrying the brooms in the Selling Brooms with My Grandmother

Like the grandmother in the Selling Brooms with My Grandmother, the parents in the Da-tou Has a Son also show their industriousness throughout the story rhyme verse and the illustrator's notes at the end of the picturebook. According to the illustrator:

Taiwanese traditional food is special. The writer wrote a verse in rhyme based on this topic and it became an interesting children's song. Moreover, the content of this verse and the term "Da-tou Has a Son" naturally reveals that the Taiwanese devote themselves to make a better life for the younger generation. (G2-04)

In order to visualize his interpretation of this verse, the illustrations depict the parents working hard to make a better life for their child. Moreover, no matter how busy the 
parents were, they always kept their child around them in order to look after him. By the same token, the child also learned the value of industriousness from their actions.

The picturebook Free Tea for Everyone is a contemporary tale, which introduces a traditional Taiwanese custom. That is, there is a big pot of water or tea offered by someone for free and located in the corners of different places, such as an intersection of mountain paths, a village entrance, a transportation center, or a spot under a big tree near a village temple. In the story, a village deity searched for the reason that made a pot of free tea taste delicious. Throughout the search, he found that those who voluntarily offered free tea for travelers who were thirsty due to their kindness and human sympathy was the major reason for that made the tea delicious. This conclusion explicitly commends the traditional custom and reinforces the value of friendliness and human sympathy.

\section{4. the theme of mental growth is often shown in the Taiwanese Teenagers.}

Mental growth is a psychological aspect of child development, which is a popular theme in children's literature. This theme helps young readers explore unfamiliar life experiences and the idea of becoming. Five picturebooks touch on this theme because the main child characters encountered unknown situations and gained their experiences by going through the process. Four of them are in the category of the Taiwanese Teenagers, while only one of them falls into the Taiwanese Children's Picturebook Selection. These experiences include loss of a significant person, participating in an adventure alone, and adaptation to a new environment. When taking a close look at the psychological aspect of the children's mental growth in these picturebooks, it is also important to note when the 
event depicted in the story occurred, because it helps to understand whether these events show a general pattern that reflects similar societal values in a particular time period.

Two male writers recall their childhood memories of the loss of their significant others. First, in the Yi Gong-gong the granduncle serves as a role model for the writer. $\mathrm{He}$ encouraged the writer to set up a goal of studying for his tribe rather than for his own benefit before he passed away (in the early 1960s). ${ }^{63}$ His wisdom and contributions to his tribe have enlightened the writer, as the writer puts his own words in the story:

On the day of the funeral for my granduncle, I took one day off to participate in it. I remembered that he wore a suit of traditional Beinan formal cloth from the hat to the leggings, which were as beautiful as the rosy clouds at dusk. That image was just like a picture that never faded, which became my memory forever. During my childhood, the conversation between my granduncle and me on the night he passed away has become the conversation between me, as an adult, and my childhood. My growth is actually an extension of that conversation. I learned about my granduncle and I learned even more about myself from the conversation... (G3-04)

This story indicates the writer's self-awareness of his ethnic identity through the interaction with his granduncle, which reflects a specific cultural experience. In addition, this is the only one of the picturebooks mentioning an ethnic relationship between aborigines (the Pai-Nan tribe) and Han Chinese.

Second, the mother of the writer in the picturebook A River Resembling a Mother died when he was four years old (in the early 1960s). He recalled his memory of the last words from his mother, "Be good and study hard..." (G3-06). After she passed away, he and his father together burned funeral money for his mother, which is a traditional Taiwanese custom. Although he lost his mother, nature became the place where he could devote his time and energy. He says: 
The death of my mother was the beginning of my life memory.

Although I lost my mother's love, my childhood was actually joyful

because of living and playing in a natural environment.

Nature was like another mother for me. (G3-06)

Although the writer had a happy childhood, he had deeply missed his mother, as mentioned at the end of the story. Unlike the Yi Gong-gong focusing on an individual's cultural awareness, this story indicates a child's natural need for a mother's love, which is a general psychological necessity.

The theme of adventure is shown in the two picturebooks When I was Eight, I Went on a Journey and Story Map. These stories portray the independent aspect of being a child. The main character of the former is a young boy asked to independently complete a task because his courage was being tested by his father. In contrast, the latter is about a young girl who intended to run away from home due to having a fight with her mother and by doing this she tried to prove her independence. Although they left home for their very own reasons, both of them gained experiences on the way to their destinations and eventually safely returned home. The boy exercised his quick wit by helping an old lady on a train. The girl cooled herself down from the fight while enjoying the scenery on the way and recalling her memories of stories about it told by her grandmother. Both grew more mature as a result of their travels.

In these two stories, the concept of "home" is a metaphor of protection and the action of "leaving home" symbolizes growing up and independence. The two children demonstrate their maturity through leaving home alone. The boy was expected to be independent (the event occurred in the 1960s), while the girl tried to prove her

\footnotetext{
${ }^{63}$ According to the present ages of the writers and the events described in their stories, they together indicate the possible time periods when the events happened.
} 
independence (the event took place in the 1970s). This contrast suggests different expectations for different gender roles embedded in social norms. That is, the male role needs to be strong to fulfill the social expectation. However, the female role struggles for independence with the protection set up by social norms.

The picturebook Yue-yue's Dancing Lessons, in the Taiwanese Children's Picturebook Selection, depicts a little girl with anxiety and fear when attending her first dancing lesson. The story is a documentary of her participations in a series of dancing lessons and adaptation to a new environment. Due to both her mother and teacher being patient, this little girl had gradually overcome her fear and was able to independently join the class at the first meeting of the new term. Unlike the other picturebooks, the Yueyue's Dancing Lessons was created based on a child-centered idea, which means that the author closely captures the little girl's emotion and reaction to the new teacher, classmates, and classroom environment. For example, the little girl stood behind her mother and tightly held her leg when she first came to the class. Then later, she could sit with her mother in the classroom and watch the activity of the other children. Little by little, she was able to participate in the activity with her mother sitting in the corner of the classroom. Finally, her mother could stay outside of the classroom and watch her through the window. There is no moral lesson or traditional value embedded in this story. The author presents this story from observing the recent life situations in which children live, such as the popularity of attending art related activities for a middle-class family.

5. hunting, storytelling, and forefathers' spirit are the common motifs shown in the aborigine related stories. 
Three picturebooks out of the three sets are on aborigine related themes. One is the myth, Shooting Sun, written and illustrated by a Han author and the other two reflect an individual's life experiences written by two aboriginal writers, including Story Map and Yi Gong-gong. The common motifs shown in these aboriginal stories are hunting, storytelling, and forefathers' spirit, all of which indicate typical aboriginal culture differences from Han culture.

Hunting is associated with males in aboriginal cultures. A hunter should learn about the natural environment in which he lives and this knowledge is passed down from the elder to the young, as mentioned in the picturebooks Shooting Suns and Yi Gonggong. Particularly, the aboriginal writer of the Yi Gong-gong describes the criteria for being a real hunter in his childhood memory. He wrote:

After growing up, I gradually understood that a real hunter does not use guns, according to our traditional value. The design, set up, and evaluation of a trap and bravery are the criteria for judging a good hunter. These criteria are a representation of the combination of knowledge, experience, physical strength, and will. Meanwhile, in order to be a qualified hunter, one should be able to dream, to understand his dream, and to believe his dream. That is because the dream is the place where a hunter, his forefathers' spirit, and the universal meet together. (G3-04)

In this description above, forefathers' spirit is mentioned. And, they are portrayed as living with the folks and providing their guidance whenever they are needed. This notion is also supported by the writer of the Story Map. In this story, the grandmother made a comment about a special protection from the forefathers' spirit for children. That is, "In summer, although the heat from the land is hot enough to burn one's feet, the children of the Paiwan tribe have a special protection which can stand the heat. That is because of forefathers' spirit" (G3-03). 
Storytelling is a way to transmit oral history and the myths of a tribe from generation to generation, which is emphasized in the picturebooks Shooting Suns and Story Map through the teachings of the grandparents' generation. This teaching is to functions as cultural transmission, such as when the grandfather teaches his son and grandson about the tribe they left behind in the Shooting Suns. However, it also functions as a means to cultivate the relationship between the elders and the young. The writer of the Story Map, for example, recalled her memories of oral stories told by her grandmother, which implies their closed relationship.

According to the two aboriginal writers, the male writer identifies with his granduncle, while the female writer relates her experience to her grandmother. These associations indicate the possible gender identity constructions in their cultures. For example, the male writer is from the Beinan tribe. According to their traditional convention, males receive a challenging training program, which is similar to the contemporary educational system; however, it emphasizes the cultural transmission based on the elder's wisdom (Chen, 2004). Males are divided into two different groups according to their ages. The young adult group consists of children of ages 13 through 18 , while the adult group includes males over the age of 18 . This traditional training strengthens the relationship and connection between the male elders and the young and reinforces the identity of being male.

Plots

This section is discussed primarily based on the verbal narratives and is divided into two segments: plot structures and plots and conflicts. 


\section{1. the common plot structure convention of problem solving is widely used in the}

picturebooks.

"Most plots in children's literature are presented in linear fashion" (Huck, Hepler, Hickman \& Kiefer, 2001, p. 15), which is also true in the three sets of picturebooks. This helps young readers have a good understanding of the stories. Moreover, a conventional plot structure is also commonly adopted in story telling, which invloves a process of problem solving. As Temple, Martinez, Yokota, \& Naylor (2002) remark:

The events in a typical plot are set in motion by a complication, in which the main character experiences a problem and explicitly or implicitly sets a goal. The plot continues with rising action, in which the character strives to reach the goal and solve the problem. Toward the end, the plot arrives at a climax, in which tension is at its height as the matter of the character's success or failure is about to be decided. (p. 40)

Fourteen out of twenty-two picturebooks use this plot structure (see Table 4.8). This structure sets up a reading mode, where readers unconsciously receive rules and are capable of recognizing them in a story.

Another noticeable pattern is the repetition of three things linked together, which is frequently used in the Taiwanese Folktales. This pattern includes three tricks, three strategies, three exchanges, three valuable treasures, three cheatings, and three tries. This repetition is also popular in folktales from other cultural traditions. It is safe to say that this plot structure is more universal rather than culturally specific.

Due to the editorial expectations, the picturebooks in the Taiwanese Teenagers tend to tell the famous writers' childhood memories. The plot structure shown in most of these stories indicates personally significant events associated with a person or a place rather than having a clear linear story line. Therefore, these memories provide readers 
with some impressions about the events mentioned in the stories and encourage readers to recall their own memories and make connections to the writers' memories.

\begin{tabular}{|c|c|c|c|c|}
\hline Category & Verbal Pattern & Picturebook & \multicolumn{2}{|c|}{ Frequency } \\
\hline $\begin{array}{l}\text { No Clear } \\
\text { Events }\end{array}$ & - Nursery rhymes & G2-05 & 1 & 1 \\
\hline \multirow[t]{3}{*}{$\begin{array}{l}\text { One Major } \\
\text { Plots with } \\
\text { Different } \\
\text { Events }\end{array}$} & $\begin{array}{l}\text { Following the problem-solving } \\
\text { process } \\
\text { Posting a task/problem-Rising } \\
\text { action - Completing the task/ } \\
\text { Solving the problem (success or } \\
\text { failure) }\end{array}$ & $\begin{array}{l}\text { G1-01, G1-02, G1-03, } \\
\text { G1-04, G1-06, G2-02, } \\
\text { G2-03, G2-04, G2-06, } \\
\text { G2-07, G2-08, G2-09, } \\
\text { G2-10, G3-02 }\end{array}$ & 14 & \multirow[t]{3}{*}{20} \\
\hline & - Following the memories & $\begin{array}{l}\text { G3-01, G3-03, G3-04, } \\
\text { G3-05, G3-06 }\end{array}$ & 5 & \\
\hline & $\begin{array}{l}\text { - Following the time frame } \\
\text { Morning-Afternoon-Evening }\end{array}$ & G2-01 & 1 & \\
\hline $\begin{array}{l}\text { Two Plots } \\
\text { with } \\
\text { Different } \\
\text { Events }\end{array}$ & $\begin{array}{l}\text { - 1. Exchanging objects ( } 3 \text { times) } \\
\text { - 2. Contrast between two } \\
\text { brothers ( } 3 \text { events })\end{array}$ & G1-05 & 1 & 1 \\
\hline
\end{tabular}

Table 4.8: A distribution of plot structure presented in the three sets of picturebooks

2. the types of conflicts between characters and within a character are used in the picturebooks more often than those of conflicts between a character and environment or a character and society.

Conflicts in stories consists of four different types: (1) conflict between characters, (2) conflict within a character, (3) conflict between a character and environment, and (4) conflict between a character and society (Temple, Martinez, Yokota, \& Naylor, 2002). The first two categories are used in the picturebooks more often than the last two (see Table 4.9). Moreover, a noticeable pattern is that most 
conflicts between characters are due to different values held by the characters, which include diverse relationships, such as father and daughter, husband and wife, friends, grandmother and granddaughter, and leader and followers. Another obvious point is that six out of eight picturebooks, in the category of conflict within a character, deal with child characters. Especially, four of them are about the writers' childhood memories and two of them depict children from the perspective of current life experience. The conflicts set up in these stories help the child characters become more mature or satisfied with the situation they have encountered.

\begin{tabular}{|c|c|c|c|c|}
\hline Category & Verbal Pattern & Picturebook & & ency \\
\hline \multirow[t]{3}{*}{$\begin{array}{l}\text { Conflict between } \\
\text { Characters }\end{array}$} & - Different values & $\begin{array}{l}\text { G1-03, G1-06, } \\
\text { G2-06, G3-01, } \\
\text { G3-02, G3-04 }\end{array}$ & 6 & \multirow{3}{*}{$\begin{array}{l}10 \\
(2)\end{array}$} \\
\hline & - Cheating & G1-02, G1-04, G1-05 & 3 & \\
\hline & - Survival struggle & G1-01 & 1 & \\
\hline \multirow{4}{*}{$\begin{array}{l}\text { Conflict within } \\
\text { a Character }\end{array}$} & - Friendship & G1-06 & 1 & \multirow{4}{*}{$\begin{array}{l}8 \\
(6)\end{array}$} \\
\hline & - Emotion controlling & $\begin{array}{l}\text { G2-09, G3-02 (Fear) } \\
\text { G3-3 (Anger) }\end{array}$ & 3 & \\
\hline & - Facing death & G3-04, G3-06 & 2 & \\
\hline & - Search for answers & G2-03, G2-07 & 2 & \\
\hline \multirow{2}{*}{$\begin{array}{l}\text { Conflict between a } \\
\text { Character and the } \\
\text { Environment }\end{array}$} & $\begin{array}{l}\text { - Two suns affecting } \\
\text { people's living }\end{array}$ & $G 2-02$ & 1 & \multirow[t]{2}{*}{$\begin{array}{c}2 \\
(1)\end{array}$} \\
\hline & - Environmental pollution & G2-10 & 1 & \\
\hline \multirow{2}{*}{$\begin{array}{l}\text { Conflict between a } \\
\text { Character and Society }\end{array}$} & $\begin{array}{l}\text { - Artwork was not } \\
\text { appreciated. }\end{array}$ & G2-01 & 1 & \multirow[t]{2}{*}{$\begin{array}{c}2 \\
(1)\end{array}$} \\
\hline & $\begin{array}{l}\text { - Making a living in } \\
\text { society }\end{array}$ & $G 2-04$ & 1 & \\
\hline No Conflict & & G2-08, G3-05 & 2 & $\begin{array}{c}2 \\
(2)\end{array}$ \\
\hline
\end{tabular}

Table 4.9: A distribution of plot conflict presented in the three sets of picturebooks 


\section{Point of View}

According to Huck, Hepler, Hickman, and Kiefer (2001), "the term point of view is often used to indicate the author's choice of narrator(s) and the way the narrator reveals the story. Whose story is it? Who tells it?" (p. 19). Moreover, Nikolajeva and Scott (2001) remark that point of view is associated with "who sees" while the narrative voice is related to "who speaks" in a literary work and they suggest that "in a picturebook we should probably treat the words as primarily conveying the narrative voice, and pictures as primarily conveying the point of view" (p. 117). They further argue that the narrative voice and point of view in the picutrebook may be contradictory.

An example of this contraction would be where the narrative voice in the text is first person (meaning that it presents a limited view), while the picture shows an omniscient perspective on the same spread page. Another common contradiction is that the narrative voice is first person, but readers can see the narrator in pictures. This places the reader in a point of view outside of and apart from the narrator, which makes it difficult to identify with the first person narrative voice. In other words, readers take the same position as the narrator's while the text is speaking in the first person. Thus, readers see things through the narrator's eye. However, when readers see the narrator in pictures, this image separates readers' position from the narrator's. The contradiction between the narrator's voice and point of view creates a gap, which may generate different meanings and inspire diverse interpretations. Despite this contradiction, in order to emphasize settings, characters, or actions in plots, focalization in words or pictures is oftentimes used in storytelling with the intention of drawing the readers' attention to the writer's focus. 
Based on the discussion above, the notion of point of view is divided into three categories: the first person (an autobiographical voice or the narrative's imagination), a limited omniscient perspective (a focalized voice or view of a particular character), and an omniscient perspective (the narrator knowing everything about the story or the image displaying an overview of the plot).

The narrative voices used in the three sets of picturebooks show a diversity of patterns (see Table 4.10). Childhood memories in the Taiwanese Teenagers are described in the first person; stories in the Taiwanese Children's Picturebook Selection tend to use the third person to tell the stories from a particular character's perspective, which is a limited omniscient perspective; and the Taiwanese Folktales are told in the third person with an omniscient perspective. The only one exception in the Taiwanese Children's Picturebook Selection is the aboriginal myth Shooting Suns, which uses the third person with an omniscient perspective in the narrative voice. Moreover, the narrator talks to readers in order to explain the reason why there is a sun and a moon in the sky at the end of the story. The text is translated as follows:

Before long, the silver sun came out after the recovery [from being shot down by the hunters.] It only came out at night and was no longer hot and bright. Do you know? As a matter of fact, the silver sun became the moon. Under the sun and moon, folks always joyfully sang and danced. They felt happiness because they had one sun and one moon taking turns to protect them. Since then, this story has been passed down from generation to generation. (G202)

This strategy is to catch readers' interest and draw attention to the myth of the natural environment we live in. It also implies that the representation of aboriginal cultures 
portrayed in this story is based on their cultural tradition originating in the past.

Moreover, this ending also echoes the fact that a history of oral storytelling is part of aboriginal cultural traditions.

\begin{tabular}{|c|c|ll|}
\hline Picturebook & Narrative Voice & \multicolumn{1}{c|}{ Point of View } \\
\hline $\begin{array}{c}\text { Taiwanese Folktales } \\
\text { (Including the Story } \\
\text { Shooting Suns) }\end{array}$ & $\begin{array}{c}\text { The third person with } \\
\text { an omniscient } \\
\text { perspective }\end{array}$ & $\bullet$ An omniscient perspective \\
\hline $\begin{array}{c}\text { Taiwanese Children's } \\
\text { Picturebook Selection } \\
\text { (Except the Story } \\
\text { Shooting Suns) }\end{array}$ & $\begin{array}{c}\text { The third person from } \\
\text { the view of a } \\
\text { particular character }\end{array}$ & $\bullet$ An omniscient perspective \\
\hline Taiwanese Teenagers & The first person & $\bullet$ Focalization \\
\hline
\end{tabular}

Table 4.10: A distribution of point of view presented in the three sets of picturebooks

In terms of the visual pattern shown in the picturebooks regarding the point of view, three categories are covered. In other words, the pictures of each picturebook may present the narrative voice from different perspectives. For example, an omniscient perspective is presented by a long shot of a landscape, multiple separate pictures depicting a sequence of action, or a picture with events occurring during different time frames (see Illustration 26). A limited omniscient perspective or focalization is conveyed by a close-up of a gesture of characters or objects (see Illustration 27). The first person or subjective perspective is shown by an image with a bubble shape representing a thought from a particular character, taking a closer look at oneself through water, or a close-up of objects mentioned by the narrator without showing an image of the narrator (see Illustration 28). The use of multiple perspectives within a picturebook is to demonstrate a 
dynamic relationship between pictures on different pages. By so doing, the pictures can catch readers' interest easier when they turn over a picturebook page by page.
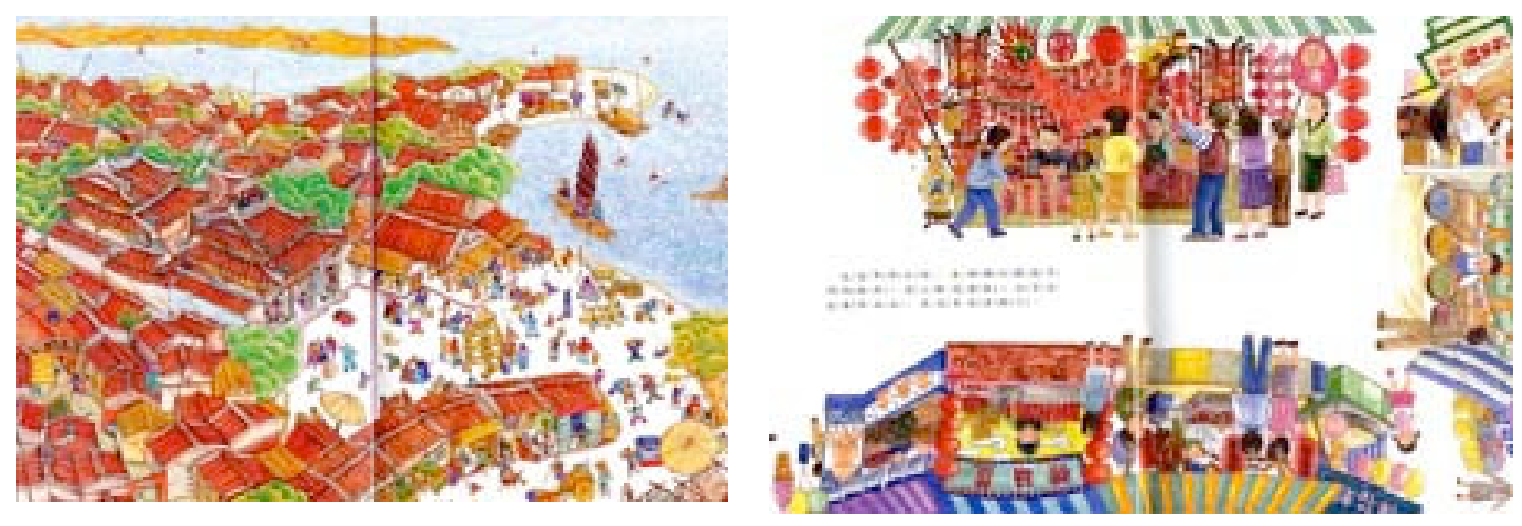

Illustration 4.26: The images of an omniscient perspective shown in the picturebooks
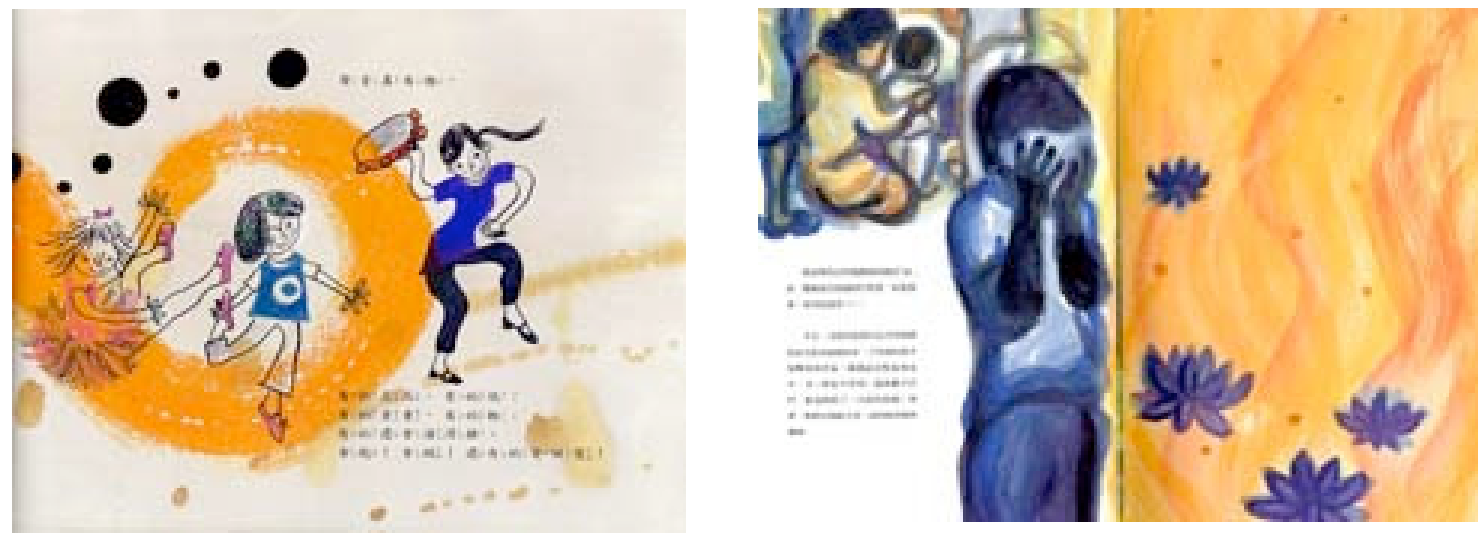

Illustration 4.27: The images of a limited omniscient perspective shown in the picturebooks 

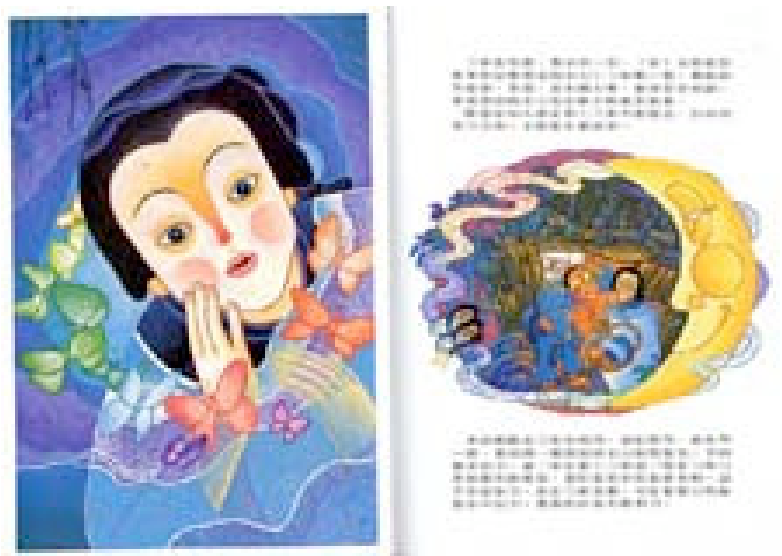

Illustration 4.28: The image of the first person perspective shown in the picturebooks (the image on the left)

Style

The use of style in the picturebook consists of two major components: (1) verbal, which includes words, images (created based on the description in words), metaphors, sounds, and voice (Temple, Martinez, Yokota \& Naylor, 2002) and (2) visual, which includes elements of design, the artist's choice of media, artistic conventions, and the format of the book (Huck, Hepler, Hickman \& Kiefer, 2001). Since the literary and aesthetic quality of the picturebooks is excluded from this study, an analysis of formal quality is not considered. Although these elements contribute to an understanding of meaning making in the picturebook, the use of style in the picturebooks in this section is limited to the discussion of the use of language (sounds and voice) and artistic conventions because they are more relevant to this study. 
1. the technique of writing with rhymes is often used in the Taiwanese Folktales and children's songs.

Four out twenty-two picturebooks are written with rhymes, including three folktales, one story rhyme verse, and one nursery rhyme and songs for children (see Table 4.11). The dramatic focus of the three folktales, Hu Gu-po, Bo-zei Chi, and Hao-bi$s h i$, is on the intelligence or wittiness used by the main characters. And, writing with rhymes enhances the dramatic effects of these stories. The Taiwanese story rhyme verse, Da-tou Has a Son, and the Taiwanese Nursery Rhymes are designed for learning language (mainly Min-na Hua) because rhymes are interesting and easy for children to memorize.

\begin{tabular}{|c|c|c|c|}
\hline Category & Pattern & Picturebook & Total \\
\hline \multirow{2}{*}{$\begin{array}{l}\text { Sounds } \\
\text { (rhymes) }\end{array}$} & - Folktale & G1-01, G1-02, G1-04 & \multirow[t]{2}{*}{5} \\
\hline & - Nursery Rhymes & G2-03, G2-05 & \\
\hline \multirow{10}{*}{ Voice } & \multirow[b]{2}{*}{ - Personalizing } & G2-01, G2-07 & \multirow[b]{2}{*}{8} \\
\hline & & $\begin{array}{l}\text { G3-01, G3-03, G3-06 (soft \& emotional) } \\
\text { G3-02, G3-04, G3-05 }\end{array}$ & \\
\hline & - Folksy & G1-03, G1-04, G1-06, G2-02, G2-04, G2-10 & 6 \\
\hline & - Knowledgeable & $\mathrm{G} 2-06, \mathrm{G} 2-08, * \mathrm{G} 3-05$ & 3 \\
\hline & - Witty & G1-02, G1-05 & 2 \\
\hline & - Authoritative & G1-01, G3-04 & 2 \\
\hline & - Impersonal & G2-03 & 1 \\
\hline & - Encouraging & G2-09 & 1 \\
\hline & - Bold & G3-02 & 1 \\
\hline & - Local dialect & G2-04, G2-05, G2-10, G3-01, G3-02, G3-5 & 4 \\
\hline
\end{tabular}

Table 4.11: A distribution of the use of language presented in the three sets of picturebooks 


\section{2. the voice used in most of the picturebooks tends to be folksy and personalized.}

Eight picturebooks have personalizing voices, which can be divided into two types (see Table 4.11). First, the narrator personalizes the Taiwanese senior artists' names by calling them grandfather or grandmother when introducing their artworks in two picturebooks. They include the Mei-shu A-gong and A Sparrow in the Museum. And, the artists are mentioned in the stories, such as Mei-shu A-gong (meaning grandfather in Min-na Hua), Lin Yu-shan Ye-ye (meaning grandfather in Mandarin), and Chen Jin Nainai (meaning grandmother in Mandarin). These titles imply the value of respecting the elders and by using this strategy the social distance between the senior artists and young readers is decreased.

Second, the personalizing voice is intended to share personal experience in the first person. The stories in the Taiwanese Teenagers are told in the first person. However, each one of them may also contain another similar or different voice. For example, the writers of picturebooks Selling Brooms with My Grandmother, Story Map, and A River Resembling a Mother convey a soft and emotional feeling when recalling their memories of their grandmothers or mothers in the stories. The voice of the Yi Gong-gong is more authoritative because the focus of the story is on the influence of the male role model. The voice of the A Memory of Tea Plantation tends to be knowledgeable when the writer informatively describes the tea plantation where he grew up. The voice of the When I was Eight, I Went on a Journey is bold due to depicting an adventure. It shows that the tone of the voice relies on the content of the story. Moreover, it is significant that the soft and emotional voice is usually associated with the grandmother or mother role. 


\section{3. the use of local dialect adds a local culture flavor to the story.}

The story of Da-tou Has a Son is the only one out of the twenty-two picturebooks written in Mandarin with the pronunciation based on Min-na Hua. The Taiwanese Nursery Rhymes consists of fifteen nursery rhymes for playing games with Mandarin and three different local dialects. These include five in Mandarin, seven in Min-nan Hua, two in Hakka Hua, and one in an indigenous language (Zou tribe). All the words in these rhymes are written based on Mandarin, and one audio $\mathrm{CD}$ is included for demonstration. Besides Mandarin, Min-na Hua is the most popular local dialect spoken in Taiwan; thus, it is also more often used in the picturebooks than others.

Four picturebooks contain a few terms in Min-na Hua when the writers describe something with a local cultural expression. This usage is often shown in the picturebook Selling Brooms with My Grandmother when the writer mentions the conversations she had with her mother or grandmother or the conversations her grandmother had with other folks. These terms are used in the text and their explanations are placed within parenthesizes right after the terms. The mix of the different languages not only maintains the personality of the character, but also reflects the culture in which the character lives. This also demonstrates the notion that language can present culture in a particular time period.

4. the use of representational art in the picturebooks increases the authenticity of the stories .

The term "representational art" refers to pictures which mimic real objects and represent them in a realistic manner. Simplified representational art style is widely used in the picturebooks, such as folktales, folkways, and personal childhood memories (see 
Table 4.12). These stories are based on realistic life experiences. For example, the Meishu A-gong and the When I was Eight, I Went on a Journey. The first story is written based on an artist's life while the second one is an autobiography. The illustrators tend to objectively present these stories by capturing the scenes based on what one sees. By doing this, the story is made more real. In particular, the medium and style of the artworks created by the artist Li Mei-shu are realistic oil paintings. This illustrator tried to capture the essence of the artist's work (see Illustration 29). Despite the popularity of simplified representational art style used in the picturebooks, the design of the characters shown in them contains an individual's style (see Illustration 30).

\begin{tabular}{|c|c|c|c|}
\hline Category & Implied Meaning & Picturebook & Total \\
\hline $\begin{array}{c}\text { Representational } \\
\text { Art }\end{array}$ & Showing real life experience & $\begin{array}{l}\text { G1-02, G1-03, G1-05, G1-06, } \\
\text { G2-01, G2-03, G2-04, G2-07, } \\
\text { G2-08, G2-09, G2-10, G3-02, } \\
\text { G3-03, G3-05 }\end{array}$ & 14 \\
\hline $\begin{array}{l}\text { Expressionistic } \\
\text { Art }\end{array}$ & $\begin{array}{l}\text { Showing the emotional } \\
\text { feeling of the story }\end{array}$ & G2-06, G3-01, G3-04, G3-06 & 4 \\
\hline Cartoon Art & $\begin{array}{l}\text { Modern interpretation: } \\
\text { making a connection to the } \\
\text { reader's life experience. }\end{array}$ & G1-01, G2-02 & 2 \\
\hline Folk Art & $\begin{array}{l}\text { Shadow puppetry: showing a } \\
\text { traditional Chinese flavor }\end{array}$ & G1-04 & 1 \\
\hline Combination & $\begin{array}{l}15 \text { illustrations with different } \\
\text { style: showing diverse art } \\
\text { styles }\end{array}$ & G2-05 & 1 \\
\hline
\end{tabular}

Table 4.12: A distribution of the artistic convention presented in the three sets of picturebooks 

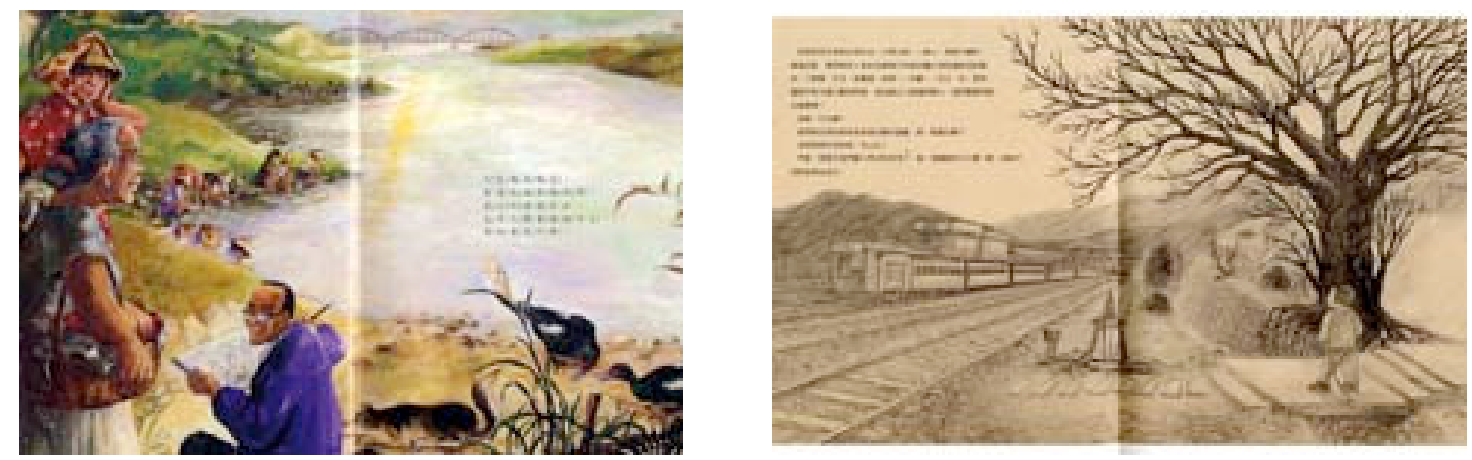

Illustration 4.29: The images of the illustrations with the style of representational art
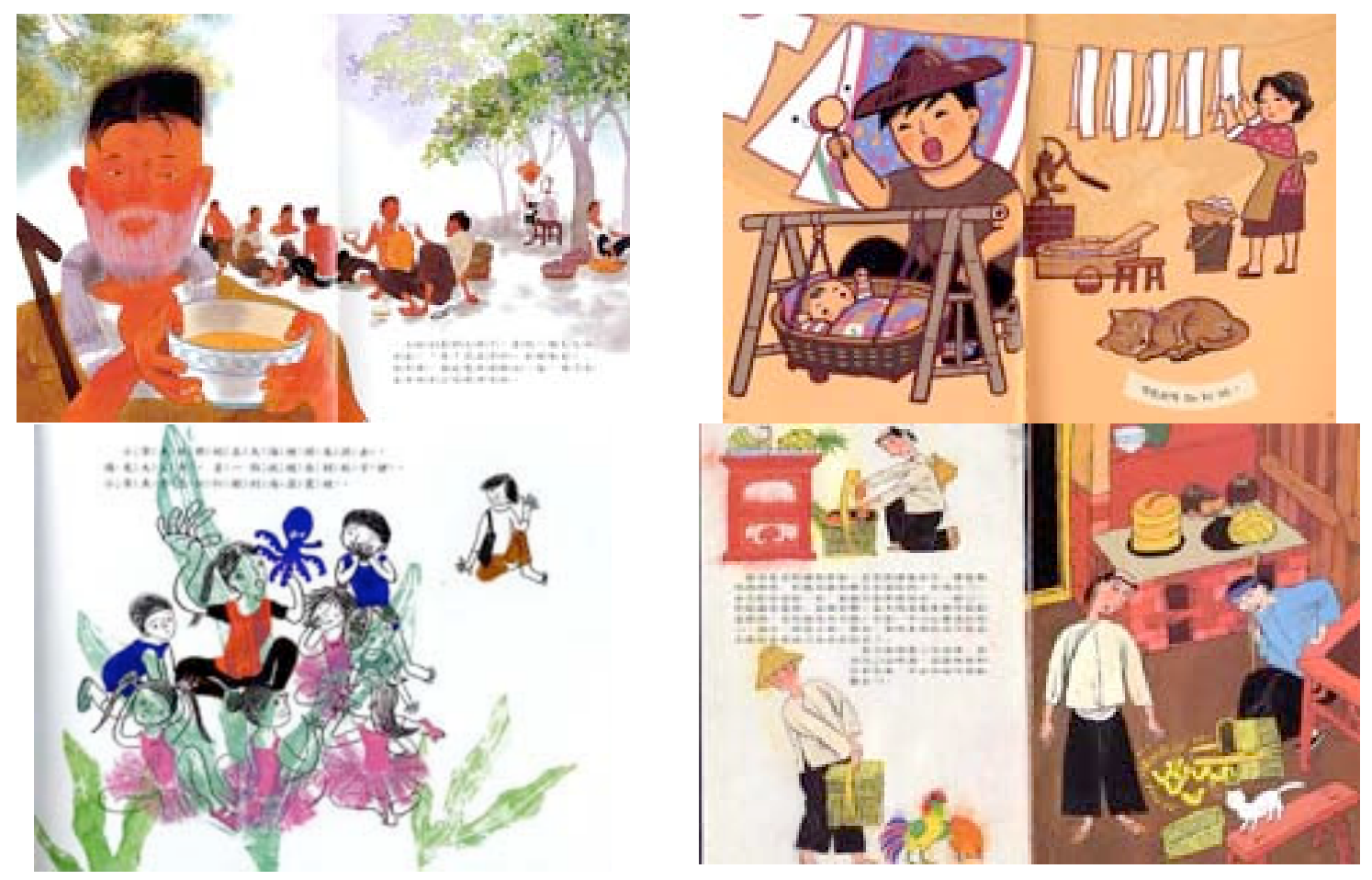

Illustration 4.30: The images of the illustrations with personal style 
5. the style of expressionistic art used in the picturebooks tends to enhance the emotional feeling of the story.

According to Huck, Hepler, Hickman, and Kiefer (2001), “[a]spects of expressionistic art include shocking colors, figures slightly out of proportion, and rough, rapid brushwork. The emphasis is on the artist's own inner emotions and on selfexpression rather than the reproduction of what he or she sees" (p. 184). Four picturebooks are presented in the style of expressionistic art. In particular, the visuals in the picturebook A River Resembling a Mother fully extend the feeling of loss beyond the words in the story by using rough and bold paint strokes (see Illustration 31). In addition, the illustrations in the picturebook Yi Gong-gong tend to express a feeling of being part of nature and living with the forefathers' spirit, representing the essence of aboriginal culture. This feeling is created by juxtaposing the images of animals and tribe patterns and limiting the use of color to green and brown tones. The exaggerated main characters are also painted with color similar to the background color (see Illustration 31).
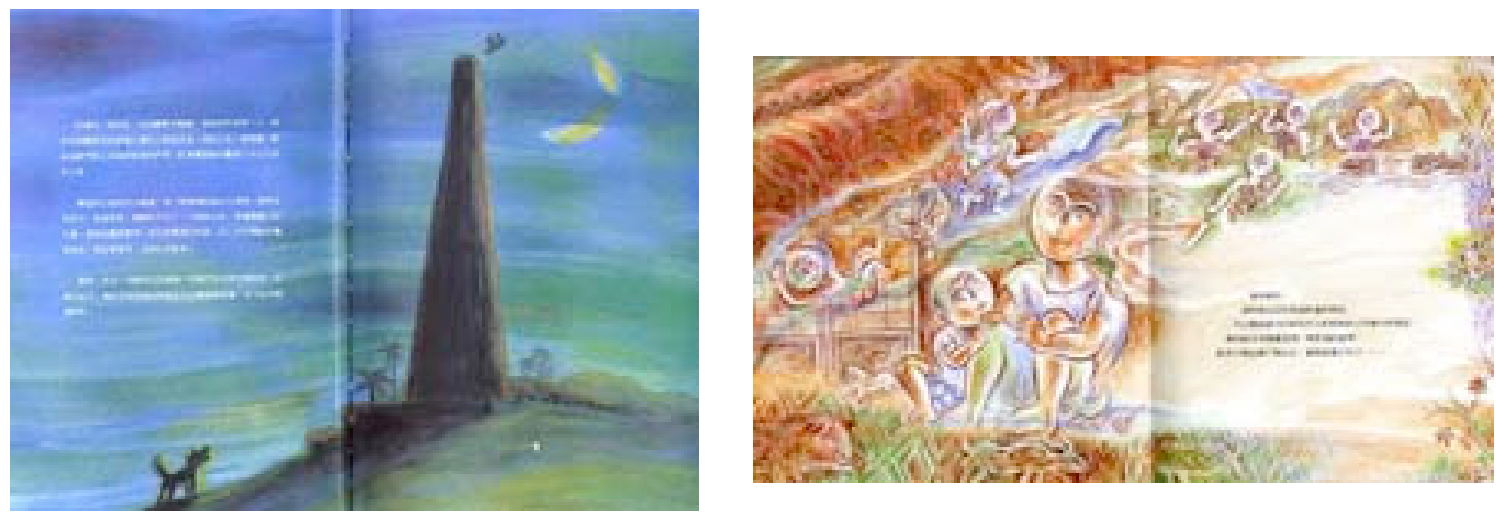

Illustration 4.31: The images of the illustrations in the A River Resembling a Mother and Yi Gong-gong 


\section{6. the choice of cartoon art in the picturebooks implies a connection to the}

reader's life experience.

The term "cartoon art" refers to the style relying on "a lively line to create movement and humor" (Huck, Hepler, Hickman \& Kiefer, 2001, p. 186). This style generally combines simplicity with exaggerated features to produce dramatic effects. It has become well known to children in contemporary society through television, comic books, newspapers, and other media forms. Two picturebooks adopting a cartoon art style include a Taiwanese folktale and an aboriginal myth. In contrast, only one folktale, Fragrance for Sale, is created based on Chinese shadow puppetry, which adds a traditional Chinese flavor. In order to extend dramatic effects, animals in cartoons oftentimes are portrayed as characters in the story, even though they play a silent role. This can be seen in two picturebooks. For example, two mice helped the little girl set up a trap to defeat the magic tiger in the picturebook $H u$ Gu-po. Three rabbits and two bats were happily dancing while the honest man holding his son found a large amount of coal in the Li Tain-luo ${ }^{64}$ (see Illustration 32). These additional messages shown through animals in the pictures explicitly reinforces the readers' desire to place sympathy on the good characters' side.

\footnotetext{
${ }^{64}$ Although the use of style in this picturebook is simplified representational art style, the illustrator adds facial expression on the sun and dramatic feelings on the animals in the pictures, such as rabbits, bats, and birds.
} 

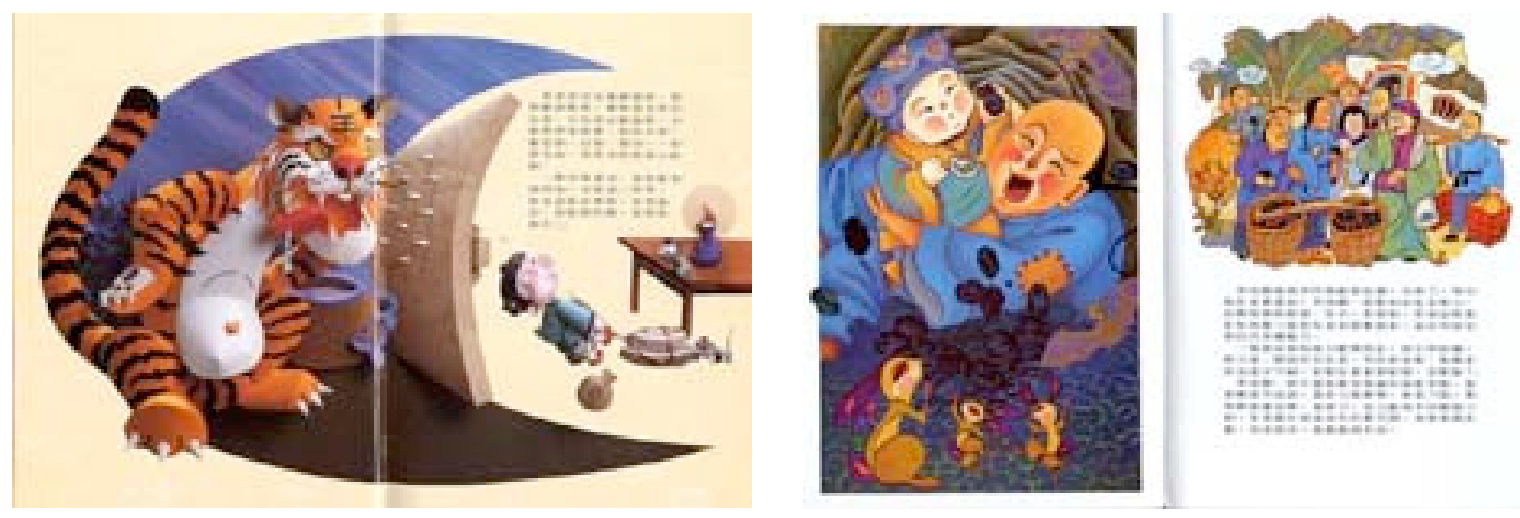

Illustration 4.32: The images of animals shown in the picturebooks

According to Mr. Lin, the publisher of Children's Publications, the author of the picturebook Shooting Suns presents this myth from a contemporary viewpoint and this visual representation will interest young readers today (see Illustration 4.33). Based on his account, a picturebook with the style of cartoon art represents a contemporary flavor, which children are familiar with. This also shows his main concern about how to make a traditional tale acceptable to children in contemporary society.
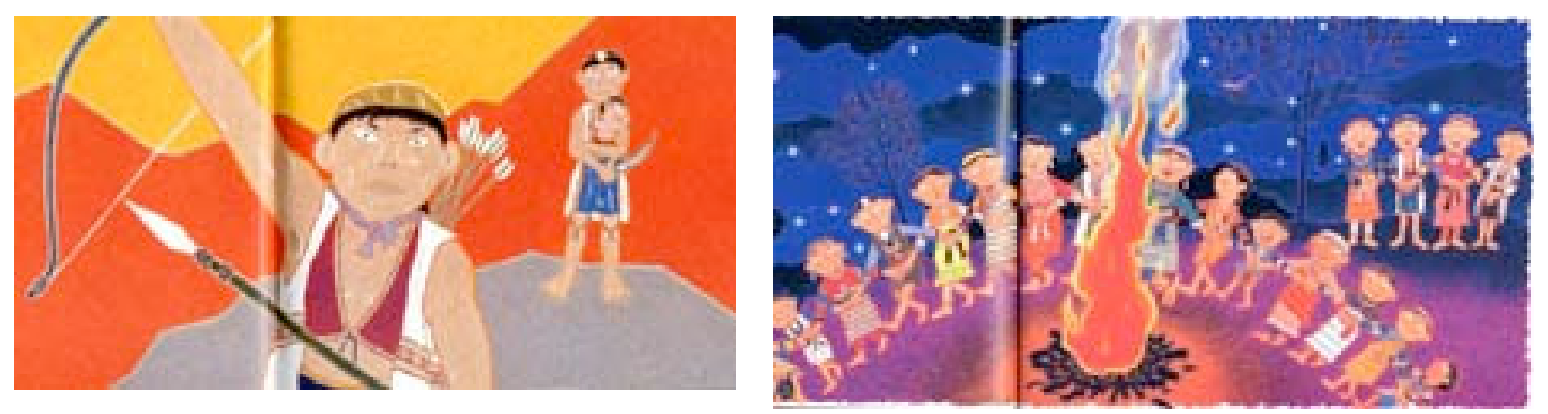

Illustration 4.33: The images of the representation of the myth Shooting Suns 


\section{A Summary of the Verbal and Visual Narrative Patterns}

Thirty narrative patterns of the three sets of picturebooks were discussed in part II based on the six elements: setting, characterization, theme, plot, point of view, and style. A summary of the patterns is as follows (see Table 4.13).

\begin{tabular}{|c|c|}
\hline Category & Pattern \\
\hline \multirow{3}{*}{ Setting } & $\begin{array}{l}\text { 1. Settings in the folktales and rural communities use the term "once } \\
\text { upon a time" to start the stories. }\end{array}$ \\
\hline & $\begin{array}{l}\text { 2. Settings during a particular time period in the past and in } \\
\text { suburban/rural communities start the stories by using four different } \\
\text { types, which include: (1) to imply it is happening now, (2) to indicate } \\
\text { the age of the writer in the story, (3) to indicate a general time period, } \\
\text { and (4) a lack of description in words, but indicating the time based on } \\
\text { the pictures. }\end{array}$ \\
\hline & $\begin{array}{l}\text { 3. Settings in the present time and in suburban/urban communities use } \\
\text { two ways to indicate the time, which include: (1) to mention the term } \\
\text { "Today" and (2) to indicate a particular holiday. }\end{array}$ \\
\hline \multirow{11}{*}{ Characterization } & 1. Male role is dominating in the picturebooks. \\
\hline & 2. Stereotypes of male roles in folktales are reinforced by the visuals. \\
\hline & 3. Adult males play responsible and strict roles in the story. \\
\hline & 4. Female roles emphasize human relationships. \\
\hline & $\begin{array}{l}\text { 5. Some stereotypes of female roles in the picturebooks have changed, } \\
\text { but some remain the same. }\end{array}$ \\
\hline & 6. Diverse child characters are shown in both gender roles. \\
\hline & 7. The role of the child is to receive teaching from the elders. \\
\hline & $\begin{array}{l}\text { 8. Supernatural beings in Han stories show gods' judgment on } \\
\text { humans. }\end{array}$ \\
\hline & 9. Spirits of the dead who died accidental deaths behave like humans. \\
\hline & 10. Supernatural beings in aboriginal stories bring blessings to folks. \\
\hline & 1 \\
\hline
\end{tabular}

Table 4.13: A summary of the narrative patterns of the three sets of picturebooks (Continued) 
Table 4.13 (Continued)

\begin{tabular}{|c|c|}
\hline \multirow{5}{*}{ Theme } & $\begin{array}{l}\text { 1. The concept of consequences teaches moral lessons, but some } \\
\text { exceptional examples demonstrate different perspectives. }\end{array}$ \\
\hline & $\begin{array}{l}\text { 2. The ways of filial obedience are implicitly demonstrated in the } \\
\text { picturebooks. }\end{array}$ \\
\hline & $\begin{array}{l}\text { 3. The values of industriousness, friendliness, and human sympathy } \\
\text { are explicitly and implicitly emphasized in the stories and the authors' } \\
\text { notes. }\end{array}$ \\
\hline & $\begin{array}{l}\text { 4. The theme of mental growth is often shown in the Taiwanese } \\
\text { Teenagers. }\end{array}$ \\
\hline & $\begin{array}{l}\text { 5. Hunting, storytelling, and forefathers' spirit are the common motifs } \\
\text { shown in the aborigine related stories. }\end{array}$ \\
\hline \multirow[b]{2}{*}{ Plot } & $\begin{array}{l}\text { 1. Plot structure showing the common convention of problem solving } \\
\text { is widely used in the picturebooks. }\end{array}$ \\
\hline & $\begin{array}{l}\text { 2. The types of conflicts between characters and within a character are } \\
\text { used in the picturebooks more often than those of conflicts between a } \\
\text { character and environment or a character and society. }\end{array}$ \\
\hline \multirow{3}{*}{ Point of View } & $\begin{array}{l}\text { 1. Childhood memories in the Taiwanese Teenagers are described in } \\
\text { the first person. }\end{array}$ \\
\hline & $\begin{array}{l}\text { 2. Stories in the Taiwanese Children's Picturebook Selection tend to } \\
\text { use the third person to tell the stories from a particular character, } \\
\text { which is a limited omniscient perspective. }\end{array}$ \\
\hline & $\begin{array}{l}\text { 3. The Taiwanese Folktales are told in the third person with an } \\
\text { omniscient perspective. }\end{array}$ \\
\hline \multirow{6}{*}{ Style } & $\begin{array}{l}\text { 1. The technique of writing with rhymes is often used in the Taiwanese } \\
\text { Folktales and children's songs. }\end{array}$ \\
\hline & $\begin{array}{l}\text { 2. The voice used in most of the picturebooks tends to be folksy and } \\
\text { personalized. }\end{array}$ \\
\hline & 3. The use of local dialect adds a local culture flavor to the story. \\
\hline & $\begin{array}{l}\text { 4. The use of representational art in the picturebooks increases the } \\
\text { authenticity of the stories. }\end{array}$ \\
\hline & $\begin{array}{l}\text { 5. The style of expressionistic art used in the picturebooks tends to } \\
\text { enhance the emotional feeling of the story. }\end{array}$ \\
\hline & $\begin{array}{l}\text { 6. The choice of cartoon art in the picturebooks implies a connection } \\
\text { to the reader's life experience. }\end{array}$ \\
\hline
\end{tabular}




\section{Cultural Clues}

For non-Chinese speakers, young readers who are not able to read Mandarin, or children who are learning to read, the visuals in the picturebooks are fundamental to helping them make sense of the stories. For this reason, the visuals play a crucial role in conveying a cultural representation of Taiwan to readers. Therefore, the artist's choice for presenting culture through the visual narrative patterns in the picturebooks is examined. The three sets of picturebooks are used as a means to explore Taiwanese culture from a traditional perspective based on the editors' intentions. In this case, the term "tradition" refers to those cultural practices in Taiwan's society during the agricultural era. Thus, the focus of this section is to analyze the visual elements frequently used in the picturebooks to present traditional Taiwanese culture, particularly in setting and characterization. As a result, four major components are identified and they consist of: (1) the articles of daily use, such as bamboo products (hats, furniture, and containers), (2) costumes, such as the Qing style, the modified clothing based on the Qing style for Han women, modern white shirt with pants for men, and the traditional aboriginal outfits, (3) architecture, such as southern Chinese house style, Chinese palace, and the Baroque style, and (4) cultural symbols used in rituals, such as funerals, weddings, and celebrations for the new born (see Table 4.14). These visual elements function as cultural clues for indicating the characteristics of Taiwanese culture during different time frames, including early Taiwan (the segregation between aborigines and Han immigrants), the 1940s 1960s (agricultural Taiwan), and after the 1970s (industrialized Taiwan). 


\begin{tabular}{|c|c|c|c|}
\hline \multicolumn{2}{|c|}{ Category } & Explanation & Picturebook \\
\hline \multirow{13}{*}{$\begin{array}{l}\text { The } \\
\text { Use of } \\
\text { Symbol }\end{array}$} & \multirow{3}{*}{$\begin{array}{l}\text { The articles } \\
\text { of daily use }\end{array}$} & $\begin{array}{l}\text { A wide-brimmed rain hat made } \\
\text { of bamboo leaves }\end{array}$ & $\begin{array}{l}\text { G2-01, G2-03, G2-04, G3-01 } \\
\text { G3-02, G3-05, G3-06 }\end{array}$ \\
\hline & & $\begin{array}{l}\text { Furniture made of bamboo or } \\
\text { wood }\end{array}$ & G2-02, G2-04 \\
\hline & & Container made of bamboo & G2-08 \\
\hline & \multirow{4}{*}{ Costumes } & The Qing style & $\begin{array}{l}\text { G1-01, G1-02, G1-03, G1-05 } \\
\text { G1-06 }\end{array}$ \\
\hline & & $\begin{array}{l}\text { Modern white shirt with pants } \\
\text { (for men) }\end{array}$ & $\begin{array}{l}\text { G2-03, G2-04, G3-01, G3-02 } \\
\text { G3-04, G3-05, G3-06 }\end{array}$ \\
\hline & & $\begin{array}{l}\text { Modified traditional clothing } \\
\text { based on the Qing style (for } \\
\text { women) }\end{array}$ & $\begin{array}{l}\text { G2-01, G2-04, G3-01, G3-02 } \\
\text { G3-05 }\end{array}$ \\
\hline & & Traditional aboriginal outfits & G2-02, G3-03, G3-04 \\
\hline & \multirow[t]{3}{*}{ Architecture } & Southern Chinese house style & $\begin{array}{l}\text { G1-02, G1-03, G1-06 } \\
\text { G2-06, G3-01, G3-05 }\end{array}$ \\
\hline & & Chinese Palace & G1-05, G2-07 \\
\hline & & Baroque style & G2-01, G2-08 \\
\hline & \multirow[t]{3}{*}{ Rituals } & Funeral & $\begin{array}{l}\text { G1-03, G3-04, G3-06 } \\
\text { (Funeral), } \\
\text { G2-06 (celebration for the } \\
\text { dead) }\end{array}$ \\
\hline & & Wedding & G2-04 \\
\hline & & $\begin{array}{l}\text { Celebration for a newborn } \\
\text { baby }\end{array}$ & G1-03 \\
\hline
\end{tabular}

Table 4.14: A distribution of the use of symbol presented in the three sets of picturebooks

1. the image of bamboo products shown in the picturebooks symbolizes a life style of agricultural society.

The traditional articles of daily use depicted in the picturebooks are made of natural resources, such as bamboo and wood. It is significant that the image of widebrimmed rain hats made of bamboo leaves is shown in seven picturebooks. These are generally associated with agricultural activities that Han folks participated in, such as farming, picking tea leaves, and selling agricultural products (see Illustration 34). 

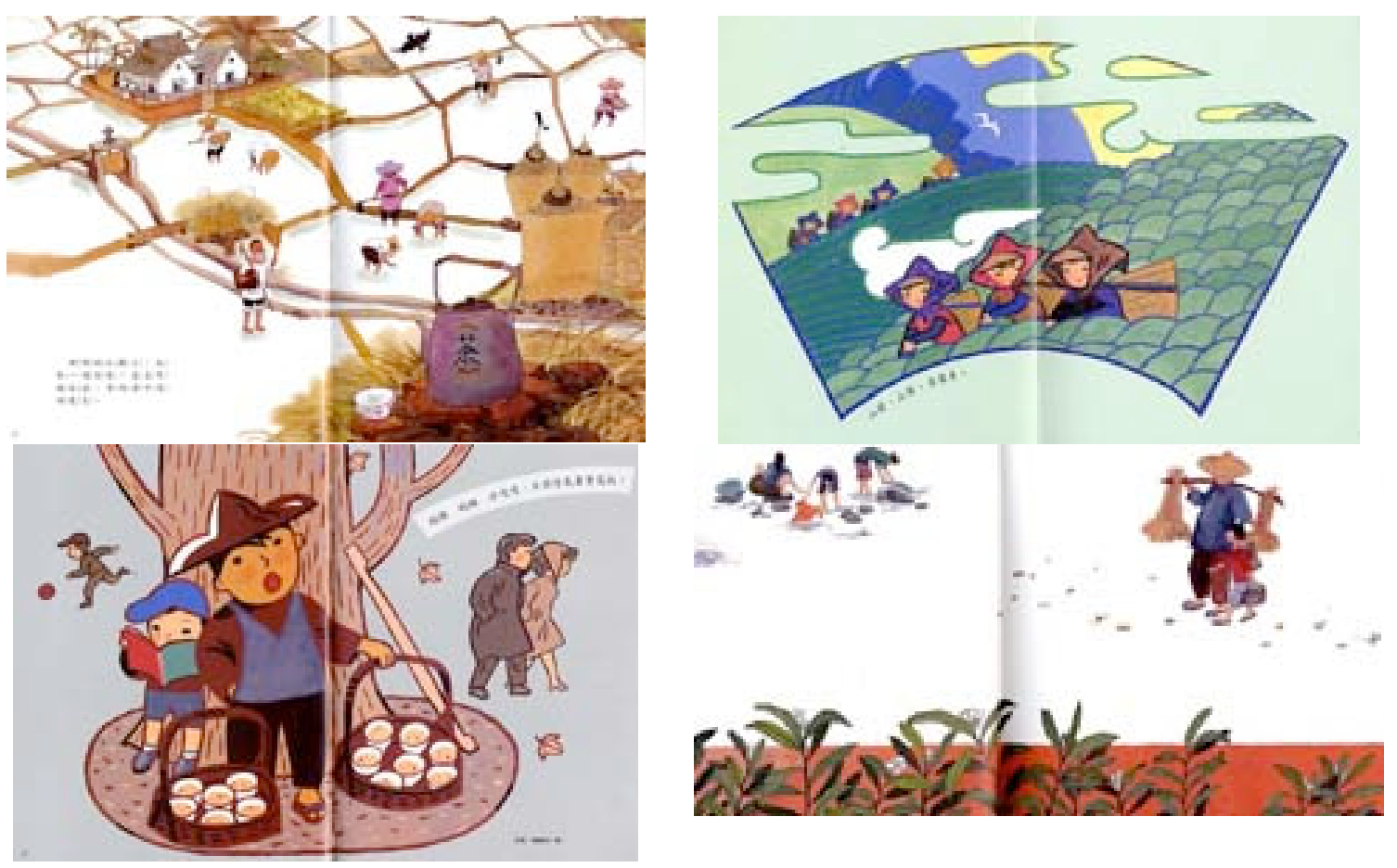

Illustration 4.34: The images of the bamboo products shown in the picturebooks

In particular, the illustrator of the picturebook Da-tou Has a Son intended to depict the traditional articles of daily use that were popular used during the 1940s to 1960s through his pictures. In order to draw readers' attention to them, the design of the end papers also repetitively shows these images and has their names written in Mandarin based on the Min-na Hua pronunciation (see Illustration 35). This shows that the purpose of the picturebook is to demonstrate a traditional life experience in a particular time frame. 

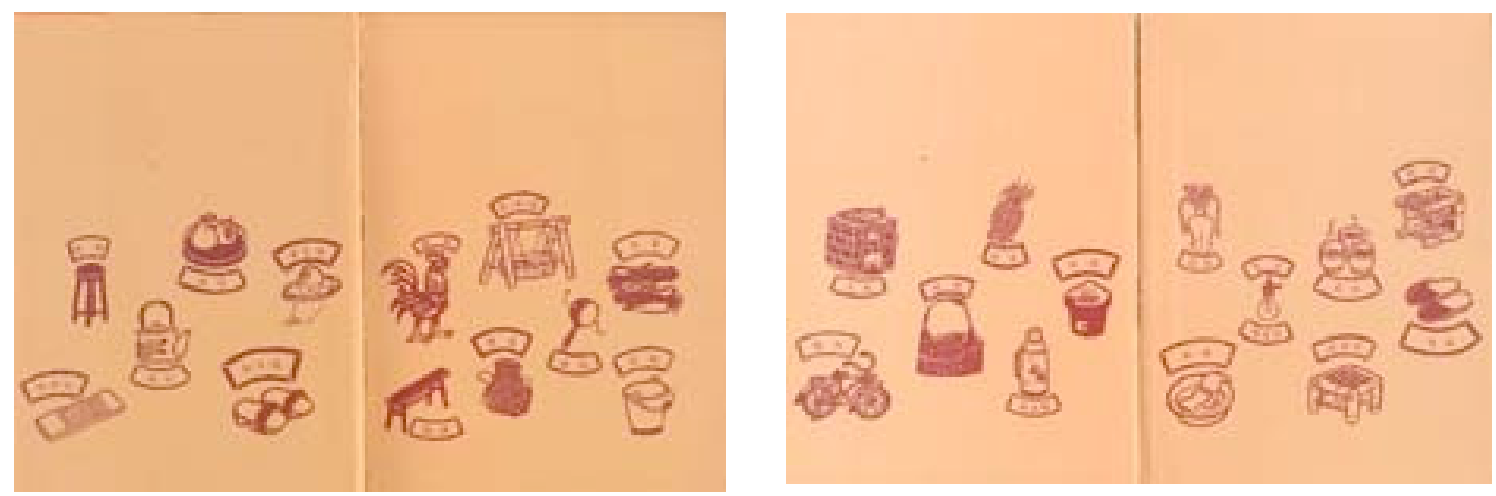

Illustration 4.35: The image of the design of the end papers in the Da-tou Has a Son

In contrast, the picturebook Going Shopping on Dihua Street for Chinese New Year tells the story during the present time but introduces traditional articles that some people still use in their daily lives. In the story, one picture depicts various kinds of articles made of bamboo in a traditional craft shop where the grandfather wanted to purchase a small wooden tub (see Illustration 36). From this shopping experience, his grandson is able to see some traditional artifacts that are rarely used by the younger generation. 

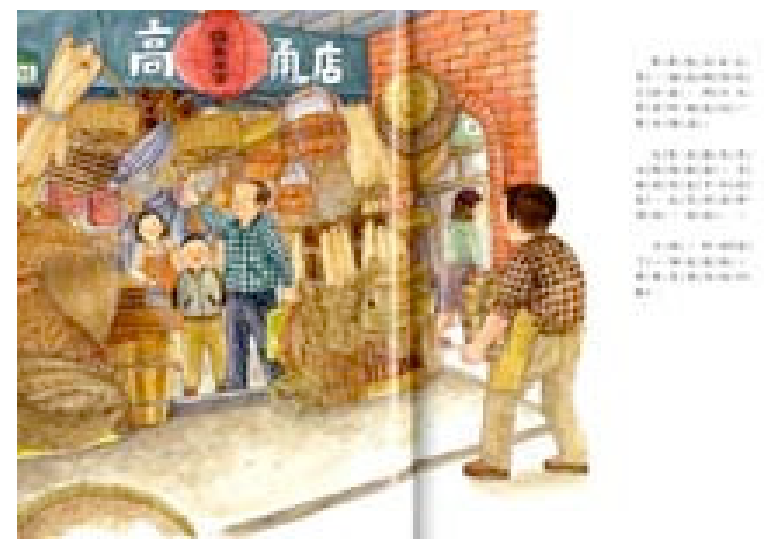

Illustration 4.36: The image of the traditional craft shop in the Going Shopping on Dihua Street for Chinese New Year

2. costumes indicate the characters' ethnic identity and the time frame of the story.

Since Taiwan has been modernized or westernized, the outfits people wear today look similar to those worn in western countries. In order to emphasize the origin of the story or the character, costumes function as cultural clues to tell what ethnic group is involved. Because of costumes, it is a simple matter to distinguish the difference between Taiwanese aborigines and Han Chinese.

Taiwanese aborigines consist of, at least, twelve tribes recognized by the current government and each of them has its own unique traditional costumes. In the three picturebooks associated with the aboriginal theme, the costumes show characteristics of aboriginal cultures to some degree. For example, the writer of the Yi Gong-gong is from the Beinan tribe. Wearing a floral hoop and cloth with rhombus patterns is used to accurately portray this tribe (see Illustration 37). In contrast, the illustrator of the Story Map does not depict the aboriginal traditional symbols of human head, pot, and snake on the costumes worn by the main characters, even though the writer is the descendant of the 
Paiwan tribe. A possible explanation is that these symbols may represent the aristocrat class and are used only for a noble family. If the writer's family does not belong to the aristocrat class, their costumes would not have these symbols. However, other more general clothing items may provide symbolic clues to a character's aboriginal ethnic identity, such as a scarf or floral hoop worn around the head (see Illustration 38). This comparison raises a significant issue regarding the representation of minorities in the picturebooks; that is, what cultural clues should be included in pictures to remind readers of a particular culture? This is a challenge for illustrators.

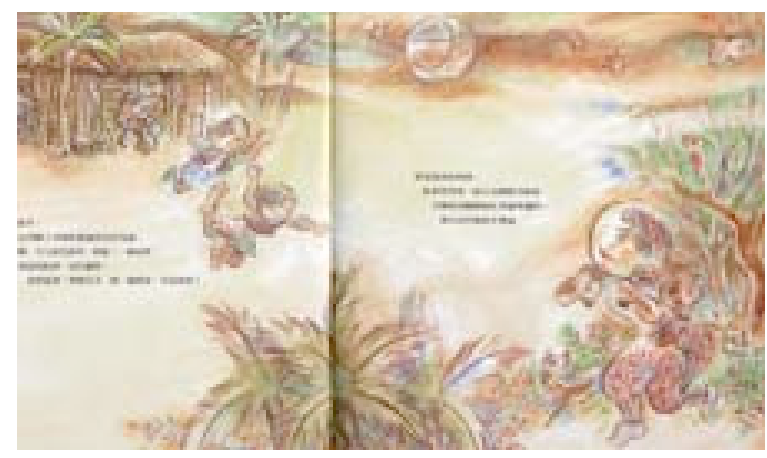

Illustration 4.37: The image of the costume shown in the Yi Gong-gong 

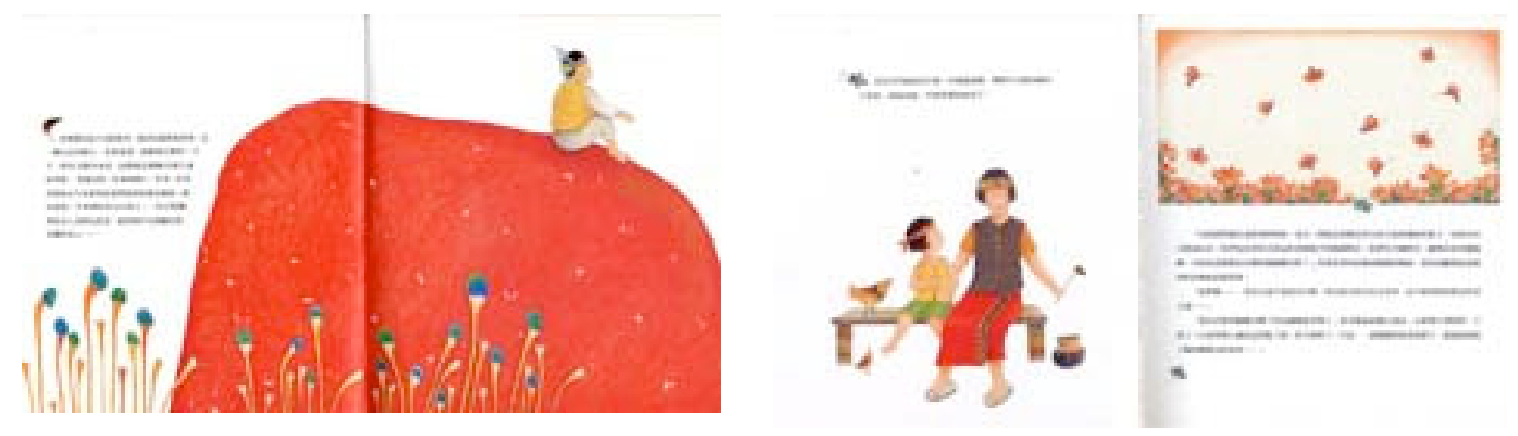

Illustration 4.38: The image of the costume shown in the Story Map

The images of the costumes shown in most of the Han Taiwanese Folktales are based on the Qing style, which is an identifiable culture period (see Illustration 39). The basic design of Qing clothing for common folks, including the design of the collar and front part, is still used on modified Chinese clothing today. This type of clothing was usually worn by the grandmother's generation from the Han group. This traditional Qing style is worn by the grandmothers in the picturebooks Mei-shu A-gong, Selling Brooms with My Grandmother, When I was Eight, I Went on a Journey, and A Memory of Tea Plantation (see Illustration 40). White shirt with pants were commonly worn by men in their daily lives during the 1940s to 1960 s, and this is shown in seven picturebooks (see Illustration 41). These typical images of the traditional Han Chinese clothing and modernized clothing provide cultural clues, which indicate a time period in the past. 

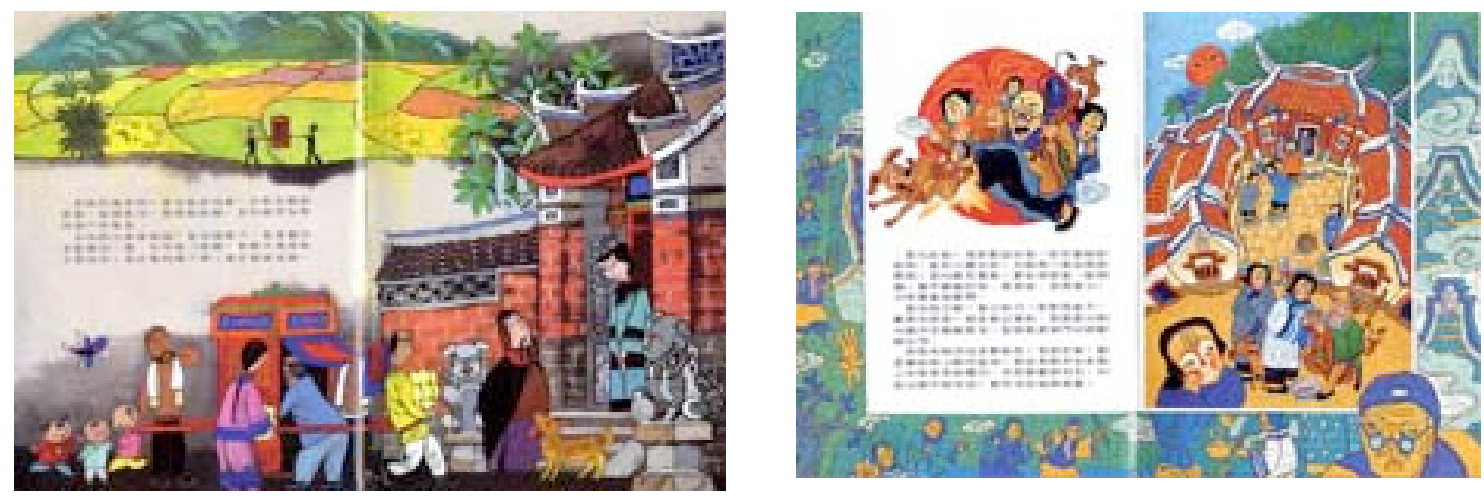

Illustration 4.39: The images of the Qing style costumes
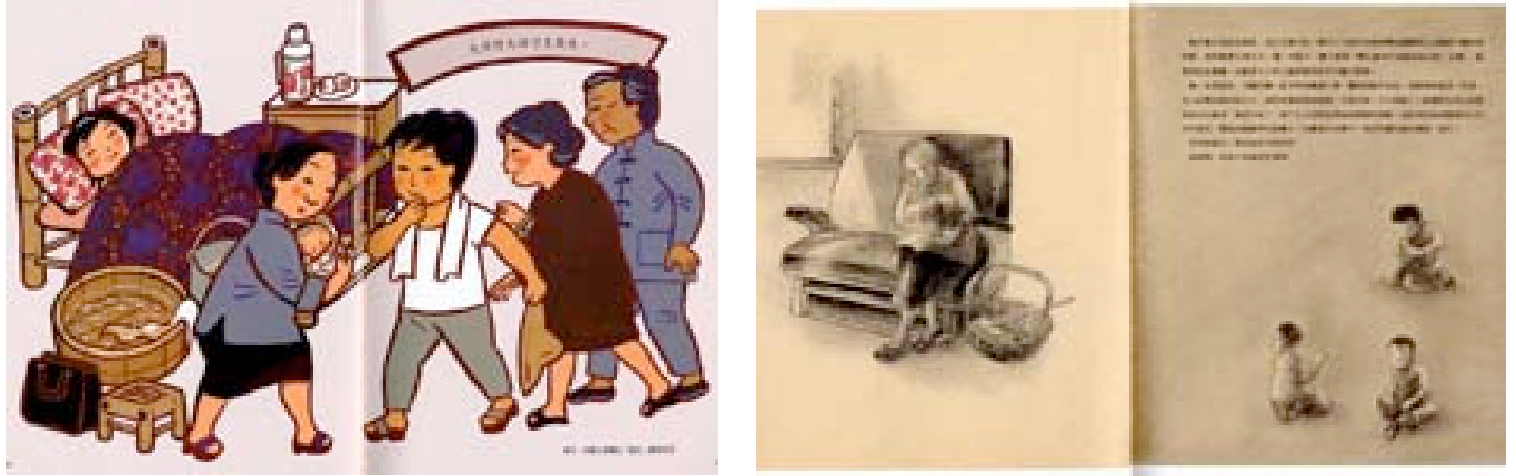

Illustration 4.40: The images of the modified Chinese clothing
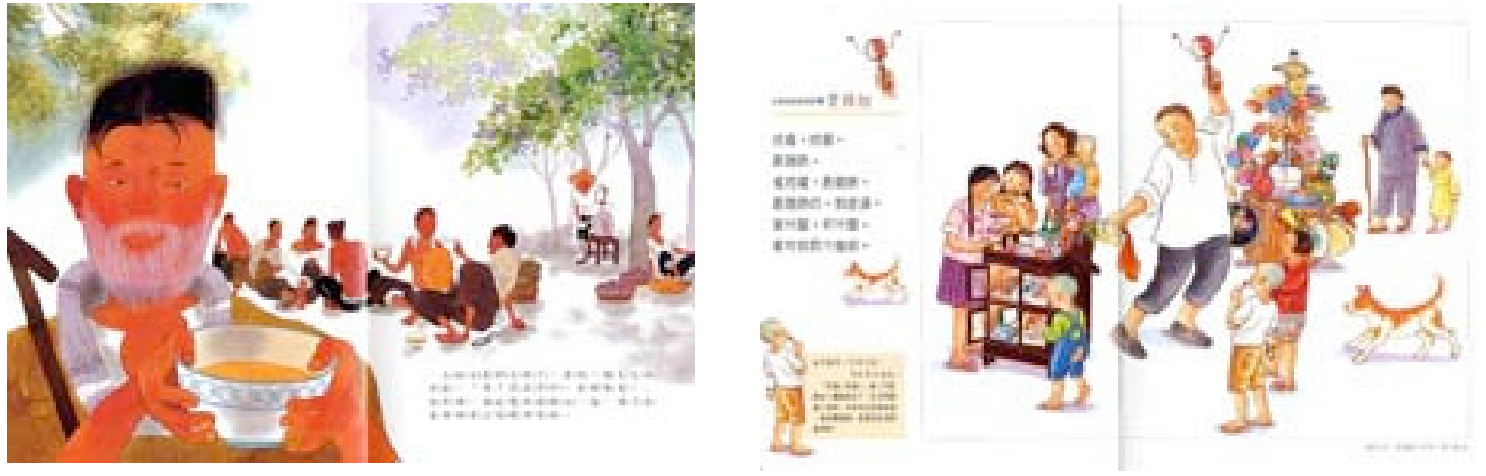

Illustration 4.41: The images of the clothing worn by men 


\section{3. the styles of architecture presented in the picturebooks imply meanings.}

There are three different styles of architecture depicted in the picturebooks, which consist of the southern Chinese house, the Chinese palace, and Baroque style buildings. In the Qing dynasty, common folks lived in the southern Chinese houses named "san-heyuan" (meaning three rows of houses arranging like an upside down U), while Chinese palaces were only for emperors and noble families. "San-he-yuan" is the architecture associated with agricultural Taiwan, and it is widely used in the picturebooks telling stories placed in a rural community setting. "San-he-yuan" dwellings can be seen in the Taiwanese Folktales and other stories with realistic life experience associated with agricultural activities. On the other hand, buildings with the Baroque and traditional Chinese palace style, when shown in the picturebooks, are used to indicate particular places, such as a historical street or art museum.

Buildings with the Baroque style were built during the Japanese era and have become historical buildings. Two historical streets mentioned in two picturebooks the Mei-shu A-gong and Going Shopping on Dihua Street for Chinese New Year are famous for the Baroque style buildings on the streets. The choice to illustrate these two streets in the pictures is inevitable because they are the locations which the writers specifically mention in their stories. By showing the images of buildings with the Baroque style, a

message is conveyed that the west has influenced Taiwan since the $19^{\text {th }}$ century. And, this message is also explicitly mentioned in the Going Shopping on Dihua Street for Chinese New Year.

Buildings with the Chinese palace style in contemporary Taiwan are usually museums, auditoriums, or commemoration halls, such as the National Palace Museum, 
National Museum of History, Sun Yeh-shen Memorial Hall, and Chiang Kai-shek

Memorial Hall. The picturebook A Sparrow in the Museum is an attempt to introduce the Taiwanese senior artists and their artworks to young readers. The verbal description of the setting in this picturebook lacks clear clues about the specific location. Thus, the illustrator's selection of the setting for the story plays a crucial role in interpreting the artwork in association with its cultural context, which is suggested by the museum setting.

The artist's choice of the art museum in this picturebook implies some ideology because she places the Taiwanese senior artists and their work in the position under the name of tradition and connects it to the traditional Chinese cultural heritage. To do this, she depicts the art museum based on the National Museum of History, a traditional palace architecture with garden (see Illustration 42). The major collections held by this museum are traditional Chinese paintings, calligraphy, and crafts. Situating the artwork created by the Taiwanese senior artists in such a historical museum gives credit to its traditional value, but seems to ignore its modern spirit.
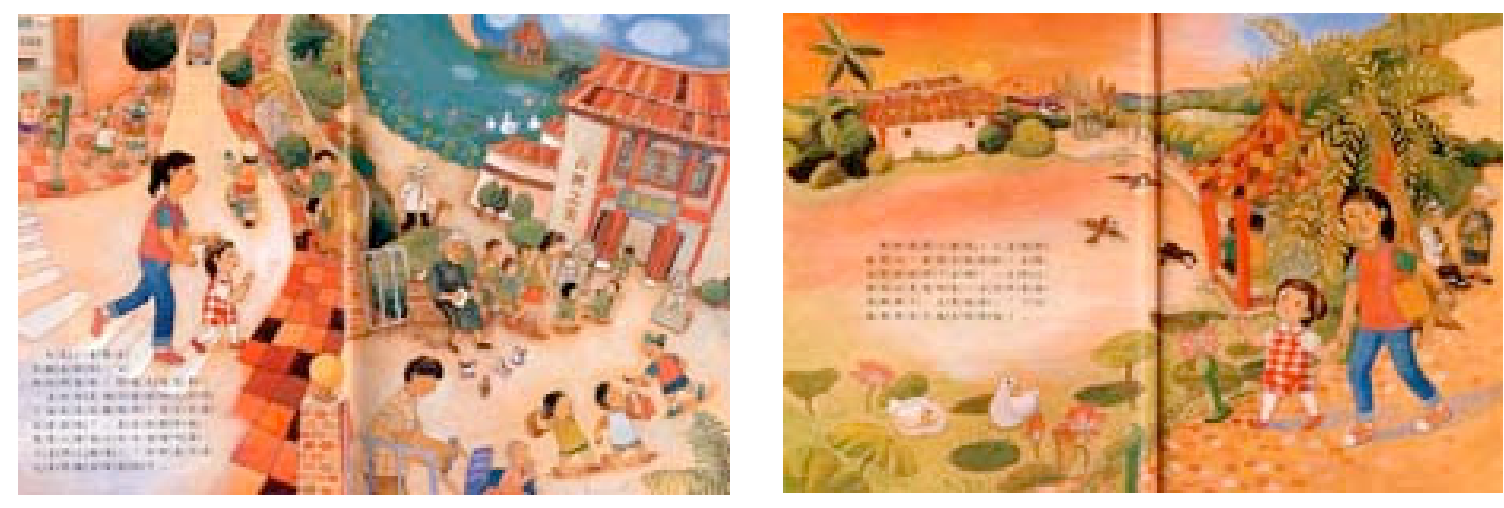

Illustration 4.42: The image of the traditional Chinese palace architecture with garden 
Most of the senior artists adopted the modernist ideas which grew from Japanese Impressionism during the Japanese colonial era. That is because modern art was first introduced to Taiwan by a Japanese officer named 石川欽一郎, who was a watercolor artist, in the Taipei Teacher School, and who had studied in England. His art students were encouraged to pursue higher education in studio art in Japan. As a result, these art students who received a degree and won the major art competitions in Japan or Taiwan became Taiwanese elites and gained their reputations in society. It was not until the Chiang Kei-shek government took over Taiwan that they lost their social status.

The title of the exhibition in the picturebook was "The Beauty of Taiwan," which had the artworks created by the Taiwanese senior artists on display. The subject matters shown in their artworks oftentimes depicted Taiwanese local folks, objects, or landscapes, which are considered representative of Taiwanese culture and art today. Moreover, most of their artworks are collected by the Taipei Fine Arts Museum. The mission of this museum is to collect Taiwan art from the modern era. In order to reveal its mission, the museum has an outlook that supports modern architecture.

In sum, the setting of the art museum in this picturebook is placed in the National Museum of History rather than the Taipei Fine Arts Museums. This visual interpretation by the illustrator provides a viewpoint showing the Taiwanese senior artists and their artworks as part of Taiwanese cultural traditions. However, it does not show the perspective of the modern spirit of the Taiwanese senior artists and their artwork. Moreover, it also shows how the visual conveys cultural clues that mediate readers' interpretations regarding the story. 
4. particular symbols presented in the pictures provides additional cultural clues related to rituals.

Funerals, weddings, and celebrations for a newborn baby are social activities shared across cultures. From the visual representation of these rituals in the picturebooks readers' attention is drawn to the clothing, artifacts, human gestures, environment, and perspective associated with them. For example, the pictures in the two picturebooks $Y i$ Gong-gong and A River Resembling a Mother show two different traditional funerals, including those of the Beinan tribe and Han group. The illustrations in the picturebook $Y i$ Gong-gong tends to create a sense of nature from an aboriginal perspective and present some cultural characteristics through the use of simplified figures like sculptures. The main focus of the funeral is on the dead wearing colorful clothing and a floral hoop with a peaceful face. The picture implies his spirit joining the forefathers' spirit (see Illustration 43). In contrast, the funeral portrayed in the A River Resembling a Mother suggests that the dead was apart from her family because she was already placed in a coffin and carried on the way to a cemetery. The long shot of the picture separates readers from the funeral group and the dominating skyline shown in the picture makes humans look insignificantly small, which implies an unattached feeling (see Illustration 44). 


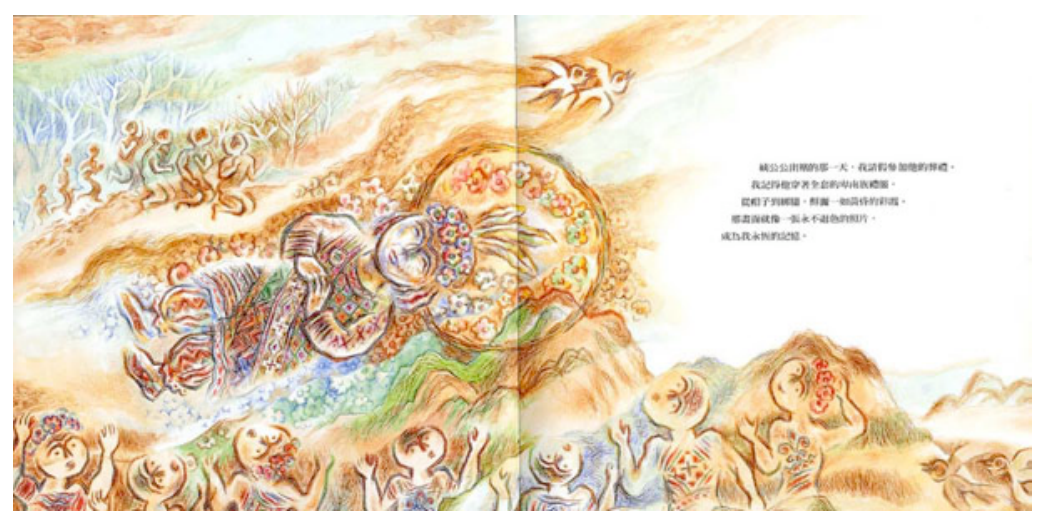

Illustration 4.43: The images of the funeral in the Yi Gong-gong

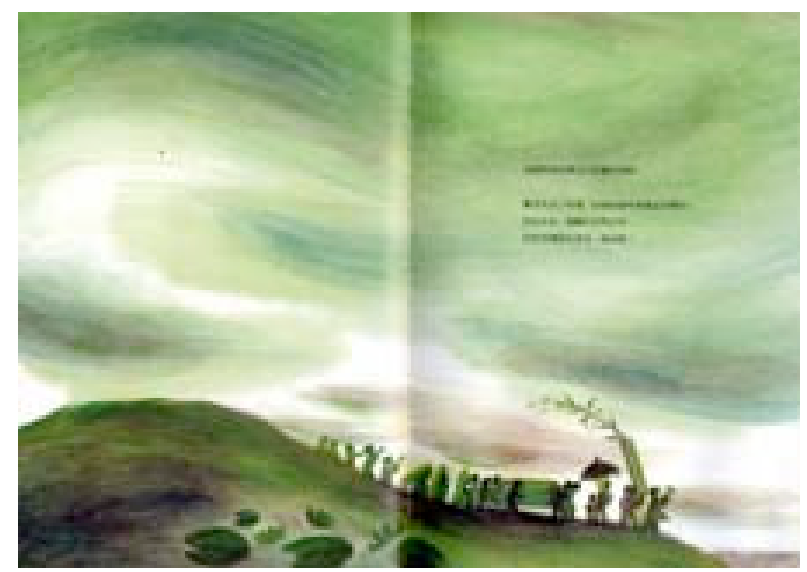

Illustration 4.44: The image of the funeral in the A River Resembling a Mother

Weddings and celebrations for a newborn baby are two major rituals associated with happiness in one's life. In order to gain good luck, certain customs need to be followed. In the picturebook Da-tou Has a Son, one picture shows a special Taiwanese custom (see Illustration 45); A little boy holds a plate with two tangerines and carries them to welcome the bride as soon as she gets out of the car. The bride needs to give the little boy a luck envelope with money inside. According to the author's note, the word 
"tangerine" in both Mandarin and Min-na Hua means "willingness" and "sweetness" due to the similarity of the pronunciation (G2-04). In other words, this custom symbolizes that the new couple has made their commitment to their marriage and will have a close relationship as sweet as the two tangerines. Meanwhile, a woman holds a black umbrella to block the sky from the bride and guides her to walk into the house. Traditionally, a bride is considered as the most important person on her wedding day and the heaven ruler is the most powerful one in the sky. Because it is a taboo for the bride to compete with the heaven ruler, she needs to avoid violating him by not exposing herself under the sky. The symbolic meanings associated with this picture are not explained in words. The visual expresses the traditional customs beyond the verbal narrative.

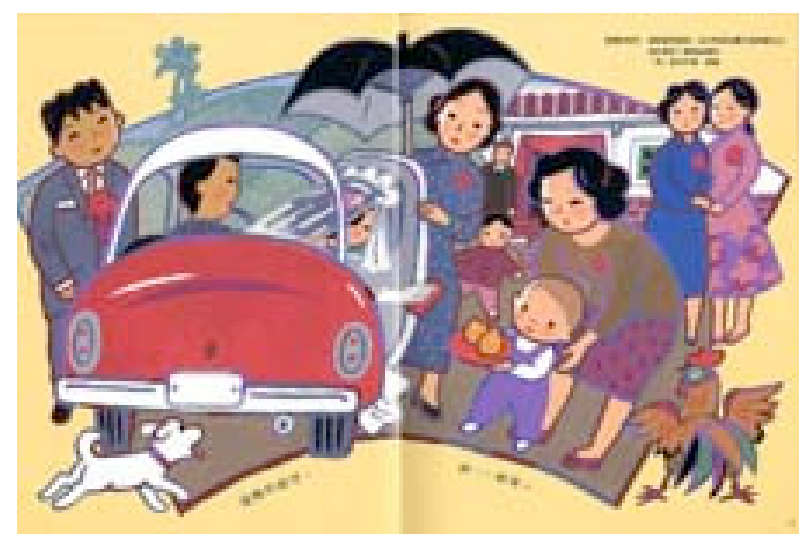

Illustration 4.45: The image of the wedding in the Da-tou Has a Son

In the picturebook Li Tain-luo, one double-spread page depicts a celebration for a newborn baby (see Illustration 46). According to the traditional Hakka custom, mentioned in the story, as soon as a newborn baby turns one month old, his or her mother prepares a pot of water with green onions, small rocks, coins, and eggs and then gives the 216 
baby a first hair cut. The symbolic meanings associated with the objects include being smart (green onion), being safe (small rocks), and having good fortune (coins). Another custom is to pray to the stone goddess for the baby to grow up safely. Although these messages are carried by both the text and pictures, the visual provides additional information about the clothing the little boy wears. For example, the hat and the necklace are special decorations for a newborn baby.

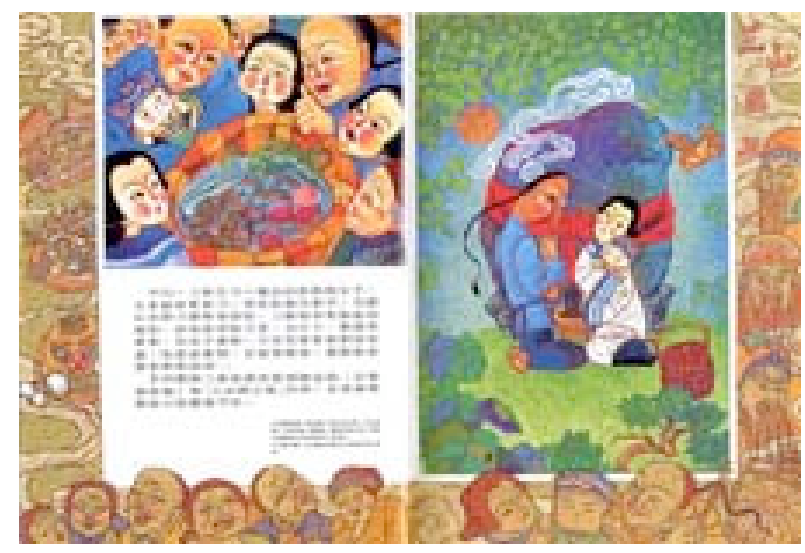

Illustration 4.46: The image of the celebration for the newborn baby in the Li Tain-luo

In sum, this section examines the additional cultural clues in the picturebooks conveyed by the visual through a discussion of the articles of daily use, costumes, architecture, and rituals. These visual elements help the stories to clarify the setting, indicate the ethnicity of the characters, and to convey symbolic meanings associated with the rituals or customs mentioned in the picturebooks. 


\section{Summary}

This chapter provides a descriptive and interpretative data analysis of the picturebooks. It aims to examine the objectives and strategies of the picturebooks and the implied verbal and visual narrative patterns shown in them. Thus, two publishing models regarding children's picturebooks and thirty narrative patterns based on setting, characterization, theme, plot, point of view, and style were found. Moreover, the illustrations showing cultural clues, such as the article of daily use, customs, architecture, and rituals, were analyzed. 


\section{CHAPTER 5}

\section{DISCUSSION}

\section{Overview of the Discussion}

This chapter will discuss and critique the ideologies associated with the objectives and marketing strategies in the three sets of Taiwanese picturebooks as well as the cultural representations shown in the stories presented in them. In this study, the work of these picturebooks as a whole is read as a negotiation with the pressures of globalization and the cultural scope of its critique is based on a post-colonial perspective, mainly the ideas of Bhabha's “cultural hybridity” and Fanon's "national culture.” The cultural context reviewed in this study, including the current indigenization movement in Taiwan and its relationship to the development of Taiwanese consciousness, exemplifies the major cultural issues commonly discussed in Taiwan within this era of globalization. They deal with the definition of Taiwanese identity and its implications and applications for society, including ideas such as a resistance to the hegemony of "Sino-centralism," strategies of "deChineseness" and "reTaiwaneseness," and the promotion of cultural diversity. When situating the three sets of picturebooks, published during 2001 2004, in the discourse of "Taiwanese identity," the cultural representations in these picturebooks reveal certain cultural concerns and beliefs for a reconstruction of Taiwanese culture 
promoted by the editors. ${ }^{65}$ These concerns and beliefs suggest the strategies for providing Taiwanization. What they include or exclude and how these concepts complement or contradict each other are the focus of this critique. Moreover, suggestions for publication and education are provided.

An Interpretative Critique of the Cultural Representations in the Picturebooks The objectives of the three sets of Taiwanese picturebooks are to emphasize the significance of cultural transmission and to recall collective memories of Taiwanese culture in order to establish the concept of "Taiwaneseness," which refers to a Taiwanese identity (Chiu, 2003a). To do this, strategies are used to convey the idea of Taiwanese culture that include subject matter focusing on folktales and myths, local cultural practices, cultural elites, and personal narratives about Taiwan within a particular period of time in the past. As a result, these objectives and strategies heavily influence the cultural representations of Taiwan shown in the picturebooks. This concept can be shown as a model, in accordance with Barthes' idea of two orders of signification (see figure $5.1)$.

In this figure, the first order is denotation, including the three labels of the picturebooks (D.1) and their signified meanings (D.2): the Taiwanese Folktales associated with Traditional Han folktales, the Taiwanese Children's Picturebook Selection associated with folkways, art, and the environment, and the Taiwanese Teenagers associated with childhood memories from the 1950s 1970s. At this level, readers gain a literary understanding of the stories presented in the picturebooks. The

\footnotetext{
${ }^{65}$ The reason that this study focuses on the editors' intention is because they are the key persons in controlling the publishing channel in terms of creating a specific group label for picturebooks, namely
} 
second level is connotation, consisting of a signifier (the combination of D.1 and D.2) and an additional signified where ideology is involved (Taiwaneseness and Taiwanese identity.) Thus, the work of Taiwanese picturebooks, the real sign in this case, read as a negotiation with the pressure of globalization reveals and reflects the ideology of localization.

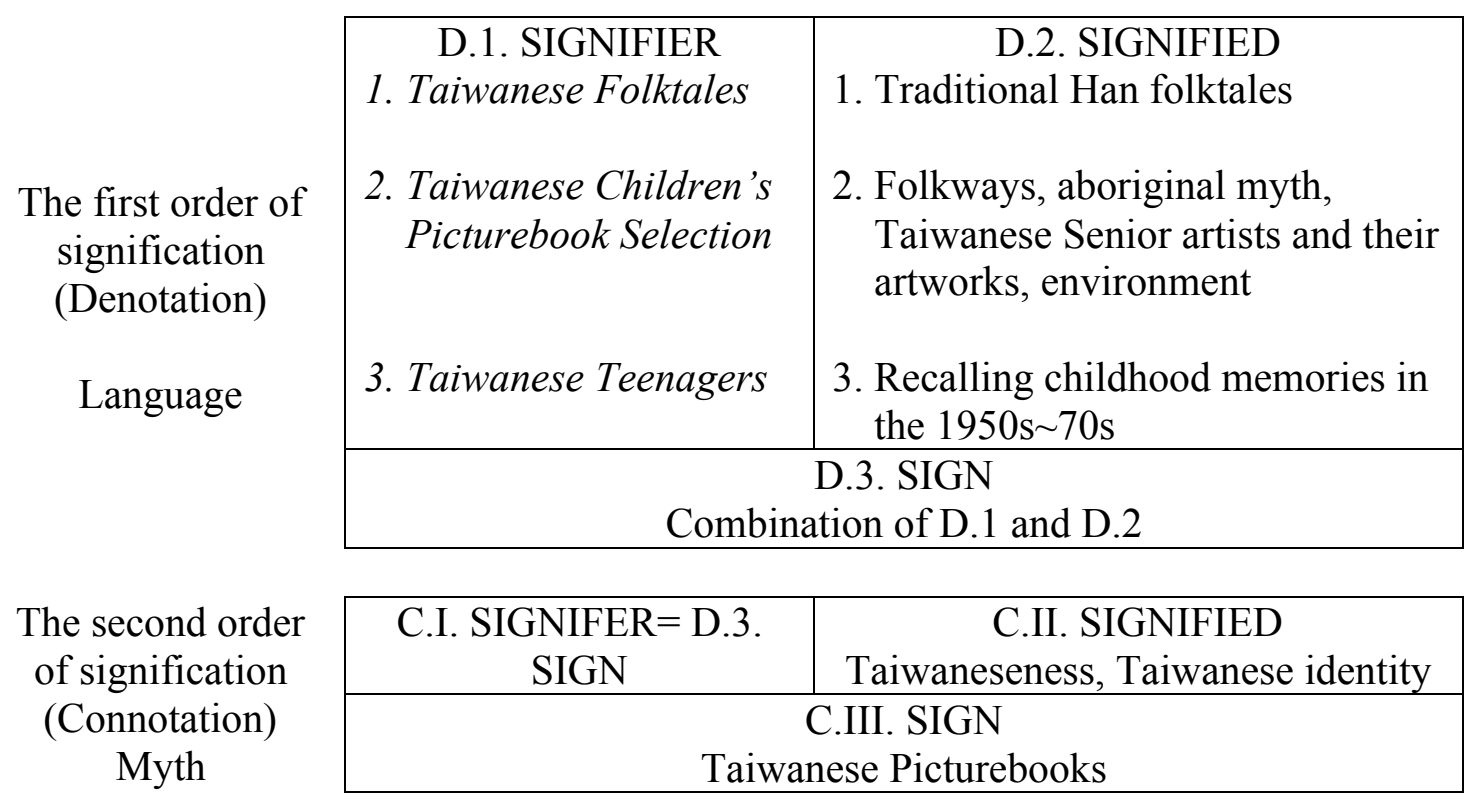

Figure 5.1: The myth of Taiwanese identity (adopted based on Barthes' notion)

Approaches to Culture from the Perspectives of Bhabha and Fanon

It is significant that this interpretative critique is based on a post-colonial perspective in which Bhabha and Fanon contribute to my understanding of culture formation. According to Bhabha (1994), there are two ways of culture formations. One is to emphasize and retain pre-given cultural forms. In other words, a pure and authentic 
culture is accepted. For example, a grand narrative that Taiwan is the successor to a fivethousand-year Chinese traditional heritage was installed into Taiwan during the Chiang Kei-shek era and this orthodox Chinese culture was emphasized as anthentic based on Confucianism, without being disturbed by Marx's Communism. This Chinese cultural renaissance movement was an attempt to free Taiwan from Japanese cultural influence and to distinguish the difference between Chinese culture in Taiwan and Mainland China. Moreover, Bhabha remarks that the concept of cultural diversity based on multiculturalism is to retain individual cultures rather than to emphasize the mix of cultures. Thus, minorities are encouraged to preserve their own cultures. This aspect of retaining a previously established culture can be seen in the Taiwanese indigenous cultural renaissance movement of the 1980s, which reflected the demand for cultural diversity in Taiwan's society. This concept has gradually grown and been emphasized in contemporary Taiwan.

In contrast, the other method of cultural formation is one that refuses the ideas of cultural purity and the envelopment of culture. Rather, it believes that culture is dynamic and hybrid; it is located in the site of struggles with conflicts and changes, which Bhabha calls the "Third Space." In this space, cultural difference is a negotiated and an on-going process, which shows ambivalence and is always "in-between" different cultures. This type of cultural formation is a major concept in Bhabha's idea of "cultural hybridity." An example of this hybridity can be seen in the transformation of traditional Chinese painting during the 1960s by young artists who adopts western modern art theories. 
Unlike Bhabha's belief in cultural hybridity, Fanon tends to promote the idea of cultural purity as a means to reconstruct local cultural practices in colonies in order to provoke cultural awareness of the colonized. Moreover, Fanon (1997) asserts the significance of local cultures and the local intellectuals in constructing national literature in order to promote a national culture within a new nation. According to Fanon (1997), there are three phases of the evolution of national literature within a post-colonial society. In the first phrase, writers have been influenced by the colonial power and their work reflects this influence. In the second phrase, writers intend to look into their native cultures and depict local cultural practices in their work. Finally, in the third phase, their work tends to move against the colonial power and produce "a fighting literature, a revolutionary literature, and a national literature" in order to awaken people (p. 12).

Bhabha and Fanon have opposite positions when considering cultural formation. Their positions provide the researcher with different views for considering similar cultural issues. However, I personally agree with Bhabha's position more than that of Fanon because when thinking about current cultural formation in Taiwan, Bhabha's "cultural hybridity" theory is more suitable for explaining the complicated cultural and political situation in Taiwan.

\section{A Critique through the Post-Colonial Lens}

According to the analysis of the narrative patterns and cultural clues discussed in chapter four, the cultural representations in the picturebooks, taken together, construct an interpretation of what Taiwanese culture is, and this tends to promote a romantic view of an agricultural Taiwan. This choice mainly falls into Bhabha's idea of the first type of cultural formation, placing an emphasis on cultural purity. Moreover, this choice reflects 
the second phase of the evolution of national literature, according to Fanon. However, a few of the picturebooks suggest an alternative way of thinking about Taiwanese culture through Bhabha's "cultural hybridity." This indicates that the hybrid cultural aspect of Taiwan can not be ignored. In order to analyze the statements above more in-depth, a discussion of the myth embedded in the cultural representations in the picturebooks is necessary and three concepts need to be considered, including space, time, and ethnicity. To be more specific, the cultural representations are based on three major principles: first, the settings of the stories should occur in Taiwan; second, the stories show time periods from early Taiwan up to the present; and third, the stories can represent local cultures or life experiences from diverse ethnic groups. These will be elaborated in the following sections, respectively.

\section{Regarding Space}

The three principles outline the common notions embedded in the current native cultural education in Taiwan. The objective of this native cultural education is to cultivate in students a cultural consciousness rooted in the land where they live. It emphasizes that Taiwanese are permanent residents of this island rather than passing travelers who seek opportunities to return to Mainland China when it is restored to the government of the Republic of China, a goal embedded in the political ideology of the Chiang Kei-shek era. This political ideology had shaped the notion that China is the center while Taiwan is marginal. An effect of globalization has been to elevate the position of the local and make it more visible. Global and post-colonialism approaches have deconstructed the binary “Center/Margin” concept of imperialism (Ashcroft, Griffiths and Tiffin, 1995), and reinforced a new emerging idea of positioning Taiwan in the center of the world. The 
native cultural education movement is a result of this trend and it breaks up the myth of Mainland China as the homeland for Chinese in Taiwan. Thus, situating the stories within Taiwan itself, rather than China, is an essential ingredient in promoting the Taiwanese culture used in the picturebooks. To do this, four strategies are identified and discussed: (1) the term "Taiwan," used for naming the group labels of the picturebooks, shows a geographical identity; (2) the imagery of an agricultural Taiwan implies the purity of Taiwanese culture; (3) the concept of cultural diversity is presented through sharing various life experiences from different regions of Taiwan; and (4) telling stories that use the natural environment contributes to identity construction.

\section{Naming the Group Labels for the Picturebook Suggests a Geographical Identity}

Although the stories rarely mention the place where the events depicted in the plots occur, the group labels of the picturebooks, such as the Taiwanese Folktales, Taiwanese Children's Picturebook Selection, and Taiwanese Teenagers, suggest that readers should place their attention on Taiwan. When competing with picturebooks translated from other counties, which dominate Taiwan's book market, the label "Taiwan" refers to "local culture," while the translated picturebooks, with or without any group labels, are considered as "foreign culture." In order to emphasize the uniqueness of Taiwanese culture and its difference from other countries, an emphasis on its history, traditions, and natural environment is attached to the group label of "Taiwanese" picturebooks. The marketing strategy associated with this usage can be considered an invention of a tradition in response to global culture (Robertson, 2002). That is, using a modern picturebook format documents, preserves, and conveys tales about Taiwanese local cultures. 


\section{An Imagery of an Agricultural Taiwan Implies the Purity of Taiwanese Culture}

The settings in the picturebooks implicitly or explicitly deliver the messages of locations regarding the stories. A few of them indicate specific locations or regions in Taiwan, while most of them depict a general rural or suburban community setting. These settings visually show an ideal landscape differing from the suburban or urban environment in today's Taiwan, which is extremely modernized. It is significant that none of the picturebooks depict contemporary buildings in the pictures, even in the stories depicting present daily life experiences. Instead, the images of the traditional southern Chinese house style and open fields are often shown in the pictures to represent a traditional view of Taiwanese culture. Moreover, in the Taiwanese Teenagers, additional cultural information about the location shown in the story is designed to accompany each picturebook. The information helps readers understand some important cultural conventions practiced in a particular location. These strategies are selected to emphasize Taiwanese culture through the significance of Taiwanese traditions, which implies its purity.

\section{The Concept of Cultural Diversity is Presented through Sharing Various Life} Experiences from Different Regions of Taiwan

Taiwan's literature, based on a Taiwanese consciousness, emphasizes that the content of this literature should be rooted in the life experiences embedded in this land (Chiu, 2003). This suggests that Taiwanese consciousness is not limited to the binary thinking of "China versus Taiwan" or the political view of "nation versus native land." Rather, it should include diverse life experiences from all walks of life in this land. This indicates that the acceptance of cultural diversity in Taiwan is crucial. Many literary 
movements have grown in Taiwan since the 1980s, including those of indigenous literature, women's literature, gay and lesbian literature, senior military veterans' literature, and environmental literature. This literature covers different issues regarding ethnicity, gender, class, sexual orientation, and environment, as they relate to Taiwan. However, these themes are rarely covered in the Taiwanese children's picturebooks because the picturebook is oftentimes associated with young children. Common themes in picturebooks for young children are usually related to self development with regard to both physical and emotional aspects. This may be due to marketing demand but it also limits the choice of themes in children's picturebooks. For example, the realistic stories depicted in the Taiwanese Children's Picturebook Selection and Taiwanese Teenagers tend to focus on the relationships among family members and the community they live in. The implied readers of these stories are parents and their children, according to the web promotions for the picturebooks. For this reason, cultural heritage and the transmission of culture from one generation to the next is a common theme portrayed in the picturebooks that appeal to parents. Despite the intention of this choice, life experiences told from different regions of Taiwan are emphasized in the picturebooks, which demonstrate a sense of cultural diversity.

\section{Although Natural Environment Contributes to Identity Construction, It was less}

\section{Emphasized in the Picturebooks}

Besides cultural environment, natural environment is an important component in shaping local cultures. It is however noteworthy that Taiwan's natural environment is less frequently mentioned in the picturebooks. Only one story Little White and Little Grey in the Taiwanese Children's Picturebook Selection introduces Taiwanese typical animal 
creatures and addresses the environmental issue in the countryside. In the story, the narrative describes the special habits of two different types of egrets, which inform the readers about the natural environment in which these birds live. In addition, the two egrets decided to leave their original home for a better living environment, which implies the resistance of natural creature to the human-made pollution.

Since themes related to natural creatures and the environment are oftentimes introduced in a non-fiction format, this particular picturebook tends to point out a pollution problem due to the overuse of machines for farming through the conversations between the two egrets. This indicates a contrast between traditions (the use of farming cattle) versus modern (the utilization of technology). And, the story also implies that human beings should respect animal rights and live with them in a harmonious state. In sum, dealing with an environment issue through the eyes of natural creatures is one of the ideas regarding environment literature. And, this subject matter is a possible direction for future picturebook publication.

\section{Regarding Time}

Time line in the story and the meaning of retelling the past in a contemporary time period are two major aspects when considering the time element in the picturebooks. The time lines depicted in the picturebooks reveals several different time periods, including the era of aboriginal myths, the early era of Han Chinese immigrants, the life experiences during the $1950 \mathrm{~s} \sim 70 \mathrm{~s}$, and also recent life experiences. However, the Japanese colonial era is excluded from this time line, which implies the idea of cultural 
purity ${ }^{66}$ rather than cultural hybridity. This statement will be elaborated based on evidence from: (1) a continuity of Taiwan's history from aboriginal myths and Han Chinese folktales, (2) an exclusion of the Japanese colonial era from this continuity, and (3) a supplementation of the missing history by recalling memories during the1950s 1970s.

The concept of retelling the past in a contemporary time period raises, at least, two questions. One is how to present the past in order to interest readers and the other is what to present and how to present it in the story. To be more specific, the first question focuses on the visual representation in the picturebooks, while the second question deals with the values embedded in the stories. Moreover, the concepts of cultural hybridity and purity are shown in the presentations. In addition, other elements are involved including: (4) the adopting of a contemporary visual language in presenting local culture for attracting today's young readers shows a type of hybrid culture, (5) the use of a nostalgic approach to Taiwanese traditions reinforces a positive light on the past, and (6) the use of gender stereotypes portrayed in the folktales sometimes contradicts current values. As a result, the discussion of this section follows the order mentioned above.

\footnotetext{
${ }^{66}$ Although I have spent most of my time doing research in the United States since I started this project, I visited Taiwan twice during the winter breaks of 2003 and 2004. During these two visits, I interviewed various senior experts in the field, such as Cheng Ming-jin, Taso Jun-yan, Cao Kuo-chong, and Gao MingMei in 2003, and the publisher and editors of the picturebooks, such as Lin Husn-min, Lin Chu-chi, and Lain Tsuey-moh in 2004. They hold different ideas about what Taiwanese culture is. To some extent, several of them, like Cheng Ming-jin, Taso Jun-yan, and Lin Husn-min, emphasize Taiwanese culture in a pure form. In other words, this representative Taiwanese culture had existed during the 1940s $\sim 1950$ s, when
} 
1. A Continuity of Taiwan's History from Aboriginal Myths and Han Chinese Folktales is Implicitly Shown in the Picturebooks

The subject matters depicted in the picturebooks imply a continuity of Taiwan's history from aboriginal myths and Han Chinese folktales to the present. In the Kuomintang's era, the position of Taiwan was placed within a five-thousand-year Chinese history. Based on this perspective, Taiwan's history is part of this grand Chinese narrative. However, from the view of Han immigrant history, Taiwan's history can be dated back to the Ming dynasty (the $17^{\text {th }}$ century). In contrast, based on a Taiwanese aboriginal view, Taiwan's history is far longer than the past three hundred years. When placing Taiwan's history on a global scale, it can be traced back to the Dutch colonial era in the $16^{\text {th }}$ century. These different viewpoints demonstrate the complexity of defining the beginning of Taiwan's history. This debate affects one's perception of what Taiwan's literature should include and when it starts.

Tuobas Tamapima, an indigenous writer (Bunong tribe), asserts that Taiwan's literature already existed before the Han Chinese immigrants came to Taiwan three hundred years ago, but it was spread in an oral form, including indigenous oral myths and tales (as cited in Walisi Nogang, 2000). His argument tends to break up the ideology of Han-centrism. And, it also moves the position of Taiwanese aborigines from margin to center. In this sense, Taiwan's literature, at least, should contain oral literature by Taiwanese aborigines as well as Han Chinese. By withdrawing from the grand narrative of Taiwan having a five-thousand-year Chinese traditional heritage, the three sets of picturebooks reveal the Taiwanese cultural traditions going back to aboriginal myths and 
Han Chinese folktales of the Qing dynasty. Thus, six Taiwanese folktales and one aboriginal myth are included on the book list. This indicates that Taiwan's history should place a focus on Han Chinese immigrants and Taiwanese aborigines.

\section{An Exclusion of the Japanese Colonial Era from the Continuity is Noticeable}

It is obvious that stories regarding the Japanese colonial era are excluded in the

picturebooks. Only two stories out of twenty-two picturebooks mention events occurring during this period. For example, in the picturebook Meei-Shu A-gong (a tale of the Taiwanese senior artist Li Mei-shu), the artist recalled his memory of going to Japan for study, but the writer does not mention when the event happened. In the picturebook $Y i$ Gong-gong (a tale of an aboriginal leader), the writer describes his granduncle's contributions to their tribe during the Japanese colonial era. In this story, the term "the Japanese colonial era" is mentioned for indicating the particular time period. The exclusion of the Japanese colonial era from the picturebooks implies that the origin of a Taiwanese culture is being presented through the idea of pureness. That is, Han Chinese culture and aboriginal cultures are presented by their recognizable cultural characteristics without being influenced by other foreign cultures. To do this, the stereotypical cultural elements have remained and this notion will be elaborated later.

\section{A Supplementation of the Missing History by Recalling Memories during the} 1950s 1970s is a Means to Reinforce a Pure Form of Traditional Taiwanese Culture

Telling personal life experiences during the 1950s 1970s or introducing traditional local cultural practices having been practiced since Han Chinese immigrated into this island are popular themes shown in ten out of twenty-two picturebooks. Both the

practice. 
individual life experiences and local cultural practices contribute to the construction of a collective imagery of the particular period. While the Chiang Kei-shek government was ruling Taiwan, the orthodox Chinese culture was installed. In order to be rid of the Japanese influence, Mandarin became the official language, while local dialects and local cultural practices were forbidden and considered inferior. The political intention of these policies was to strengthen "Chineseness," and transform Japanized Taiwanese to Chinese. It was not until martial law was abolished in 1987 that people had freedom of speech. In addition, accompanying the political and social movements of fighting for national identity since the 1980s, "de-Chineseness" and "re-Taiwaneseness" have become important ideals associated with political and cultural policy (Hsiao, 2002). Meanwhile, this indigenization movement serves to resist the hegemony of Mainland China. As a result, reconstructing and restoring memories of the past, which have not always been honestly told, is extremely important.

However, Taiwan had lost its local cultural heritage in the Kuomintang monocracy period. Thus, to supplement the missing history by valuing local cultural practices and collecting oral history is a means to reestablish and reinforce Taiwanese local cultures. The concept of this action is an attempt to create and retain a pure form of traditional Taiwanese culture. Moreover, literature advocating this approach falls into the second phase of the evolution of national literature within a post-colonial culture, according to Fanon (1997). The characteristics of these literary works are firmly attached to tradition. The examples shown in the picturebooks include the personal narratives of childhood memories during the 1950s 1970s in the Taiwanese Teenagers, introductions to Taiwanese senior artists in the Mei-shu A-gong and A Sparrow in the Museum, and 
local cultural practices mentioned in My Father is Going to a Festival Competition and Free Tea for Everyone.

Although the intention of this strategy emphasizes the idea of cultural purity, the way of expression is an example of hybrid culture. That is, these stories are written in the Mandarin language which was enforced in the public school system during the Chiang Kei-shek era and now is widely used in Taiwan. The use of Mandarin has heavily influenced Taiwanese culture. By the same token, the Taiwanese also have changed the usage of Mandarin by adding a local flavor, such as Mandarin with a Taiwanese accent and local cultural expressions, which is in keeping with Bhabha's idea of cultural hybridity (1994). For example, the writer of the picturebook Selling Brooms with My Grandmother mixes Mandarin and Min-na Hua (a local dialect) in the story when giving different expressions from her grandmother's point of view (Min-na Hua) and her own perspective (Mandarin). This writing strategy can be seen as not only a form of hybrid culture, but also an element of post-colonial work. That is, it demonstrates a resistance to the hegemony of Mainland China, which emphasizes the "Sino-centrism" (Chu, 2003), while embracing a Chinese of difference in Taiwan.

4. Adopting a Contemporary Visual Language in Presenting Local Culture for Attracting Today's Young Readers is Widely Used and Shows a Type of Hybrid Culture

A form of cultural hybridity is also shown in the use of style and book design in the picturebooks. This is predictable because the concept of modern children's literature has been introduced to Taiwan only since the 1960s (Hong, 2004). Visually, in order to provide a contemporary interpretation of the traditional folktales and aboriginal myths, the artistic choices of the styles used most often are simplified representational art and 
comic art styles. These are the most popular and familiar elements of today's visual language. This strategy is designed to attract young readers. In contrast, folk art is less frequently used in the picturebooks. Only one of seven picturebooks in this category adopts a folk art style of shadow puppetry. This mix of the verbal text based on a traditional approach and illustrations adopting a modern look demonstrate a case of cultural hybridity, which is a feature of the Taiwanese picturebooks. However, this feature has been criticized by picturebook critics. According to Cheng Ming-jin, for example, recent Taiwanese children's picturebooks lack a unique characteristic representing the culture. Due to a perceived lack of native culture for the past five decades, the styles of the pictures look like either westernized or Japanized (personal communication, December 17, 2003).

When reviewing Taiwan's history from the political perspective, different powers have ruled this land and installed the desired cultures based on the political privileged group's view. As a result, local cultures were frequently repressed. It is inevitable that assimilation has occurred and hybrid cultures have evolved. Besides this, foreign cultures have continually been introduced to Taiwan, especially those from the United States, Japan, and European areas, and have strongly influenced Taiwanese illustrators and readers. All these cultural interactions contribute to create a new Taiwanese culture based on the presumption that culture changes over time and is never static. Therefore, to expect that a unified representative Taiwanese style will emerge seems impossible because there was no such style in the past and it would be hard to generate one now. Instead, a collective of diverse Taiwanese styles appearing in picturebooks is observable. However, various traditions are a major part of Taiwanese culture and these are examined 
and redefined within an on-going process. To be aware of the social construction of these traditions is to raise an understanding of one's native culture. And, this understanding may help to clarify one's cultural identity and tolerate or embrace cultural difference.

\section{A Nostalgic Approach to Taiwanese Traditions Reinforces a Positive Light on the Past}

The traditions shown in the picturebooks are based on the notion of an agricultural Taiwan which represents a positive cultural icon. Industriousness, thoughtfulness, friendliness, and human sympathy are values oftentimes associated with the agricultural society shown in the picturebooks. These values are precious in the eyes of those writers who grew up in the 1950s 1960s. When compared with the industrialized Taiwan today, these values become the most memorable traits of this time period. This idea is also shown in "hsiang-t'u" literature, promoted in the native cultural movement during the 1970s. This genre of literary work tends to reflect social realism (Chen, 1991). Unlike the stories in the picturebooks, which present the healthy and bright side of society during the time period, most of the "hsian-t'u" literary works explore the conflicts between different values of traditional and industrial society (Chen, 1991). In other words, they show a competition between tradition versus modernization. Thus, the problems of cultural change from an agricultural society to an industrial one is emphasized in "hsiang-t'u" literature. In response to modernization in the 1970s, cultural revival movements have grown. One of the major functions of these movements was to preserve traditional customs.

As Taiwan has become more and more internationalized, the desire for traditional cultural preservation has grown. This intention is obviously shown in the three sets of picturebooks. For this reason, a nostalgic approach to Taiwanese traditions is adopted in 
telling the stories and promoting the picturebooks. For example, the writers in the Taiwanese Teenagers recall their unforgettable childhood memories from a romantic point of view. Moreover, the web promotion for the Taiwanese Folktales, by Yuan-Liou Publishing, emphasizes that parents should not forget the traditional folktales they heard from their elders and it is time for the parents to pass down these stories to their children. These stories and the marketing strategy reinforce the idea of good old days. Although Bhabha (1994) emphasizes that cultural formation is ambivalent and is changing within a continuity of conflicts, it is obvious that cultural conflicts and ambivalence are excluded or avoided from the positive representation of the past in the picturebooks.

\section{Gender Stereotypes Portrayed in the Folktales Sometimes Contradict the Current}

\section{Values}

An emphasis on cultural purity is embedded in traditional local cultures, as mentioned above. To do this, the use of recognizable cultural characteristics is a strategy that can be seen in the Taiwanese Folktales, which tells the traditional folktales based on their original versions. In these tales, the male roles are portrayed as more active, while the female is more passive. These roles were authentic in the past but may be controversial in today's society. The stereotypes of gender roles have been criticized since the women's rights movement in Taiwan promoted equal rights between men and women in the 1980s. The notion of equal rights has become one of the major issues in the current school curricula, according to the recent curriculum standards regulated by the Ministry of Education. This raises the issue of whether these traditional folktales maintain cultural heritage or perpetuate stereotypes, which may involve value conflicts between the traditional and the modern. 
The debate of tradition versus modern is a controversy that has been addressed by the intellectuals in Taiwan, such as during the art debates of the 1950s and 1990s. In the first debate, the notion of adopting western theories to reform Chinese traditional painting was strongly supported by the young artists, whereas the conservative older artists tended to be attached to the traditional ways (Lin, 1987). The art debate in the 1990s generated an inquiry into what Taiwanese identity is when foreign art theories and practices have occupied Taiwan's art world (Ni, 1994). The first debate shows that cultural adoption is used as a means to reform the old culture, while the second debate argues that a lack of identity is due to cultural adoption. These debates indicate the fact that Taiwan has been heavily influenced by western theories and has struggled with a search for its own identity.

When considering the intertwined relationship between cultural adoption and Taiwanese identity, the reason for retelling the traditional Taiwanese folktales in contemporary society is complicated. That is, these folktales are promoted based on their value as cultural heritage which has been passed down from generation to generation. Moreover, they create a collective imagery about the past with which most Taiwanese may agree based on the origin of the tales. For example, the Taiwanese whose ancestors are Han Chinese immigrants coming to Taiwan during the Qing dynasty can identify with the Han Chinese folktales. However, the embedded values associated with the stories may not apply to contemporary Taiwan based on the western concepts of human rights. This contradiction, according to Bhabha's idea (1994), is inevitable and should not be considered negative. Rather, it encourages negotiation among different cultures. In this sense, the introduction of the traditional values embedded in the traditional folktales into 
contemporary society can be read as a resistance to foreign cultural influences. By the same token, it can be read as an examination to what extent Taiwanese identity has modified and reestablished over time.

\section{Regarding Ethnicity}

In this section the representation of the "Other," of writing positions, and of writers' ethnic identity, are seen as three components when considering the picturebooks as related to ethnicity. They are elaborated and include the ideas that: (1) cultural hybridity is a strategy to deal with the issue of accuracy of Taiwanese aborigines in the picturebook, (2) aboriginal writers situate aborigines in the center of their stories and provide a general aboriginal cultural perspective, (3) demonstrating cultural hybridity in the story reflects current Taiwanese life experiences with a western cultural flavor; and (4) a new emerging ethnic group challenges the representation of Taiwanese culture in the picturebooks.

\section{Cultural Hybridity is a Strategy to Deal with the Issue of Accuracy of the Representation of Taiwanese Aborigines in the Picturebooks}

It is crucial to promote the idea of cultural pluralism in this era of globalization. To achieve this goal, the visibility of minorities in children's book publication is an important issue. This can be seen in the politics of cultural representation in the Taiwanese picturebooks, including who is writing about whom for what purpose, who has more privileges to be represented in the picturebooks, who is underrepresented, who is the subject of the writing, and the like, which are some essential questions of postcolonial criticism (Tyson, 1999). Despite the political ideology of "deChineseness" mentioned above, marketing and social resources are major factors manipulating the 
cultural representations shown in the picturebooks since these picturebooks are produced for sale under the title "Taiwanese culture." It is inevitable that Han Chinese ideas dominate the picturebooks because it is the major population and holds most of the social resources in society. For example, more Han Chinese writers and illustrators are available to the publishing houses and the majority of readers and consumers are also Han Chinese.

Oral storytelling is part of a tradition in aboriginal cultures and aboriginal myths or tales have been collected by Japanese and Chinese researchers. Meanwhile, aborigines and their cultures have been documented and written about by non-aborigines. As a result, aborigines in literature were generally presented as the "Other," according to Chen (as cited in Sun, 2003). It was not until the mid-1980s that written aboriginal literature began to grown, as more and more aboriginal writers devoted themselves to presenting their voices (Sun, 2003). However, it is rare to find aboriginal writers and illustrators who specialize in children's picturebooks.

For those who are underrepresented groups or hold less social resources for presenting their own voices, their cultural representations in the picturebooks may be interpreted and presented by Han writers or illustrators. For example, an aboriginal myth was retold and illustrated by a Han illustrator and two aboriginal writers' childhood memories were illustrated by two Han illustrators. The editors remarked that they considered the quality of illustration for the aboriginal stories rather than the ethnic background of the illustrators and they intended to avoid possible mistakes in advance (T. Lain, personal communication, December 15, 2004 \& H. Lin, personal communication, 
December 23, 2004). They are sensitive to the accuracy of the interpretations regarding aboriginal cultures, but also believe that illustrators should have freedom to express their interpretations.

The author of the picturebook Shooting Suns had studied the information and visual references related to this myth and constructed his own interpretation based on different versions of the myth from different tribes (H. Lin, personal communication, December 23, 2004). This interpretation refers to no particular tribe, but aborigines in general, which can be seen as another aspect of hybrid culture. Therefore, it avoided being accused of inaccuracy, as it might have been, if the picturebook indicated a particular tribe in the story. Moreover, this interpretation places an emphasis on the notion of cultural transmission by showing three generations together completing an important mission for their tribe's well being. This story is presented in a positive way. The artistic choice in the pictures is a cartoon art style, which is the author's characteristic and strength. According to Bhahba's notion of cultural hybridity, there is no right or wrong answer for this artistic choice. Rather, it provides a new visual interpretation of the myth in today's Taiwan, which is in keeping with the editor's intention of providing young readers with a contemporary flavor to approach this old myth from a Han illustrator's perspective.

2. Aboriginal Writers Situate Aborigines in the Center of Their Stories and Provide a General Aboriginal Cultural Perspective

The picturebooks of the Taiwanese Teenagers were created based on the idea that every writer should write a story for children. It was unexpected that the Taiwanese Teenagers also contained two childhood memories written by aboriginal writers, 
according to the senior editor (T. Lain, personal communication, December 23, 2004). However, these two aboriginal writers consciously intended to present stories reflecting their ethnic cultures. For example, the repetitive themes related to aborigines in three picturebooks consist of hunter culture, oral storytelling, and the blessings from forefathers' spirit, which are some cultural identifications differing from Han Chinese culture. As a result, it is not surprising that the two writers, who were aware of their ethnic identity, presented the three cultural characteristics in their stories.

These three aboriginal stories were carefully developed and presented to show the uniqueness of aboriginal cultures in a romantic light. The intention of this positive representation is like that of the Han Chinese stories based on realistic life experiences. That is to reinstall their native cultures that have been missed in today's society. Since the significance of diverse voices in society has been gradually recognized, there is a demand for aboriginal writers and illustrators to present their own voices in their stories with a picturebook format. Their interpretations of their own cultural heritage and experiences are being encouraged and this provides an opportunity to establish their identity. Moreover, the themes in their stories are not necessarily limited to the stereotypical cultural characteristics.

\section{Demonstrating Cultural Hybridity in the Story Reflects Current Taiwanese Life} Experiences with a Western Cultural Flavor

Culture is a dynamic process rather than a static one, especially in a world where the nation-state boundary is rapidly vanishing. Thus, cultural hybridity is a common phenomenon shown in current life experiences. It is significant to notice that a western life style has been gradually practiced more and more in contemporary Taiwan. In order 
to retain Taiwanese traditions, children currently learn the traditional culture practiced in their grandparents' generation through school curricula, which emphasizes native cultural education. Due to this constricted definition of Taiwanese culture, contemporary life experiences that children encounter on a daily basis are rarely present in the three sets of picturebooks.

Unlike most of the picturebooks revealing traditional customs and values or life experiences in the past, the picturebook Yue-yue's Dancing Lessons conveys a modern educational concept, which is not rooted in traditional Han Chinese culture or aboriginal traditions. ${ }^{67}$ Rather, it was adopted from western culture. The use of the artistic techniques and style are also westernized and the theme of this story is more universal rather than culturally specific as well. What makes this picturebook a Taiwanese picturebook is the author's identity and the representation of a child's life experience in contemporary Taiwan. ${ }^{68}$ According to the author, the classroom in the story was a space symbolizing Taiwan, which was small but contained many possibilities, where children could explore and play with their creativity (Y. He, personal communication, July 19, 2004). This interpretation indicates the author's feeling and imagination about Taiwan. This case challenges the limited definition of Taiwanese culture in the picturebooks which only emphasizes traditions on one hand, and it elaborates the content of Taiwanese picturebooks as a means of showing current life experiences on the other hand.

\footnotetext{
${ }^{67}$ This picturebook was not on the book list in the original proposal for the Taiwanese Children's Picturebook Selection. It was a manuscript submitted by the author when Children's Publications was working on the publishing process for ten picturebooks (Y. He, personal communication, July 19, 2004). As a result, this manuscript was chosen and became one of the ten picturebooks in the Taiwanese Children's Picturebook Selection. According to Mr. Lin, the publisher, this picturebook fell into the category of art, which is one of the three categories created for the picturebook selection: folkways, art, and environment.
} 
Ironically, many individually published picturebooks have a similar approach to Taiwanese culture as that of Yue-yue's Dancing Lessons, but they are not grouped and labeled as "Taiwanese Picturebooks." In this sense, the label "Taiwanese Picturebooks" oftentimes refers to the stories about traditional Taiwanese rituals, costumes, and values, which is a marketing strategy. However, the connotative message associated with the label may suggest that readers think about what Taiwanese picturebooks should be.

Although the purpose of the group labels is a convenient usage to indicate the function of picutrebooks for parents and educators, they also limit readers' imagination and interpretation toward each individual picturebook in a set.

\section{A New Emerging Ethnic Group Challenges the Representation of Taiwanese Culture in the Picturebooks}

Ethnic groups are diverse in Taiwan according to the concept of ethnicity referred to as "the sharing of norms, values, beliefs, cultural symbols and practices" (Barker, 2000, p. 195). However, there is a recent concept of the "Neo-Taiwanese" based on the political concern suggested by the former president Li Deng-hui, which categories the Taiwanese population body as Hokklo, Hakka, "hsin-chu-min" (new residents or mainlanders - immigrants from China after 1945), and "yuan-chu-min" (aborigines). The first three categories fall into one racial group - Han Chinese. When adopting this political identification, sixteen out of twenty-two picturebooks reflect the experiences related to Han Chinese immigrants before 1945, three of them connect to aborigines, and three of them are not specific. Mainlanders, who used to be the political privilege group in Taiwanese society during the Kuomintang era, are excluded from the book list. This

\footnotetext{
${ }^{68}$ This idea is also supported by the chief editor Gao Ming-Mei (personal communication, December 22,
} 
evidence indicates that, under the "hsin-chu-min" criteria, mainlanders are considered cultural outsiders when defining the fundamental traits of Taiwanese culture. Ideologically, this exclusion tends to preserve the idea of Taiwanese culture in a pure form before the influence by the Kuomintang and American popular culture (which has gradually grown since the 1960s, when the United States Army base was established in Taiwan due to the defense agreement with the Kuomintang against the Communist China.)

However, this so-called "pure" Taiwanese culture has gradually disappeared and it no longer reflects today's social reality due to the fact that the structure of the Taiwanese population has dramatically changed in the last decade, according to recent population statistics. One eighth of newborn babies were delivered by foreign brides from Mainland China, Southeastern Asia, and other areas in 2004. This shows that intercultural marriage increases social change and strengthens hybrid cultures in Taiwan.

Strategically, the picturebooks reflecting nostalgic Taiwanese culture can be seen as a strategy to reinstall local cultural heritage as a resistance to the hegemony of Sinocentrism. In reality, however, the imagery of this pure form of Taiwanese culture is not able to unify a collective contemporary Taiwanese culture, especially when ethnicity is taken into consideration. Therefore, the cultivation of Taiwanese consciousness should move from a resistance discourse to a culture discourse, discussed in chapter two (Huang, 2000), that elaborates the definition of Taiwanese culture by reflecting current social reality. To do this, the concepts of cultural bybridity need to be considered and included. 


\section{Implications and Suggestions}

There is no conclusion regarding the issues of tradition versus the modern and localization versus globalization because they are on-going debates and open to interpretation. In this study, the three sets of picturebooks have exemplified the complexity of these issues. In addition, the social construction of the Taiwanese picturebooks is discussed throughout the critique. The nature of publishing involves business and the nature of education is about learning. Both of them contribute to knowledge construction and convey some ideologies to readers or learners. Children's picturebooks consist of these two elements, which are cultural productions for educational purpose to some extent. Thus, this section will provide implications of this study for both publication and education, and suggestions for future studies will also include.

\section{Implications of this Study for Publication}

Picturebooks published in a set is a common strategy used in Taiwan's book market, but may not be frequently used in other countries. Thus, the implication of this study for publication is particularly to Taiwanese publishing houses. Since the cultural representations shown in the picturebooks are the main focus of this study, these are inclusions and exclusions, as discussed in this critique. Thus, the idea of a limited definition of Taiwanese culture based on the label of "Taiwanese picturebooks" was addressed. That is, to promote traditional heritage is the purpose of this limited definition used in the picturebooks. This indicates that the publishing houses have their own political assumptions and marketing strategies for productions. 
However, when considering new possible themes or subject matters representing Taiwanese culture for new picturebooks, editors should notice that a broader definition of culture can provide new directions, such as adopting Bhabha's "cultural hybridity" for embracing more life experiences from the present time and different groups of people living in Taiwan. Taiwanese culture has become more and more diverse. Thus, picturebooks intended to present Taiwanese culture should be able to reflect elements of current social reality because this current social reality will become part of future traditions.

\section{Implications of this Study for Education}

This study does not intend to provide a guideline for book selection or create curricula for teaching Taiwanese native culture. It is rather intended to exemplify the complexity of cultural representation in children's picturebooks. By so doing, it raises an awareness of how social construction of the Taiwanese picturebooks shapes one's perception of culture. Especially, when situating these books in the current native education movement in Taiwan, which places an emphasis on local cultures and Taiwanese consciousness and limits the concept of culture to only "native" culture. Conceptually, this indicates that educators should be sensitive to the assumptions embedded in the cultural values they hold true or take for granted, especially the assumption associated with the current educational movements. To examine this notion, this study provides an inclusive literature review on the issue of globalization versus localization and the cultural movements in Taiwan through the past five decades, as well as an in-depth critique of the picturebooks entitled "Taiwanese picturebooks." Together these demonstrate and discuss that the idea that children's picturebooks are not neutral 
and naïve. Instead, they present a certain point of view, referring to the social values promoted in the time when they were produced. Moreover, editors' intentions and marketing strategies were explored in this study. This reminds educators of how knowledge is constructed and selected for presentation in the picturebooks. When reading or using a picturebook for understanding or introducing cultures to students, educators should be aware of the reasons for their book choice, as well as the environment in which the text was generated.

\section{Suggestions for Future Studies}

The analysis of this study was based on the researcher's interpretation situated in a broad cultural context based on Barthes' semiotic approach, in which authors' intentions were not considered. Currently, readers have been empowered in the interpretation of texts based on the field of literary theories. For future studies, reader response regarding the picturebooks, such as those from young children and parents, can be explored more in depth because they are primary targeted readers for these picturebooks. The research subjects in such a study could be divided into different groups, such as a children's group, parents' group, and children and their parents' group. The research questions could focus on how they make personal connections to the text and what interests them in the stories.

Another possible follow-up study involving research subjects is to investigate readers' interpretations regarding the picturebooks, according to a series of semistructured interview questions from three aspects. First, questions regarding the understanding of cultural clues in the pictures could help examine how the reader decodes the symbols shown in the pictures to make sense of the story. Second, questions 
related to one's cultural identity could look into how the reader constructs cultural meaning through the story. This research could focus on the comparison of the interpretations between different readers from various backgrounds.

This study limited its data to the three sets of Taiwanese picturebooks published during 2001 2004 and placed the focus on the editors' intentions. Thus, individual picturebooks created by Taiwanese writers and illustrators are excluded from this study. A future study emphasizing textual analysis could examine the cultural representations in the individual picturebooks and place the focus on the editors' criteria for individual book selection. Such a study may include the following assumptions: (1) writers and illustrators of these individual picturebooks may have more freedom of selecting subject matters and creating the content based on a chosen subject; (2) the channels for publication at least may include the creators voluntarily submitting their manuscripts to publishing houses or participanting in national picturebook competitions to seek opportunities for publishing; and (3) publishing houses could also invite well-known writers and illustrators to submit their work. Therefore, publishing houses have their own criteria for book selection due to their brand images. Based on the assumptions above, the possible criteria for data selection may consider picturebooks (1) receiving a national award, (2) published in different languages other than Chinese, (3) recommended by librarians, (4) published by the same publishing houses, or the like. These possible research projects may reflect different or similar cultural representations in the selected picturebooks. 
APPENDIX A

A CONCEPTUAL MAP OF THE STUDY

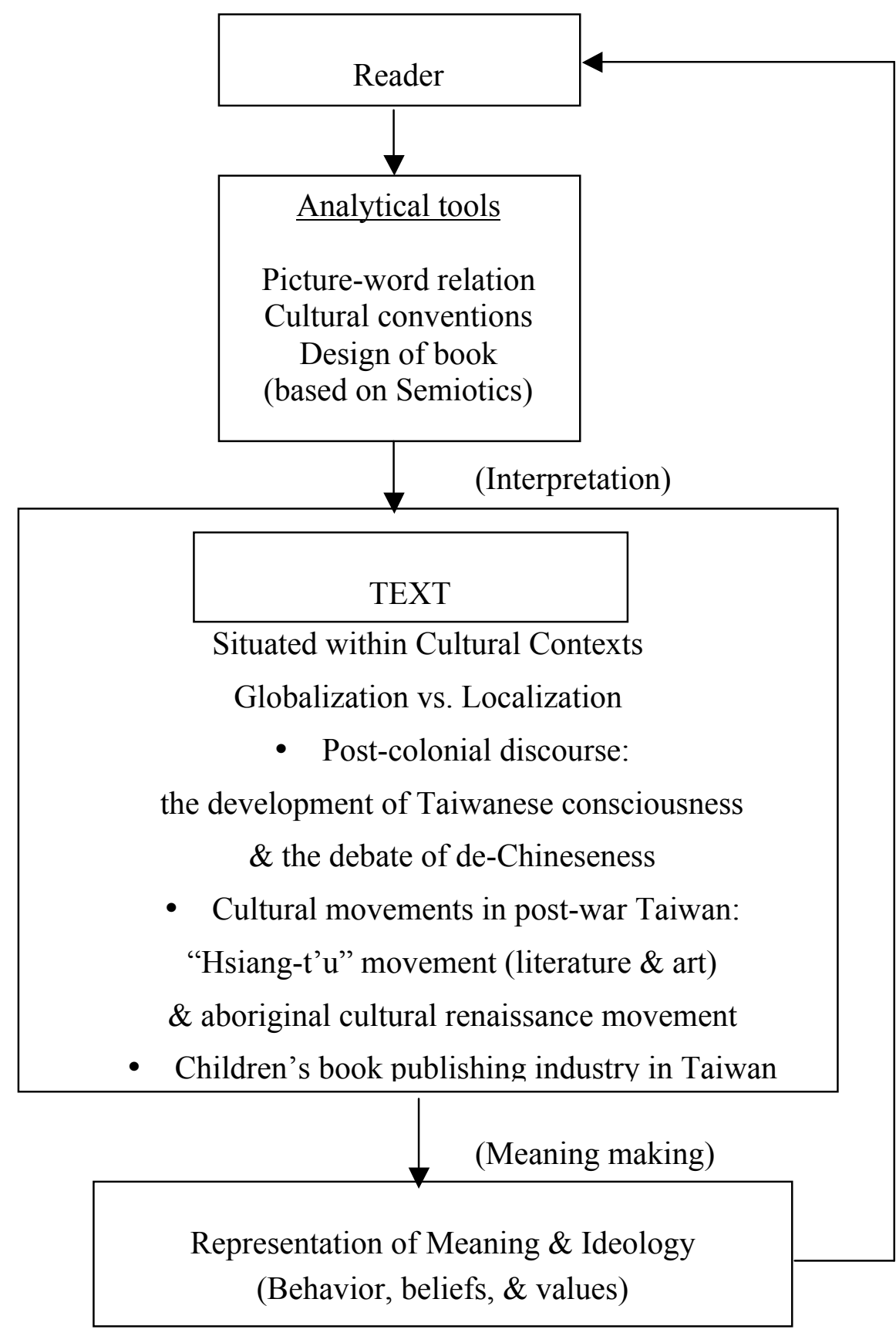

(Reflection) 


\section{APPENDIX B}

\section{A BOOK LIST OF THE SELECTED TAIWANESE PICTUREBOOKS}

I. Title of the Label: Firefly Picturebook Selection-Taiwanese Folktales / Yuan-Liou Publishing/ 2001

--(6) Traditional Han Taiwanese Folktales

\begin{tabular}{|c|c|c|c|}
\hline No & Code/ Title of the Book & Writer & Illustrator \\
\hline 1 & $\begin{array}{l}\text { G1-01 Hu Gu-po (Grandaunt Tiger)_-A } \\
\text { Taiwanese tale of the Little Red Hook }\end{array}$ & Kuan, Kuan & Li, Han-wen \\
\hline 2 & $\begin{array}{l}\text { G1-02 Bo-zei Chi (The Liar Named Chi)_-A } \\
\text { Taiwanese tale of a man having wits to cheat a } \\
\text { rich and greedy man of his money }\end{array}$ & $\begin{array}{l}\text { Hao, Kuang- } \\
\text { chai }\end{array}$ & $\begin{array}{l}\text { Wang, Char- } \\
\text { chu }\end{array}$ \\
\hline 3 & $\begin{array}{l}\text { G1-03 Li Tian-luo (The Person Selling Field } \\
\text { Snails Named Li)_-A Taiwanese tale of a honest } \\
\text { but poor man becoming rich due to marrying a } \\
\text { good wife }\end{array}$ & Chen, Yi-chen & $\begin{array}{l}\text { Yang, Tsui- } \\
\text { yu }\end{array}$ \\
\hline 4 & $\begin{array}{l}\text { G1-04 Mai Hsiang-pi (Fragrance for Sale)-A } \\
\text { Taiwanese tale of two brothers }\end{array}$ & $\begin{array}{l}\text { Cheng, Ling- } \\
\text { ling }\end{array}$ & Li, Han-wen \\
\hline 5 & $\begin{array}{l}\text { G1-05 Hao-bi-shi (The Person having a Good } \\
\text { Sense of Smell)_ A Taiwanese tale of why ants } \\
\text { have a good sense of smelling }\end{array}$ & $\begin{array}{l}\text { Hao, Kuang- } \\
\text { chai }\end{array}$ & $\begin{array}{l}\text { Wang, Jin- } \\
\text { tai }\end{array}$ \\
\hline 6 & $\begin{array}{l}\text { G1-06 Shui-gui Cheng-huang-A Taiwanese tale } \\
\text { of a water spirit becoming a city ruling deity }\end{array}$ & Li, Ang & Hsiao, Taso \\
\hline
\end{tabular}

Note: The title of each label and each book as well as the name of the writers and illustrators were translated by the researcher. The number in each parenthesis indicates the number of picturebooks. 
II. Title of the Label: Taiwanese Children's Picturebook Selection/ Children's Publication/ 2002

Multiple themes:

Folkways - (2) children's rhymes, (1) aboriginal myth, (1) historical place, (1) traditional custom, and (1) traditional ritual.

Art-(2) Taiwanese senior artists and (1) a child's dancing lessons

Environment-(1) typical Taiwanese birds.

\begin{tabular}{|c|l|l|l|}
\hline 7 & $\begin{array}{l}\text { G2-01 Mei-shu A-gong (Grandfather Mei- } \\
\text { shu)_A story of a Taiwanese senior artist }\end{array}$ & Su, Chen-ming & $\begin{array}{l}\text { Chen, Min- } \\
\text { jie }\end{array}$ \\
\hline 8 & $\begin{array}{l}\text { G2-02 Shooting Suns_A Taiwanese aboriginal } \\
\text { myth }\end{array}$ & Lai, Mo & Lai, Mo \\
\hline 9 & $\begin{array}{l}\text { G2-03 Feng-cha (Free Tea for Everyone)_A } \\
\text { story of a traditional Taiwanese custom }\end{array}$ & Liu, Bo-le & Liu, Bo-le \\
\hline 10 & $\begin{array}{l}\text { G2-04 Da-tou Has a Son-A contemporary } \\
\text { Taiwanese story rhyme verse }\end{array}$ & $\begin{array}{l}\text { Jian, Shang- } \\
\text { ren }\end{array}$ & $\begin{array}{l}\text { Taso, Jun- } \\
\text { yan }\end{array}$ \\
\hline 11 & $\begin{array}{l}\text { G2-05 Taiwanese Nursery Rhymes-15 items of } \\
\text { nursery rhymes, songs, and games }\end{array}$ & $\begin{array}{l}\text { Li, Wu-hsian } \\
\text { etc. }\end{array}$ & $\begin{array}{l}\text { Chuo, Kuo- } \\
\text { chong etc. }\end{array}$ \\
\hline 12 & $\begin{array}{l}\text { G2-06 My Father is Going to a Festival } \\
\text { Competition-An introduction to a traditional } \\
\text { ritual in Yilan County }\end{array}$ & Li, Tong & Li, Zan-chen \\
\hline 13 & $\begin{array}{l}\text { G2-07 A Sparrow in the Museum-A story of } \\
\text { Taiwanese senior artists }\end{array}$ & Li, Man-chio & $\begin{array}{l}\text { Chen, Ying- } \\
\text { fan }\end{array}$ \\
\hline 14 & $\begin{array}{l}\text { G2-08 Going Shopping on Dihua Street for } \\
\text { Chinese New Year-A story of a historical street } \\
\text { in Taipei City }\end{array}$ & Chu, Hsiu-fan & Chen, Li-ya \\
\hline 15 & $\begin{array}{l}\text { G2-09 Yue-yue's Dancing Lessons-A story of a } \\
\text { little girl going to her first dancing class }\end{array}$ & He, Yun-tzu & He, Yun-tzu \\
\hline 16 & $\begin{array}{l}\text { G2-10 Little White and Little Grey-A story of } \\
\text { two Taiwanese egrets }\end{array}$ & Hsu, Ling-hui & Jiang, Bin-ru \\
\hline
\end{tabular}


III. Title of the Label: Taiwanese Teenagers/ Yuan-Liou Publising/ 2003 --(6) Childhood memories from six famous Taiwanese writers

\begin{tabular}{|c|c|c|c|}
\hline 17 & $\begin{array}{l}\text { G3-01 Selling Brooms with My Grandmother-A } \\
\text { story of the writer's selling hand-made brooms } \\
\text { with her grandmother. }\end{array}$ & Jian, Cheng & $\begin{array}{l}\text { Huang, } \\
\text { Hsiao-yan }\end{array}$ \\
\hline 18 & $\begin{array}{l}\text { G3-02 When I was Eight, I Went on a Journey-A } \\
\text { story of the writer accomplishing a mission } \\
\text { ordered by his father }\end{array}$ & $\begin{array}{l}\text { Wu, Nian- } \\
\text { cheng }\end{array}$ & $\begin{array}{l}\text { Kuan, Yue- } \\
\text { shu }\end{array}$ \\
\hline 19 & $\begin{array}{l}\text { G3-03 Story Map - A story of the writer running } \\
\text { away from home and returning it after all }\end{array}$ & Awu & Aduan \\
\hline 20 & $\begin{array}{l}\text { G3-04 Yi Gong-gong (Granduncle)_-A story of } \\
\text { the writer's granduncle who was a leader in his } \\
\text { tribe }\end{array}$ & Sun, Da-chuan & $\begin{array}{l}\text { Jian, Shang- } \\
\text { ren }\end{array}$ \\
\hline 21 & $\begin{array}{l}\text { G3-05 A Memory of the Tea Plantation-A story } \\
\text { of the writer's family running a tea business in } \\
\text { countryside during the } 1960 \mathrm{~s}\end{array}$ & Hsiang, Yang & $\begin{array}{l}\text { Hsu, Wen- } \\
\text { chi }\end{array}$ \\
\hline 22 & $\begin{array}{l}\text { G3-06 A River Resembling a Mother-A story of } \\
\text { the writer's memory of the loss of his mother }\end{array}$ & Lu, Han-hsiu & He, Yun-tzu \\
\hline
\end{tabular}




\section{APPENDIX C}

\section{NARRATIVE ANALYSIS OF EACH INDIVIDUAL PICTUREBOOK}

I. Firefly Picturebook Selection-Taiwanese Folk Tales/Yuan-Liou Publishing/ 2001

\begin{tabular}{|c|c|c|}
\hline Code/Category & \multicolumn{2}{|l|}{ Group 1-01 } \\
\hline Title \& Content & ing & $\begin{array}{l}\text { Hu Gu-po (Grandaunt Tiger) } \\
\text { —A Taiwanese tale of the Little Red Hook }\end{array}$ \\
\hline Theme & \multicolumn{2}{|c|}{$\begin{array}{l}\text { - } \\
\text { - }\end{array}$} \\
\hline Setting & \multicolumn{2}{|c|}{$\begin{array}{l}\text { - Time: The Qing dynasty } \\
\text { - Place: Rural community }\end{array}$} \\
\hline Characterization & \multicolumn{2}{|c|}{$\begin{array}{l}\text { - A magic tiger can transform into a human form and it is fond of } \\
\text { eating young children. } \\
\text { - A little girl, who is an eldest sister, is clever, brave, and } \\
\text { resourceful. } \\
\text { - A little boy is immature and needs protection. } \\
\text { - The role of the mother is not emphasized. } \\
\text { - A grandaunt is simple and honest. She doesn't keep vigil over } \\
\text { suspicious people. } \\
\text { Three kind male strangers, who are street vendors, offer the little } \\
\text { girl their products and strategies for defeating the tiger. }\end{array}$} \\
\hline Plot conflicts & \multicolumn{2}{|c|}{$\begin{array}{l}\text { - Conflicts between the little girl and the tiger } \\
\text { The tiger intends to eat the little girl and she tries to protect herself. }\end{array}$} \\
\hline Plot structures & \multicolumn{2}{|c|}{$\begin{array}{l}\text { (1) The magic tiger had special tricks and two children were eaten by } \\
\text { it. } \\
\text { (2) The mother left home for some business and two young children } \\
\text { stayed home. The tiger played two tricks, but they didn't work }\end{array}$} \\
\hline
\end{tabular}




\begin{tabular}{|c|c|}
\hline Plot structures & $\begin{array}{l}\text { because the little girl stopped him. } \\
\text { (3)The tiger pretended to be the grandaunt of the children and the } \\
\text { little girl let it come into the house. } \\
\text { (4) The tiger ate the little boy and the girl found out. She hid herself } \\
\text { from the tiger. However, the tiger left but would be back to eat her } \\
\text { up. } \\
\text { (5) Three kind vendors provided materials and strategies for defeating } \\
\text { the tiger. } \\
\text { (6) The little girl set up the traps, but they didn't work after all. The } \\
\text { little girl came up with her own trick and finally beat the tiger. } \\
\text { (7) The mother came home and they were crying because of the death } \\
\text { of the little boy. }\end{array}$ \\
\hline Point of view & $\begin{array}{l}\text { - Narrative voice: the third person with an omniscient perspective } \\
\text { - Point of view (Visual): An omniscient perspective \& focalization }\end{array}$ \\
\hline Style & $\begin{array}{l}\text { - The story was written with rhymes and the voice was straight. } \\
\text { - The text tells the whole story. } \\
\text { - The use of style (visual): Cartoon art }\end{array}$ \\
\hline Code/Category & Group 1-02 \\
\hline Title \& Content & $\begin{array}{l}\text { Bo-zei Chi (The Liar Named Chi) } \\
\text {-A Taiwanese tale of a man using his wits to } \\
\text { cheat a rich and greedy man of his money }\end{array}$ \\
\hline Theme & $\begin{array}{ll}- & \text { Traditional Taiwanese folktale } \\
\text { - } & \text { Witty } \\
\text { Consequence of greed }\end{array}$ \\
\hline Setting & $\begin{array}{l}\text { - } \quad \text { Time: The Qing dynasty } \\
\text { - } \quad \text { Place: Rural community }\end{array}$ \\
\hline Characterization & $\begin{array}{l}\text { - A liar is a lazy, tricky, and wily person. } \\
\text { - A rich man is greedy, rude, and unreasonable. } \\
\text { - The wife of the liar follows her husband's orders. } \\
\text { - The wife of the rich man follows her husband's orders. }\end{array}$ \\
\hline Plot conflicts & $\begin{array}{l}\text { Conflicts between the liar and the rich man } \\
\text { The liar cheated the rich man three times, but the rich man believed } \\
\text { him because of his greed. }\end{array}$ \\
\hline
\end{tabular}




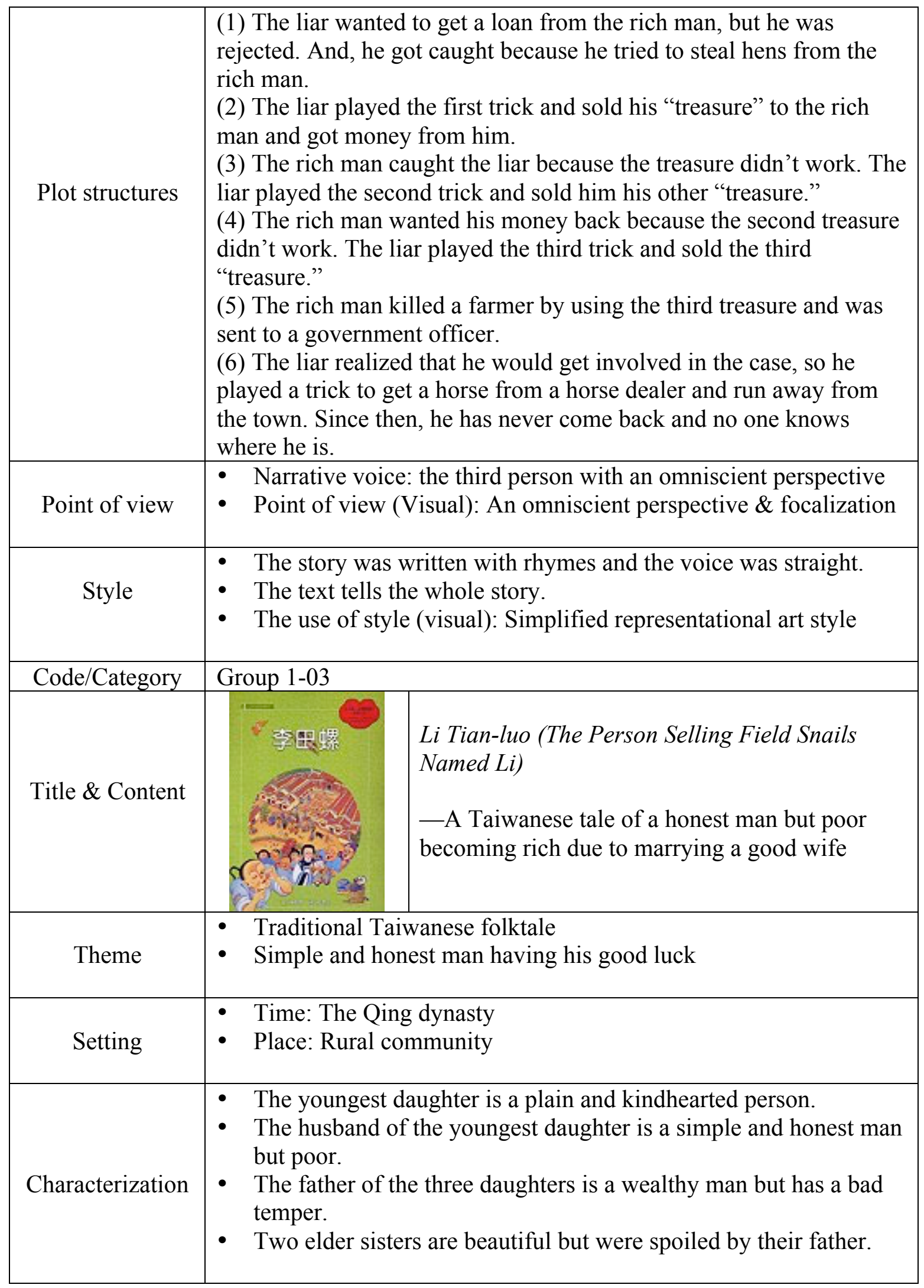




\begin{tabular}{|c|c|}
\hline Characterization & $\begin{array}{l}\text { - The husbands of the elder sisters are rich but lazy and arrogant. } \\
\text { - An old beggar is a supernatural being. }\end{array}$ \\
\hline Plot conflicts & $\begin{array}{l}\text { - Conflicts between the third daughter and her father } \\
\text { - The youngest daughter didn't want to marry a lazy rich man that } \\
\text { offended her father who believed that being rich is more } \\
\text { important than being assiduous. }\end{array}$ \\
\hline Plot structures & $\begin{array}{l}\text { (1) The comparison between the youngest daughter and her elder } \\
\text { sisters. (The youngest daughter was nice to servants, like her mother, } \\
\text { while the elder sisters were mean, like their father.) } \\
\text { (2) The mother died. The father remarried and the two elder sisters } \\
\text { also married into two rich families. The youngest daughter didn't } \\
\text { want to marry a rich but lazy man. So, her father found a poor } \\
\text { husband for her. } \\
\text { (3) The new couple had a poor but peaceful life. After the youngest } \\
\text { daughter got pregnant, the husband found a coal pit, which belonged } \\
\text { to his future son (he didn't know at this point.) } \\
\text { (4) The youngest daughter became a beauty because of her } \\
\text { willingness to help an old beggar, who played a magic trick on her. } \\
\text { (5) After the baby was born and turned to several months old, the } \\
\text { couple took the baby to meet the daughter's father and asked for } \\
\text { naming the baby. } \\
\text { (6) As soon as the name was chosen, the husband recognized the fact } \\
\text { that the coal pit was owned by his son. He sold the coals and made a } \\
\text { fortune, but still had a simple life. } \\
\text { (7) The couple took the baby to visit the father at the second day of } \\
\text { the Chinese New Year. Because of a bet, he bought the farms from } \\
\text { his brother-in-laws and paid half price for them. Meanwhile, the two } \\
\text { elder sisters learned the secret from the youngest daughter about her } \\
\text { beauty. Then they found the old beggar and did the same thing as the } \\
\text { youngest daughter did. However, they turned ugly because of their } \\
\text { unsympathetic behavior. The lesson was: a simple and honest man } \\
\text { will have his good luck in life. }\end{array}$ \\
\hline Point of view & $\begin{array}{l}\text { - Narrative voice: the third person with an omniscient perspective } \\
\text { - Point of view (Visual): An omniscient perspective \& focalization }\end{array}$ \\
\hline Style & $\begin{array}{l}\text { - The text tells the whole story. } \\
\text { - The voice was straight. In the story, the writer explains two } \\
\text { traditional Hakka customs regarding death and birth. } \\
\text { - The use of style (visual): Simplified representational art style }\end{array}$ \\
\hline
\end{tabular}




\begin{tabular}{|c|c|}
\hline Code/Category & Group 1-04 \\
\hline Title \& Content & $\begin{array}{l}\text { Mai Hsiang-pi (Fragrance for Sale) } \\
\text {-A Taiwanese tale of two brothers }\end{array}$ \\
\hline Theme & $\begin{array}{l}\text { - Traditional Taiwanese folktale } \\
\text { - Simple and honest men having their good luck }\end{array}$ \\
\hline Setting & $\begin{array}{l}\text { - Time: The Qing dynasty } \\
\text { - Place: Rural community }\end{array}$ \\
\hline Characterization & $\begin{array}{l}\text { - The younger brother is a simple and honest person. } \\
\text { - The elder brother is greedy and has a bad temper. } \\
\text { - The elder brother's wife is greedy and tricky. } \\
\text { punishment) }\end{array}$ \\
\hline Plot conflicts & $\begin{array}{l}\text { - Conflicts between the two bothers } \\
\text { The elder brother and his wife were jealous about the young brother's } \\
\text { good luck and fortune. }\end{array}$ \\
\hline Plot structures & $\begin{array}{l}\text { (1) There were two brothers sharing a farming cow. The land was } \\
\text { well farmed by the younger brother because he was good to the cow } \\
\text { while his elder brother did not farm the land very well because he } \\
\text { treated the cow badly. The elder brother played a trick, suggested by } \\
\text { his wife, to get the ownership of the cow. As a result, the younger } \\
\text { brother only got a parasite from the cow. } \\
\text { (2) The younger brother got a hen because the hen ate the parasite. } \\
\text { Then, he got a dog because the dog killed the hen. } \\
\text { (3) The younger brother won a bet from a business man because his } \\
\text { dog could farm the land. The elder brother learned about the news } \\
\text { and borrowed the dog. However, he lost a bet and therefore he lost } \\
\text { his land. As a result, he killed the dog. } \\
\text { (4) The younger brother was sad because of the death of the dog, who } \\
\text { was his friend. He buried the dog and visited its grave very often. } \\
\text { Bamboo grew around the grave. He shook the bamboo and got a lot } \\
\text { of golden leaves. His brother found out his secret and shook the } \\
\text { bamboo, but a lot of caterpillars fell down. So, he cut down the } \\
\text { bamboo. } \\
\text { (5) The younger brother saw the bamboo lying down and collected } \\
\text { some of them and used them as firewood for cooking soy beans. He }\end{array}$ \\
\hline
\end{tabular}




\begin{tabular}{|c|c|}
\hline Plot structures & $\begin{array}{l}\text { ate some of them and they made the gas from his intestines smell } \\
\text { good. As a result, he earned a lot of money from the governor for } \\
\text { selling his gas. } \\
\text { (6) In contrast, his elder brother asked for the secret and followed the } \\
\text { way. However, he produced excrement and bad gas and got } \\
\text { punishment from the governor. }\end{array}$ \\
\hline Point of view & $\begin{array}{l}\text { - Narrative voice: the third person with an omniscient perspective } \\
\text { - Point of view (Visual): An omniscient perspective \& focalization }\end{array}$ \\
\hline Style & $\begin{array}{l}\text { - The text tells the whole story and the voice was straight. } \\
\text { - The use of style (visual): Folk art (shadow puppetry) }\end{array}$ \\
\hline Code/Category & Group 1-05 \\
\hline Title \& Content & $\begin{array}{l}\text { Hao-bi-shi (The Person Having a Good Sense of } \\
\text { Smell) } \\
\text { — A Taiwanese tale of why ants have a good } \\
\text { sense of smell }\end{array}$ \\
\hline Theme & $\begin{array}{ll}\text { - } & \text { Traditional Taiwanese folktale } \\
\text { - } & \text { Witty } \\
\text { - Consequence of lying }\end{array}$ \\
\hline Setting & $\begin{array}{l}\text { - Time: The Qing dynasty } \\
\text { - Place: Rural community }\end{array}$ \\
\hline Characterization & $\begin{array}{l}\text { - The man likes gambling and tells lies in order to avoid his } \\
\text { responsibility. } \\
\text { - Folks in a small town are naive. } \\
\text { - The emperor is authoritative. } \\
\text { - The heaven god is authoritative. }\end{array}$ \\
\hline Plot conflicts & $\begin{array}{l}\text { - Conflicts within the man who lies about his magic nose } \\
\text { The consequence accompanying the lies made by the man caused him } \\
\text { to be trouble and he had to find a way out. }\end{array}$ \\
\hline Plot structures & $\begin{array}{l}\text { (1) A man spent his money on gambling and lied to his wife. } \\
\text { However, he got beat by his wife because she didn't trust him. } \\
\text { Children made fun of his big red nose caused by the fight. He } \\
\text { carelessly run into a pig and fell down. That made him angry at the } \\
\text { pig and he kicked it into a manure pit. } \\
\text { (2) When a group of folks were searching for the pig, the man }\end{array}$ \\
\hline
\end{tabular}




\begin{tabular}{|c|c|}
\hline Plot structures & $\begin{array}{l}\text { volunteered to help them and finally found the pig. The man bragged } \\
\text { himself about his magic nose, which could smell anything from a } \\
\text { long distance. As a result, he was famous for his good sense of smell } \\
\text { in the town. } \\
\text { (3) He played a trick to get money from his rich cousin. } \\
\text { (4) The emperor lost his stamp and called for the man to find it. } \\
\text { However, when the officers got to the town, nobody knew where the } \\
\text { man was because they thought that he might commit some crime. The } \\
\text { cousin told the officers about where to find the man in order to get a } \\
\text { reward from the emperor. } \\
\text { (5) The man went to meet the emperor and was assigned to find the } \\
\text { stamp. If he couldn't find it, then he would be killed. He was lucky } \\
\text { enough to solve his problem by accident. Finally, he got a reward } \\
\text { from the emperor. } \\
\text { (6) The man planned to run away from people who knew him by } \\
\text { telling a lie that he needed to return to heaven because he was a } \\
\text { celestial being. However, a real celestial being, who learned about his } \\
\text { story, took him to heaven. The heaven god ordered him to smell the } \\
\text { smoke from where folks prayed and burned joss sticks and paper } \\
\text { money, so thunder god and goddess could make rain for them. He } \\
\text { failed his task and intended to run away. On the way back to earth, he } \\
\text { fell down and disappeared. Unbelievably, there were million of ants } \\
\text { that appeared in the place that he disappeared. }\end{array}$ \\
\hline Point of view & $\begin{array}{l}\text { - Narrative voice: the third person with an omniscient perspective } \\
\text { - Point of view (visual): An omniscient perspective \& focalization }\end{array}$ \\
\hline Style & $\begin{array}{l}\text { - The story was written with rhymes and the voice was straight. } \\
\text { - The text tells the whole story. } \\
\text { - The use of style (visual): Simplified representational art style }\end{array}$ \\
\hline Code/Category & Group 1-06 \\
\hline Title \& Content & $\begin{array}{l}\text { Shui-gui Cheng-huang } \\
\text {-A Taiwanese tale of a water spirit becoming a } \\
\text { city ruling deity }\end{array}$ \\
\hline Theme & $\begin{array}{l}\text { - } \quad \text { Traditional Taiwanese folktale } \\
\text { - } \quad \text { Consequence of doing good things }\end{array}$ \\
\hline Setting & $\begin{array}{l}\text { - } \quad \text { Time: The Qing dynasty } \\
\text { - } \quad \text { Place: Rural community }\end{array}$ \\
\hline
\end{tabular}




\begin{tabular}{|c|c|}
\hline Characterization & $\begin{array}{l}\text { A spirit in a river, who was a rich man murdered by two laborers, } \\
\text { values friendship with a fishing man. } \\
\text { - A fishing man is kindhearted and shows filial obedience to his } \\
\text { mother. } \\
\text { - The mother of the fishing man deeply relies on her son. } \\
\text { - Two laborers are greedy. }\end{array}$ \\
\hline Plot conflicts & $\begin{array}{l}\text { - Conflicts within the spirit } \\
\text { The spirit wanted to transform his suffering in the river by finding } \\
\text { someone to replace him. } \\
\text { - Conflicts between the spirit and the fishing man } \\
\text { The fishing man stopped the spirit from pulling someone into the } \\
\text { river. } \\
\text { - Conflicts within the fishing man } \\
\text { The fishing man didn't want to prevent his good fried, the spirit, from } \\
\text { finding a chance to be reborn as a man. However, he was not willing } \\
\text { to see someone else have to sacrifice his/her life to providing such a } \\
\text { chance. }\end{array}$ \\
\hline Plot structures & $\begin{array}{l}\text { (1) There was a rich man who usually traveled around his lands to } \\
\text { collect money from his farmers in the autumn. One year, he was } \\
\text { murdered by two laborers who were hired to carry his sedan chair. He } \\
\text { fell into a river and became a spirit. } \\
\text { (2) There was a poor young fishing man living with his mother. He } \\
\text { showed filial obedience to his mother. } \\
\text { (3) This fishing man met the spirit and they became good friends. The } \\
\text { spirit helped him catch more fish and by doing this the fishing man } \\
\text { had a better life with his mother. } \\
\text { (4) One day, the spirit told the fishing man that he would have a } \\
\text { chance to be reborn if he pulled a person into the river. When the } \\
\text { chance came, the spirit told the fishing man and said good-bye to } \\
\text { him. However, he stopped him from doing it because the person was } \\
\text { a pregnant woman. } \\
\text { (5) When the spirit got the second chance, he told the fishing man } \\
\text { again. However, the fishing man stopped him again because the } \\
\text { person just got married. } \\
\text { (6) When the spirit got a third chance, he wanted to tell the fishing } \\
\text { man about it. However, the fishing man didn't want to know, so he } \\
\text { would not have to stop him again. Next day, the spirit came to say } \\
\text { good-bye and told the fishing man that he would be a city ruling deity } \\
\text { because he received this reward from the hell god for giving up his } \\
\text { third chance to be reborn. } \\
\text { (7) One day, the fishing man carried a basket of food to a temple for a } \\
\text { prayer. And, he felt familiar with the city ruling deity. After praying, } \\
\text { he put the food back into his basket. When he got home, there was a }\end{array}$ \\
\hline
\end{tabular}




\begin{tabular}{|c|l|}
\hline Plot structures & $\begin{array}{l}\text { lot of money in the basket. Since then, he no needed to go fishing. } \\
\text { Rather, he stayed home to take care of his mother. }\end{array}$ \\
\hline Point of view & $\begin{array}{l}\bullet \quad \text { Narrative voice: the third person with an omniscient perspective } \\
\text { - Point of view (Visual): An omniscient perspective \& focalization }\end{array}$ \\
\hline Style & $\begin{array}{l}\text { - The text tells the whole story. } \\
\text { - The voice was straight. }\end{array}$ \\
\hline
\end{tabular}

II. Taiwanese Children's Picturebook Selection/Children's Publications/ 2002

\begin{tabular}{|c|l|l|}
\hline Code/Category & Group 2-01 \\
\hline Title \& Content & $\begin{array}{l}\text { Mei-shu A-gong (Grandfather Mei-shu) } \\
\text { In the story, the artist was about } 60 \text { years old. } \\
\text { The story attempted to present the artist's daily } \\
\text { life and some important remarks in the artist's } \\
\text { life and career. }\end{array}$ \\
\hline Theme & $\begin{array}{l}\text { Taiwanese senior artist and his contribution to the community } \\
\text { (biography) }\end{array}$ \\
\hline Setting & $\begin{array}{l}\text { Time: The1950s } \\
\text { Place: The town of Sanshia - Suburban community }\end{array}$ \\
\hline Characterization & $\begin{array}{l}\text { The grandfather, a Taiwanese senior artist, is the main character } \\
\text { in this story. The writer attempted to describe his love for his art, } \\
\text { with his grandson and shared his artwork with him. By doing this, } \\
\text { the conversations describe the artist's early life experience. } \\
\text { The role of the grandmother, the wife of the artist, was not } \\
\text { depicted too much in the story. } \\
\text { The friends of the artist are supporters of his artwork. They are } \\
\text { mentioned in the story, but not much. }\end{array}$ \\
\hline Plot conflicts & $\begin{array}{l}\text { Conflicts between the grandfather and society } \\
\text { His artwork had been criticized as out of fashion during the time } \\
\text { period that abstract expressionism had been introduced to the Taiwan } \\
\text { art world. }\end{array}$ \\
\hline
\end{tabular}




\begin{tabular}{|c|c|}
\hline Plot structures & $\begin{array}{l}\text { (1) In the morning, the artist went out for outdoor sketching or } \\
\text { painting. } \\
\text { (2) He came home and had conversations with the grandson } \\
\text { a. talking about loving Taiwanese puppetry and making drawings of } \\
\text { it at age } 13 \text { (the } 1920 \mathrm{~s} \text { ) } \\
\text { b. collecting about new design of lions for the temple } \\
\text { c. talking about two paintings done by the artist } \\
\text { d. talking about a memory of going to Japan for studying art at age } 28 \\
\text { (the } 1930 \text { s) } \\
\text { (3) In the late afternoon, the artist went to his friend's home and had a } \\
\text { conversation. } \\
\text { a. talking about how his artwork had been criticized by other young } \\
\text { modern artists (the } 1950 \text { s-May Painting Society) } \\
\text { b. talking about his insistence on devoting himself to his hometown }\end{array}$ \\
\hline Point of view & $\begin{array}{l}\text { - Narrative voice: the third person from the view of a particular } \\
\text { character (the little boy and the artist) } \\
\text { - Point of view (visual): An omniscient perspective \& focalization }\end{array}$ \\
\hline Style & $\begin{array}{l}\text { The writer articulated the artist's personal life experience and } \\
\text { reconstructed a story about the artist based on five paintings } \\
\text { created by the artist. At the end of the story, there are two spread } \\
\text { pages introducing the five paintings. } \\
\text { In order to engage young readers in the story, the writer creates a } \\
\text { role of the grandson of the artist who loves drawing and also } \\
\text { designs several conversations between them to tell the artist's } \\
\text { own story. Thus, the reader takes the role of the grandson when } \\
\text { reading the story. In addition, the title of this book is } \\
\text { "Grandfather Mei-shu" and the word choice of this title implies } \\
\text { the notion of paying respect to the elders. } \\
\text { - The use of style (visual): Representational art style }\end{array}$ \\
\hline Code/Category & Group 2-02 \\
\hline Title \& Content & $\begin{array}{l}\text { Shooting Suns } \\
\text { —A Taiwanese aboriginal myth }\end{array}$ \\
\hline Theme & $\begin{array}{l}\text { - Taiwanese aboriginal myth } \\
\text { - } \quad \text { Cultural transmission from one generation to another } \\
\text { - Survival story }\end{array}$ \\
\hline Setting & $\begin{array}{l}\text { - Time: Unknown (far away) } \\
\text { - Place: Rural community }\end{array}$ \\
\hline
\end{tabular}




\begin{tabular}{|c|c|}
\hline Characterization & $\begin{array}{l}\text { - Father is the best hunter, who is wise, brave, and has a sense of } \\
\text { responsibility. } \\
\text { - Son, who is wise, follows the teachings of his father. } \\
\text { - Grandson is trained to be a great hunter, who follows the way of } \\
\text { his grandfather's teaching. } \\
\text { Wizard is a translator, who can understand the message of the } \\
\text { spiritual bird. } \\
\text { - The spiritual bird is a messenger of god, who knows everything. } \\
\text { - Folks in the tribe follow decisions based on divinations. }\end{array}$ \\
\hline Plot conflicts & $\begin{array}{l}\text { - Conflicts between the hunters and their environment } \\
\text { There were two suns making people suffer. }\end{array}$ \\
\hline Plot structures & $\begin{array}{l}\text { (1) Once upon a time, there was one golden sun and no moon or stars } \\
\text { in the sky. However, one day there was another silver sun jumping } \\
\text { into the sky after the golden sun left. Since then, there was no night } \\
\text { anymore. This caused a lot of problems. A wizard divined and } \\
\text { decided that the only way to solve the problem was to shoot one sun. } \\
\text { The messenger of god- the spiritual bird also echoed the decision. } \\
\text { The tribe chose the best hunter knew no fear and he took his son and } \\
\text { grandson on the journey guided by the spiritual bird. } \\
\text { (2) The son brought seeds and grew them as they journeyed to find } \\
\text { the suns. On the way, the father taught his son and grandson about } \\
\text { nature and hunting as well as oral myths and life stories about the } \\
\text { tribe until the day he died. The son and grandson kept going. } \\
\text { (3) After several years, they finally found the silver sun and the } \\
\text { grandson, who was now a great hunter, shot the sun and the silver } \\
\text { blood turning into stars. The silver sun became weak and this caused } \\
\text { the sky to turn dark with sparkling stars. However, the golden sun } \\
\text { was afraid of the hunters and hid itself. The son and grandson guided } \\
\text { by the spiritual bird walked back to the tribe. } \\
\text { (4) The spiritual bird suggested that the tribe began singing and } \\
\text { dancing to invite the golden sun to come back to the sky because it } \\
\text { was afraid of being shot down too. After this, the silver sun only } \\
\text { showed in the night with no heat. Now, there was a sun during the } \\
\text { daytime and a moon at night. }\end{array}$ \\
\hline Point of view & $\begin{array}{l}\text { - Narrative voice: the third person with an omniscient perspective } \\
\text { - Point of view (visual): An omniscient perspective \& focalization }\end{array}$ \\
\hline Style & $\begin{array}{l}\text { - The text tells the whole story. The illustrations enhance the } \\
\text { imagination of the story, which creates dramatic effect. } \\
\text { - The use of style (visual): Cartoon art }\end{array}$ \\
\hline
\end{tabular}




\begin{tabular}{|c|c|}
\hline Code/Category & Group 2-03 \\
\hline Title \& Content & $\begin{array}{l}\text { Feng-cha (Free Tea for Everyone) } \\
\text {-A story of a traditional Taiwanese custom }\end{array}$ \\
\hline Theme & - Friendliness, human sympathy \\
\hline Setting & $\begin{array}{l}\text { - Time: The 1940s } \sim 1970 \mathrm{~s} \\
\text { - Place: Rural community }\end{array}$ \\
\hline Characterization & $\begin{array}{l}\text { - Village deity } \\
\text { - The heaven god } \\
\text { Folks in different places show their kindheartedness by offering } \\
\text { free tea to strangers and the strangers also appreciate these } \\
\text { offerings. }\end{array}$ \\
\hline Plot conflicts & $\begin{array}{l}\text { - Conflict within the village deity } \\
\text { He was wondering why free tea at the different corners of many } \\
\text { places was tasty and wanted to find the reason. }\end{array}$ \\
\hline Plot structures & $\begin{array}{l}\text { (1) Once a year, village deities needed to report what happened in the } \\
\text { villages they took care of. There was one village deity traveling } \\
\text { around his assigned area who wanted to find out how folks were } \\
\text { doing. He was thirsty and asked for water from a woodcutter. The } \\
\text { wood cutter pointed to a place where he could get free tea. The } \\
\text { village deity drank the tea and it was really tasty, so he decided to } \\
\text { find out why the tea tastes so good. } \\
\text { (2) The village deity went to different places and observed how folks } \\
\text { reacted to the free tea. } \\
\text { a. The entrance to a village } \\
\text { b. A path into the field } \\
\text { c. A transportation centre } \\
\text { d. An open space in front of a temple } \\
\text { e. An intersection, an entrance of a mountain path, the countryside } \\
\text { f. A temple of the village deity } \\
\text { (3) The village deity carried a big teapot of free tea to meet the } \\
\text { heaven god in order to show what he found in his assigned area. The } \\
\text { heaven god enjoyed the tea and remarked that the taste of the tea was } \\
\text { so delicious because the folks added their kindness into it. Although } \\
\text { their lives were hard, they shared their kindness and human sympathy } \\
\text { with others. }\end{array}$ \\
\hline
\end{tabular}




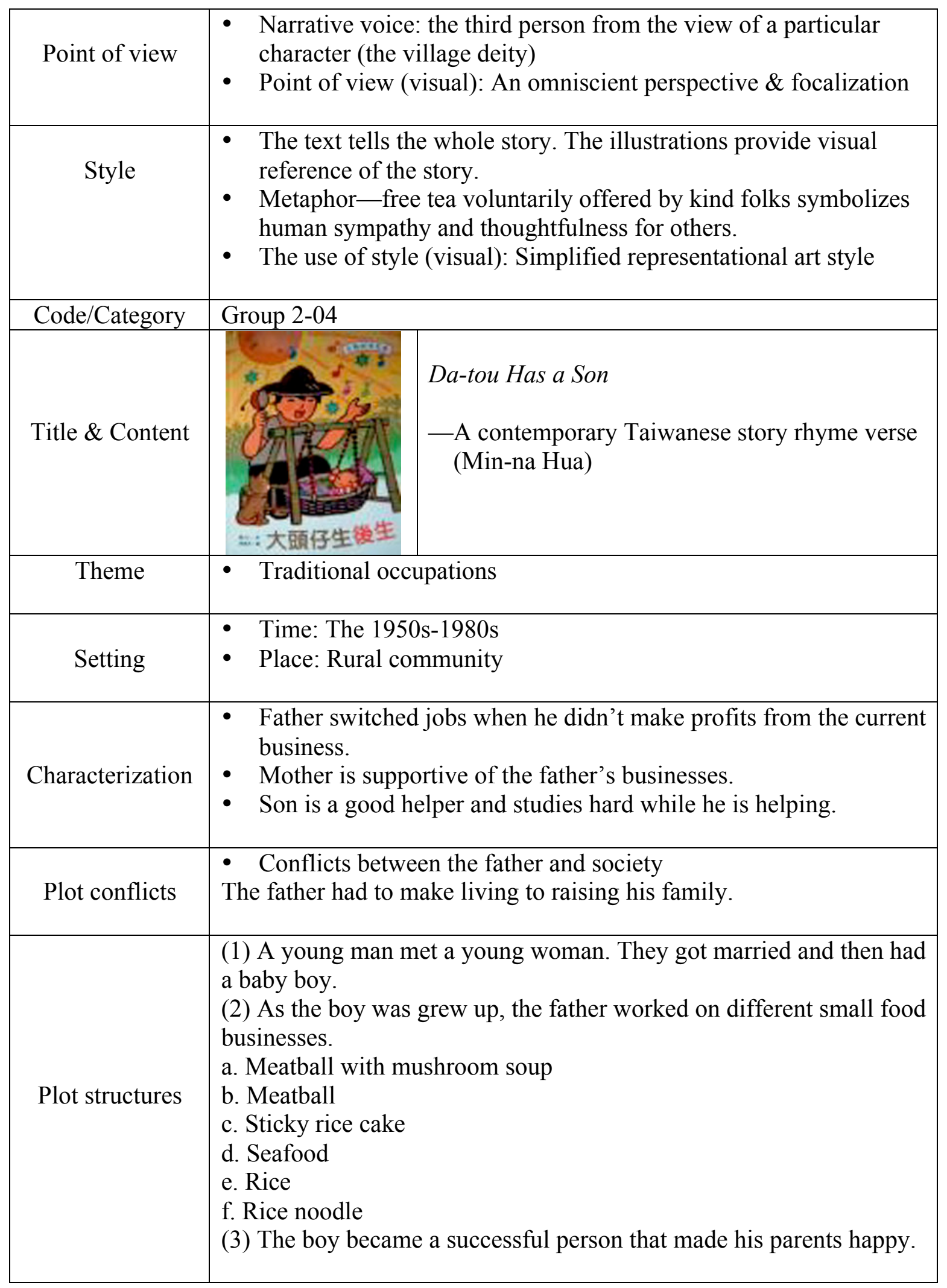




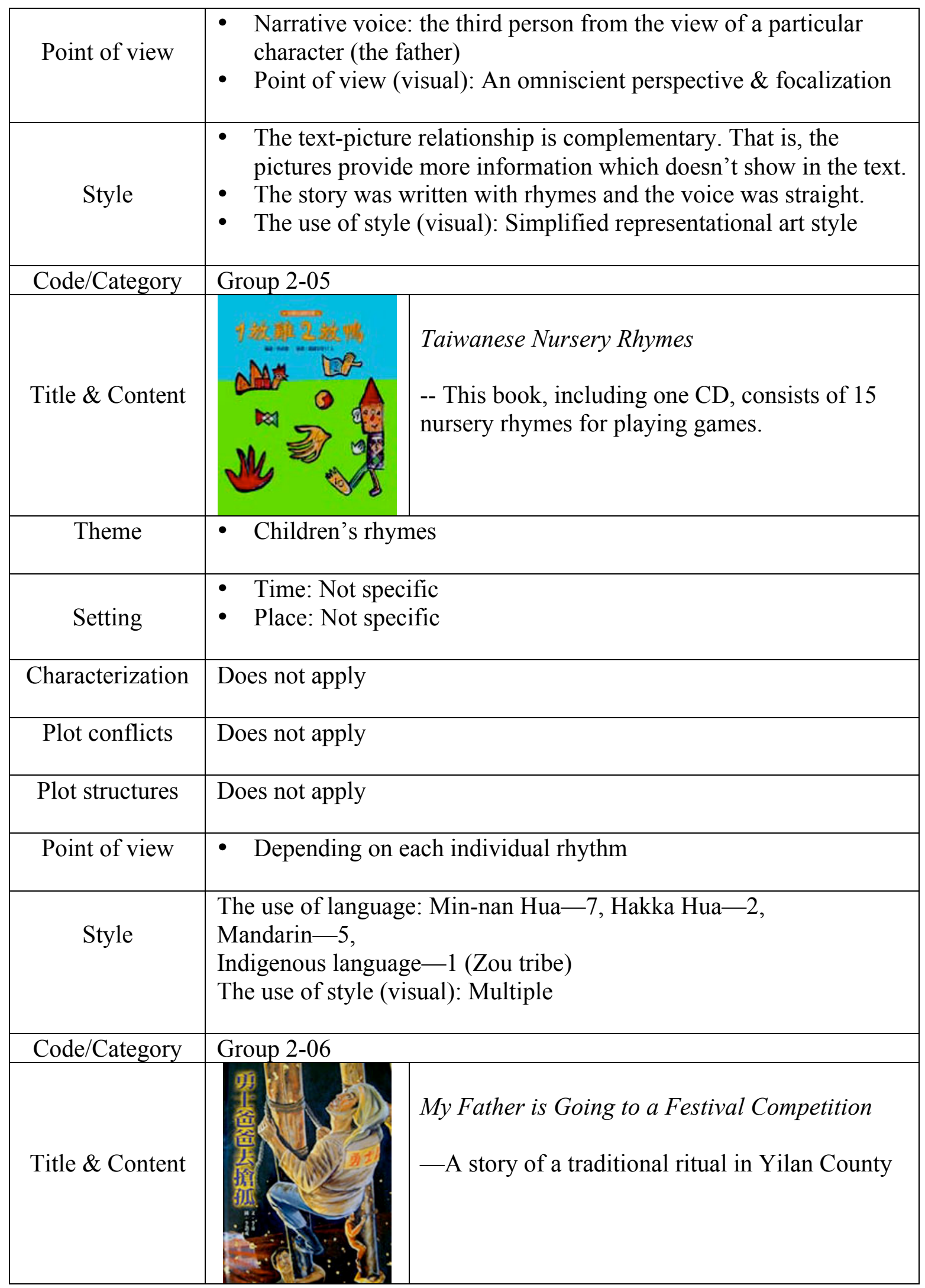




\begin{tabular}{|c|c|}
\hline Theme & Traditional ritual and celebration \\
\hline Setting & $\begin{array}{l}\text { - Time: Current } \\
\text { - Place: Yilan County (North part of Taiwan) — Suburban } \\
\text { community }\end{array}$ \\
\hline Characterization & $\begin{array}{l}\text { - Father is calm and sensible about what he wants to do. } \\
\text { - } \text { Mother is emotional and denies accepting his husband's plan. } \\
\text { - Team is naïve and curious about the plan. } \\
\text { Teammates firmly follow the difficult training. }\end{array}$ \\
\hline Plot conflicts & $\begin{array}{l}\text { - Conflict between the father and the mother } \\
\text { The father wanted to participate in a dangerous competition. }\end{array}$ \\
\hline Plot structures & $\begin{array}{l}\text { (1) The father told his family that he decided to participate in a ritual } \\
\text { competition in the town of Toucheng. His wife strongly disagreed } \\
\text { with the decision. And, his son was wondering what he meant by the } \\
\text { ritual. The father explained the training plan he had been doing. } \\
\text { However, his wife still disagreed. The son asked what the ritual was } \\
\text { and his father explained the process of it. They needed to climb on } \\
\text { sticky high poles to get a flag on the top. } \\
\text { (2) The father and his teammates took the training very seriously and } \\
\text { they were well-prepared for the competition. He also explained the } \\
\text { meaning of the ritual and the sponsoring for welfare. Finally, his wife } \\
\text { supported his plan and helped the team prepare for the competition. } \\
\text { (3) On the day of the competition all families of the team went to the } \\
\text { ritual and showed their support. However, the team lost the } \\
\text { competition because they fell down from the high poles. All wives of } \\
\text { the team said that the team was successful and all teams who } \\
\text { participated in the competition won the game. }\end{array}$ \\
\hline Point of view & $\begin{array}{l}\text { - Narrative voice: the third person from the view of a particular } \\
\text { character (the father) } \\
\text { - Point of view (visual): An omniscient perspective \& focalization }\end{array}$ \\
\hline Style & $\begin{array}{l}\text { - The text tells the whole story. } \\
\text { - The illustrations provide detailed information about the processes } \\
\text { of the training and competition. } \\
\text { - The use of style (visual): Expressionistic art }\end{array}$ \\
\hline
\end{tabular}




\begin{tabular}{|c|c|c|}
\hline Code/Category & \multicolumn{2}{|l|}{ Group 2-07 } \\
\hline Title \& Content & 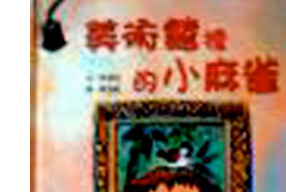 & $\begin{array}{l}\text { A Sparrow in the Museum } \\
\text { —A story of Taiwanese senior artists }\end{array}$ \\
\hline Theme & \multicolumn{2}{|c|}{ - Taiwanese senior artists } \\
\hline Setting & \multicolumn{2}{|c|}{$\begin{array}{l}\text { - Time: Current } \\
\text { - Place: Museum (architecture: traditional Chinese palace) —Urban } \\
\text { community }\end{array}$} \\
\hline Characterization & \multicolumn{2}{|c|}{$\begin{array}{l}\text { - The young girl is full of imagination. } \\
\text { Mother follows the young girl's interest to see each painting and } \\
\text { encourages her to look closely at the paintings. } \\
\text { - Docent encourages the young girl to find her answer by observing } \\
\text { the paintings. }\end{array}$} \\
\hline Plot conflicts & \multicolumn{2}{|c|}{$\begin{array}{l}\text { - Conflicts within the little girl } \\
\text { The young girl searched for a sparrow in the paintings. }\end{array}$} \\
\hline Plot structures & \multicolumn{2}{|c|}{$\begin{array}{l}\text { (1) The young girl was wondering what was inside the art museum } \\
\text { where she would visit for the first time. After coming into the } \\
\text { museum, she realized that the art museum was a place where } \\
\text { paintings, sculptures, and other artworks were on display. The theme } \\
\text { of the exhibition was "the beauty of Taiwan." } \\
\text { (2) The young girl searched for the sparrow shown in the painting } \\
\text { created by the artist Lin Yu-san. Then she checked each painting to } \\
\text { see whether the sparrow was in the painting or not. } \\
\text { a. The painting created by the artist Yang San- lang. } \\
\text { b. The painting created by the artist Liao Ji-chun } \\
\text { c. The painting created by the artist Li Tse-fan. } \\
\text { Her mother asked her to sit down and look closely at the painting } \\
\text { "The Instrumental Ensemble" created by the artist Chen Jin. } \\
\text { **In each painting, the young girl talked to the objects in the } \\
\text { paintings. } \\
\text { (3) Meanwhile, someone's voice said that there was a bird. The } \\
\text { young girl followed the voice and checked the artwork, which was a } \\
\text { sculpture created by the artist Yang Yi-fan, and found that it was not } \\
\text { the sparrow. She searched for it in the painting created by the artist } \\
\text { Lin Yu-san. }\end{array}$} \\
\hline
\end{tabular}




\begin{tabular}{|c|c|}
\hline Plot structures & $\begin{array}{l}\text { (4) The young girl checked the sparrow on the first painting she saw } \\
\text { and was sure that it flew back to the painting. She told the rest of } \\
\text { sparrows that it was fun to visit the museum. }\end{array}$ \\
\hline Point of view & $\begin{array}{l}\text { Narrative voice: the third person from the view of a particular } \\
\text { character (the little girl) } \\
\text { - Point of view (visual): An omniscient perspective \& focalization }\end{array}$ \\
\hline Style & $\begin{array}{l}\text { The text tells the whole story. Besides telling the story, the } \\
\text { illustrations serve as a visual game, which tends to catch readers' } \\
\text { attention. } \\
\text { - The use of style (visual): Simplified representational art style } \\
\text { - At the end of the book, contextual information of the artist for } \\
\text { each painting that the young girl mentioned in the story is } \\
\text { provided. }\end{array}$ \\
\hline Code/Category & Group 2-08 \\
\hline Title \& Content & 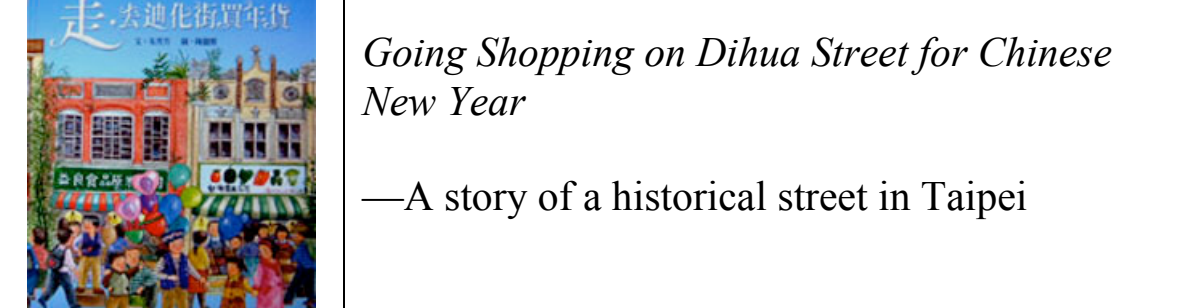 \\
\hline Theme & $\begin{array}{l}\text { - } \text { Preparation for Chinese New Year } \\
\text { - Introduction to a traditional street }\end{array}$ \\
\hline Setting & $\begin{array}{l}\text { - Time: Current } \\
\text { - Place: Dihua Street, Taipei_Urban community }\end{array}$ \\
\hline Characterization & $\begin{array}{l}\text { - Grandfather is knowledgeable about the history of the street. } \\
\text { - Grandson is interested in listening to his grandfather talking about } \\
\text { the history. }\end{array}$ \\
\hline Plot conflicts & Does not apply \\
\hline Plot structures & $\begin{array}{l}\text { (1) The grandson was excited about going shopping on the Dihua } \\
\text { Street with his grandfather for the Chinese New Year. They went to a } \\
\text { temple near the street and the grandfather mentioned the history of } \\
\text { the temple. } \\
\text { (2) Next, they went to a store selling all kinds of fabrics. The owner } \\
\text { complained about the hardship for his business. } \\
\text { (3) They walked on the street where different grocery stores sold } \\
\text { numbers of food products, such as Chinese medicines, dried seafood, }\end{array}$ \\
\hline
\end{tabular}




\begin{tabular}{|c|c|c|}
\hline Plot structures & \multicolumn{2}{|c|}{$\begin{array}{l}\text { grains, etc. } \\
\text { (4) The grandfather introduced the buildings on the street and the } \\
\text { history of the street. } \\
\text { (5) The grandfather took his grandson to a farming store and bought a } \\
\text { knife. On the way back home they bought a traditional lantern in a } \\
\text { store which was on a corner at the end of the street. }\end{array}$} \\
\hline Point of view & \multicolumn{2}{|c|}{$\begin{array}{l}\text { Narrative voice: the third person from the view of a particular } \\
\text { character (the little boy) } \\
\text { - Point of view (visual): An omniscient perspective \& focalization }\end{array}$} \\
\hline Style & \multicolumn{2}{|c|}{$\begin{array}{l}\text { - The text tells the whole story. The illustrations visualize the street } \\
\text { described in the text. } \\
\text { - The use of style (visual): Simplified representational art style }\end{array}$} \\
\hline Code/Category & \multicolumn{2}{|l|}{ Group 2-09 } \\
\hline Title \& Content & ? & $\begin{array}{l}\text { Yue-yue's Dancing Lessons } \\
\text { —A story of a little girl going to her first } \\
\text { dancing class }\end{array}$ \\
\hline Theme & \multicolumn{2}{|c|}{ - Child development, fear of unfamiliar an environment } \\
\hline Setting & \multicolumn{2}{|c|}{$\begin{array}{l}\text { - Time: Current } \\
\text { - Place: Dance studio-Urban community }\end{array}$} \\
\hline Characterization & \multicolumn{2}{|c|}{$\begin{array}{l}\text { - Little girl is anxious and depends on her mother. } \\
\text { - Teacher understands well the children's demands and encourages } \\
\text { them to work with each other through playing games or drama. } \\
\text { - Mother is patient with her daughter's anxiety. } \\
\text { - Other children }\end{array}$} \\
\hline Plot conflicts & \multicolumn{2}{|c|}{$\begin{array}{l}\text { - Conflict within the little girl } \\
\text { The little girl was anxious when going to get into a new environment. } \\
\text { It is a process of self discovery }\end{array}$} \\
\hline Plot structures & \multicolumn{2}{|c|}{$\begin{array}{l}\text { (1) The little girl first came to a dancing class with anxiety, so her } \\
\text { mother kept her company in the classroom. They sat together and } \\
\text { watched other children playing. } \\
\text { (2) The little girl wanted to go to the class, but she still needed her } \\
\text { mother in the classroom. They played games together. } \\
\text { (3) The little girl and her mother played games with other children in } \\
\text { the third class. Finally, she could play with other children while her } \\
\text { mother was sitting inside the classroom. }\end{array}$} \\
\hline
\end{tabular}




\begin{tabular}{|c|c|}
\hline Plot structures & $\begin{array}{l}\text { (4) The little girl was interested in the story told by the teacher and } \\
\text { also checked on her mother, who was sitting at the corner of the } \\
\text { classroom. } \\
\text { (5) Later, the little girl came into the classroom with her mother. } \\
\text { When the little girl could play with the class, her mother watched } \\
\text { outside the classroom and showed her support. } \\
\text { (6) The mother told her daughter that she would wait for her and } \\
\text { watch her from outside the classroom. She came into the classroom } \\
\text { with her teacher. The teacher asked everyone to pretend to be a bud } \\
\text { and to grow up. After class, everyone praised her for her } \\
\text { independence. } \\
\text { (7) The little girl came to the classroom by herself and her mother } \\
\text { was waiting outside. The teacher told a story about a caterpillar } \\
\text { turning into a cocoon, and then into a butterfly. } \\
\text { (8) The new class started, the little girl was willing to wear her } \\
\text { dancing suit and enjoyed the class with her friends. }\end{array}$ \\
\hline Point of view & $\begin{array}{l}\text { Narrative voice: the third person from the view of a particular } \\
\text { character (the little girl) } \\
\text { - Point of view (visual): An omniscient perspective \& focalization }\end{array}$ \\
\hline Style & $\begin{array}{l}\text { The text-picture relationship is complementary. } \\
\text { - Metaphor-the teacher asked the class members to pretend they } \\
\text { were a bud and a caterpillar, which is a metaphor depicting the } \\
\text { transformation of the little girl. } \\
\text { - The narrator's voice is with patience and encouragement. } \\
\text { - The use of style (visual): Simplified representational art style }\end{array}$ \\
\hline Code/Category & Group 2-10 \\
\hline Title \& Content & $\begin{array}{l}\text { Little White and Little Grey } \\
\text {-A story of two Taiwanese egrets }\end{array}$ \\
\hline Theme & - Typical Taiwanese creatures \\
\hline Setting & $\begin{array}{l}\text { - Time: Current } \\
\text { - Place: Rural community }\end{array}$ \\
\hline Characterization & $\begin{array}{l}\text { - Little White is an egret who likes to share his adventure with } \\
\text { Little Grey. } \\
\text { - Little Grey is a night egret who likes to chat with Little White. }\end{array}$ \\
\hline
\end{tabular}




\begin{tabular}{|c|l|}
\hline Plot conflicts & $\begin{array}{l}\text { - Conflict between the egrets and their environment } \\
\text { The use of farming machines has gradually produced environmental } \\
\text { pollution. Egrets are sensitive to their living environment. They } \\
\text { usually disappear due to a serious pollution problem. }\end{array}$ \\
\hline Plot structures & $\begin{array}{l}\text { (1) A description of the characteristics of Little White-an egret and } \\
\text { Little Grey -a night egret. They were friends and liked to chat with } \\
\text { each other. They chatted about a farming cow who was a friend of } \\
\text { Little White. } \\
\text { (2) Little White mentioned that a new machine (mechanic cow) was } \\
\text { used for farming and it replaced the real cow. Thus, Little White } \\
\text { followed the new mechanic cow to find his food (which implies that } \\
\text { the soil pollution has gradually decreased Little White's health). } \\
\text { (3) When winter came, Little Grey and Litter White became sick } \\
\text { because the environment had been changed. They promised each } \\
\text { other to look for a new place to stay. }\end{array}$ \\
\hline Point of view & $\begin{array}{l}\text { - Narrative voice: the third person from the view of a particular } \\
\text { character (the egrets) } \\
\text { Point of view (visual): An omniscient perspective \& focalization }\end{array}$ \\
\hline Style & $\begin{array}{l}\text { The text tells the whole story. The pictures illustrate what is } \\
\text { mentioned in the text. } \\
\text { The story tends to introduce two different types of egrets and also } \\
\text { raises the issue of environmental pollution. } \\
\text { The use of style (visual): Simplified representational art style }\end{array}$ \\
\hline
\end{tabular}

III. Taiwanese Teenagers/ Yuan-Liou Publishing/ 2003

\begin{tabular}{|c|l|l|}
\hline Code/Category & Group 3-01 & Selling Brooms with My Grandmother \\
\hline Title \& Content & -A story of the writer's memory of selling \\
& & \\
\hline Tand-made brooms with her grandmother.
\end{tabular}




\begin{tabular}{|c|l|}
\hline Setting & $\begin{array}{l}\text { - Time: The 1960s } \\
\text { - Place Yilan County (North part of Taiwan) - Rural community }\end{array}$ \\
\hline Characterization & $\begin{array}{l}\text { - The narrator (a young girl) } \\
\text { - Her mother }\end{array}$ \\
- Female folks are kindhearted and honest.
\end{tabular}




\begin{tabular}{|c|l|}
\hline Code/Category & Group 3-02 \\
\hline Title \& Content & $\begin{array}{l}\text { - Childhood memory } \\
\text { - Someone like grandmother } \\
\text { Theme }\end{array}$ \\
\hline - Adventure \\
Setting
\end{tabular}




\begin{tabular}{|c|c|}
\hline Plot structures & $\begin{array}{l}\text { (5) The boy reached his destination and said good bye to the old lady. } \\
\text { He walked to his grandaunt's home and took the umbrella and a } \\
\text { bundle of green onions back. He took another train back home. His } \\
\text { grandmother waited for him while he was approaching home. }\end{array}$ \\
\hline Point of view & $\begin{array}{l}\text { - Narrative voice: the first person } \\
\text { - Point of view (visual): An omniscient perspective \& focalization }\end{array}$ \\
\hline Style & $\begin{array}{l}\text { - The text tells the whole story. The tone of the text was plain, but } \\
\text { the plots were dramatic. } \\
\text { - The use of style (visual): Simplified representational art style } \\
\text { - The illustrations (black and white drawings) tend to create a } \\
\text { simple and plain feeling in order to present the tone of the story. }\end{array}$ \\
\hline Code/Category & Group 3-03 \\
\hline Title \& Content & Story Map \\
\hline Theme & $\begin{array}{l}\text { - } \text { Childhood memory } \\
\text { - } \text { Grandmother } \\
\text { - } \text { Adventure } \\
\text { Traditional values }\end{array}$ \\
\hline Setting & $\begin{array}{l}\text { - Time: The } 1970 \text { s } \\
\text { - Place: Pintung County (the Paiwan tribe)— Rural community }\end{array}$ \\
\hline Characterization & $\begin{array}{l}\text { - The writer (a young girl) is anxious to grow up and liked to go on } \\
\text { adventures. } \\
\text { - Her grandmother likes telling traditional stories to children and } \\
\text { thinks that children should respect the elders. }\end{array}$ \\
\hline Plot conflicts & $\begin{array}{l}-\quad \text { Conflict within the young girl } \\
\text { The young girl ran away from home }\end{array}$ \\
\hline Plot structures & $\begin{array}{l}\text { (1) One summer, the young girl ran away from home because she had } \\
\text { a fight with her mother. Due to two mistakes, she didn't succeed. One } \\
\text { was that the distance between the tribe where she lived and the place } \\
\text { she wanted to go was too long. And the other one was that the beauty } \\
\text { of the way to the place made her sleep on the sidewalk. }\end{array}$ \\
\hline
\end{tabular}




\begin{tabular}{|c|c|c|}
\hline Plot structures & \multicolumn{2}{|c|}{$\begin{array}{l}\text { (2) The beauty of the road reminded her of the stories told by her } \\
\text { grandmother. } \\
\text { a. Plants } \\
\text { b. A tale about a big red rock } \\
\text { c. A tale about the butterfly valley } \\
\text { d. A tale of walking feet } \\
\text { e. The spirit of forefathers } \\
\text { f. Singing traditional songs } \\
\text { g. A visit to an artisan's home and a tale of a girl } \\
\text { (3) The young girl safely came home and the grandmother said that it } \\
\text { was because of the blessing by the spirits of forefathers. }\end{array}$} \\
\hline Point of view & \multicolumn{2}{|c|}{$\begin{array}{l}\text { - Narrative voice: the first person } \\
\text { - Point of view (visual): An omniscient perspective \& focalization }\end{array}$} \\
\hline Style & \multicolumn{2}{|c|}{$\begin{array}{l}\text { - The text tells the whole story. The stylized illustrations tend to } \\
\text { visualize the text. } \\
\text { - The use of style (visual): Simplified representational art style }\end{array}$} \\
\hline Code/Category & \multicolumn{2}{|l|}{ Group 3-04 } \\
\hline Title \& Content & 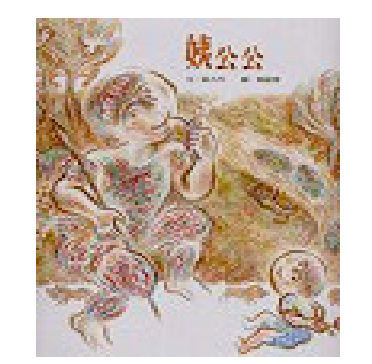 & $\begin{array}{l}\text { Yi Gong-gong } \\
\text {-A story of the writer's granduncle who was } \\
\text { a leader in his tribe }\end{array}$ \\
\hline Theme & \multicolumn{2}{|c|}{$\begin{array}{ll}\text { - } & \text { Childhood memory } \\
\text { - } & \text { Relative (granduncle) } \\
\text { - } & \text { Death } \\
\text { - } & \text { Growth }\end{array}$} \\
\hline Setting & \multicolumn{2}{|c|}{$\begin{array}{l}\text { - Time: The } 1950 \sim 60 \mathrm{~s} \\
\text { Place: Taitung County (the Beinan tribe in the mountain } \\
\text { area)-Rural community }\end{array}$} \\
\hline Characterization & \multicolumn{2}{|c|}{$\begin{array}{l}\text { - The writer (a young boy) is young and naïve. } \\
\text { - His parents are supportive of their children's education. } \\
\text { His granduncle is intelligent, brave, thoughtful, and has a sense of } \\
\text { responsibility to his tribe. }\end{array}$} \\
\hline Plot conflicts & \multicolumn{2}{|c|}{$\begin{array}{l}\text { - Conflict between the granduncle and other folks } \\
\text { The granduncle tried to stop a possible conflict between two tribes. }\end{array}$} \\
\hline
\end{tabular}




\begin{tabular}{|c|c|c|}
\hline Plot conflicts & \multicolumn{2}{|c|}{$\begin{array}{l}\text { - Conflict within the little boy } \mathrm{T} \\
\text { The death of the granduncle }\end{array}$} \\
\hline Plot structures & \multicolumn{2}{|c|}{$\begin{array}{l}\text { (1) The granduncle gave a lesson to the } 7 \text { year old boy before the day } \\
\text { he would go to an elementary school--"Going to school for study is } \\
\text { for our tribe and our people rather than for your own good." During } \\
\text { midnight of the same day, the granduncle died due to a heart attack. } \\
\text { Next day was the first day that the young boy went to school. } \\
\text { (2) The boy recalled his memories of the granduncle when he was a } \\
\text { young adult. He was a leader of the tribe not only dealing with public } \\
\text { affairs in the tribe, but also negotiating to stop possible conflicts } \\
\text { among different tribes. In his memories, the granduncle enjoyed } \\
\text { singing old songs and was a great hunter, who understood how to set } \\
\text { up traps and to analyze his dreams for an understanding of himself. } \\
\text { (3) The boy recalled the funeral he attended and realized that the } \\
\text { conversation between the granduncle and him on the night he past } \\
\text { away was a dialog between him and his childhood, in which he } \\
\text { learned to understand his granduncle and even himself. }\end{array}$} \\
\hline Point of view & \multicolumn{2}{|c|}{$\begin{array}{l}\text { - Narrative voice: the first person } \\
\text { - Point of view (visual): An omniscient perspective \& focalization }\end{array}$} \\
\hline Style & \multicolumn{2}{|c|}{$\begin{array}{l}\text { - The text tells the whole story. The stylized illustrations tend to } \\
\text { visualize the essence of the story and the aboriginal culture. } \\
\text { - The use of style (visual): Expressionistic art }\end{array}$} \\
\hline Code/Category & \multicolumn{2}{|l|}{ Group 3-05 } \\
\hline Title \& Content & $\lim _{3}$ & $\begin{array}{l}\text { A Memory of the Tea Plantation } \\
\text {-A story of the writer's family running a tea } \\
\text { business in the countryside during the } \\
\text { 1950s } 1960 \text { s. }\end{array}$ \\
\hline Theme & \multicolumn{2}{|c|}{ - Childhood memory } \\
\hline Setting & \multicolumn{2}{|c|}{$\begin{array}{l}\text { - Time: The } 1950 \mathrm{~s} \sim 1960 \mathrm{~s} \\
\text { - Place: Mountain (middle part of Taiwan)—Rural community }\end{array}$} \\
\hline Characterization & \multicolumn{2}{|c|}{$\begin{array}{l}\text { This book mainly depicts life in a small town. The characters are flat. } \\
\text { - The writer (a young boy) likes reading and playing outdoors. } \\
\text { - His parents } \\
\text { simply and (uncles and aunts), who live on the mountain, are } \\
\text { simply }\end{array}$} \\
\hline
\end{tabular}




\begin{tabular}{|c|c|c|}
\hline Plot conflicts & \multicolumn{2}{|l|}{ Does not apply } \\
\hline Plot structures & \multicolumn{2}{|c|}{$\begin{array}{l}\text { (1) A general description of the tea plantation "Dongding" } \\
\text { (2) A description of the location of the writer's old house and his } \\
\text { father's store } \\
\text { a. The design of the billboard created by his father } \\
\text { b. The collaboration between the tea plantation and the store (family } \\
\text { business) } \\
\text { c. The different tastes of new and old tea leaves } \\
\text { (3) A description of the additional business in the tea store } \\
\text { a. Books and stationery } \\
\text { b. Stamps } \\
\text { c. Cigarettes and alcohol } \\
\text { (4) A description of the outdoors } \\
\text { a. Catching lizards } \\
\text { b. Picking olives } \\
\text { c. Army game } \\
\text { d. Baking yams (autumn) } \\
\text { e. Swimming } \\
\text { f. Secret place (winter) } \\
\text { (5) The writer yearned for his childhood memories. }\end{array}$} \\
\hline Point of view & \multicolumn{2}{|c|}{$\begin{array}{l}\text { - Narrative voice: the first person } \\
\text { - Point of view (visual): An omniscient perspective \& focalization }\end{array}$} \\
\hline Style & \multicolumn{2}{|c|}{$\begin{array}{l}\text { The text tells the whole story, which provides detailed } \\
\text { information about the place. The pictures illustrate the place in } \\
\text { detail. } \\
\text { - The use of style (visual): Simplified representational art style }\end{array}$} \\
\hline Code/Category & \multicolumn{2}{|l|}{ Group 3-06 } \\
\hline Title \& Content & $\int_{0}^{A}$ & $\begin{array}{l}\text { A River Resembling a Mother } \\
\text {-A story of the writer's memory of the loss } \\
\text { of his mother }\end{array}$ \\
\hline Theme & \multicolumn{2}{|l|}{$\begin{array}{l}\text { - } \text { Childhood memory } \\
\text { - Death }\end{array}$} \\
\hline
\end{tabular}




\begin{tabular}{|c|c|}
\hline Setting & $\begin{array}{l}\text { - Time: The } 1960 \mathrm{~s} \\
\text { - Place: Middle part of Taiwan around a river-Rural community }\end{array}$ \\
\hline Characterization & $\begin{array}{l}\text { - The writer (a young boy) enjoys outdoors and is sensitive. } \\
\text { - The father is rigorous and pays close attention to his child's } \\
\text { education. } \\
\text { - The mother's image is vague. }\end{array}$ \\
\hline Plot conflicts & $\begin{array}{l}\text { - Conflict within the child } \\
\text { Overcoming the loss of his mother }\end{array}$ \\
\hline Plot structures & $\begin{array}{l}\text { (1) The writer faced the death of his mother when he was } 4 \text { years old. } \\
\text { He was comforted by his relatives (grandparents, uncles and aunts). } \\
\text { (2) Although he lost his mother and his father disciplined him } \\
\text { rigorously, he was happy during his childhood because he enjoyed } \\
\text { playing in nature. } \\
\text { a. Going fishing } \\
\text { b. Catching frogs (it might cause trouble if the farmers of the field } \\
\text { found out.) } \\
\text { c. Going swimming (it might cause punishment if adults found out. } \\
\text { However, it was worth a punishment.) } \\
\text { (3) Dreaming of the dead mother represented his missing her. }\end{array}$ \\
\hline Point of view & $\begin{array}{l}\text { - Narrative voice: the first person } \\
\text { - Point of view (visual): An omniscient perspective \& focalization }\end{array}$ \\
\hline Style & $\begin{array}{l}\text { - Although the text tells the whole story, the illustrations enhance } \\
\text { the story by using metaphors (the use of color creating emotions } \\
\text { for the story, a woman holding an umbrella, and a mother cat } \\
\text { looking over her kitties.) } \\
\text { - The use of style (visual): expressionistic art }\end{array}$ \\
\hline
\end{tabular}




\section{APPENDIX D}

\section{INTERVIEW DATA}

\section{The Purpose of the Interview}

The purpose of the interviews with the editors from the two publishing houses, which published the three sets of Taiwanese picturebooks, is to understand the editors' intentions and objectives for their publications. Their personal accounts serve as contextual information to understand their concerns with Taiwanese culture. Since these interviews were informal conversations, interview questions were unstructured. However, the conversations were based on three main ideas: (1) the objective of the particular set of the picturebooks, (2) the making process of the picturebooks, and (3) the marketing strategy for selling the picturebooks. These ideas are paraphrased as the following questions:

1. Objective-What is the goal or objective of the picturebooks, and how did the ideas evolve?

2. Process - How did the editors select the subject matters, the writers, and the illustrators? What was the collaboration model between the writer and the illustrator in the making process? What challenges did the editors meet in the publishing process regarding the picturebooks?

3. Marketing - How did the publishing house develop the marketing strategy for selling the picturebooks?

\section{Interview Subjects}

The titles of the three sets of picturebooks are the Firefly Picturebook SelectionTaiwanese Folk Tales, the Taiwanese Teenagers (both published by Yuan-Liou Publishing), and the Taiwanese Children's Picturebook Selection (published by Children's Publications).

The Firefly Picturebook Selection-Taiwanese Folktales was published in 1989 and re-issued in 2003. When I contacted Yuan-Liou Publishing, the editor who originally executed the publishing project of the Taiwanese Folk Tales no longer worked for the publishing house. Moreover, the current editor, who was responsible for re-issuing these picturebooks, was not able to provide any information regarding why and how the 
editorial team created this set of picturebooks. For this reason, the current editor of this set of picturebooks was excluded from the interviews.

The Taiwanese Folk Tales, first published in 1989, consisted of 12 picturebooks. Six of them were Han folktales while the other six picturebooks were aboriginal myths. However, only the six Han folktales were re-issued and published in 2003. I wondered why the six aboriginal myths were excluded. In order to clarify this question, I contacted the current editor by phone on December 22, 2004. And, she replied that on their list, the six aboriginal myths would be reissued and published accompanying the other books related to aboriginal culture later.

As a result, the interview participants consisted of the editor Ms. Lain for the Taiwanese Teenagers and the senior editor Ms. Lin and the publisher Mr. Lin for the Taiwanese Children's Picturebook Selection. Both the interviews were conducted in their offices on December 15, 2004 and December 23, 2004, respectively.

\section{Interview Notes}

\section{Interview I}

Date: December 15, 2004

Publication: Taiwanese Teenagers by Yuan-Liou Publishing Senior Editor: Ms. Lain Tsuey-moh

Note: This interview text is written and translated based on the notes I took while I was talking to Ms. Lain. That is because Ms. Lain did not feel conformable with tape recoding. The text is construed in a way to present Ms. Lain's notions regarding the three main questions above. I avoid reporting them with a format of question and answer because our conversations did not follow a list of structured questions. Rather, it was an informal talk like friends, although this was the first time we met each other.

The initial idea about the Taiwanese Teenagers was inspired by Japanese novelist Kenzaburo Oe, who is a winner of the 1994 Nobel Prize in Literature, according to Ms. Lain. Oe remarked that every writer should write a book for children. Ms. Lain agreed with this idea and put it into action. She proposed a project, which was to invite wellknown writers or artists to write a story for children in a picturebook format. The publisher also supported her idea because Taiwanese local culture was one of the themes on their book list. Thus, she sent out invitation letters to the writers and artists whom she could reach. However, not many of them were willing to do it because they were not familiar with children's picturebooks and they usually wrote novels or essays for adults. It was a challenge for them to write a short story in a few hundred words. Finally, Ms. Lain found a way to solve the problem by providing a short guideline. That is, the writers were asked to write an unforgettable personal childhood memory with regard to a person, an event, or a place. As a result, this guideline did help the writers pin down their ideas for the books. 
Since these writers had already established their own reputations in the literary world in Taiwan, Ms. Lain intended to choose inexperienced illustrators to create pictures for the stories. That was because she wanted to promote the new illustrators by providing these opportunities, which was a way to encourage local illustrators to make picturebooks for children. However, the collaboration between the writers and the illustrators was another challenge because the writers tended to describe every detail about their stories in words. They lacked the concepts about the text-picture relationship in the picturebook. Thus, Ms. Lain needed to be a mediator for negotiating the integration of the text and pictures. It took more than one year to complete the first six picturebooks. Considering the challenges they had encountered, Ms. Lain was pleased by the results.

The implied readers for this set of picturebooks were designated as children and their parents, according to Ms. Lain. Through the reading process parents could share their childhood memories with their children. The contextual information attached to each book provided some details about the places mentioned in the stories. This information was designed to help children learn more about Taiwan. However, these picturebooks were also welcomed by adults and even seniors. For example, some adult book clubs picked out these picturebooks and had group discussions on them. A senior book club was assigned to discuss the book "When I was Eight, I Went on A Journey," one picturebook of the Taiwanese Teenagers, and took a train following the route mentioned in the book. Compared with the drawings shown in the book, they were surprised by the scenery they saw on the way to Yilan County, the destination of the trip. Their response to this particular picturebook pleased Ms. Lain.

When asked the reason for the selection of the stories, Ms. Lain said that the diversity of the six stories, including two aboriginal writers (one male and one female) and four Han writers (three males and one female) who lived in different regions (such as the plain, mountain, and riverside including the north, south, east, and west parts of Taiwan), were unexpected. They just happened to show the diverse life experiences in Taiwan. The reason for selecting these six writers was because they submitted their manuscripts earlier than others. These six stories were not the only picturebooks in the Taiwanese Teenagers set on her list. Rather, there would be more titles to add to this category. Ms. Lain said that there were four more picturebooks coming soon in 2005. One of them even took two years to complete. This showed how time consuming accomplishing such a project was. However, she was willing to continually work with potential writers and illustrators to add their stories to this category.

In terms of the issue of authenticity the illustrators for the stories written by the two aboriginal writers were not from the same cultures as the writers because Ms. Lain did not want to emphasize that the picturebooks authentically represented a particular aboriginal culture. To overemphasize this would create stereotypes regarding the culture. Rather, she wanted to show an individual's life experience through the picturebooks. Therefore, she liked to give artistic freedom to the illustrators as long as the illustrations did not show mistakes. However, it was difficult to find illustrators who could properly match the results she expected. 
The marketing strategy regarding this set of picturebooks relied on the marketing team of the publishing house. Ms. Lain did not participate in their meetings. The team reviewed the picturebooks and identified the strengths of the products and the targeted consumers. The layout for promoting the books on the publishing web pages was one of their outcomes. Although promotion was not Ms. Lain's duty, she also needed to consider this issue when generating new proposals for children's picturebooks. To do this, she needed to place more weight on publishing translated picturebooks and less on picturebooks created by Taiwanese writers and illustrators because the former had a lower cost than the that of the latter.

Ms. Lain stated that the 1950s and 1960s was the period that segregation between local Taiwanese and Mainland Chinese was most serious. The film The Time to Live and the Time to Die, directed by Hsiao-hsian Hou, vividly depicted the situation. Ms. Lain thought that there should have been more communication between people in order to have a better understanding of each other. Taiwan was growing. The title Taiwanese Teenagers was to show the energy of Taiwanese. Ms. Lain hoped that the stories in the Taiwanese Teenagers, like different pieces of a puzzle, came together to reveal Taiwanese culture.

\section{Interview II}

Date: December 23, 2004

Publication: Taiwanese Children's Picturebook Selection by Children's Publications Chief Editor: Ms. Lin

Publisher: Mr. Lin

Note: This interview text is transcribed based on the recorded tape and translated from Chinese to English. Thus, the wording is based on my understanding of the conversations and the use of English. In this case, I tend to use the third person to describe what the interview subjects thought about the questions I asked. In other words, I do not use the first person to present their voices because this is a translated text, which means I can not present their exact ideas by using the same words they said in Chinese. The reason I present this text with a format of question and answer is because the conversations were involved with two subjects. Thus, I need to identify whose view was presented. Moreover, I skip the conversations which are not relevant to my study, such as some personal conversations related to my previous working experience. That is because I had some contact with Ms. Lin and Mr. Lin when I was working for the Caterpillar Foundation of Philosophy for Children during 1999 and 2000. As a result, this interview text is consciously selected and constructed by the writer.

Kuo: How did you develop the proposal for publishing this set of picturebooks? Was this proposal related to the cultural policy "Taiwanese Cultural Heritage Year" promoted by the Council for Cultural Affairs in 2001? I asked because these picturebooks were 
published in 2002 and there was a partnership between the publishing house and the Council for Cultural Affairs.

According to Ms. Lin, this project did not relate to this specific cultural policy. The Council for Cultural Affairs has annually held the Bologna International Illustration Exhibition in Taiwan for several years. The artworks were invited from all over the world. It was not until 2000 that the Council decided to set up a special theme of Taiwanese Picturebooks, which could reflect Taiwanese culture, in the exhibition. Thus, they called for proposals and selected one of them to publish a set of picturebooks. The Taiwanese Children's Picturebook Selection was the result of it.

Ms. Lin stated that they selected a picturebook format to present Taiwanese culture. They were aware that this format was not like an encyclopedia, which could cover many themes and topics, but rather it would focus on a specific idea. When considering the selection of stories, they took the perspective that current children needed to learn about Taiwanese culture. They then came up with the different subject matters. In today's society children lack an understanding of the early agricultural Taiwanese society with its unique aspect of Taiwanese culture, such as friendliness and hospitality. Therefore, they decided to search for more subjects based on this idea. Therefore, they invited scholars with a good understanding of Taiwanese culture to come together and discuss the possible subjects for the picturebooks. They invited Cheng Ming-jin, the father of Taiwanese picturebooks and an elementary art teacher for 25 years; Su Chenming, a current art education professor in the Taipei Teacher College; and Taso Jun-yan, an art teacher, illustrator, writer, and editor. Their goal was to introduce some traditional cultural practices to children, which are still practiced in today's life. For example, the book Free Tea for Everyone is about a traditional custom, but it still exists nowadays. When selecting Taiwanese nursery rhymes, they chose the ones which children can use in the games they play in their daily lives. In sum, the selection of stories was intended to connect children to the customs and traditions introduced in the picturebooks. For example, the book Let's go to Dihua Street, which is a story of a historical street in Taipei, is intended to introduce the street as it still exists.

Kuo: How about the story Shooting Suns, which is a myth?

According to Ms. Lin, although Shooting Suns was a Taiwanese aboriginal myth, the spirit of the story was contemporary and children should understand it. In the story, a father took his son and grandson with him to find the two suns and shoot down one of them. It contained the idea of passing down knowledge, courage, and responsibility. This differed from the Chinese version of this myth, in which a hero named Hou Yi shot down nine suns on his own within a short time period.

Kuo: So, the subjects in the picturebooks were generated in the group discussions with the three consultants. Then, you invited writers and illustrators to create stories and pictures based on them. 
Ms. Lin agreed with this and Mr. Lin stated that there were three categories in this project: folkways, art, and environment. For example, the book My Father is Going to a Festival Competition fell in the category of folkways and was about a traditional ritual in Yilan County. The art category consisted of the books Taiwanese Nursery Rhymes, $A$ Sparrow in the Museum, Yue-yue's Dancing Lessons, and Mei-shu A-gong, the story of a Taiwanese senior artist. The book Little White and Little Grey-A Story of Two Taiwanese Egrets was about the environment.

Ms. Lin emphasized that their intention was to introduce something from the past to children with a connection to their current lives. For example, in the story about the senior artist Li Mei-shu, the writer set up a plot showing the interaction between the artist and his grandson. In so doing, children readers could relate the characters in the story to themselves and their own grandfather.

Kuo: How did you pick out the illustrator?

Ms. Lin stated that they relied on the consultants' recommendations because the consultants had rich experiences with making picturebooks and sources to find the illustrators who could meet the needs of the stories.

Mr. Lin added his comments to Ms. Lin's remark. He said that they were also concerned with how the illustrators could properly present the local cultures in the stories. For example, the book My Father is Going to a Festival Competition was a ritual in Yilan County. Both the writer and the illustrator were from Yilan. They were very well familiar with the ritual. The writer had already written and published articles about the ritual. For this particular picturebook, he was asked to write about it in a story format for children. And, the illustrator had already created many paintings about the ritual before he illustrated this story.

Ms. Lin also remarked that it was easy for the illustrator to create pictures for this book because he was from that culture and understood every detail about the ritual, so he was able to catch the essence of it. This book was an attempt to introduce the ritual in a fictional way, in keeping with the spirit and process of the ritual itself. The illustrator did an excellent job on this book.

Kuo: It was very interesting to see that the story ended up with the main character failing the competition. In this way, it made readers pay more attention to the training process for the competition and understand the meaning of the ritual.

Ms. Lin agreed with my point and said that it was something different from the conventional stories that they wanted to present in these picturebooks. She tied her point back to the idea mentioned above. That is, they wanted to introduce some important traditional concepts through the stories rather than just presenting an information book format. In so doing, children could relate better to the characters in the stories. 
Mr. Lin also emphasized that they intended to present the stories from a new perspective. For example, the writer of the book My Father is Going to a Festival Competition not only provided a historical perspective of the ritual in the story, but also emphasized that although one did not succeed after working hard, they could be considered successful for doing their best to reach the goal. The conventional way of story telling usually reinforced the concept that if one does his best, he will succeed. However, the writer wanted to provide an alterative way of thinking. That is, to do one's best is a success and the process is important.

Ms. Lin added that the training program the father received in the story helped readers understand the process of preparing for the competition.

Mr. Lin stated that another book Shooting Suns also shows changes within a process.

Kuo: Why did you choose Mr. Lai to illustrator this aboriginal myth even though he was not an aborigine?

According to Mr. Lin, there were several reasons why they picked the illustrator for this particular story. They tended to select someone who could properly depict the story, which was the most important concern. Moreover, this was a collaborative project with the Council for Cultural Affairs, so they needed to publish the picturebooks within one year. The time issue forced them to choose someone who could finish work on time. And, the illustrator was able to accept the pay they could offer. At first, they considered finding an aboriginal illustrator for this book. However, due to the factors mentioned above, they shifted their direction to considering the individual's ability to deal with the story rather than having an illustrator because of his/her ethnic identity. To do this, they provided the illustrator with a lot of information and studies regarding the story. They also wanted to use an unconventional way to present this traditional myth. Thus, they found a video Shooting Suns by Cloud Gate from 1992 (a professional performing group in Taiwan), which showed a contemporary interpretation of it. The task of shooting suns was completed by a group of people rather than a hero. They intended to present the story in a contemporary form which contained a sense of warmth and softness. He thought it was not necessary to depict aborigines in a usual manner of toughness and ferocity.

Kuo: The visual representation of the two suns in this book was very interesting.

Both Ms. Lin and Mr. Lin said that the style of the suns was based on the design in the performance Shooting Suns, which has been acceptable by children.

Ms. Lin added her comments about how they chose the illustrators for the books. She stated that experience was a very important matter for illustrating stories. If illustrators did not have concepts about creating picturebooks, communication would become extremely difficult. That was another aspect they needed to take into consideration when choosing illustrators. 
Mr. Lin stated that they found an aboriginal illustrator for the book, but it did not work out.

Ms. Lin added that making picturebooks differed from creating fine artworks. It required the illustrator to have a sense of rhythm in considering the relationship between pictures.

Kuo: I thought the design of the suns looked like a Japanese style.

Mr. Lin mentioned that in an illustration exhibition, showing the original work of this particular picturebook, some Japanese audiences also wondered why the suns looked like a Japanese style.

Ms. Lin replied that the design of the suns was for a dramatic effect. The illustrator adopted the idea from the performance, but also made some changes in the outlook. The human look of the suns was an attempt to attract children.

Kuo: How about the design of the end papers? (The author drew comic strips to show the process of making this particular picturebook.) Why did you have this idea?

Both Ms. Lin and Mr. Lin agreed that the illustrator was depressed while he was working on the project due to time limitation and delay caused by a typhoon. They let the illustrator draw what he felt about the making process and put it on the end papers. $\mathrm{Mr}$. Lin explained that although some of his complaints were not accurate, they still let him do it without changing the content. Ms. Lin also stated that they played the role of the complaint receiver.

Kuo: Was the style of the costumes shown in this book based on the Taiya tribe?

Mr. Lin replied that the story was mainly based on the Taiya tribe, but this myth could be found in other different tribes in Taiwan. They did not identify this story as a Taiya myth in this book in order to avoid any possible complaints. Moreover, integrating a variety of cultural elements from different tribes was emphasized in the book. This book was not an information book and did not try to introduce facts to children.

Ms. Lin also remarked that this was a myth, not a history.

Mr. Lin emphasized that they used a new way to interpret this story rather than just providing knowledge about the traditional story.

Kuo: Have you considered publishing a series of aboriginal children's books?

Ms. Lin said that they did consider it, but it depended on whether they were able to find appropriate work from writers and illustrators. However, some books on this topic were still in the publishing process. For example, authors might consider what their 
strengths were and wanted to present the stories in a way they felt right, such as the new book An Owl on a Little Island, which introduced animals in nature from the island of Lanyu, where the Dawu tribe lived.

Mr. Lin mentioned that they had planned to publish picturebooks that introduced folktales from different places in Taiwan, such as the town of Tamsui and the island of Pengwu. However, they could not find appropriate stories.

Kuo: What do you mean by the appropriate stories? Do you mean good stories already written or having writers to produce stories based on the subject matters you decided upon?

Mr. Lin explained that they already had the subjects for the stories they expected, but it was difficult to have good stories based on them. For example, they invited Liu Kehsing, who was a famous environmental writer, to write a story about the town of gandau. But it was another challenge to find appropriate illustrators to present the stories.

Kuo: It seems that your publishing process is to first set up themes, then invite writers to compose stories based on the subjects, then find illustrators to create pictures matching the stories, and then print books. The first ten picturebooks were published in 2002 because they were finished within the assigned time frame.

Mr. Lin agreed with my summary and pointed out again that the subjects were based on the three major categories of folkways, art, and environment. They were working on several books based on these three categories currently without the pressure of the time issue.

Ms. Lin said that there would be a picturebook about Li Tse-fan, who was a senior artist from Hsinchu County, published sooner or latter based on the biography authored by Liu Su-shia, who was an art education professor at the Hsinchu Teacher College. This book took her two years to complete. It was very important to find a writer and illustrator who had some feeling about the subject, so they could do a good job translating the story into a picturebook. To do this, the key was finding writers and illustrators who already knew the subject matters well. They had done this before with the artist Li Mei-shu. They found the writer Su Chen-ming, who had studied the artist before he wrote the story, and the illustrator Chen Ming-jie, who was from the artist's hometown of Sanshia.

Kuo: How did you promote the picturebooks?

According to Mr. Lin, there were 4,000 children's books published in 2003. Most of them were not shown in book stores after 2 or 3 months on display. They were considered out of date because too many new books were waiting for displaying. The strategies for promotion used by Yuan-Liou Publishing, another publishing in Taiwan, consisted of DMs, websites, book exhibitions in schools, and promotions for book clubs. 
While the Children's Publications promoted its publications by holding special events for the books, sponsoring book clubs, providing special discounts, and having book autograph activities.

Kuo: The Taiwanese Children's Picturebook Selection was a collaboration of the Council for Cultural Affairs and the Children's Publications. What was the meaning in terms of this collaboration model?

Mr. Lin thought that the Council for Cultural Affairs encouraged cultural activities held by non-profit and profit originations. They called for art and culture proposals and gave different supports. These proposals should be officially reviewed and selected. Although the proposal of the Taiwanese Children's Picturebook Selection received some funding from the Council for Cultural Affairs, the publishing house also needed to share the cost, take care of the production process, and promote the books. Overall, it was challenging when they tried to deal with the administration and with the government. For example, they needed to finish the project in a certain time period; the administrators did not understand the picturebook; too many opinions were involved in the project; and the administrative process was complicated.

Ms. Lin remarked that the meaning of this collaboration was to demonstrate their "profession" to the government. The government usually had budgets for supporting publication. However, a lack of professional knowledge about publication they sponsored might affect the outcomes. In other words, publishing houses knew better about how to produce and promote books. In this collaboration, the publishing house directed the production process while the Council for Cultural Affairs sponsored and purchased the books and provided cultural sources that helped the writers and illustrators to collect information related to the stories for the picturebooks.

Kuo: Did you try to promote these Taiwanese picturebooks in a global book market? Did you think that these picturebooks telling local cultures would attract international publishers?

Mr. Lin stated that they did display their picturebooks in the international book market, such as the Bologna Book Fair. Some of them attracted foreign buyers. Although books with a local cultural characteristic were unique in their very own ways, they might not attract international buyers because the stories were too specific, which were unfamiliar to readers from other cultures.

Ms. Lin said that generally speaking, picturebooks with copy rights sold out to other countries were created by the illustrators who had high reputations in the filed or the subjects contained a universal theme. In terms of the Taiwanese Children's Picturebook Selection, they were particularly created for Taiwanese children. 


\section{APPENDIX E}

\section{WEBSITE PROMOTIONS FOR THE PICTUREBOOKS}

This section consists of the on-line promotions regarding the three sets of Taiwanese picturebooks. The information was gathered from the websites, which are created and maintained by the two publishing houses: Yuan-Liou Publishing and Children's Publications, and accessed on April 4, 2005. These promotions present the perspectives of the publishing houses when considering the major targeted consumers - parents and teachers. In order to get the buyers' attention and fulfill their educational demands for children, the contents of these promotions reinforce the ideologies that the publishing houses tend to emphasize and influence their readers to believe. These provide the contextual information that can help the researcher examine the texts from an aspect of commercial concern.

The description of the three websites is divided into two segments: the map of the website and the description of each web page. The description is not a translation on a word by word basis. Rather, it highlights the points which are relevant to my study. Thus, the information accompanying the web pages is selected and constructed by the researcher. 


\section{The Firefly Picturebook Selection-Taiwanese Folktales}

A. The Map of the Website

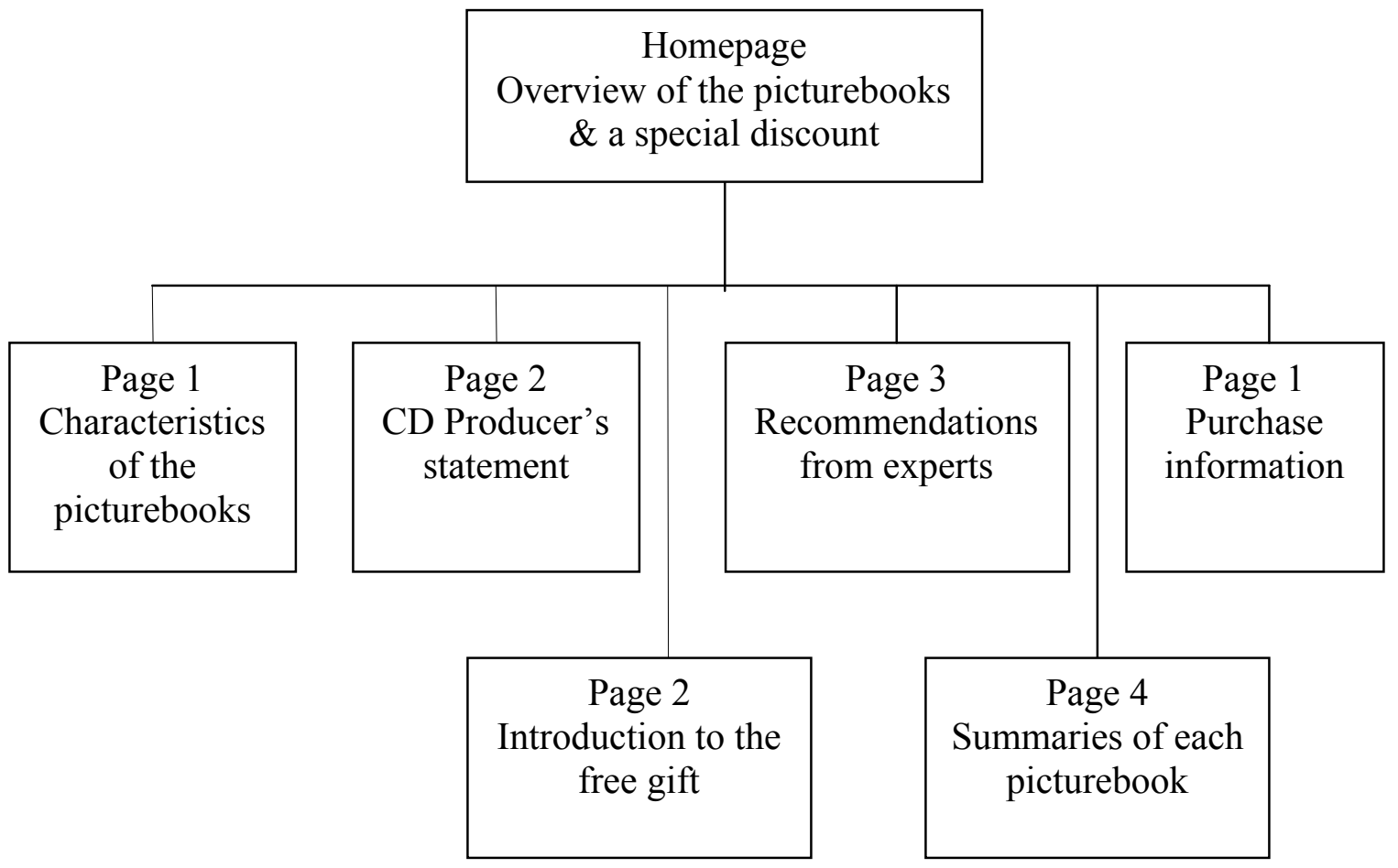

B. Description of Each Webpage

Homepage: Overview of the picturebooks \& a special discount http://www.ylib.com/hotsale/firefly/default.htm
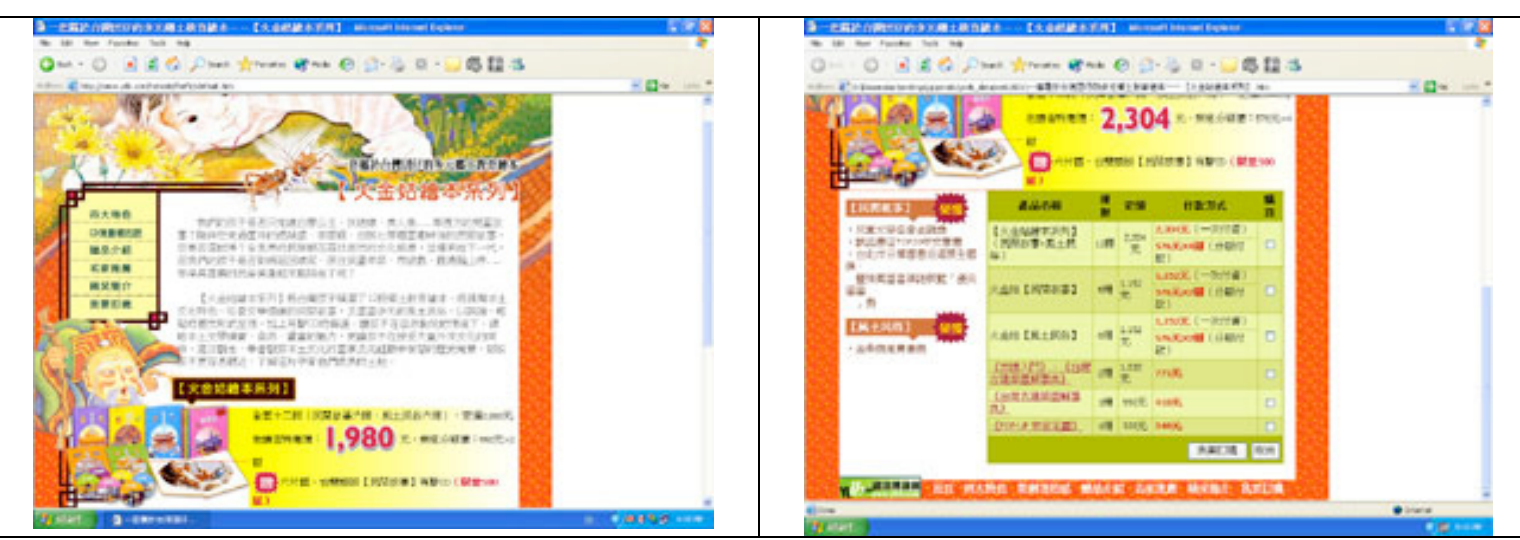

Description-

The promoting points:

1. to emphasize multiple native cultural education

2. to encourage parents to transmit cultural heritages

3. easy to learn and have fun 
Purchase information:

1. a record of award receiving

2. a special discount for purchasing the set of the picturebooks

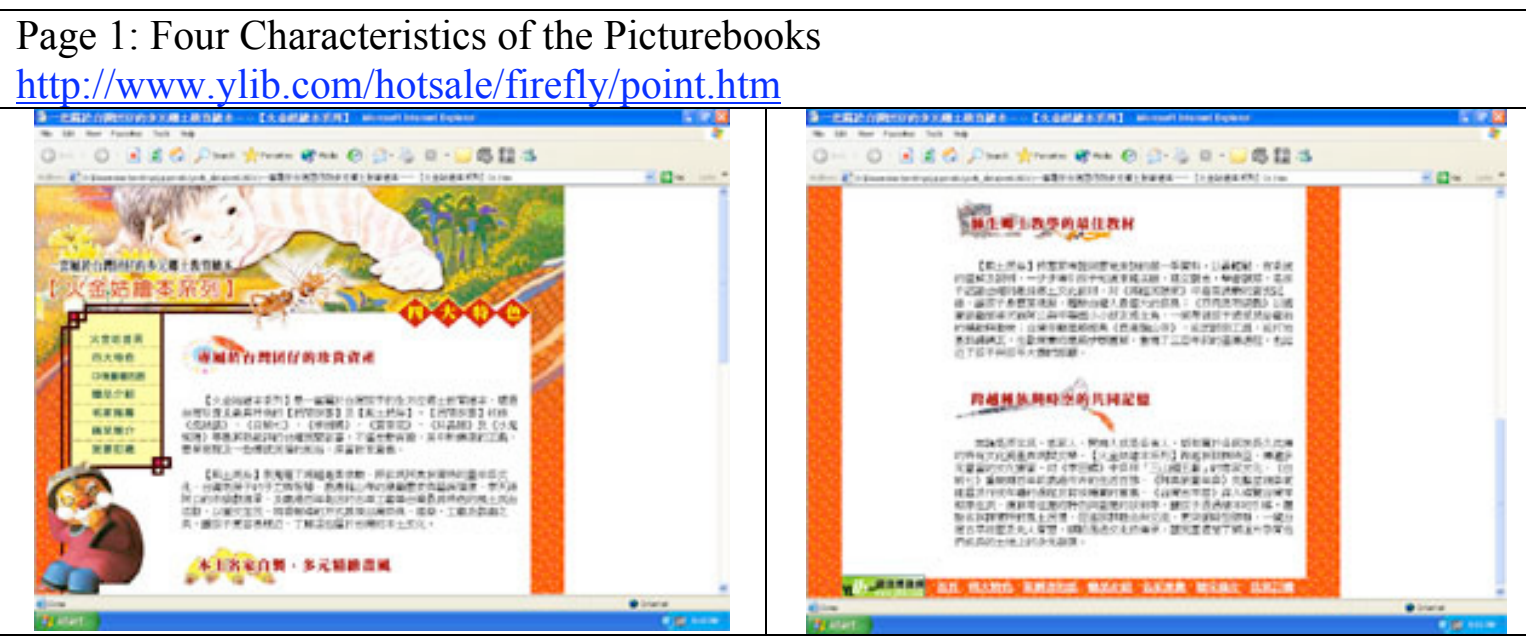

Description-

1. the special treasure for Taiwanese children — to learn about justice and consequence from traditional Taiwanese folktales

2. the picturebooks were created by the local writers and illustrators and show multiple artistic styles

3. the best material for native cultural education for teachers and students

4. cultural heritages across various ethnic groups in Taiwan

\section{Page 2: CD Producer's Statement}

http://www.ylib.com/hotsale/firefly/planner.htm
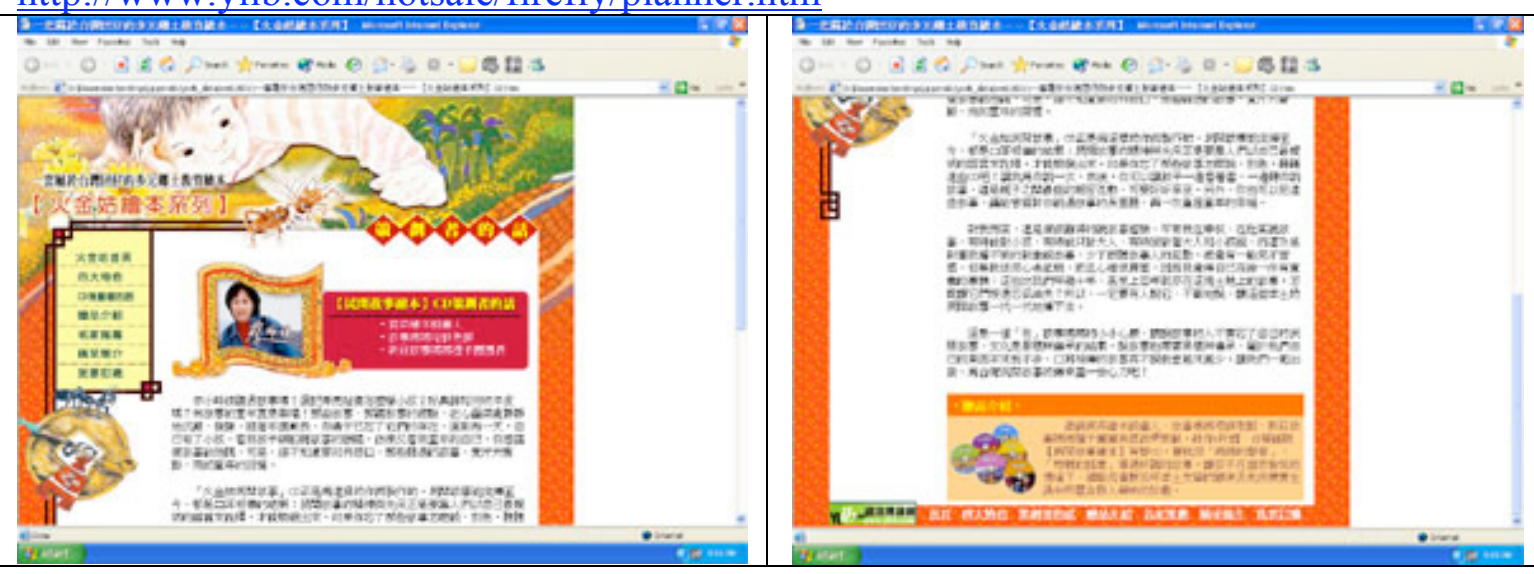

Description-

CD producer's statement:

A story teller expressed her childhood memories regarding the Taiwanese folktales and gave a personal account of why this was a meaningful task to produce a story CD of these folktales for children. 
On the bottom of this page is an introduction to the free gift:

The story $\mathrm{CD}$ is an additional giveaway, which was told by a senior story teller who is a mother speaking with a mother's tongue.

\section{Page 3: Recommendations from Experts}

http://www.ylib.com/hotsale/firefly/present.htm
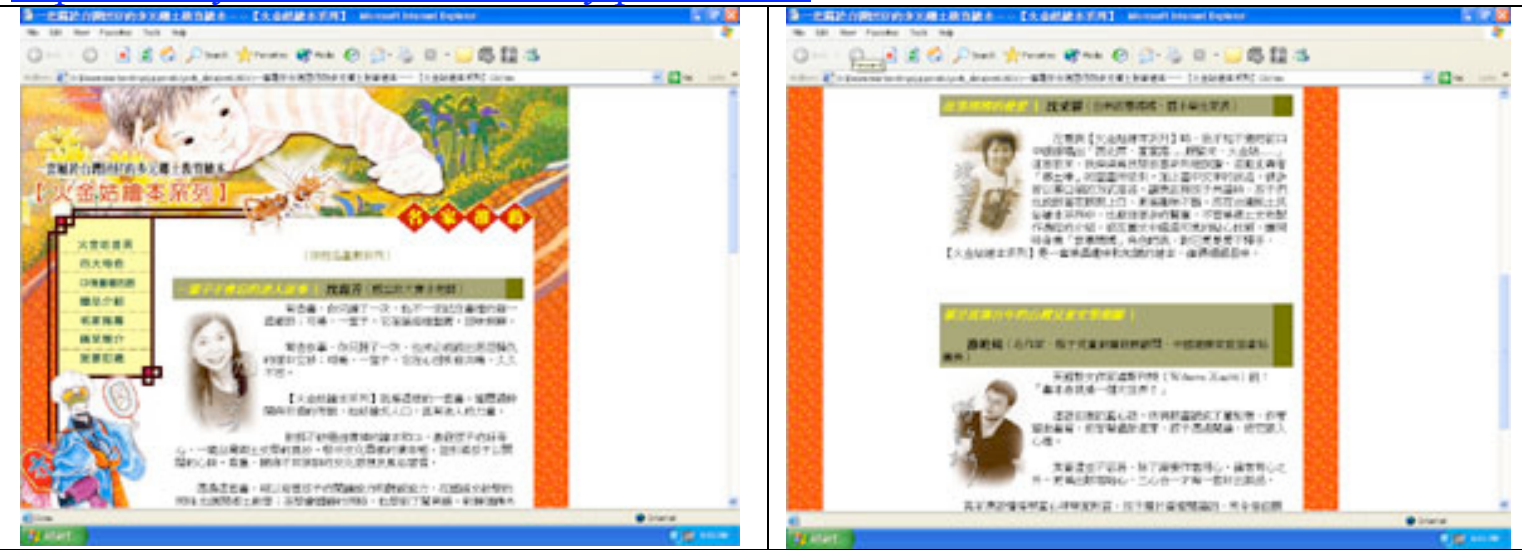

Description-

There are three references on this page. For each reference, it shows a heading of the recommendation, a name and a title of the person, a photo of the person, and a personal account regarding the recommended picturebooks.

1. An elementary teacher: the heading is "Unforgettable stories"

2. A mother \& representative of a parents' body in an elementary school: the heading is "Mothers' favorite stories"

3. A well-known writer \& consultant of a children's theatrical group: the heading is "Listening to the Taiwanese children's literature that has been passed down for generations."

\section{Page 4: Summaries of Each Picturebook}

http://www.ylib.com/hotsale/firefly/prospectus.htm
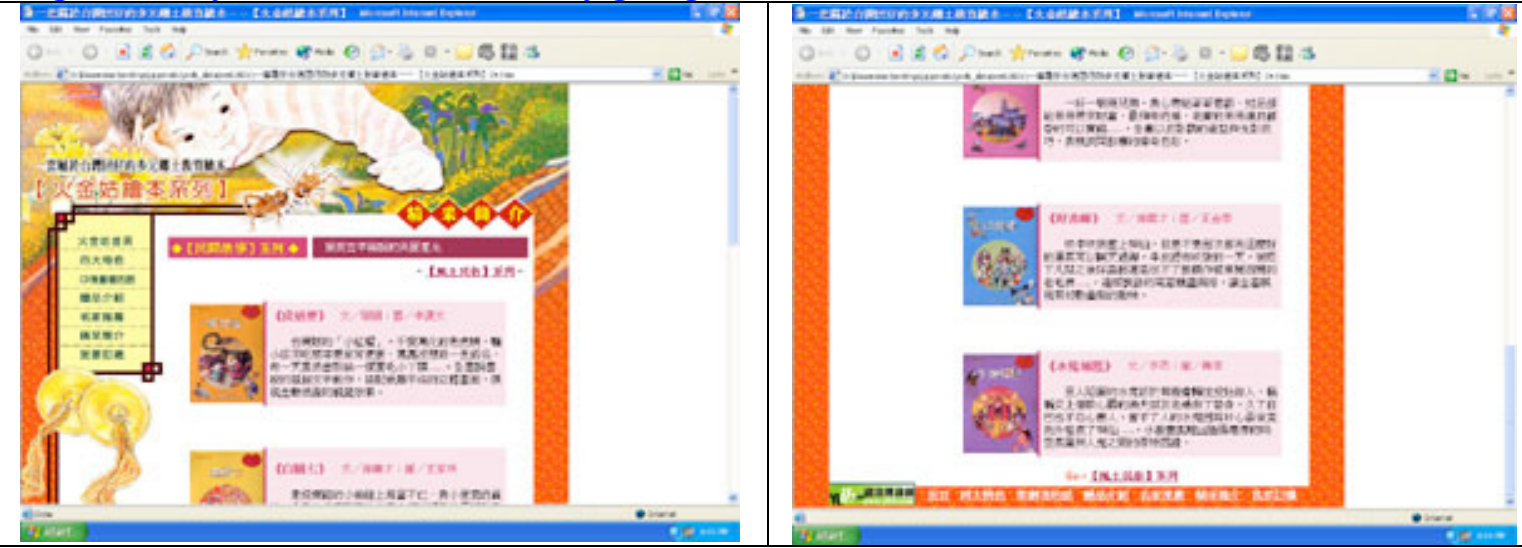

Description-

Brief summary of the story for each book and art style used in the book

1. Hu Gu-po-A Taiwanese tale of the Little Red Hook:

Through the use of paper sculpture the illustrator vividly presents the story. 
2. Bo-zei Chi-A Taiwanese tale of a man using wits to cheat a rich and greedy man of his money:

Delicate painting style shows traditional life in Lukang a hundred year ago

3. Li Tian-luo-A Taiwanese tale of a good man but poor becoming rich due to marrying a good wife:

Decorative illustration shows Hakka culture.

4. Mai Hsiang-pi (Fragrance for Sale) -A Taiwanese tale of two brothers:

The illustration shows the effect of shadow play and enhances the story.

5. Hao-bi-shi- A Taiwanese tale of why ants have a good sense of smell:

Decorative illustration provides interesting details about the story.

6. Shui-gui Cheng-huang-A Taiwanese tale of a city ruling deity:

The illustrator uses ink painting to present the story.

\section{The Taiwanese Children's Picturebook Selection}

A. The Map of the Website

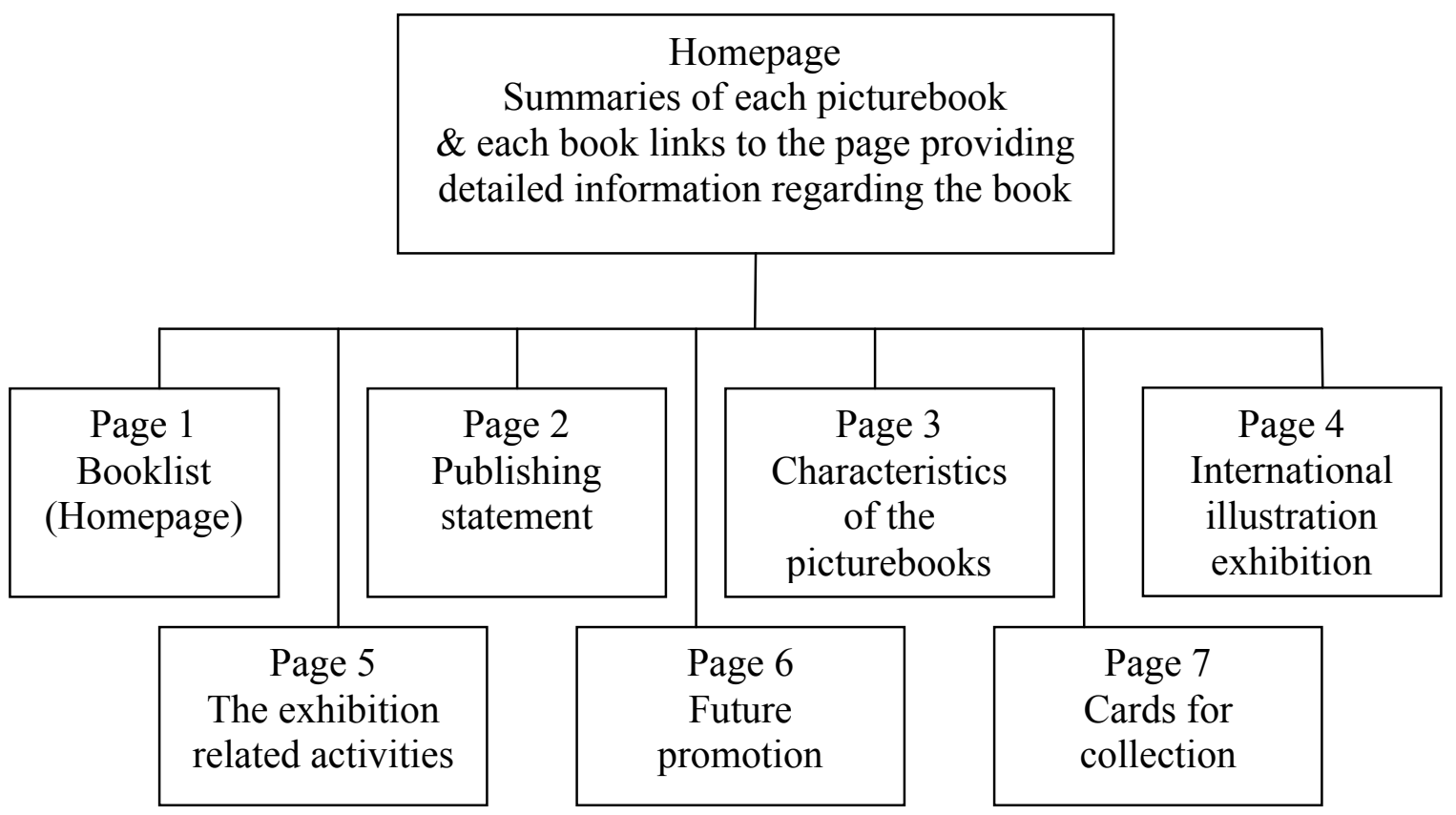




\section{B. Description of Each Webpage}

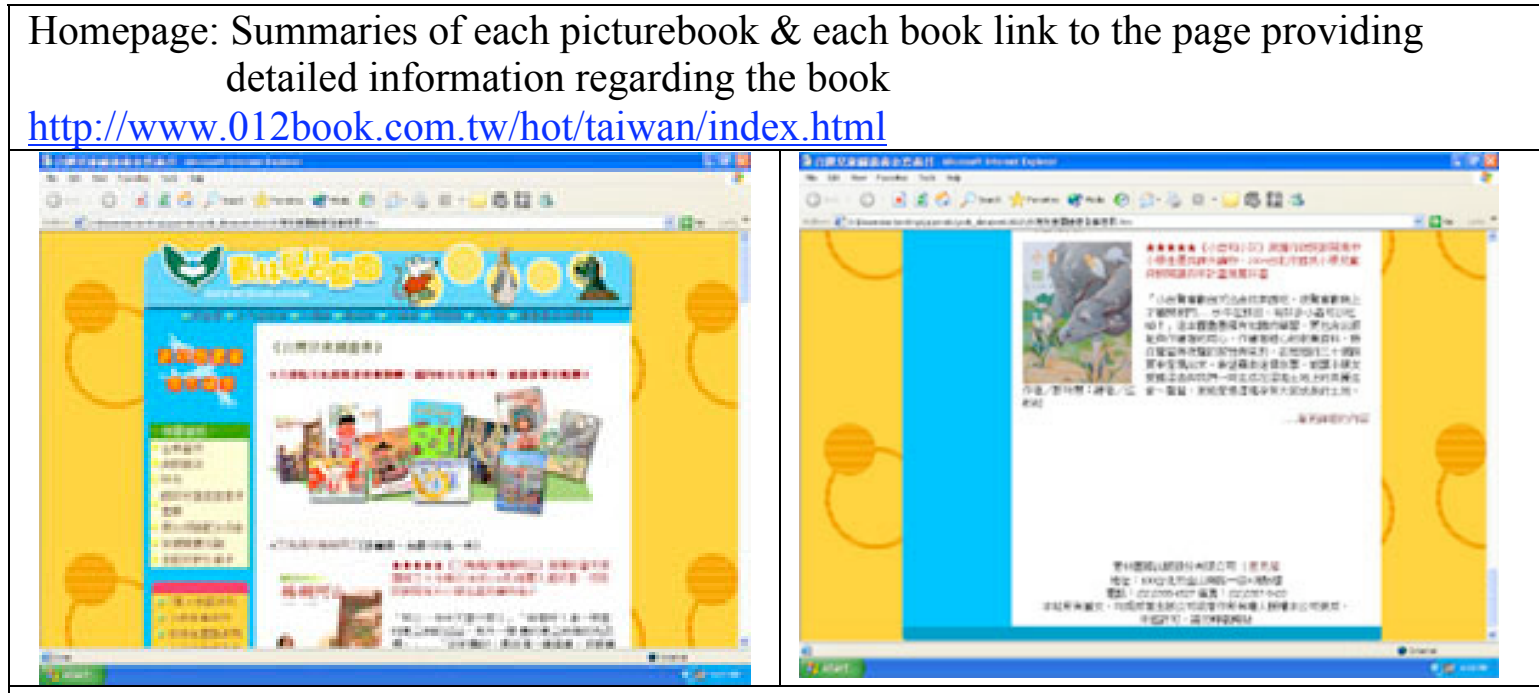

Description-

The promoting points:

Each picturebook consists of a list of recommendations and a brief summary of the main idea of the picturebook with the emphasis by the publishing house.

1. Mei-shu A-gong - A story of a Taiwanese senior artist:

Children will learn the artist's devotion to his hometown and society through the conversation between the grandfather and his grandson in the story. (This book includes a story CD both in Mandarin and Min-nan Hua.)

2. Shooting Suns - A Taiwanese Aboriginal myth:

The illustrator Lai Ma provides a best interpretation of the Taiyi myth "Two Suns" through his careful illustration.

3. Feng-cha (Free Tea for Everyone) - A story of a traditional Taiwanese custom: What is the meaning behind the traditional Taiwanese custom "offering free tea to travelers."

4. Da-tou Has a Son-A modern Taiwanese nursery rhyme:

This rhyme was inspired by the experience that the writer had while waiting for his wife to give birth. The content and illustration shows that Taiwanese are assiduous and capable of enduring hardship.

5. Taiwanese Nursery Rhymes - 15 nursery rhymes, songs, and games:

Children will learn aesthetic experience through the 15 pictures with different styles accompanying 15 nursery rhymes. They will also learn the meanings associated with the rhymes selected from Min-nan Hua, Hakka Hua, Mandarin, and indigenous language and the beauty of the languages through the audio CD.

6. My Father is Going to a Festival Competition-An introduction to a traditional ritual in Yilan County:

This book was illustrated by the artist who has lived in Yilan and understands the ritual very well. The 81 pictures with different sizes in this book vividly depict the emotion of the ritual, which is hard to see in foreign picturebooks. 
7. A Sparrow in the Museum-A story of Taiwanese senior artists:

How to appreciate artworks in a museum? This book takes children to a museum and leads them to walk into the artworks created by the Taiwanese senior artists. In so doing, this book enlarges children's vision of art and cultivates their aesthetic experience.

8. Going Shopping on Dihua Street for Chinese New Year-A story of a historical street in Taipei:

The writer and illustrator oftentimes visited the street together to capture the history and architectures of the street. They hope to show the street from both a historical and a contemporary perspective.

9. Yue-yue 's Dancing Lessons - A story of a little girl going to her first dancing class:

Through reading parents can help children overcome the anxiety caused by joining a new group. This book documents a little girl's learning process.

10. Little White and Little Grey-A story of two Taiwanese egrets:

Through a careful study the writer and illustrator tell the difference between two types of Taiwanese egrets. They hope that children will learn to care about nature and the land we live in.

\section{Page 1: Booklist (link to Homepage)}

http://www.012book.com.tw/hot/taiwan/index.html

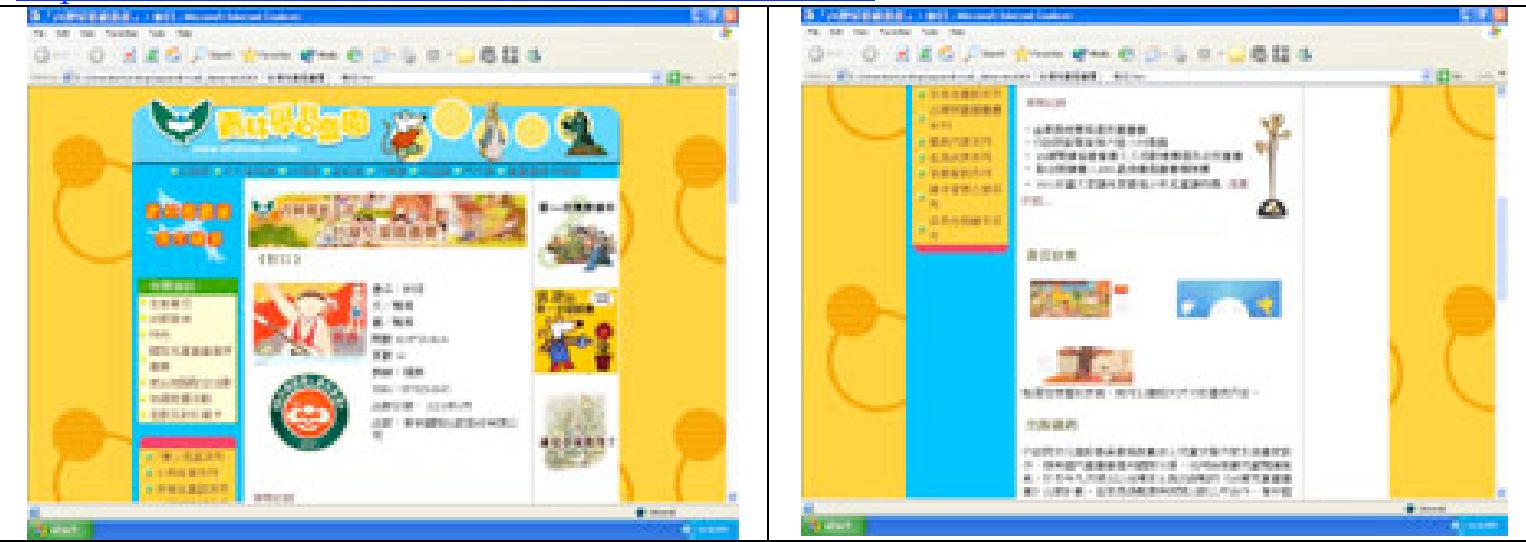

Description-

Each summary of the picturebook consists of a link connecting to another page, which provides detailed information about the particular book.

The information includes:

1. Award record

2. Information about the book (writer/illustrator/size/page/ISBN/ publishing year, publishing house)

3. Several pages of the illustrations

4. Reasons for this publication

5. Summary of the story

6. About the writer

7. About the illustrator

8. Recommendation 


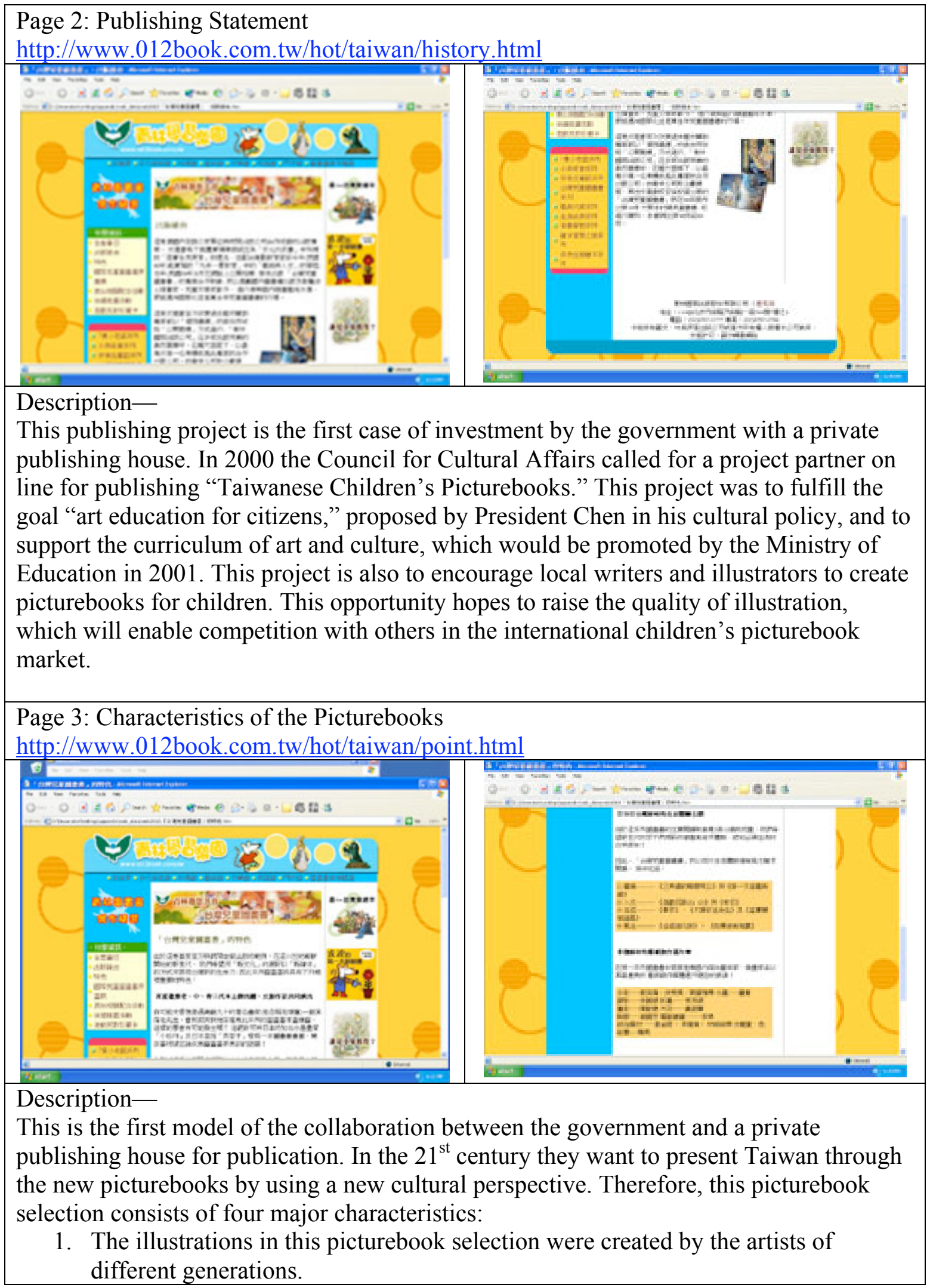


2. The subjects in this selection authentically reflect Taiwanese life experiences. The implied readers for this set of picturebooks are children of ages from 3 to 12 . These picturebooks intend to help children learn about traditional Taiwanese culture by using a new visual style to interpret it. Therefore, these picturebooks fall in four categories:

(1) Art-Mei-shu A-gong, A Sparrow in the Museum

(2) Humanities-Taiwanese Nursery Rhymes, Shooting Suns

(3) Folk life_-Da Tou Has a Son, Free Tea for Everyone, My Father is Going to a Festival Competition

(4) Folk ways - Let's go to Dihua Street, If There is no Earthquake (this book was not published.)

3. The illustrations in the picturebooks show diverse art styles, such as watercolor, ink painting, oil painting, gouache, clay painting, woodcut, digital art, mixed media, color pencil, and crayon.

Audio CDs were created accompanying the picturebooks. The picturebooks contain a good quality of printing.

Page 4: International Illustration Exhibition

http://www.012book.com.tw/hot/taiwan/exhibition.html

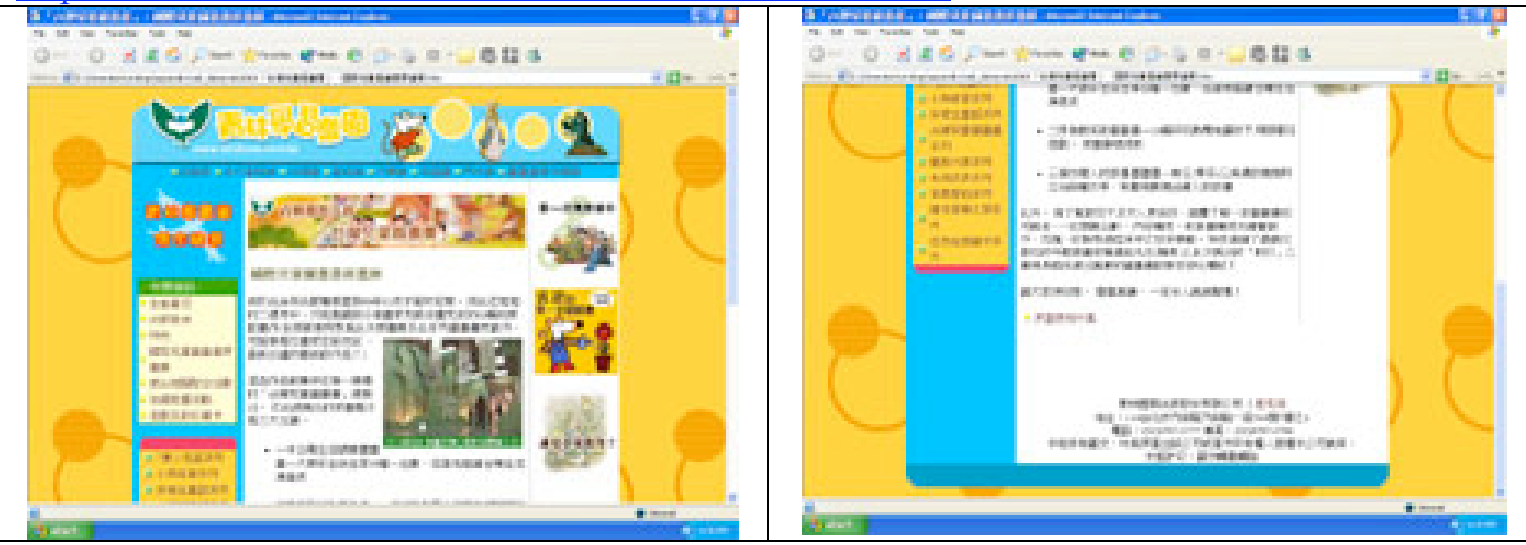

Description-

There were 62 original illustrations shown in the exhibit under the category of

"Taiwanese Children's Picturebook Selections." This category was divided into three segments:

1. One Taiwanese rhyme-Da Tou Has A Son: There were16 pictures vividly depicting the change of Taiwanese life

2. Two children's books for songs and games - There were16 pictures with which children could use their eyes to play.

3. Three Taiwanese picturebooks-

Shooting Suns, Free Tea for Everyone, and Mei-shu A-gong. There were 30 pictures showing Taiwanese stories.

The illustrator Lai Mo used comic strips with a sense of humor to tell his story of creating the picturebook Shootng Suns. 


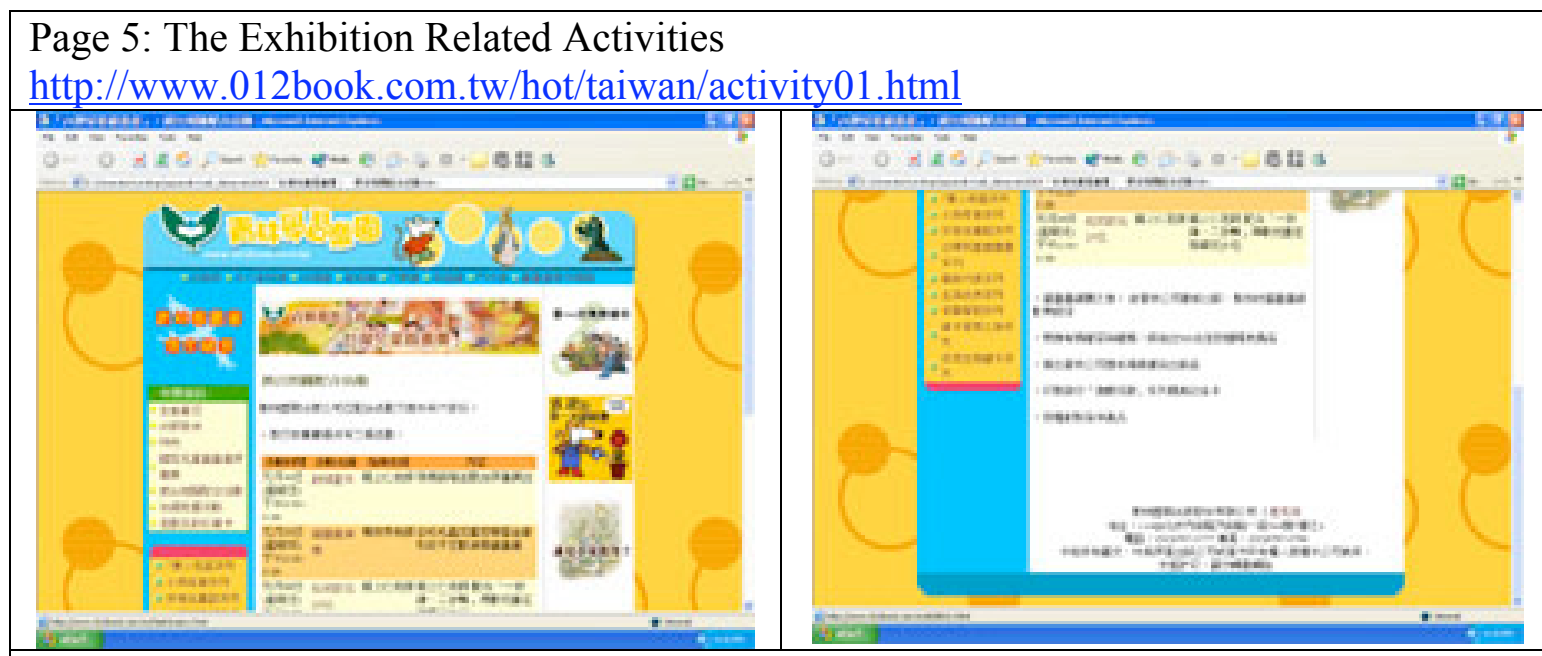

Description-

Children's Publications provided exhibit related activities, including six segments:

1. Story time - songs for children, story telling

2. Picturebooks on videos

3. Games

4. Book exhibition

5. Cards

6. Related product design

\section{Page 6: Future Promotion}

http://www.012book.com.tw/hot/taiwan/activity02.html

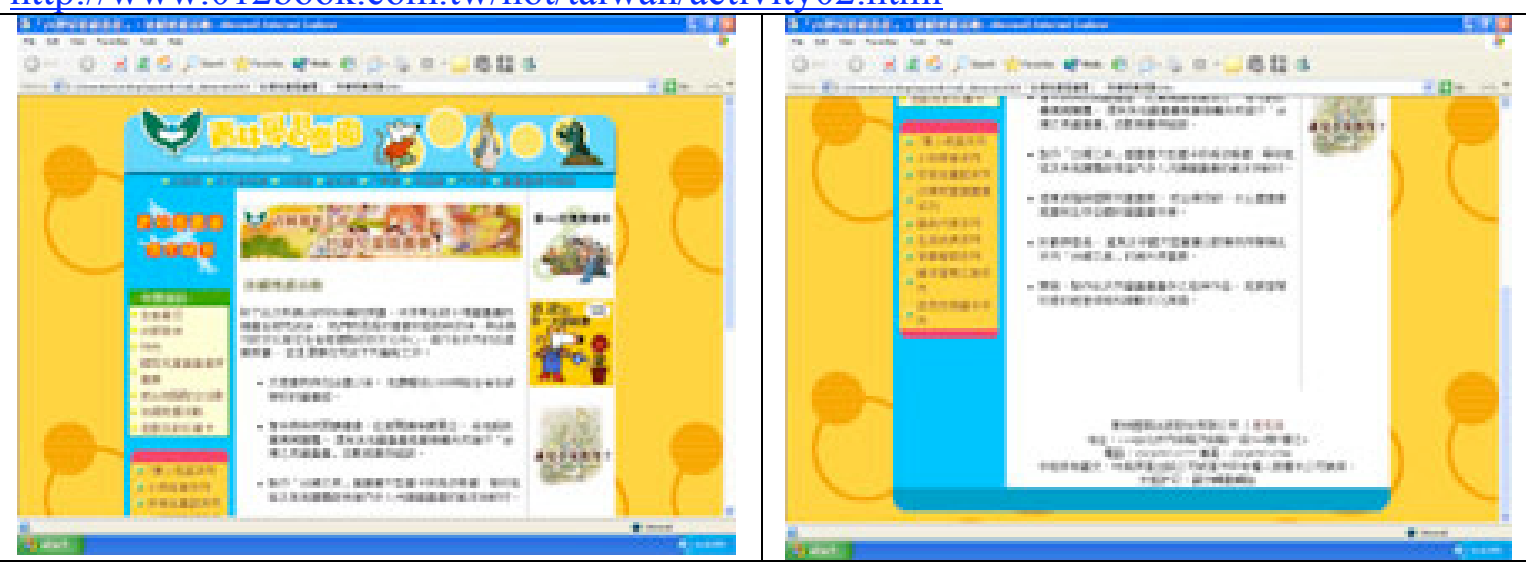

Description-

After the ten picturebooks were published, the original illustration exhibition of these picturebooks would be shown in different cultural centers across cities. Besides this, there are several important tasks as follows:

1. 2000 sets of the picturebooks would be given to school libraries.

2. Children's Publications would work with local book clubs and associations to promote picturebooks showing "the beauty of Taiwan."

3. Producing teaching materials of "the beauty of Taiwan" for classroom use

4. Promoting Taiwanese picturebooks to the Bologna International Illustration 


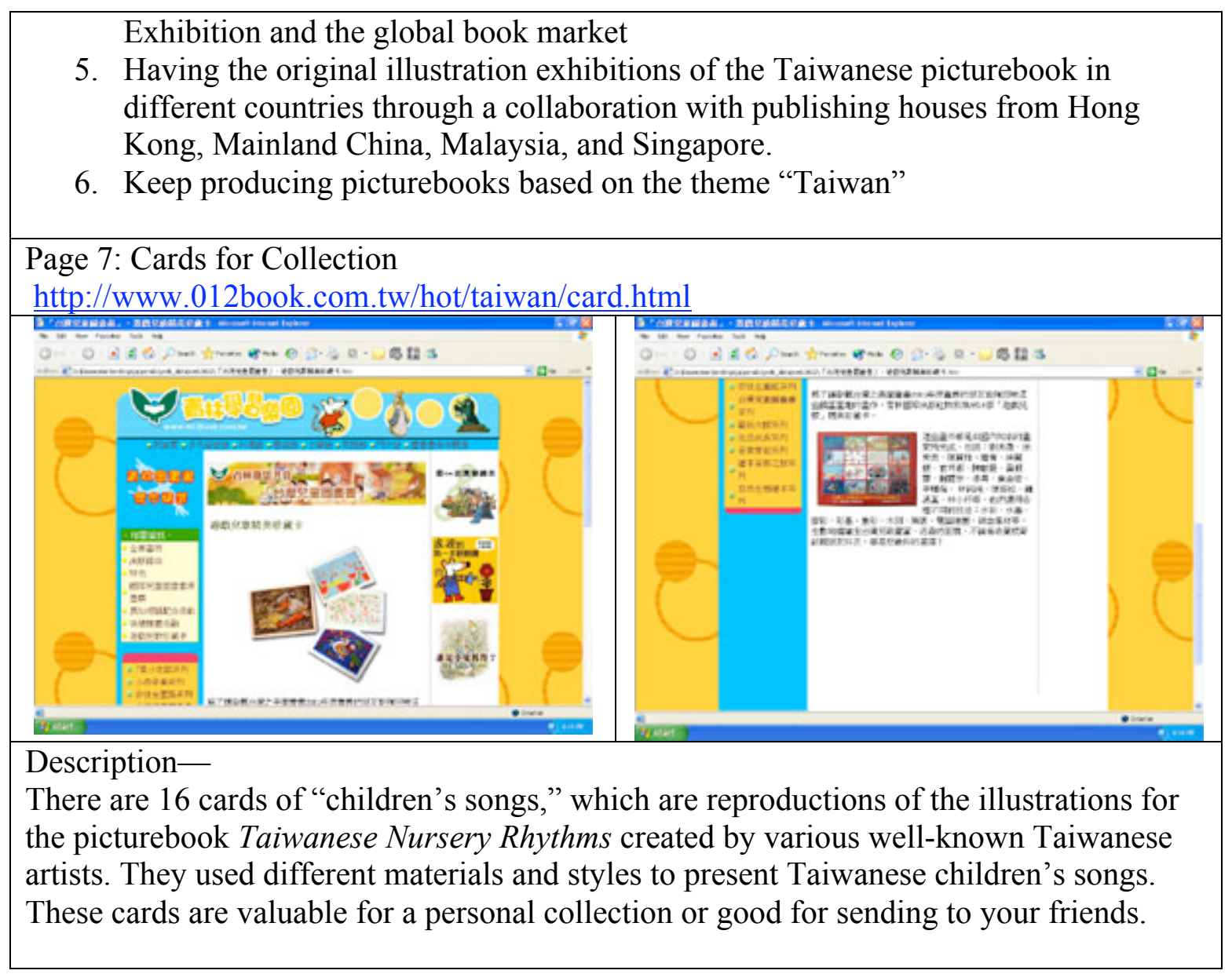

III. The Taiwanese Teenagers

A. The Map of the Website

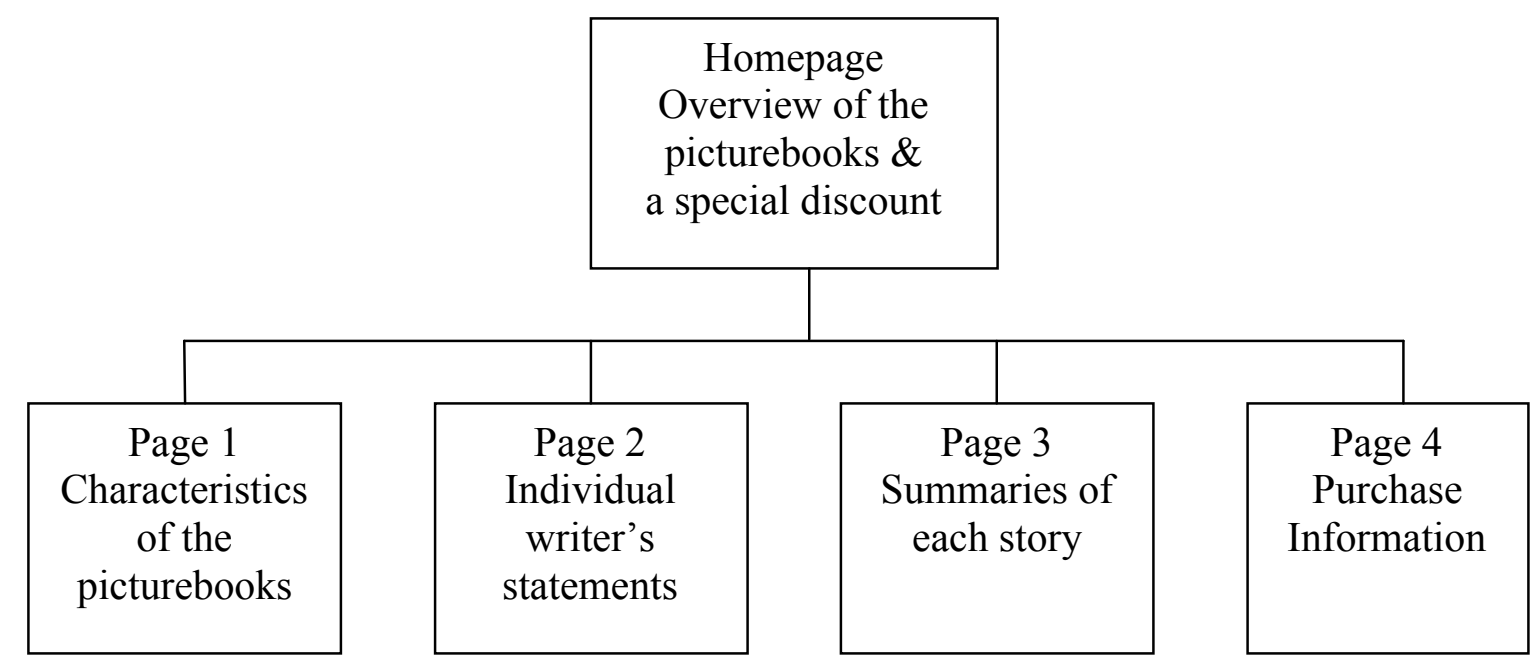




\section{B. Description of Each Webpage}

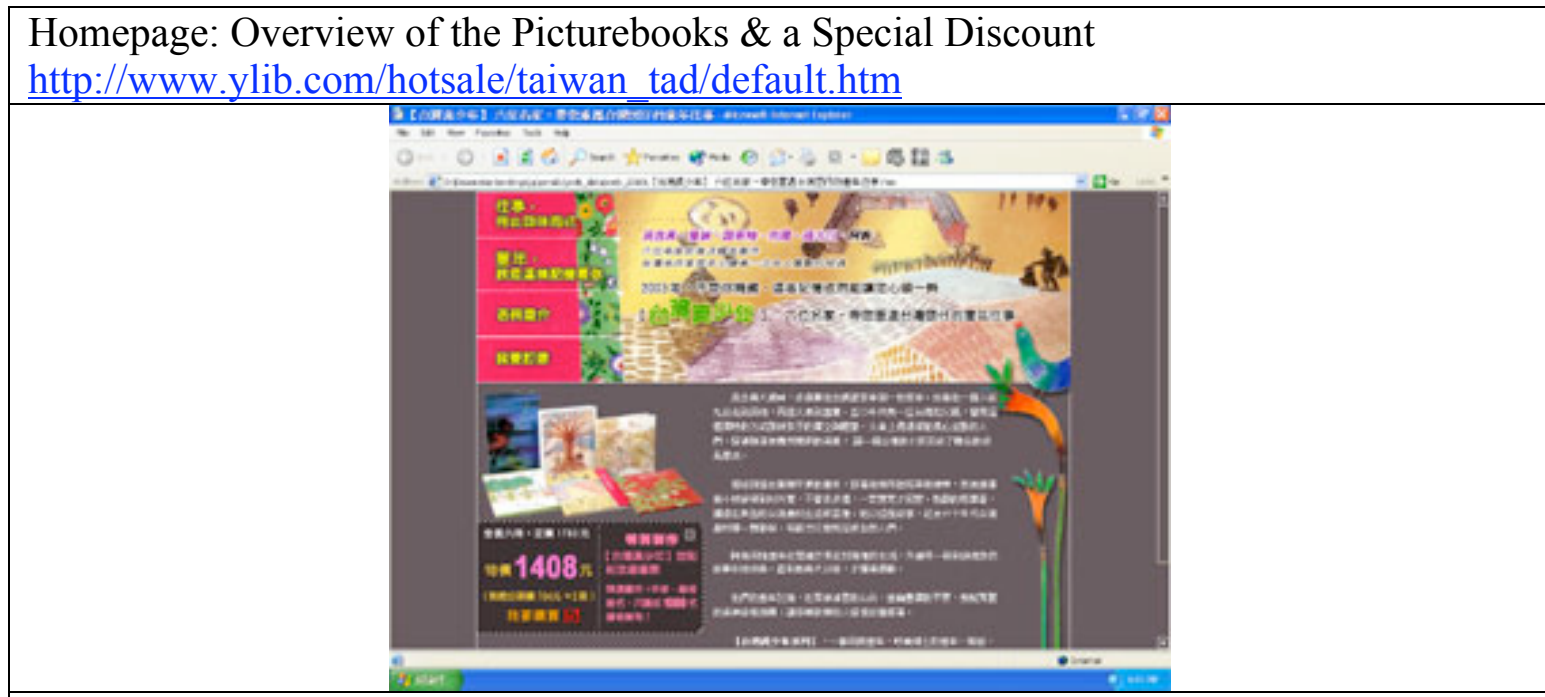

Description-

The heading emphasizes six well-known writers and their first picturebooks as well as the collaboration of the famous writers and local illustrators. No matter how old you are in 2003, the six writers take you walking into Taiwanese childhood memories.

The description starts with a summary of the stories regarding the writers Wu Nian-cheng $\mathrm{Wu}$ (his story representing the 1950s Taiwan), Jian Cheng (her story representing the 1960s Taiwan), and Awu (her story about her aboriginal grandmother). Their childhood memories tell stories about the diverse life experiences of the grandparent generation. Their memories also depict the beauty of nature and culture in Taiwan. The warm and touching stories shown in the picturebooks connect the collective memories to the young generation.

Page 1: Characteristics of the Picturebooks

http://www.ylib.com/hotsale/taiwan tad/about.htm
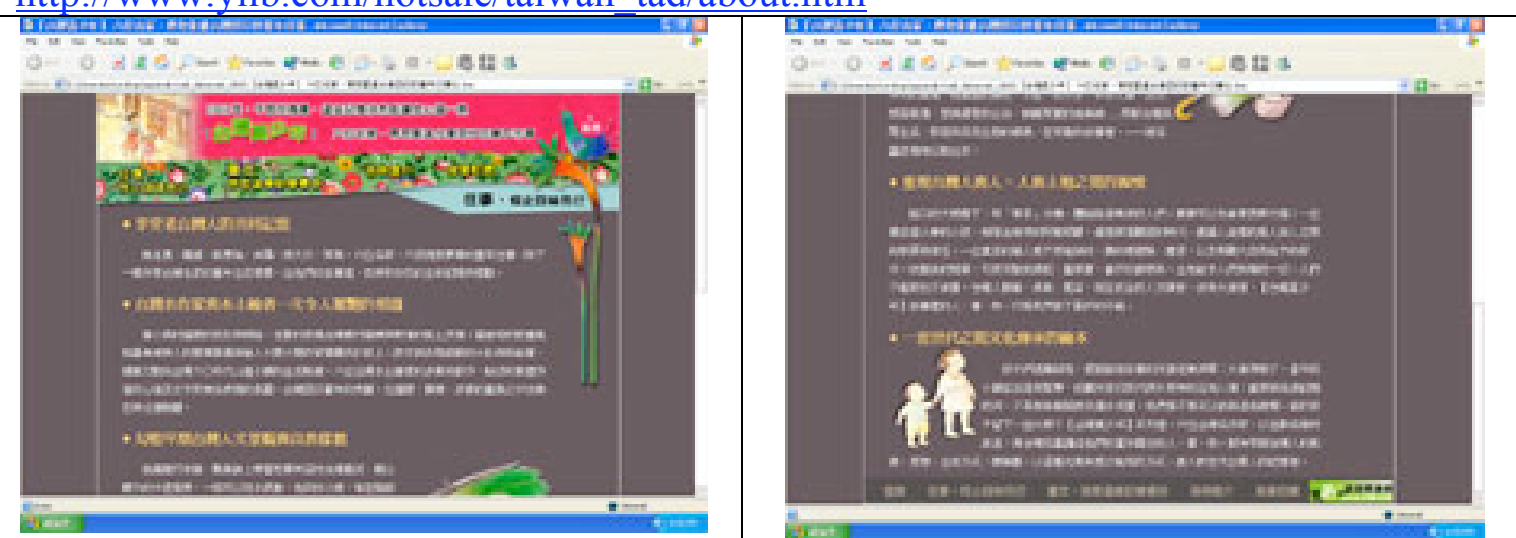

Description-

1. Enjoy the collective memories of the old generation about Taiwan through the well-known writers' childhood stories.

2. A collaboration of well-known writers and local illustrators: The six illustrators 
vividly visualize the stories through the diverse art styles, such as collage, woodcut, watercolor, and color pencil.

3. The picturebooks depict nature and culture in early Taiwan:

Honest and kind farmers showing smiles on their faces, wooden houses, a hut at the center of field, brooms made of rice straw, clogs, trains, and beautiful seashores are all shown in the stories.

4. The picturebooks represent the relationships between people and people as well as people and environment:

In the early Taiwan, trust and kindness were the values people held, such as free tea for travelers under a big tree, taking a product before paying for it; and a little boy taking a train alone but having an old lady taking care of him. A real hunter listens to nature. Rice straw could be used to make brooms, huts, or fuel. These are the examples showing the relationship between humans and nature. Taiwanese are industrious, generous, and help each other, as shown in the picturebooks.

5. This is a set of picturebooks that can pass down our cultural heritages:

As time goes by, the grandparent generation has gone and landscapes have been changed. Could we leave something for the young generation? The Taiwanese Teenagers provide the six writers' unforgettable memories of a person, an event, or a place. We hope that the young Taiwanese generation can learn something from the early Taiwanese way of thinking, life, and values by experiencing the lives told in the picturebooks.

\section{Page 2: Individual Writer's Statements \\ http://www.ylib.com/hotsale/taiwan tad/remembr.htm}
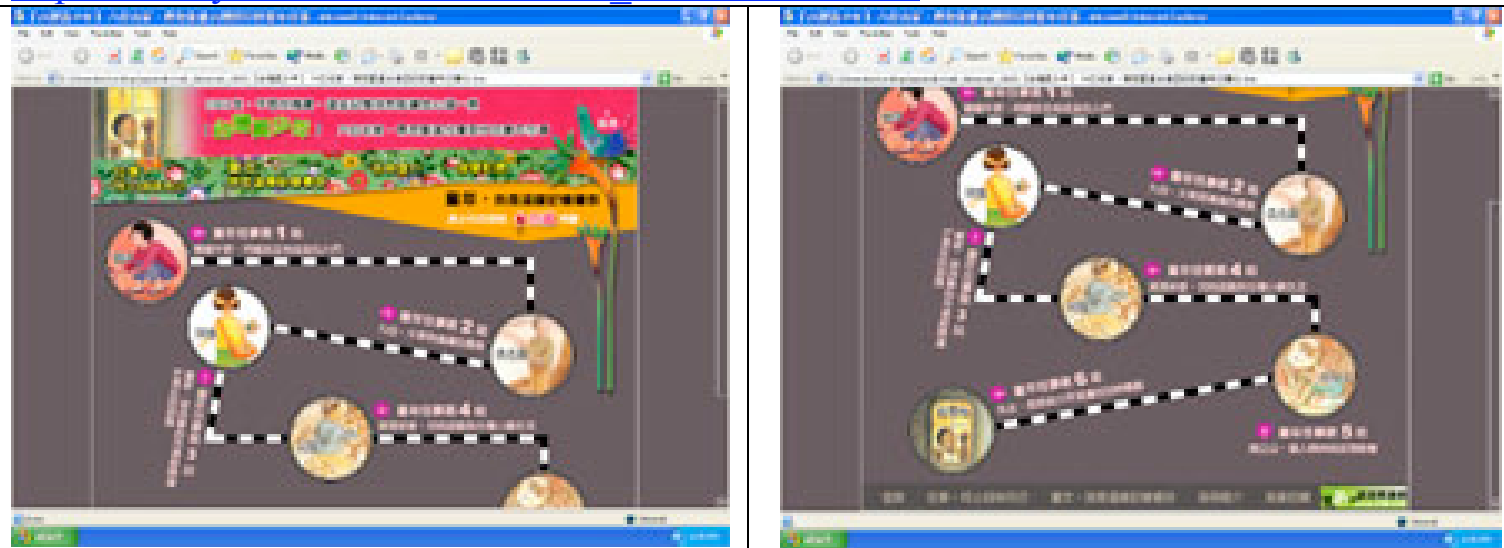

Description-

The heading: Childhood, I am dreaming of you.

This page presents the six writers' statements. Readers can click on each icon to read each individual writer's statement. The visual is designed as a map where readers pretend to take a train for visiting each writer.

1. Jian Cheng: Lanyang Plain, grandmother, and people helping each other

2. Wu Nian-cheng: Jiufen (a small town in the north part of Taiwan), a train, and encouragement

3. Awu: Escaping from home, grandmother telling stories, and the aboriginal tribe

4. Sun Da-chuan: Granduncle, hunter spirit, and wisdom 
5. Hsiang Yang: Tea fragment, game play, and life in a small town

6. Lu Han-hsiu: Loss, miss, and game play in the Dajia River (in the middle part of Taiwan)

Page 3: Summaries of Each Picturebook http://www.ylib.com/hotsale/taiwan tad/allbk.htm

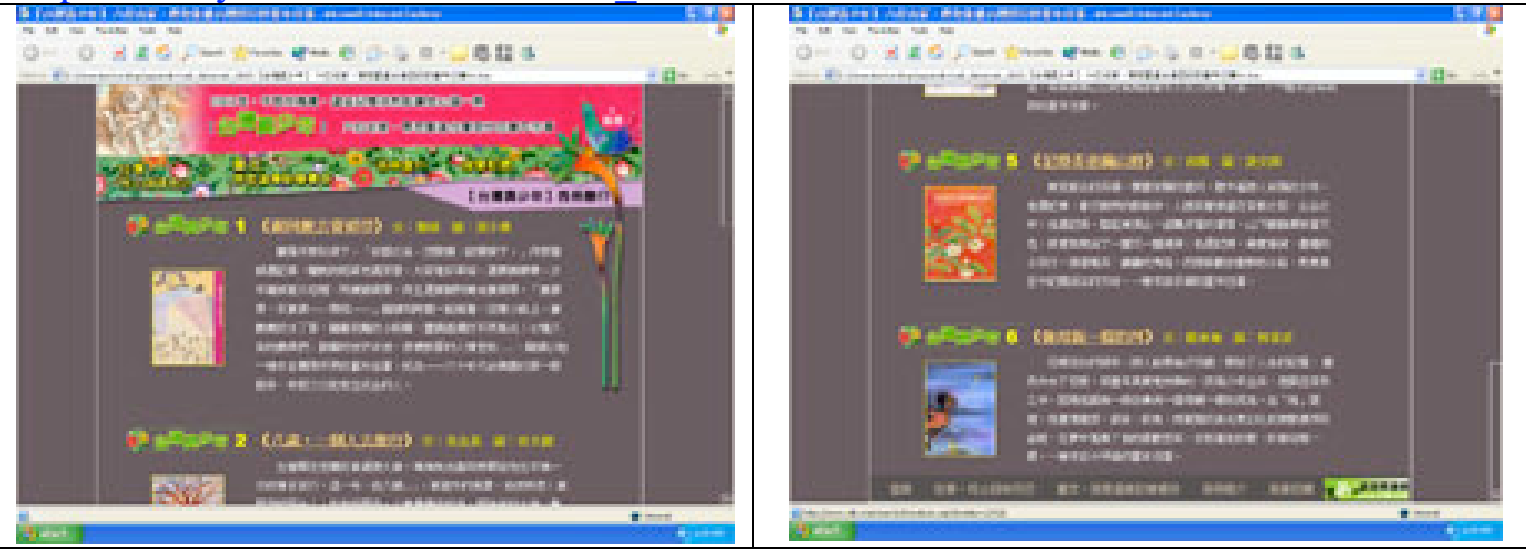

Description-

This page shows the covers and provides the names of the writers and illustrators, and brief summaries of the six stories.

1. Selling Brooms with My Grandmother-A story of the writer's going selling hand-made brooms with her grandmother. A childhood memory from Lanyang Plain.

2. When I was Eight, I Went on a Journey-A story of the writer accomplishing a mission ordered by his father. A childhood memory from a mining town in the north part of Taiwan.

3. Story Map - A story of the writer running away from home and returning to it after all. A childhood memory from the Paiwan tribe.

4. Yi Gong-gong - A story of the writer's granduncle who was a leader in his tribe. A story from the Beinan tribe.

5. A Memory of the Tea Plantation - A story of the writer's family running a tea business in the countryside during the 1960s. A childhood memory from a tea plantation.

6. A River Resembling a Mother-A story of the writer's memory of the loss of his mother. A childhood memory from the Dajia River. 


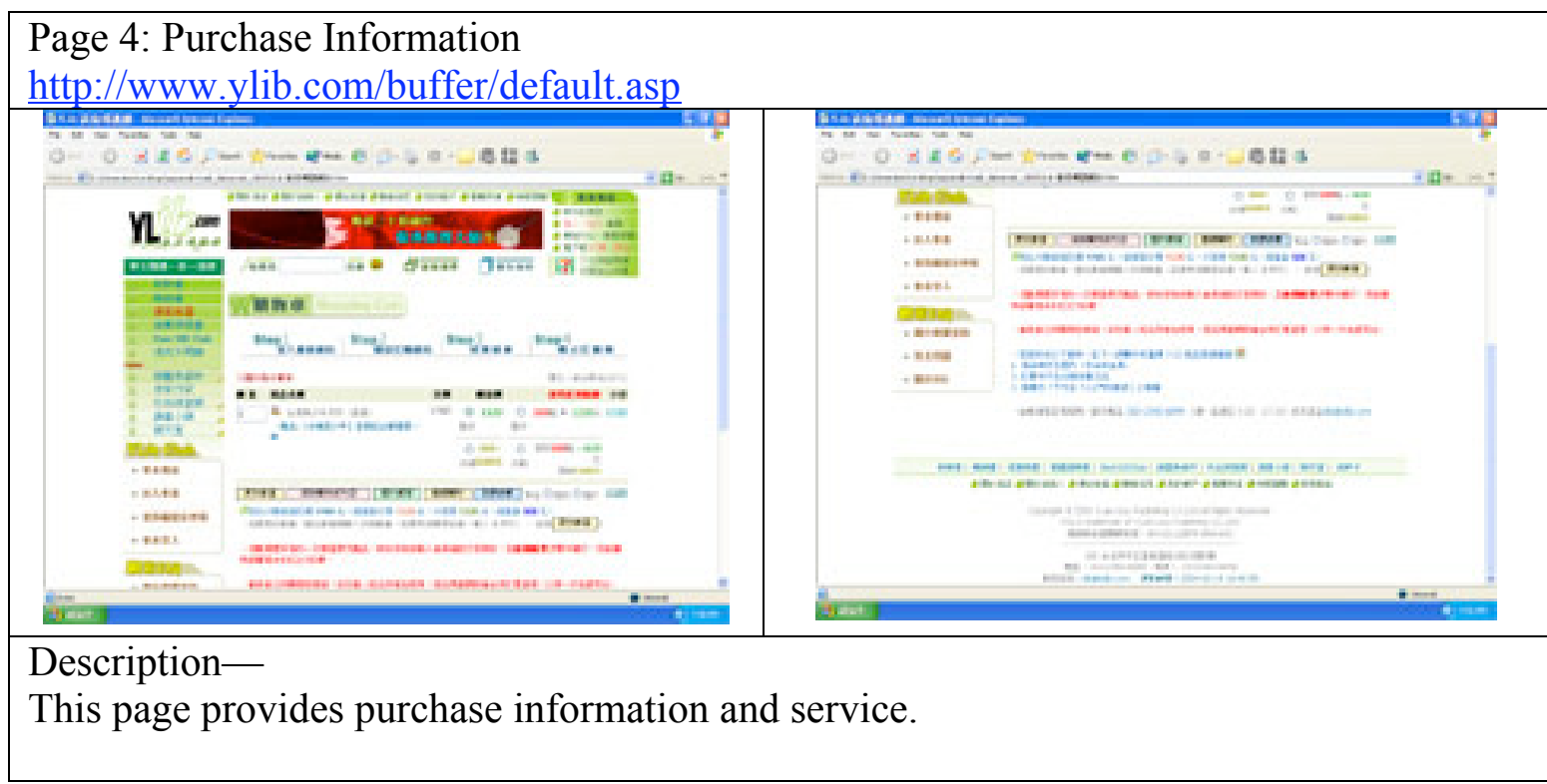




\section{REFERENCES}

Ashcroft, B., Griffiths, G. \& Tiffin, H. (1995). Introduction. In B. Ashcroft, G. Griffiths, \& H. Tiffin (Eds), The post-colonial studies reader (pp. 117-118). London and New York: Routledge.

Bal, M. (1994). On meaning-making. Sonoma, California: Polebridge Press.

Ballengee-Morris, C. \& Stuhr, P. (2001). Multicultural art and visual cultural education in a changing world. Art Education. July, pp. 6-13.

Barker, C. (2000). Cultural studies: Theory and practice. London, Thousand Oaks, \& New Delhi: Sage Publications.

Barnard, M. (2001). Approaches to understanding visual culture. New York: Palgrave.

Barrett, T. (2003). Interpreting art: Reflecting, wondering, and responding. McGraw Hill Companies, Inc.

Barthes, R. (1977). Image-Music-Text. Glasgow, Fontana.

Barthes, R. (1996). Denotation and connotation. In P. Cobley (Ed), The communication theory reader (pp. 129-33). New York: Routledge.

Beger, A. A. (1995). Cultural criticism: a primer of key concepts. London, Thousand Oaks, New Delhi: SAGE Publications.

Bertens, H. (2001). Literary theory: The basics. London and New York: Routledge.

Bhabha, H. K. (1994). The location of culture. London and New York: Routledge.

Bradbury, S. \& Liu, F. (2003). Everywhere a children's book: The view form Taiwan. Horn Book, March/April, 237-48.

Bradford, C. (2003). An aboriginal visual narrative for children: A politics of place. In M. Styles \& E. Bearne (Eds.), Ways of being male: Representing masculinities in children's literature and film (pp. 65-77). New York: Routledge. 
Chandler, D. (2001). Semiotics for beginners. Retrieved February 19, 2003, from http://www.aber.ac.uk/media/Documents/S4B/sem01.html.

Chen, A. L. (1991). The search for cultural identity: Taiwan "hsiang-t'u" literature in the seventies. Dissertation: The Ohio State University.

Chen, F. M. (2000). Postmodern or post-colonial: An interpretation of history of Taiwan literature after World War II. In D. W. Wang (Eds), Writing Taiwan: Strategies of representation (pp. 41-63). Taipei: Mai-Tien Publishing.

Chen, F. M. (2002). Post-colonial Taiwan: Criticism of Taiwan literary history. Taipei: Mai-Tien Publishing.

Chen, R. W. (1994). Thinking about Taiwan's culture and local culture. In Y. J. Yeh (Ed), Taiwanese consciousness in Taiwan art (pp. 142-49). Taipei: HsiungShih Art Books.

Chen, Y. L. (2004). Taiwan aborigines. Taipei: Walkers Cultural Print in Taiwan.

Chen, Z. Y. (1998). Taiwan literature and localization. Taipei: Cheng-Chong Books.

Chen, Z. Y. (2003). Literary aborigines and aboriginal literature: From the other to subjectivity. In D. C. Sun (Ed), An anthology of criticism on Taiwan indigenous literature written in mandarin: the first volume (pp. 175-208). Taipei: Ink Publishing.

Chiu, K. F. (2000). The development of post-colonial theory in Taiwan. Studio of Taiwan Literature. Retrieved August 11, 2003, from http://ws.twl.ncku.edu.tw/hak-chia/k/khu-kui-hun/taioan-sitbin.htm.

Chiu, K. F. (2003a). Rethinking postcolonial literary criticism in Taiwan. Taipei: MaiTien Publishing.

Chiu, P. H. (2003b). Writing native culture in literature in the post-war Taiwan. Dissertation: National Kaohsiung Normal University. Kaohsiung, Taiwan.

Chou, K. C. (1998). The Kuomintang's government and Confucianism after postwar. In J. J. Huang \& J. P. He (Eds), Cultural development of Taiwan toward the $21^{\text {st }}$ century (pp. 59-90). Taipei: Taiwan University Press.

Chu, C. G. (2003). De-Chineseness: Awareness, myths and others: Centring on Wang Runhua and Huang Jinshu's related discussion. 21Century. 8(17), Retrieved August 30, 2003, from http://www.cuhk.edu.hk/ics/21c/supplem/essay/0302029.htm. 
Childs, P. \& William, P. (1997). An introduction to post-colonial theory. Essex, England: Prentice Hall.

Coffey, A. \& Atkinson, P. (1996). Making sense of qualitative data: complementary research strategies. Thousand Oaks, London, \& New Delhi: SAGE Publications.

Council of Cultural Affairs. (2004). Cultural Taiwan: New century, new face. Taipei: Yoan-Liou Publishing.

Cross, J. L. (1995). Picturebooks and Christopher Columbus: A cultural analysis. Unpublished doctoral dissertation, Ohio State University, Columbus.

Culler, J. (1981). The pursuit of signs: Semiotics, literature, deconstruction. Ithaca, New York: Cornell University Press.

Denzin, N. K. (2000). The practice and politics of interpretation. In N. K. Denzin \& Y. S. Lincoln (Eds.), Handbook of qualitative research (pp. 897-922). Thousand Oaks, CA: Sage Publications.

Eco, U. (1979). A theory of semiotics. Bloomington and London: Indiana University Press.

Eco, U. (1990). The limits of interpretation. Bloomington and London: Indiana University Press.

Fanon, F. (1997). On national culture. In B. Moore-Gilbert, G. Stanton \& W. Maley (Eds), Postcolonial criticism (pp. 91-111). London and New York: Longman.

Freeman, E. \& Lehman, B. (2001). Global perspectives in children's literature. Needham Heights, MA: Allyn \& Bacon.

Fiske, J. (1998). Culture, ideology, interpellation. In J. Rivkin \& M. Ryan (Eds). Literary theory: An anthology (pp. 305-11). Malden, Massachusetts: Blackwell Publishers.

Grant, R. \& Short, J. R. (2002). Globalization: An introduction. In R. Grant \& J. R. Short (Eds.), Globalization and the margins (pp. 3-14). New York: Palgrave Macmillan.

Guu, M. J. (2004). The development of comic Doujinshi in Taiwan-The perspective of leisure and cultural industry. Thesis: Shih-Hsin University, Taipei, Taiwan.

Hall, S. (1997a). Introduction. In S. Hall (Ed), Representation: Cultural representations and signifying practices (pp. 1-11 ). London, Thousand Oaks, New Delhi: SAGE Publications. 
Hall, S. (1997b). The work of presentation. In S. Hall (Ed.), Presentation: Cultural presentations and signifying practices (pp. 13-64). SAGE Publications \& The Open University.

Hong, W. Q. (1994). History of Taiwanese children's literature. Taipei: Chuan-Wen Publishing.

Hong, W. Q. (1994). Essays on Taiwanese children's literature. Taipei: Chuan-Wen Publishing.

Hong, W. Q. (2004a). A handbook of Taiwanese children's literature. Taipei: ChuanWen Publishing.

Hong, W. Q. (2004b). A handbook of Taiwanese picturebook. Taipei: Chuan-Wen Publishing.

Hong, W. Q. (2005). History of Taiwanese children's pictreubooks. Taipei: Chuan-Wen Publishing.

hooks, bell (1998). Making movie magic. In M. Berger (Ed), The crisis of criticism (pp. 132-46). New York: New Press.

Hsiao, H. H. (2002). Coexistence and synthesis: Cultural globalization and localization in contemporary Taiwan. In P. L. Berger \& S. P. Huntington (Eds), Many globalizations: Cultural diversity in the contemporary world (pp. 48-67). New York: Oxford University Press.

Hsieh, C. X. (1995). The location of Taiwan literature in the 1980s. Thesis: National Central University. Chungli, Taiwan.

Hsieh, L. F. (1998). Taiwanese art movement in the Japanese colonial era. Taipei: Artist Publishing.

Huang, J. J. (2000). Taiwanese consciousness and Taiwanese culture. Taipei: ChengChong Books.

Huck, C., Hepler, S. Hickman, J. \& Kiefer, B. (2001). Children's literature in the elementary school. McGraw Hill.

Inda, J. X. \& Rosaldo, R. (2002). Introduction: A world in motion. In J. X. Inda \& R. Rosaldo (Eds), The anthropology of globalization: A reader (pp. 2-34). Malden, Mass: Blackwell Publishers. 
Janesick, V. (2000). The choreography of qualitative research design: Minuets, improvisations, and crystallization. In N. K. Denzin \& Y. S. Lincoln (Eds.), Handbook of qualitative research (pp 379-99). Thousand Oaks, CA: Sage Publications.

Josephy, A. M., Nagel, J. \& Johnson, T. (1999). Introduction. In Josephy, A. M., Nagel, J. \& Johnson, T. (Eds), Red Power: The American Indian's fight for freedom (pp. 1-9). Lincoln \& London: University of Nebraska Press.

Kachru, B. B. (1995). The alchemy of English. In B. Ashcroft, G. Griffiths, \& H. Tiffin (Eds). The post-colonial studies reader (pp. 291-95). London and New York: Routledge.

Kress, G. \& van Leeween, T. (1990). Reading images. Geelong: Deakin University Press.

Kroeber, A. L. \& Kluckhohn, C. (1963). Culture: A critical review of concepts and definitions. New York: Vintage Books.

Lather, P. (1991). Getting smart: Feminist research and pedagogy with/in the postmodernism. New York, London: Routledge.

Lechner, F. J. \& Boli, J. (2000). General introduction. In F. J. Lechner \& J. Boli (Eds), The globalization reader (pp. 1-6). Malden, Mass: Blackwell Publishers.

Lehtonen, M. (2000). Cultural analysis of texts. Thousand Oaks, CA: Sage Publications.

Levi, A. (1996). Samurai from outer space: Understanding Japanese animation. Chicago: Open Court.

Li, H. M. (1993). The development of literature in Taiwan in the period of 1949-1992. Thesis: Chinese Cultural University, Taipei, Taiwan.

Lin, M. L. (2000). A study on Taiwan's art education. Taipei: Hsiung-Shih Art Books.

Lin, X. Y. (1987). Taiwanese art (1945 1987). Taipei: Zi Li Wan Bo.

Lincoln, Y. S. \& Guba, E. G. (1985). Naturalistic inquiry. Beverly Hills, CA: Sage Publications.

Lincoln, Y. S. \& Guba, E. G. (2000). Paradigmatic controversies, contradictions, and emerging confluences. In N. K. Denzin \& Y. S. Lincoln (Eds.), Handbook of qualitative research (pp 163-88). Thousand Oaks, CA: Sage Publications.

Lindkvist, K. (1981). Approaches to textual analysis. In K. E. Rosengren (Ed.), Advances 
in content analysis (pp. 23-41). Beverly Hills, CA \& London, England: Sage Publications.

Lo, C. S. (1999). Teaching philosophy of the grades 1 through 12 curriculum integration. Retrieved February 15, 2001, from http://www.iest.edu.tw/issue/j1/v16n2/1.htm

Loomba, A. (1998). Colonialism/postcolonialism. London and New York: Routledge.

Macionis, J. (1994). Sociology: The basic. New Jersey: Prentice Hall Inc.

Mailloux, S. (1995) Interpretation. In F. Lentricchia \& T. McLaughlin (Eds.), Critical terms for literary study (pp. 121-134). Chicago and London: The University of Chicago Press.

Marantz, K. (1994). Art of the picturebook: The road from Caldecott to Sendak. In The picturebook: Source and resource for art education (pp. 1-12). National Art Education Association.

Mitchell, W. J. T. (1994). Picture theory: Essays on verbal and visual representation. Chicago \& London: The University of Chicago.

Miranda, C. (1994). The art of the picturebook: An interpretation of Indian cultures. Unpublished doctoral dissertation, Ohio State University, Columbus.

Mishra, V. \& Hodge, B. (1994). What is post(-)colonialism? In P. Williams \& L. Chrisman (Eds), Colonial discourse and post-colonial theory: A reader (pp. 27690). New York: Columbia University Press.

Ni, Z. Q. (1994). Western art made in Taiwan: A critique of Taiwan modern art. In Y. J. Yeh (Ed), Taiwanese consciousness in Taiwan art (pp.37-87). Taipei: HsiungShih Art Books.

Nikolajeva, M. \& Scott, C. (2001). How picturebooks work. New York: Barland Publishing.

Nodelman, P. (1988). Words about pictures: A narrative art of children's picture books. Athens and London: The University of Georgia Press.

Nordelman, P \& Reimer, M. (2003). The pleasures of children's literature. Boston: Allyn and Bacon.

Nöth, W. (1990). Handbook of semiotics. Bloomington and Indianapolis: Indiana University Press. 
Onega, S. \& Landa, J. A. G. (1996). Introduction. In S. Onega \& J. A. G. Landa (Eds), Narratology: An introduction (pp. 1-41). London and New York: Longman.

O’Neill, J. (1992). Critical conventions: Interpretation in the literary arts and sciences. Norman and London: University of Oklahoma Press.

O'Riordan, T. \& Church, C. (2001). Synthesis and context. In T. O'Riordan \& C. Church (Eds), Globalism, localism, and identity (pp. 3-24). London and Sterling, VA: Earthscan Publications.

O'Toole, M. (1994). The language of displayed art. Rutherfore, Madison, Teaneck: Fairleigh Dickinson University Press.

Pieterse, J. N. (2000). Globalization as hybridization. In F. J. Lechner \& J. Boli (Eds), The globalization reader (pp. 99-110). Malden, Mass: Blackwell Publishers.

Reyes, G. E. (2001). Four main theories of development: Modernization, dependency, world-system, and globalization. University of Pittsburgh, Graduate School of Public and International Affairs - GSPIA. Retrieved August 30, 2003, from http://www.ucm.es/info/nomadas/4/gereyes1.htm.

Robertson, R. (2002). Opposition and resistance to globalization. In R. Grant \& J. R. Short (Eds), Globalization and the margins (pp. 25-38). New York: Palgrave Macmillan.

Rose, G. (2001).Visual methodology. London, Thousand Oaks, New Delhi: Sage Publications.

Selden, R., Widdowson, P. \& Brooker, P. (1997). A reader's guide to contemporary literary theory. Prentice Hall/Harvester Wheatsheaf.

Shulezitz, U. (1985.) Writing with pictures: How to write and illustrate children's books. New York: Watson-Guptill Publications.

So, A. Y. (1990). Social change and development: Modernization, dependency, and world-system theories. Newbury Park, Calif.: Sage Publications.

Song, K. C. (2003). Is this the indigenization we want? Cyberbees.glog. Retrieved October 7, 2003, from http://www.cyberbees.org/blog/archives/001353.html.

Spivak, G. C. (1995). Can the subaltern speak? In B. Ascroft, G. Griffiths \& H. Tiffin (Eds), The post-colonial studies reader (pp. 24-8). London and New York: Routledge.

Stephens, J. (1992). Language and ideology in children's fiction. London and New 
York: Longman.

Storey, J. (1993). An introduction guide to cultural theory and popular culture. Athens: The University of Georgia Press.

Sun, D. C. (2000). Construction of minority: Taiwanese indigenous language, culture, and politics. Taipei: Lian-He Literature Publishers.

Sun, D. C. (2003). Introduction. In D. C. Sun (Ed), An anthology of criticism on Taiwan indigenous literature written in mandarin: the first volume (pp. 5-11). Taipei: Ink Publishing.

Temple, C., Martinze, M., Yokota, J. \& Naylor, A. (2002). Children's books in children's hands: An introduction to their literature. Boston: Allyn and Bacon.

Tomlinson, J. (1999). Globalization and culture. Chicago: The University of Chicago Press.

Tsing, (2002). Conclusion: The global situation. In J. X. Inda \& R. Rosaldo (Eds), The anthropology of globalization: A reader (pp. 453-86). Malden, Mass: Blackwell Publishers.

Tyson, L. (1999). Critical theory today: A user-friendly guide. New York \& London: Garland Publishing.

Unsworth, L. (2001). Teaching multiliteracies across the curriculum: Changing contexts of text and image in classroom practice. Philadelphia: Open University Press.

Voisey, H. \& O'Riordan, T. (2001). Globalization and localization. In T. O'Riordan \& C. Church (Eds), Globalism, localism, and identity (pp. 25-42). London and Sterling, VA: Earthscan Publications.

Walisi Nogang. (2000). Thinking about Taiwanese aboriginal modern literature. In D. W. Wang (Eds), Writing Taiwan: Strategies of representation (pp. 101-19). Taipei: Mai-Tien Publishing.

Yeh, Y. J. (1994). Introduction: A review of modern Taiwan art from an art discourse of the 90s. In Y. J. Yeh (Ed), Taiwanese consciousness in Taiwan art (pp.6-36). Taipei: Hsiung-Shih Art Books. 